\title{
CO-PRODUCTION AND THE THIRD SECTOR: A COMPARATIVE STUDY OF ENGLAND AND FRANCE
}

\author{
By \\ CAITLIN MCMULLIN \\ A thesis submitted to the University of Birmingham \\ For the degree of \\ DOCTOR OF PHILOSOPHY
}

Institute of Local Government Studies

School of Government and Society

College of Social Sciences

University of Birmingham

March 2018 



\begin{abstract}
This thesis explores co-production between citizens and third sector professionals in England and France. I focus on five community regeneration organisations in Sheffield, England, and five in Lyon, France, followed by an analysis of comparator organisations in two further sectors of activity - parents' organisations, and projects to reduce older people's loneliness. The research is based on 57 semi-structured interviews, as well as event observations and documentary analysis. I employ an analytical framework of institutional logics to explore the ways in which the rules, practices and narratives of the case study organisations are specific to their city and national contexts and how these in turn drive and shape co-production practices.

The study finds that while the Sheffield organisations are characterised by an assimilation of the state, community and market logics, the Lyon organisations demonstrate a blend of a 'Napoleonic state' logic, and a 'local solidarity' (rather than community) logic. These different combinations of logics illuminate two approaches to co-production. In France, co-production is informed by notions of citizenship, solidarity and participative democracy, leading to a greater focus on citizen involvement in organisational governance and greater influence of rules as an enabler and constraint to co-production. In Sheffield, co-production is seen as a way to improve communities, services and outcomes, and we therefore see more pragmatic attention to co-design and co-delivery activities. This thesis provides an important contribution both to co-production theory as well as to policy and practice, by demonstrating some of the cultural and contextual subjectivity of coproduction, which has been overlooked in previous studies. In addition, employing institutional theory to study co-production enables me to produce evidence of meso and macro level factors that influence co-production behaviour.
\end{abstract}




\section{ACKNOWLEDGEMENTS}

Undertaking a PhD part-time while concurrently working several jobs and running a business has been a challenge of remarkable proportions, but one that I have relished. I could not have completed it without the support and encouragement of numerous colleagues, friends and family.

An enormous thank you goes to my supervisors - first and foremost to Chris Skelcher for firstly believing that I had the capacity for doctoral research, and for your vast knowledge, for helping me overcome roadblocks and for always asking the most challenging questions. Thank you to Katie Tonkiss for supporting me through the formative first years, and to Catherine Needham for helping me finally find my feet in this thesis, and encouraging me to do the impossible and complete my PhD part time in five years.

I would also like to thank the colleagues at INLOGOV and at the many conferences I had the pleasure of presenting at over the course of my $\mathrm{PhD}$, particularly the IIAS Co-Production Study Group in 2015 and 2016, where I received thoughtful and challenging comments that helped me to take my research forward.

Thank you to all of the participants who agreed to be interviewed for the research, particularly the individuals in Lyon who helped me get to grips with a new city and were so understanding of my mistakes in French.

On a personal note, I'm also grateful to my colleagues and friends on the $10^{\text {th }}$ floor of Muirhead Tower for lunchtime chats that made this PhD process much less lonely.

Thank you to my family for your valiant efforts to understand what co-production is, and particular thanks to Mom and Dad for your over-the-top excitement and enthusiasm for every minor achievement I made. Thank you to my in-laws, Sue and David, for being so understanding about my lack of free time during these five years, and for welcoming me into your family. 
Finally, a special, ginormous thank you goes to my husband, Neil, who acted as a cheerleader, human thesaurus, proof-reader, shower-thoughts transcriber, and overall sanity checker through the course of my PhD. I couldn't have done it without your endless supply of patience and support. 


\section{CONTENTS}

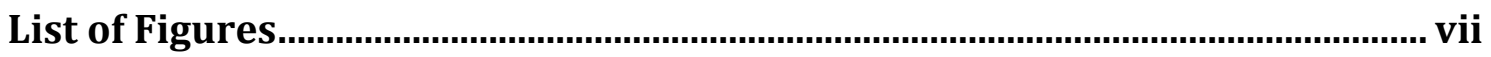

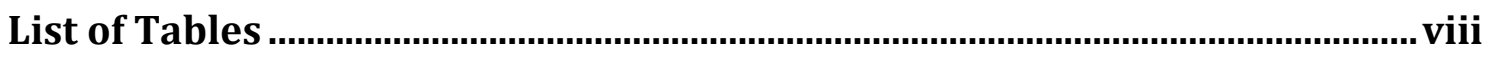

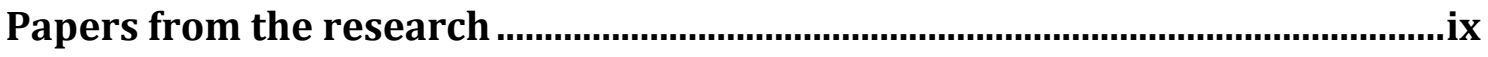

Chapter 1: Introduction............................................................................................. 1

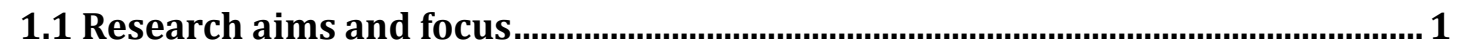

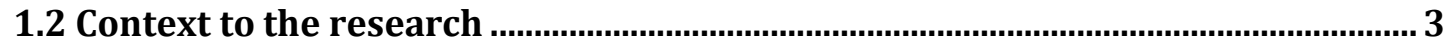

1.3 Empirical research

1.4 Contribution

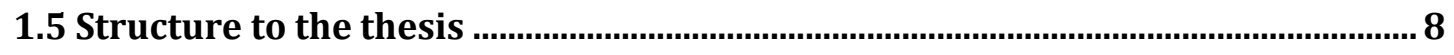

Chapter 2: Conceptualising Co-production .......................................................... 11

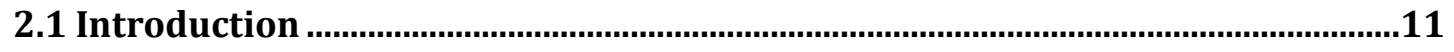

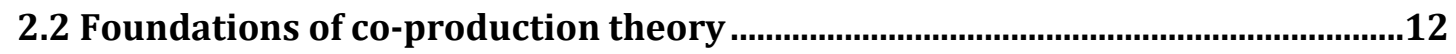

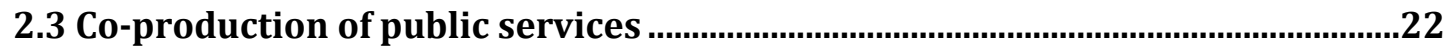

2.4 Co-production in the francophone literature ............................................................36

2.5 Gaps and weaknesses of the co-production literature ............................................41

2.6 Coming to an operational definition of co-production ..........................................47

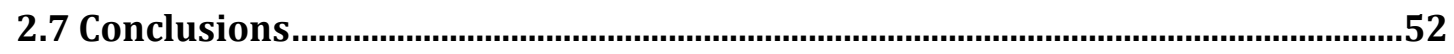

Chapter 3: Institutional Logics and Co-production ..........................................54

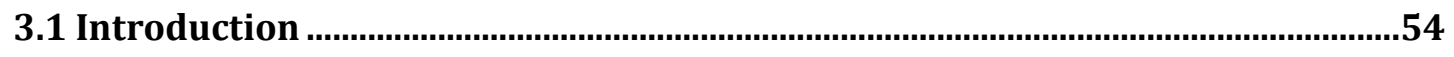

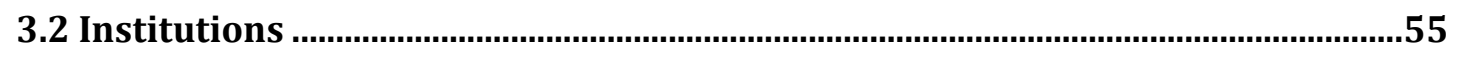

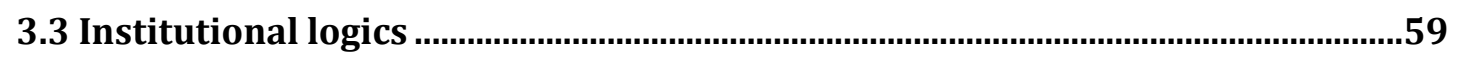

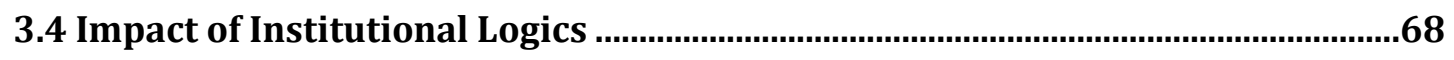




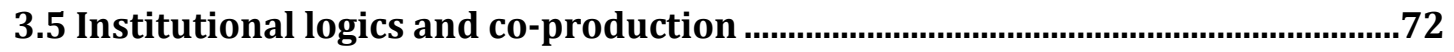

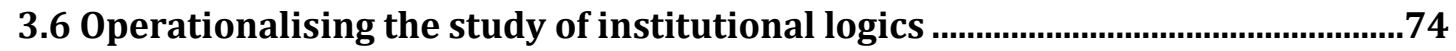

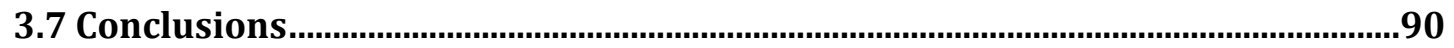

Chapter 4: Research Design and Methodology .................................................... 91

4.1 Introduction

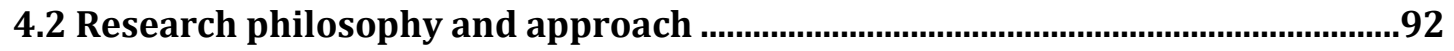

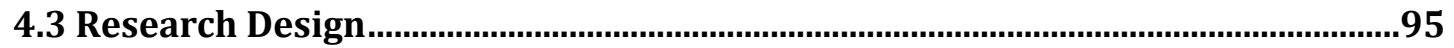

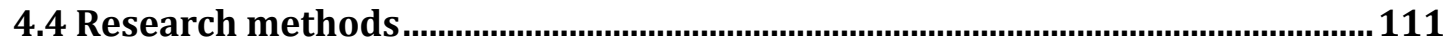

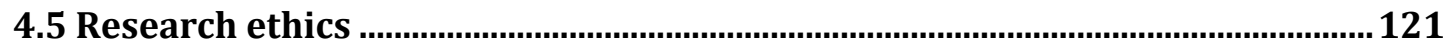

4.6 Data analysis: Applying the analytical framework ……...................................... 125

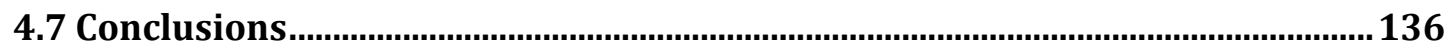

Chapter 5: Context for the Research: Societal and Field Level Logics.............138

5.1 Introduction

5.2 Societal Level: Institutional Typologies .............................................................. 140

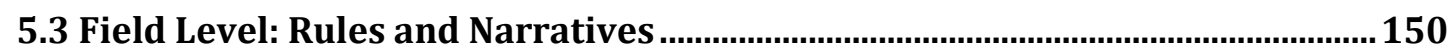

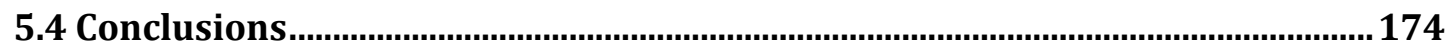

Chapter 6: Analysis of Community Regeneration Cases ...................................176

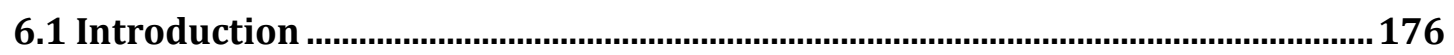

6.2 Sheffield community regeneration and Lyon social centres ............................177

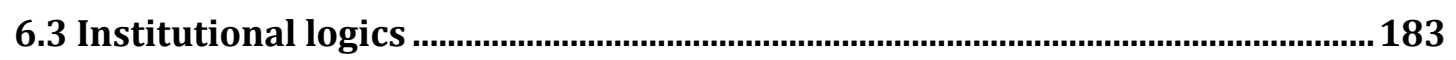

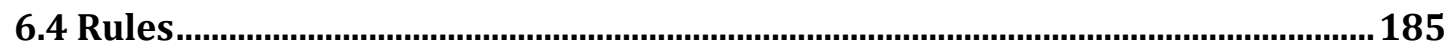

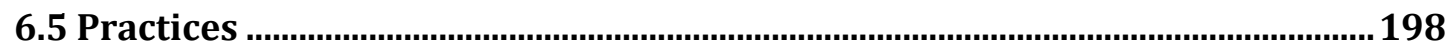

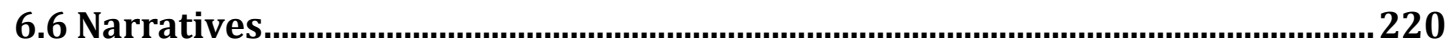

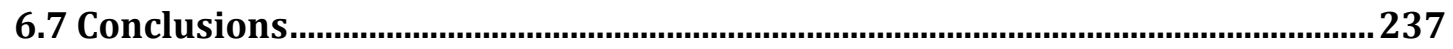

Chapter 7: Comparator Organisations - Parents and Older People's Projects ........240 
7.2 Children's services and older people's projects.

7.3 Institutional logics and co-production: Parents' organisations 246

7.4 Institutional logics and co-production: Older people's projects

Chapter 8: Models of Institutional Logics and Co-production

8.1 Introduction

8.2 Reconceptualising institutional orders 288

8.3 Models of institutional logics and co-production

8.4 Social solidarity logic and co-production 298

8.5 Service delivery logic and co-production 307

8.6 Conclusions

Chapter 9: Conclusions

9.1 Introduction

9.2 Findings of the research.

9.3 Contribution to Theory 320

9.4 Practical contributions. 323

9.5 Limitations of the research 324

9.6 Personal reflections 326

9.7 Future research

Appendices 329

Documents consulted .351

References. .353 


\section{LIST OF FIGURES}

Figure 2.1: Eight rungs on a ladder of citizen participation......................................... 15

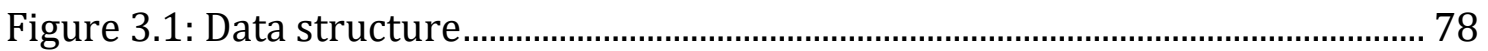

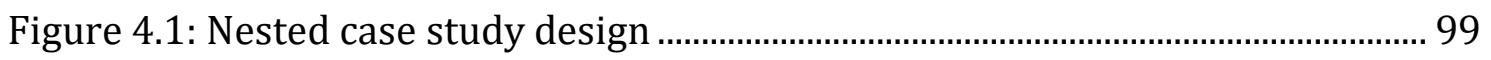

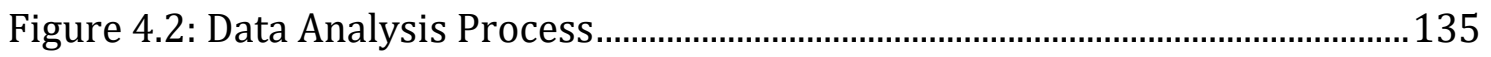

Figure 5.1: Levels of institutional analysis..................................................................

Figure 5.2: Local Government in Lyon and Sheffield .....................................................154

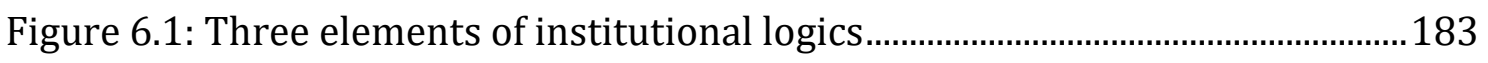

Figure 6.2: Photos from workshops at the AGM of Avancé.........................................206

Figure 6.3: Display of organisational activities at Aspire AGM ...................................206

Figure 7.1: Photo from Lyon Parents birthday celebration..........................................259

Figure 7.2: Photo of Lyon Parents 'participative diagnostic' game .............................259

Figure 7.3: Sheffield Parents Facebook group - communication with parents......261

Figure 8.1: Hierarchy of Lyon third sector organisations..............................................300 


\section{LIST OF TABLES}

Table 2.1: Types of co-production (Bovaird) ................................................................. 25

Table 2.2: Types of co-production (Brandsen and Honingh) ....................................... 27

Table 2.3: Operationalising a definition of co-production ................................................ 50

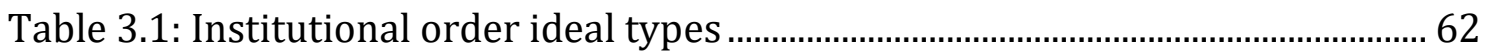

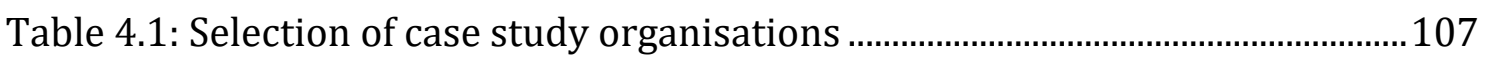

Table 4.2: NVivo node hierarchy for first stage of coding..............................................129

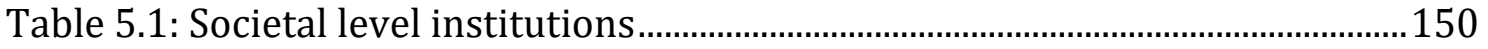

Table 5.2: Third sector narratives and rules...................................................................163

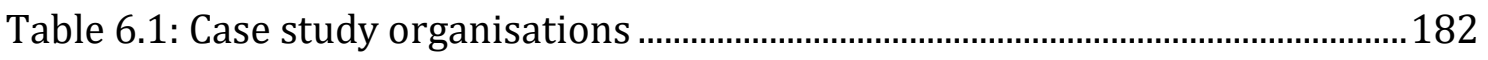

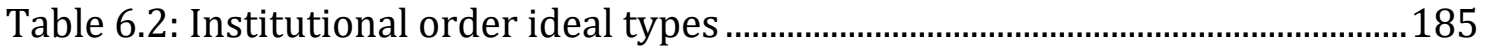

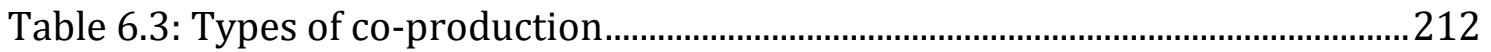

Table 6.4: Sheffield co-production examples.............................................................214

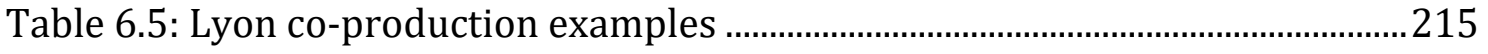

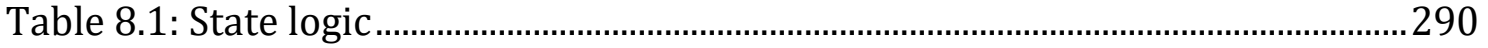

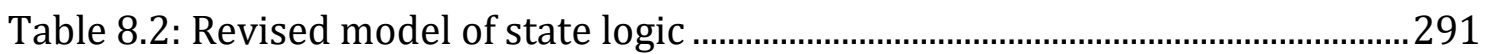

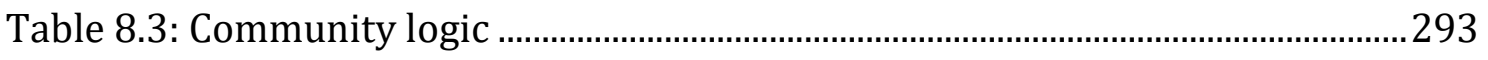

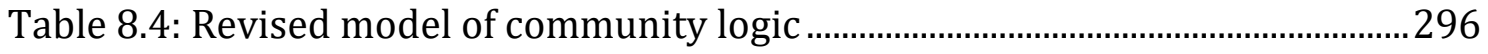




\section{PAPERS FROM THE RESEARCH}

McMullin, C. (2018) 'Co-production and community development in France' in Verschuere, B., Brandsen, T. and Steen, T., eds., Co-production and cocreation: Engaging citizens in public service delivery, Routledge.

McMullin, C. and Needham, C. (2018) 'Co-production and healthcare' in Verschuere, B., Brandsen, T. and Steen, T., eds., Co-production and co-creation: Engaging citizens in public service delivery, Routledge.

McMullin, C. and Skelcher, C. 'The impact of societal level institutional logics on hybridity: Evidence from nonprofit organizations in England and France', accepted subject to minor revisions for Voluntas special issue on 'The organizations of civil society'.

McMullin, C. (2017) 'La conceptualisation de la co-production et le secteur à but non-lucratif: Comprendre les divergences entre les traditions de participation anglaise et française', Paper presented at the International Colloquium of CRISES, Université du Québec à Montréal, Canada, 6-7 April 2017.

McMullin, C. (2016) 'How institutional logics shape co-production practices: Evidence from community regeneration organisations in England and France', Paper present at the IIAS Study Group on Co-production of Public Services, University of Tampere, Finland, 13-14 June 2016.

McMullin, C. (2015) 'Conceptualising co-production and the third sector: Understanding divergences in the English and French participation traditions', Paper presented at the IIAS Study Group on Co-production of Public Services, University of Nijmegen, The Netherlands, 8-9 June 2015.

McMullin, C. (2015) 'Governance, institutions and co-production: Understanding contextual differences between England and France', International Research Society for Public Management annual conference, University of Birmingham, England, 30 March - 1 April 2015. 


\section{CHAPTER 1: INTRODUCTION}

\subsection{Research aims and focus}

The notion of co-production of public services has become increasingly attractive to academics and policy-makers, who hope to find innovative ways to address both the growing strains on the welfare state as well as a perceived democratic deficit. Coproduction refers to the involvement of citizens or service users in the design as well as the delivery of public services, whether delivered by public, private or third sector organisations. The majority of research focuses on co-production between citizens and public bodies, but there is evidence to suggest that third sector providers of services are typically predisposed to be better at undertaking these more collaborative ways of working, making this sector an ideal arena for further investigation of the workings of co-production (Pestoff et al. 2012). While research has been carried out to explain co-production practices in countries around the world (Bovaird, 2007; Joshi and Moore, 2004; Parrado et al., 2013), we still have little evidence to explain whether co-production is undertaken in different ways in different contexts, and if so - why?

This study seeks to address this gap. In this thesis, I contribute to the literature on co-production by investigating the contextual contingency of co-production, and questioning the assumed universality of the dominant narratives and assumed practices of co-production in the English language literature. This is done by 
undertaking a comparative qualitative study of co-production and third sector organisations in England and France, two countries that, while alike in many ways, are at odds in many others both culturally and politically, making the comparison fertile ground for contribution to the theory. The study aims to remain sensitive to differences in the political, cultural and linguistic contexts that underscore how organisations conceive of and undertake co-production.

The study also responds to calls for the need for the calls for increased research that applies institutional theory to the study of co-production. As Verschuere et al. (2012) argue:

The strength of institutional theory is in the emphasis it puts on the interaction between service delivery arrangements and the environment. As such, it helps us in understanding how environmental features explain the motives for, and processes of, co-production. (Verschuere et al., 2012, p. 1098)

Institutional theory also provides a rich foundation for designing comparative studies of co-production, which is another area identified by Verschuere et al. (2012) as lacking in the literature. With this in mind, I employ an institutional logics framework to the study of co-production. The institutional logics approach allows for a novel lens to be applied to the study of co-production, investigating not only the practice of co-production, but how this is shaped and moulded by variations in the logics of organisations, which are correspondingly shaped by the combinations of and conflicts between multiple institutional logics embedded with their particular contexts. Third sector organisations are conjectured to be hybrids between the market, state and community sectors, and are therefore driven by a combination of 
the logics of each of these institutional orders (Smith, 2014). These provide multiple, often competing and contradictory, implications for the practice of co-production within third sector organisations. Institutional logics are conceptualised and explored through a framework of rules, practices and narratives (Lowndes and Roberts, 2013), allowing for an appreciation of the formal and informal constraints on organisational decision-making and behaviour, as well as the beliefs and values of actors within these settings and how these construct their motivations.

\subsection{Context to the research}

The empirical element of this research focuses on third sector organisations located in Sheffield, England and Lyon, France. England and France have been chosen as the focus for the research for several reasons based on theory. First, despite their many similarities, these two countries are frequently typologised as belonging to contrasting categories in terms of political, social and cultural factors. These typologies and the justification for the case selection will be elaborated in Chapters 4 and 5 , in relation to the methodology and context of the case studies.

Second, the rhetoric of co-production within public discourse is strikingly different between the two countries. In England, co-production gained the attention of public policy-makers in the early 2000 s, when we see a proliferation of the term in reports and policy papers (Horne and Shirley, 2009; Boyle and Harris, 2009). Co-production has been promoted by thinkers and decision-makers across the political spectrum in the UK - its extensive normative appeal can be leveraged to promote 'doing more 
with less', to giving consumers choice, or empowering citizens. The influence of this discourse can be seen by the take-up of this term by many local authorities across the UK and the establishment of networks such as Co-production Wales, the Scottish Co-production Network, and The West Midlands Co-Production Network in England. By contrast in France, while co-production technically translates to the same word in French, the term co-production is rarely used in either the academic or the public policy literature. Co-construction (in French) appears to be the closest in meaning, but this term relates more to involvement and collaboration in decision-making only, and there appears to be no term analogous to co-production that describes activities that involve both co-design and co-delivery of services. This comparative absence of a prevailing French co-production narrative leads one towards three potential hypotheses: 1) the French do engage in this same type of co-production but call it something else; 2) the co-production that takes place in France somehow presents differently or involves different types of activities; or 3) co-production simply does not take place in France, for some contextually specific reason(s).

Finally, while many of the prevailing definitions of co-production suggest that it can occur between citizens and professionals in any sector (e.g. Bovaird, 2007), less research has been undertaken that focuses on co-production between service users (or local residents/ citizens more generally) and paid professionals working for third sector organisations. Much of the literature on the third sector and coproduction concentrate at the next level of analysis, i.e. between third sector organisations and public sector organisations, whereby the involvement is in the governance of services rather than the day to day design and delivery (Ackerman, 
2012). Shifting the focus to the individual and group level brings new issues to light, as the types of organisations of the third sector (cooperatives, associations, charities), the services they provide, and relationship to the state varies from country to country. This provides another justification for the need for comparative research into the phenomenon of co-production within third sector organisations. England and France, whose third sectors have developed unique trajectories, here again provide compelling cases for comparison, which is elucidated in Chapter 5.

\subsection{Empirical research}

In order to investigate this phenomenon, the primary research questions for the study are the following:

1. How are co-production and citizen participation conceptualised and framed by third sector organisations in England and France?

2. To what extent are co-production practices similar or different between England and France?

3. How can any differences be explained, and what are the implications?

The empirical research employs a qualitative approach to address these questions, aiming to build theory to better illustrate the contrasts between third sector coproduction in different contexts. Because co-production is inherently a relational process, influenced by the beliefs, identities and motivations of actors taking part, the research naturally gravitates towards an interpretivist approach, aiming not to explain the existence of co-production in each context or prove correlates of co- 
production, but instead to explore the complex interrelationships between factors that can help us to better understand the social worlds in which co-production takes place.

Beginning from this perspective, the research utilises a design of multiple comparative case studies in one English and one French city - Sheffield and Lyon and focuses on third sector organisations and projects that operate in three arenas of activity: 1) community regeneration 2) parents' organisations/projects and 3) projects to reduce loneliness and isolation of older people. The primary focus of the research is on the first category, for which I include five organisations in Sheffield and five in Lyon, while the parents and older people's projects (one of each in each city) provide complements to the main concentration. The decision to broaden the focus to multiple case studies in each city, rather than focusing in depth on one or a handful of cases, provides a richness of data and allows for a degree of cautious speculation about the broader applicability of the results which is not typically supported by the case study method.

The primary data collection method for the research was semi-structured interviews, which were triangulated through document analysis and observation. The analysis followed an interactive, abductive process whereby the data were coded in a three stage process of open coding, theoretical coding and analysis and comparison of coded material. 


\subsection{Contribution}

This thesis aims to make both theoretical and empirical contributions to the literature. In terms of theory, the research provides findings relevant to both the coproduction debates as well as institutional logics theory. The application of institutional theory to the study of co-production, as well as the study of coproduction from a comparative perspective presents insights into the historical and contextual contingency of co-production activities. It contributes to the coproduction theory by utilising this institutional approach, from which I have developed two archetypes of co-production which reflect varying combinations of the state, market and community logics distinctive to the two locations.

Empirically, the study demonstrates examples of different forms of co-production in two national contexts. Although this thesis focuses specifically on England and France, it provides insight for research into co-production in other countries and opens the door for research that uses institutional theory to contextualise the practices of co-production. In addition, the analysis of institutional logics to understand co-production provides a new framework for differentiating between co-production in different sectors, within the same or different countries. While we have some evidence about the relative suitability of the public and third sectors to engage in co-production (e.g. Pestoff, 2009), applying an institutional logics approach has implications for the recognition of barriers and enablers to coproduction that can provide direct benefits for actors working in the field. 


\subsection{Structure to the thesis}

Chapter 2 introduces the concept of co-production, discussing the research on citizen participation and public management and governance that provide the foundation for co-production theory and research. Following this, I outline the typologies of co-production and the previous empirical research that has studied the motivations for co-production and its impacts or benefits. I also discuss the relative dearth of francophone literature on co-production which contributes to establishing the need to address the first research question. The chapter finishes by establishing the operational definition of co-production for the purposes of this research.

Chapter 3 introduces the institutional logics approach, which forms the analytical framework for the research. This review of the literature first surveys the literature on institutional theory and determines a definition of institutions, before turning to the theory on institutional logics and establishing the basis of the use of this concept as a framework for analysing co-production. Finally, the concept of institutional logics is operationalised as composed of rules, practices and narratives, which form the structure of the empirical analysis. Because institutional logics are conceived as existing within nested levels of society (Friedland and Alford, 1991), these levels are considered within Chapter 5 (society and field level) and then empirically at the organisational level in Chapters 6 and 7.

Chapter 4 explains the research design and methodology employed for the study. It begins by establishing the philosophical underpinnings of the research, which inform the choice of a comparative case study methodology and multiple data 
collection methods. Next, the chapter outlines the several stage data analysis process, before finally considering the advantages and weaknesses of the approach taken.

Chapter 5 establishes the context of the case studies - both theoretically and with discussion of some empirical results. The focus on the chapter is on determining the presentation of institutional logics at the societal and field levels in the two country contexts, as well as introducing the reader to the two cities.

Chapters 6 and 7 discuss the findings from the empirical research undertaken. Chapter 6 focuses on the data gathered in relation to the community regeneration organisations in Sheffield, and social centres in Lyon. As mentioned above, the analysis is structured according to the operational definition of institutional logics, considering the rules, practices and narratives of the 10 case study organisations as these enable and constrain co-production behaviour. The Sheffield and Lyon organisations are considered in parallel, drawing out common and contrasting themes across the cases. Chapter 7 moves to consider the comparator cases, which are parents' organisations and projects aiming to reduce isolation of older people. This analysis is structured in the same way as Chapter 6, with discussion of the parents' organisations first, followed by the older people's projects.

Chapter 8 presents an interpretation and discussion of the findings from Chapters 6 and 7. It returns to the concept of institutional logics, and reconsiders the definition of the state and community logics in light of the findings from the empirical analysis chapters. Two models of the combinations of institutional logics in the French and English cases are described which provide a basis for describing the different 
approaches to co-production. The chapter finishes by returning to the research questions and drawing out the main findings.

Chapter 9 considers the broader theoretical implications of and contributions made by the research, some challenges and limitations of the study, and some potential areas for future investigation. 


\section{CHAPTER 2: CONCEPTUALISING CO-PRODUCTION}

\subsection{Introduction}

Co-production was originally developed as a concept in the late 1970s, but regained the attention of public management scholars, sociologists and political scientists in the early 2000s as researchers aimed to understand and often promote more collaborative and cooperative ways of working between public service professionals and public service users. This growth of co-production literature has done little to fine tune conceptual consensus; on the contrary, it seems to have become more muddled with researchers using the term to refer to a wide range of activities and practices.

In this chapter, I review and appraise the extant literature on co-production of public services in order to demonstrate the range of definitions and typologies of this contested notion. The analysis begins by reviewing the two streams of research that form the foundations of research on co-production: first, I look at the literature on citizen participation and participatory democracy, followed by a review of the literature on public management and public governance as it pertains to coproduction. The next section focuses specifically on co-production, with particular focus on the different definitions used and typologies developed. I also discuss the francophone literature on citizen participation and co-construction, to examine the similarities and differences between these streams of research and the anglophone 
literature. Following this, I evaluate the weaknesses and gaps in the research. The chapter finishes by clarifying the definition of co-production that is employed in this research.

\subsection{Foundations of co-production theory}

Several key criteria were developed in order to select the literature to be included in this review. First, the review aims to outline the bases of the co-production concept, including the history, definitions and typologies. Second, I focus on the empirical evidence about co-production. Articles and books were identified through searching University of Birmingham databases using search terms such as coproduction, co-design, 'co-production of public services', citizen participation, participatory democracy, and service user involvement. The selection of studies was based firstly on degree of influence on co-production theory, measured by the number of times articles were cited (as listed in Google Scholar) as well as crossreferencing through the literature reviews of influential works. Second, I aimed to cover articles from a wide time period, representing earlier works in the 1980 s through to the more recent studies. Finally, I sought to identify articles that focused specifically on co-production in the third sector, which is a subset of the main body of work that studies public sector co-production.

Because the research was undertaken in two languages, I analysed articles and books in both English and French. The same tactics were first employed to identify relevant French literature (i.e. searching databases for relevant key words, which I 
directly translated from English). Because of the initial difficulty in finding French language literature on co-production, I also asked for recommended reading in initial scoping interviews with French academics, as well as from French colleagues at conferences.

\subsubsection{Citizen participation and participatory democracy}

Before discussing the literature on co-production of public services, I will outline the various precursors of this concept. The first of these is the literature on citizen participation and participatory democracy, which is based on the contention that Western societies are experiencing a democratic deficit and that traditional representative structures are falling short of a representing the preferences and interests of citizens. In addition to the democratic deficit, Nabatchi argues that we are seeing a citizenship deficit, which she describes as "an erosion of civil society and civic engagement and more specifically of civic skills and dispositions among the general public" (Nabatchi, 2010, p. 378). Greater direct citizen involvement is framed as a means to address these deficits, as well as to reform government bodies, which have moved away from their democratic ethos and become overly dominated by bureaucratic norms.

No literature review of citizen participation is complete without discussing Sherry Arnstein's seminal 1969 article, ‘A Ladder of Citizen Participation'. Arnstein developed a typology of levels at which citizens can be involved in decisions, ranging from non-participation (manipulation and therapy) to citizen power (partnership, delegated power and then citizen control). 
My answer to the critical 'what' question is simply that citizen participation is a categorical term for citizen power. It is the redistribution of power that enables the have-not citizens, presently excluded from the political and economic processes, to be deliberately included in the future. [...] In short, it is the means by which they can induce significant social reform which enables them to share in the benefits of the affluent society. (Arnstein, 1969, p. 216)

Writing in the context of the 1960s social movements when citizens were increasingly demanding to be involved in government decision-making, Arnstein argued that citizen participation was necessary in order to redress the systemic imbalances of power that had come to characterise public policy-making. The article contended that many participation initiatives which fall on the lower rungs of the ladder (Figure 2.1) simply recreate existing power structures between decisionmakers and those for whom decisions are being made, thereby implying that the ultimate goal of any citizen involvement should be the eighth rung, or full citizen control. 


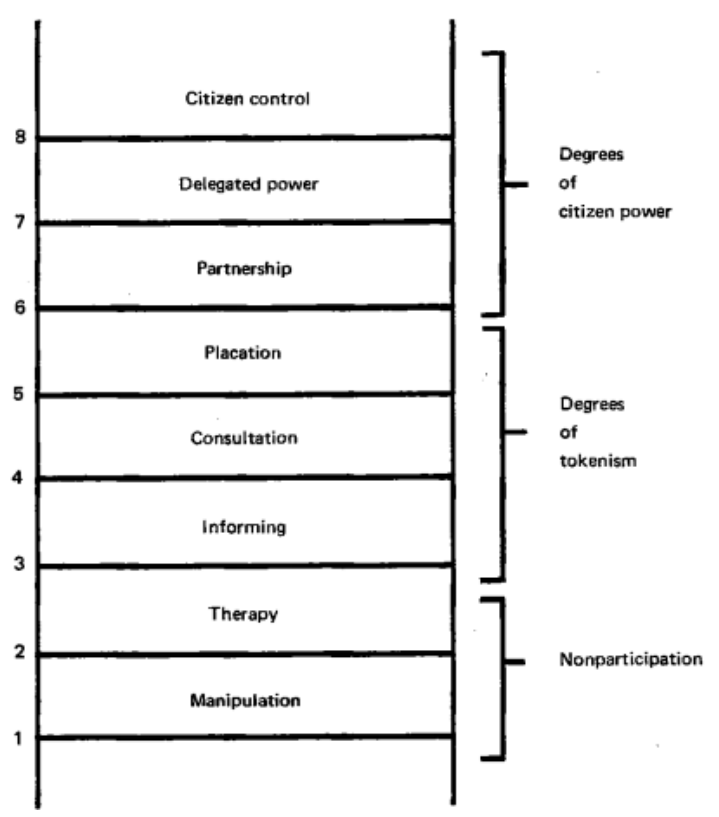

Figure 2.1: Eight rungs on a ladder of citizen participation

Source: Arnstein, 1969

Despite the fact that this typology is nearly 50 years old, the ladder of participation continues to be the mostly widely recognised model of citizen participation and empowerment. At the time of writing, the article had received over 15,000 citations, and policy-makers and practitioners continue to employ a narrative of aiming to achieve participation on the 'higher rungs' of the ladder. Recent literature has, however, critiqued this typology and revealed some of its weaknesses in providing a comprehensive model and guide for practitioners aiming to improve citizen participation, which also coincides with increasing attention to other forms of involvement, such as co-production. These critiques of the ladder of participation and subsequent participation studies that rely on this typology focus on the activities that citizens participate in, and the reasons that citizens are motivated to participate - or why they may not be motivated or interested to strive for 'full citizen 
control'. I address each of these critiques in turn in order to elucidate some of the primary questions that the co-production literature seeks to better address.

First, Arnstein's ladder as a model of participation fails to evaluate what activities or decisions citizens participate in or how they participate, arguing only that, essentially, more participation is better. However, many academics and practitioners argue that governments have exploited the normative appeal of this ladder in ways that have been counter-productive, managing to notionally employ rhetoric around participation at the higher rungs of the ladder which is in practice no more than a 'tick box exercise'. For instance, in an example given by Cornwall (2008):

Delegated power over choosing the colour of paint for a clinic's waiting room in the name of 'patient involvement' - in the absence of any involvement in decisions on what the clinic actually does - may count for little in transforming power relations. (p. 273)

This extract gives a concrete of example of how Arnstein's typology falls short - full citizen power can be meaningless if it is full power over trivial decisions. Any notion of 'real power' or 'full participation' in a typology should therefore, by Cornwall's account, be participation in and power over decisions that matter to the individuals taking part.

Proponents of deliberative democracy contend that the means by which decisions are made are also a crucial part of achieving meaningful citizen participation, and that the actual design of involvement exercises can determine whether the aims of redistribution of power and/or improved public services is realised, or whether 
existing power relationships are simply recreated (Fung and Wright, 2003). Arnstein herself asserts that with many consultation exercises, "What citizens achieve in all this activity is that they have 'participated in participation'” (Arnstein, 1969, p. 216). Fung and Wright (2003) argue that in order for participation to be meaningful for participants and lead to real change, there must be a focus on developing new, innovative processes of deliberative and participative democracy. One of the participative democratic models designed by Fung (2006), a 'Democracy Cube', is designed to consider three further dimensions - who the participants are (to address exclusion and disenfranchisement), the means by which decisions are reached, and the link between these discussions and real policy change. Improving the range of individuals involved in decision-making and a focus on empowerment of citizens has been a focus of literature on public service reform beginning in the 1990s (Skelcher, 1993).

Secondly, Arnstein's focus on a 'genuine' form of participation whereby citizens have complete control over decision-making fails to acknowledge the myriad reasons why this may not always be the preferred outcome, and that a range of experiences at the other 'levels' of participation may be beneficial. Designing the model as a ladder makes a judgement that there are 'better' and 'worse' forms of citizen participation, and implicitly devalues any of the middle rungs, or forms of participation that do not neatly fit on a typology that is solely about transferring decision-making power.

User engagement and empowerment are complex phenomena through which individuals formulate meanings and actions that reflect their desired degree of participation in individual and societal decision- 
making processes. Patient and public involvement is more likely to fail, therefore when there is a mismatch of expectation or method. Rather than rely, as Arnstein does, on models of participation constrained by a specific conceptualisation of activism, we conclude that user involvement requires dynamic structures and processes legitimised by both participants and non-participants. (Tritter and McCallum, 2006, $p$. 157)

Tritter and McCallum argue that there may be other motivations for citizens to participate in decision-making (or other involvement exercises) other than to gain power and control, such as valuing the process of participation, or to gain social capital, knowledge or experience. Furthermore, different decisions or processes may necessitate different levels or types of involvement. For instance, there are unquestionably many decisions made by policy-makers where citizens are more than happy to simply be informed or consulted but to delegate ultimate power to officers and elected officials. On the other hand, some types of involvement do not fit neatly on any of the eight rungs, such as patient participation groups, where there may be instances of information, consultation and partnership at different moments. Lowndes et al. (2006a) develop an evaluative framework in order to help organisations and public bodies to design participation initiatives and to assess their effectiveness. The CLEAR framework (which stands for 'can, like, enabled, asked, responsive') suggests that citizens will engage if they can, if they find that participation gives them a sense of identity, if they are enabled to do so, if they are asked for their opinion and if the organisation they engage with is responsive. Like the majority of participation theory and models, this framework is rooted in the normative position that more participation should be encouraged, and therefore 
seeks to provide practitioners and elected officials with a toolkit to improve the way in which they undertake involvement. It also highlights some systemic barriers to participate ('can do' refers to socioeconomic status and skills to participate) as well as the institutional design elements.

I have outlined in detail the critiques of Arnstein's typology in order to explain the scope for developing new approaches to involvement and participation. The notion of co-production of public services can be traced to an attempt to correct for these perceived weaknesses in previous works on participation and involvement notably considering some of the elements raised by the CLEAR framework, but focusing on the input of citizens into services, which are likely to be directly relevant and important to them. As I will discuss in the section 2.3, co-production scholarship aims to explain and evaluate efforts to involve citizens and service users in both decision-making or design of services, as well as in their delivery, in activities that aim to go beyond a simple linear model of involvement.

\subsubsection{Public management and governance}

The second stream of research that has influenced the development of the coproduction literature is that which focuses on the public administration and management, and the changes that have taken place since the 1980s. Much of the literature on co-production is framed in the context of the evolution of theories and philosophies of public management. Paradigms surrounding governance and the welfare state have undergone a series of ideological changes from the post-war period, which theorists identify as a period of 'traditional public administration', where government strategy was centrally defined and public services controlled by 
government hierarchies. Numerous scholars describe a shift in the 1980s towards New Public Management (NPM), where it was argued that many governments around the world began to apply market rationales and business logics to public service management to become more efficient (Hood, 1991, 1995; Dunleavy and Hood, 1994).

NPM dominated the discourse of public administration throughout the 1980s and 1990s in Britain (and many other countries), driving many Western democracies to privatise services. Under NPM, the position of citizens went from being considered beneficiaries to customers, who could exercise their rights through choice or exit (Aderbach and Christensen, 2005). NPM soon fell out of favour with scholars and politicians, with opponents arguing that the emphasis on a market for public services and the role of service user as simply a customer undermines the importance of public services to address equalities issues, for example (Ackerman, 2012). Furthermore, the reliance on choice and exit as recourse for service users has been criticised for the fact that it assumes that citizens have equal access to high quality public services and the ability to exit the market if they are unhappy (Simmons et al., 2011).

Several scholars have thus developed new models of public management/ governance which move the focus from state institutions and the market towards the citizen as driver of decision-making and change. Osborne (2006) builds upon previous work on NPM and argues that this was, in fact, a stage in the evolution towards what he terms New Public Governance (NPG): 
[NPG] posits both a plural state, where multiple inter-dependent actors contribute to the delivery of public services and a pluralist state, where multiple processes inform the policy making system. As a consequence of these two forms of plurality, its focus is very much upon interorganizational relationships and the governance of processes, and it stresses service effectiveness and outcomes. (Osborne, 2006, p. 384)

In a similar vein, Hartley (2005) suggests a model of 'networked governance', in which governance is led through partnerships with civil society. Denhardt and Denhardt (2000) likewise argue that a future beyond NPM requires public officials to 'serve rather than steer' citizens, in what they call 'New Public Service'. This forms the backdrop of much of the work on co-production, which positions co-production as part of this evolution in public governance (Pestoff et al., 2012). The common thread through this stream of the literature is that we are seeing a shift from the reforms brought in during the wave of NPM towards new, more citizen-focused models of governance and service delivery, which emphasise the role of networks, partnerships and coalitions between the state and third sector. Models such as New Public Governance suggest that the changing relationship between the state and citizen has led to an increase in the power and importance of the third sector as public service provider, as the role of the state begins to evolve towards steering rather than controlling (Pestoff, 2012b). One of the persisting legacies of NPM is that government contracts for public services are often based on performance and designed in ways that conflict with organisations' community ethos, but Smith (2010) argues that performance management and citizen engagement can be reconciled through innovative approaches like co-production. 


\subsection{Co-production of public services}

\subsubsection{Definitions and typologies}

Co-production is rooted in these two traditions of research - citizen participation and public governance - which explains the dualism that is at times present in the explanation of the barriers and approaches to, and impacts of co-production. What differentiates the concept of co-production from the citizen participation literature is that co-production encompasses the involvement in decision-making (or planning, or service design) as well as in service delivery. Scholarship on co-production over the following decades has sought to fine tune the concept, typologise the different types of co-production and demonstrate (or advocate for) the benefits of coproduction. However, the term co-production is often used in different ways to refer to different types of relationships and activities, and these distinctions are not always made explicit in the literature (Brandsen and Honingh, 2015). In this section, I will review the key literature on co-production and outline the various definitions and typologies used to describe this practice, before discussing some of the weaknesses of the concept and gaps in the literature.

Co-production was first developed in the late 1970s by theorists in the United States, who argued that service users - beyond being simply recipients or beneficiaries of services - could offer their time, expertise and/or resources to become actively involved in the process of service delivery (Sharp, 1980; Parks et al., 1981; Brudney and England, 1983). Ostrom defined co-production as the "process through which inputs used to produce a good or service are contributed by individuals who are not 'in' the same organization," e.g. between 'regular' service providers (professionals) 
and citizens (Ostrom, 1996, p. 1073). This concept originated from an effort to understand why community policing was more effective in smaller neighbourhoods than in bigger neighbourhoods, and it was concluded that a key contributing factor was the willingness of local citizens to work with police, report suspicious incidents and build relationships and trust with local officers (Parks et al., 1981).

After struggling with it, we finally decided to use the term 'coproduction' to reflect the fact that in many of these smaller units, the police were not the only producers of safety. Citizens were actively coproducing much of the safety in the neighbourhood [...] We then realized that it related to schools and many other services, including health and neighbourhood upkeep. (Ostrom, 2012, p. xvi)

Subsequent work has sought to fine tune the concept of co-production through typologising and the establishment of an evidence base through empirical research. In an effort to clarify the concept of co-production, which was at that stage quite novel, Brudney and England (1983) outline several aspects of what is and is not coproduction. The most influential of these is the distinction between individual, group and collective co-production. Individual co-production refers to activities where a service user takes part in the co-production activity and the benefit or impact is limited to that individual alone. By contrast, group co-production is defined as the collaboration of numerous citizens with service professionals in order to increase the quantity or improve the quality of the services they use. Finally, collective co-production again requires the participation of groups of citizens, but the benefit of the co-production extends to a wider population or society as a whole. 
Alford (1998) draws upon Brudney and England's definition of co-production, but is notably less focused on the intentional and group or collective aspects of coproduction, and differentiates between the different types of individuals that take part in co-production with professionals. He makes the distinction between volunteers or community members - i.e. the focus of original work by Ostrom and others - and co-production by service users or clients themselves. Client coproduction, he argues, is a necessary part of the service delivery process and often cannot take place without the contribution of clients/ service users. He gives examples that range from citizens writing postcodes on letters as a co-production of the postal service, to public housing tenets "comply[ing] with certain norms of behaviour" (p. 132), like not littering or breaking communal amenities, as coproducing building cleanliness and safety. While these two examples demonstrate ways that co-production can bring individual or collective benefits, Alford's use of the term does not require collective or collaborative actions between service users and professionals. These examples also fall under the category of what Brudney and England term passive activities, which they argue do not fall under the remit of coproduction.

A typology designed by Bovaird (2007) elegantly elucidates some of the fuzzier aspects of earlier work on co-production. He defines co-production as "the provision of services through regular, long-term relationships between professionalised service providers (in any sector) and service users or other members of the community, where all parties make substantial resource contributions." (Bovaird, 2007, p. 847). Bovaird describes seven different forms of relationships between service providers and service users: traditional professional service provision with 
user consultation; user co-delivery of professionally designed services; full userprofessional co-production; user-community co-delivery with professionals (with no formal planning/design); user-community sole delivery of professionally planned services; user-community sole delivery of co-planned services; and traditional self-organised community activity (Table 2.1). This typology demonstrates that there is a spectrum of co-production and varying degrees of participation by service users and service professionals, depending on factors such as resources available, type of service, capacity of service users, etc. Bovaird, however, stipulates that full co-production only occurs when service users or citizens are involved in both planning and delivery of the service.

Table 2.1: Types of co-production (Bovaird)

\begin{tabular}{|c|c|c|c|c|}
\hline & \multicolumn{3}{|c|}{ Service design/ planning } \\
\hline & & $\begin{array}{l}\text { Professionals } \\
\text { only }\end{array}$ & $\begin{array}{l}\text { Professionals } \\
\text { AND } \\
\text { Users }\end{array}$ & Users only \\
\hline \multirow{3}{*}{$\begin{array}{l}\text { Service } \\
\text { delivery }\end{array}$} & $\begin{array}{l}\text { Professionals } \\
\text { only }\end{array}$ & $\begin{array}{l}\text { Traditional } \\
\text { professional } \\
\text { service } \\
\text { provision }\end{array}$ & $\begin{array}{l}\text { Traditional } \\
\text { service } \\
\text { provision with } \\
\text { users involved } \\
\text { in design }\end{array}$ & $\mathrm{N} / \mathrm{A}$ \\
\hline & $\begin{array}{l}\text { Professionals } \\
\text { AND } \\
\text { Users }\end{array}$ & $\begin{array}{l}\text { User co-delivery } \\
\text { of } \\
\text { professionally } \\
\text { designed } \\
\text { services }\end{array}$ & $\begin{array}{l}\text { Full user/ } \\
\text { professional co- } \\
\text { production }\end{array}$ & $\begin{array}{l}\text { User co- } \\
\text { delivery, little } \\
\text { professional } \\
\text { planning/ } \\
\text { design }\end{array}$ \\
\hline & Users only & $\begin{array}{l}\text { User delivery of } \\
\text { professionally } \\
\text { designed } \\
\text { services }\end{array}$ & $\begin{array}{l}\text { User delivery of } \\
\text { co-designed } \\
\text { services }\end{array}$ & $\begin{array}{l}\text { Traditional } \\
\text { self-organised } \\
\text { provision }\end{array}$ \\
\hline
\end{tabular}

Adapted from Bovaird, 2007 
Whilst most analysts base their definition of co-production on Ostrom's or Bovaird's usages of the term, as Voorberg et al. (2015) demonstrate, many studies of coproduction, or 'co-creation' describe instances where citizens are involved only in the implementation or only in the design stage. To add another complication to the mix, co-production is also used to refer to the involvement of third sector organisations in the welfare mix of delivering public services (Brandsen and Pestoff, 2006). As Brandsen and Pestoff contend, 'co-production' may encompass both the involvement of service users or third sector organisations in the design and delivery of services. The latter use of the term can be extricated to include co-management, where third sector organisations deliver services in partnership with others including public bodies, or co-governance, which involves the involvement of third sector actors in decision-making about services. These variations contrast greatly from the definitions discussed in the previous paragraphs, where the focus is primarily on the co-production between citizens (as individuals) and the state or public bodies. Indeed, many studies use the term co-production to refer specifically to the co-production between citizens and government (e.g. Joshi and Moore, 2004; Sharp, 1980).

While Brudney and England (1983) typologise who participates in co-production and who benefits, and Bovaird (2007) and Pestoff (2012a) discuss the forms of involvement or various 'co's (co-design, co-delivery, co-management, cogovernance), Brandsen and Honingh (2015) present a typology that distinguishes between degrees or extent of involvement in co-production (Table 2.2). Their typology is based on the degree to which citizens are involved in the design and implementation of services, with their original contribution being that the second 
axis is whether this involvement is in the core service or complementary tasks. This model aims to be inclusive of, but build upon, different definitions in order to reflect the evolution of the literature over the past three decades, which has become increasingly interdisciplinary. This also helps us to evaluate some of the elements raised by the CLEAR framework, such as the level of relevance or perceived importance of the task they are involved in (Lowndes et al., 2006a).

Table 2.2: Types of co-production (Brandsen and Honingh)

\begin{tabular}{|l|l|l|}
\hline & Implementation & $\begin{array}{l}\text { Design and } \\
\text { Implementation }\end{array}$ \\
\hline Complementary & $\begin{array}{l}\text { Coproduction in } \\
\text { implementation of } \\
\text { complementary tasks }\end{array}$ & $\begin{array}{l}\text { Coproduction in service } \\
\text { design and implementation } \\
\text { of complementary tasks }\end{array}$ \\
\hline $\begin{array}{l}\text { Non- } \\
\text { complementary }\end{array}$ & $\begin{array}{l}\text { Coproduction in the } \\
\text { implementation of core } \\
\text { services }\end{array}$ & $\begin{array}{l}\text { Coproduction in the design } \\
\text { and implementation of core } \\
\text { services }\end{array}$ \\
\hline
\end{tabular}

Source: Adapted from Brandsen and Honingh (2015)

Finally, Osborne and Strokosch (2013) categorise three different modes of coproduction based on aims, which they define as consumer co-production, participative co-production and enhanced co-production. They argue that these modes of co-production are determined by whether the aim is user empowerment (as consumers), user participation (through consultation and participative planning), or user-led innovation, respectively. It is the third mode - enhanced coproduction - which they argue is potentially the most transformative.

In this third mode, consumer based mechanisms in operational delivery of public services are combined with participative ones at the strategic 
planning level to produce the potential for transformational effects upon the public services delivery system as a whole - user-led innovation of new forms of public service delivery. (Osborne and Strokosch 2013, p. S39)

This typology is framed as an effort to incorporate the approaches of the services management literature, which contends that services are inherently characterised by co-production, rather than seeing co-production as a potential add-on (Johnston and Clark, 2008), and the public administration perspective, which I have discussed. Osborne and Strokosch's typology provides a particularly useful basis for understanding the way in which logics and motivations influence co-production behaviour and activities, as it integrates an understanding of both the market-based motivations for co-production as well as the democratic and participative ends.

The typologies discussed are concerned with which actors are involved in coproduction, and which activities they take part in, in order to categorise different types of co-production, or often in order to determine whether the activity qualifies as 'full' co-production. I return to these models in section 2.6 where I discuss my operationalisation of the co-production concept. While some of the works discussed have included analysis of case studies to develop typologies, many are purely theoretical. The vast range of conflicting definitions and models of co-production make it nearly impossible to establish exactly what co-production is, and in many ways it may be more helpful to investigate what co-production does. Elsewhere in the literature, other scholars have conducted empirical studies in order to build the evidence base on co-production. In the next section, I discuss some of the recent studies that have been conducted, and the various theories and conclusions 
developed about the benefits of co-production and the factors that are suggested to enable and constrict actors' capacities to co-produce.

\subsubsection{What does co-production do?}

Much of the work on co-production has taken a normative position of promoting the benefits that co-production is purported to offer, centring around two primary arguments: the improvement of democracy and citizenship, and increases in efficiency and better services. However, most studies focus on processes, rather than outcomes, which has meant that the evidence base for co-production is somewhat limited (Bovaird and Loeffler, 2012; Verschuere et al., 2012). I first review the primarily normative literature that calls for an increasing attention to coproduction because of the benefits and outcomes it is suggested to produce. I then discuss the various studies that have been undertaken to produce a more cohesive and comprehensive evidence base, the research designs used and the conclusions reached, in order to establish the state of the art of co-production research and identify the weaknesses and gaps in the literature so far.

\section{Suggested benefits}

Across Europe, and especially in the UK, there is a growing body of academic and grey literature that takes a normative position in relation to co-production, promoting arguments for public service professionals and citizens to engage in more co-productive working because of a range of purported benefits (Boyle and Harris, 2009; Hampson et al., 2013; Horne and Shirley, 2009). Co-production is said to be a solution to the challenges of ageing populations and growing strain on the 
welfare state in many countries (Pestoff, 2012a). One of the qualitative arguments for co-production, influenced by Arnstein's participation ladder, is that the process of partnership between professionals and service users leads to a redistribution of power - from an expert-led model where users are 'done to' to a model where users 'do with' professionals (Dunston et al., 2009).

This redistribution of power also extends to the valuation of alternative types of knowledge. According to Needham (2008), co-production allows for a greater recognition of the expertise of both frontline staff (who may feel marginalised in technocratic service delivery systems) as well as seeing service users as 'experts by experience' rather than simply recipients of services. Through building relationships and trust between service providers and service users, Needham argues that service quality can improve as they are more aligned to citizen preferences.

$$
\begin{aligned}
& \text { Co-production can be a therapeutic tool (building trust and } \\
& \text { communication between participation, allowing bureaucrats and } \\
& \text { citizens to explain their perspective and listen to others) as well as a } \\
& \text { diagnostic one (revealing citizens' needs, identifying the main causes of } \\
& \text { delivery problems and negotiating effective means to resolve them). } \\
& \text { (Needham, 2008, p.223) }
\end{aligned}
$$

This qualitative improvement, through a reliance on relationship building and communication in order to more effectively design and deliver services, is expounded upon by several scholars. Co-production, like other deliberative and collaborative processes, is said to improve social capital and feelings of community belonging among participants (Evers, 2006). It is seen as a way to combat the 
democratic deficit and gaps in public accountability, by erasing the gap between the public sector and citizens and allowing citizens to have more direct influence over the services they use (Pestoff, 2008).

From a more financial point of view, several authors have posited that coproduction may increase efficiency and lead to cost savings (Alford and O'Flynn, 2012; Boyle and Harris, 2009). This is purported to do with the aforementioned greater coherence between the service offer and service user preferences, thereby reducing waste and inefficiencies. However, the impact of co-production on the cost of services is a debateable claim for two reasons. First, some evidence suggests that taking a more co-productive approach, like any other citizen participation activities, may in fact require greater investment and resources from service providers, at least initially (Irvin and Stansbury, 2004). Recognition of the cost of co-production is, however, relatively scarce within the co-production literature, where the primary narrative refrain insists upon these processes' capacity to reduce costs. Providers may be hesitant to invest in different structures or training for staff in order to engage in co-production, without proof that there will be cost savings in the future as a result. In addition, as Pestoff (2006) suggests, while co-produced services may be cheaper, this is often as a result of shifting work that was previously performed by paid professionals to unpaid service users and volunteers. Thus, this claim is somewhat misleading and any evidence of cost savings due to co-production needs to be investigated to explain why this might be the case. 


\section{Empirical evidence of co-production}

As several scholars have noted, whilst the theorising and typologising about coproduction has been widespread, empirical evidence has been slower to emerge. In recent years, research has been conducted that aims to investigate and explain four broad areas: who co-produces and how they are enabled to and constrained from doing so; how organisations and individuals can be encouraged or persuaded to coproduce; what the impacts of co-production are; and finally, which types of organisations are better at co-production, or as Durose et al. (2017) put it, "Most of the theorisation around co-production has been of the who/ what/ when/ how type [...] and it is less common to find accounts of why it is that co-production is expected to produce its espoused benefits" (p. 138). In this section, I will discuss some of these studies and their contribution to our overall understanding of co-production, specifically in order to better understand co-production from an international comparative perspective.

Despite the large number of purported benefits of co-production, relatively few studies have been undertaken to provide empirical evidence of these. Part of the probable justification for this gap is that proving the impacts of co-production is notoriously difficult, firstly, because of the fact that the term itself is so contested and unstable.

What is notable for debates on evidence-based policy making is that coproduction has been granted an influential role in the future of public services and indeed public governance on the basis of little formal evidence. It is used to signify and denote by a range of policy objectives and the means of achieving them. (Durose et al., 2017, p. 137) 
As demonstrated in the previous section, co-production as a term can be used to describe a wide range of dissimilar practices, making it challenging to produce comparative or generalisable evidence. In addition, previous research takes two different perspectives on the existence or purpose of co-production - whether it is a means to describe the way in which particular services are delivered, or whether it is part of a more innovative and aspirational evolution in service delivery (Needham and Carr, 2009). Whether a researcher takes the former or latter position is not always made explicit, but this posture is like to dictate the researcher's research focus and analytical framework.

Furthermore, evidence to support the claims of co-production proponents is difficult to acquire and evaluate because of the nature of the normative claims made about co-production. If we cannot adequately define and delineate what is and is not co-production, what we mean by 'better services' or an improvement to the democratic deficit, we cannot evidence these improvements. In relation to the economic benefits of co-production, or the suggestion that co-production leads to service efficiencies, this is likewise challenging to evidence because the cost savings gained may take place in a different department or service area to where the coproduction took place (Bovaird and Loeffler, 2012). Durose et al. (2017) argue that in order to produce an evidence base for co-production, we need to move away from a traditional understanding of what constitutes sufficient evidence, i.e. quantitative, controlled studies, and towards a recognition that the relational aspect of coproduction necessitates a greater appreciation of the specificity of local cases and an approach of theory-based evaluation. 
Recognising and appreciating that co-production research has been predominantly theoretical, there have been a number of empirical studies that help us to better understand co-production, particularly from a process or practice point of view. One of the primary focuses of co-production research has been on seeking to better understand who engages in co-production, and whether co-production activities attract different communities/populations than other types of citizen participation. One of the criticisms of Arnstein's ladder and some of the subsequent works on citizen participation is that there is often a lack of focus on who is taking part in participation initiatives. The contention is that unless efforts are made to involve 'vulnerable' or 'hard to reach groups', many participation activities may reinforce existing power structures and only involve the 'usual suspects'. Some studies of coproduction have provided evidence that co-producing public services may, in fact, be an effective way of engaging with and involving poorer populations. As Ackerman claims, "Even the poorest citizens are exceptionally willing and able to actively work with government in constructive ways once they perceive that their participation can make a difference" (Ackerman, 2012, p. 101). Joshi and Moore (2004) provide evidence to support this argument, demonstrating that co-production between state agencies and citizens to deliver services in developing countries did in fact engage greater populations to the process and improve service delivery.

Another area of focus has been on why people do or do not engage in co-production. Focusing first on citizens, Alford (2014) argues that citizens may initially be driven by material concerns (i.e. increasing service access or quality) but may also then gain intrinsic benefits from involvement, such as independence or confidence. Van Eijk and Steen $(2014,2016)$ conducted empirical research in Belgium and the 
Netherlands into the motivations of citizens to co-produce, and concluded that these motivations are based on a combination of three factors - community oriented drivers, self-interest, and finally a perception of the difficulty of co-production and the extent of their ability to contribute. On the side of the 'regular service providers', Tuurnas (2015) studied why professionals take part in co-production and how they manage the introduction of co-production pilot projects. In the case study she examined in Finland, she found that a dramatic change in culture was needed from the side of professionals, an argument which has been made previously (Bovaird, 2007). In addition, professionals lacked sufficient tools and training to engage in coproduction and there was a distinct gap between the rhetoric of participation and actual practice.

As previously noted, much of the literature on co-production specifically investigates co-production between government or public bodies and citizens. However, in many countries, public services are outsourced to private and third sector organisations, so there are in fact a range of organisational types that deliver services, which operate in different ways and have different types of relationships with service users and citizens. Several scholars have argued that third sector organisations are inherently better equipped than public or private sector organisations to engage in co-production with service users (Pestoff, 2009; Vamstad, 2012). Through a comparative analysis of municipal childcare and cooperative childcare services in Sweden, Pestoff demonstrates that the opportunities for parent participation and co-production are far more abundant in the third sector organisations, and that there exists a 'glass ceiling' for citizen participation with public sector providers. This was seen to be because while the culture of public 
organisations generally restricted parent participation, the structure and culture of third sector organisations easily facilitates such a close collaboration between service users and professionals. This proximity to service users and communities as a facilitator for third sector professionals to engage in co-production has also been argued by others (Alford and O’Flynn, 2012).

\subsection{Co-production in the francophone literature}

Given that this research is a comparative study of England and France, an inspection of the literature reviewed thus far reveals a glaring gap - I have not discussed any literature in French or by French scholars. Whilst the word 'co-production' does technically directly translate into French, it is a term that is conspicuously absent from the francophone literature on the third sector, public services and citizen participation. I will discuss the limited instances I found of the utilisation of the term co-production in French, and consider the related francophone literature on citizen participation and co-construction, which is a related, but not equivalent concept. As noted in section 2.1 , my ability to investigate the French literature was facilitated by my fluency in the French language, but I also received support and advice from francophone colleagues in identifying relevant articles and books. The methodology with regard to conducting research in two languages is discussed further in Chapter 4. 


\subsubsection{Citizen participation in the French literature}

Citizen involvement and participation has received somewhat limited attention in the French academic literature. French theorists recognise Arnstein's ladder as the genesis of participation research, and highlight many of the same key areas for investigation as the anglophone literature, e.g. who is participating, what impact participation has on decisions (Blondiaux and Fourniau, 2011). The field of participatory democracy is comparatively underdeveloped, however, with few researchers studying collaborative approaches, and deliberative democracy even less researched (Bacqué and Gauthier, 2011; Sintomer and De Maillard, 2007). Participation research also has seemingly been conducted in silos, as Blondiaux and Fourniau note in a special issue of Participations on 'Democracy and participation: the state of knowledge':

What is striking from reading the eight contributions in this issue is the fragmentation of references, concepts and goals. [...] It is as if participation researchers worked in separate libraries whose catalogues did not overlap. [...] Research on participation takes the appearance of a rhizome in the sense of Deleuze and Guattari, a movement whose origin and centre remain untraceable, manifested in multiple directions and of which each small offshoot constitutes a potential focus of innovation. (Blondiaux and Fourniau, 2011, p. 12, translation mine)

Many French scholars are quite sceptical or critical of public authorities' attempts to interpret and implement models of participation. In relation to urban planning, Bacqué and Gauthier (2011) argue that it is difficult to assess or evaluate collaborative planning processes because most cases are still experimental or pilots. 
In addition, this notion of involving citizens in planning has been imported from English speaking countries, to the extent that the term 'community planning' is used in English, despite the fact that Bacqué and Gauthier's article is written in French. Urban regeneration is an area in which the French state has attempted to introduce a more participatory approach, through a policy called the politique de la ville (which will be reviewed in greater detail in Chapter 5), but several scholars bemoan the ineffectiveness of these efforts. Donzelot and Epstein (2006) note in their study of urban regeneration that they were unable to find any examples that would meet the criteria of Arnstein's highest rungs of the ladder of participation. Likewise, Sintomer and De Maillard (2007) argue that the politique de la ville has fallen far short of its aims because the state continues to be resistant to the influence of citizens.

Moreover, Sintomer and De Maillard (2007) posit that this lack of attention to participatory and deliberate democracy in France is due to the strength of the republican tradition and the importance attributed to representative democracy in France. This disconnect between studies of representative democracy and those of participatory and deliberative democracy has been discussed in the English literature as well (e.g. Urbinati and Warren, 2008), but its absence is perhaps more pronounced in the French literature where representation is a cornerstone of the conception of democracy. This has led to a culture of public bodies where citizens are seldom called to participate in decision-making, compared with Anglo-Saxon countries. The story of citizen participation in France is one of conflict and paradox, where strong traditions of local social activism (such as the social centre movement, which is studied in Chapter 6) must contend with newly introduced, institutionally 
driven involvement efforts, which are often at odds with an ethos of citizen empowerment (Bresson, 2004).

\subsubsection{Co-production and co-construction}

One of the few examples of a discussion of co-production in French is by Laville $(2005,2010)$, but his understanding of co-production is somewhat different to what we find in the anglophone literature. Laville makes some mention of co-production of social services in the specific context of 'solidarity services' (services solidaires) and 'proximity services' (services de proximité), which can both roughly be defined as locally rooted, third sector based services. Solidarity services, Laville argues, are distinguished from other types of social services by their co-productive approach, where service providers and users are involved in a dialogue to "jointly construct the supply and demand" (Laville, 2005, p. 115, translation mine). This definition is more in line with the services management perspective of co-production, which contends that co-production is an inherent part of the service process as a service is both produced and consumed at the same time (Johnston and Clark, 2008; Osborne and Strokosch, 2013). Laville's approach differs from both this services management perspective as well as public management scholars, neither suggesting that all services involve co-production nor that this way of working could be applied across different types of services and organisations. He instead sees co-production as an aspect that distinguishes an ideal type of solidarity services.

What is revealed by the ideal type of solidarity-based services, drawn up on the basis of real situations which have gone far beyond the experimental stage, is how the major problem of trust has led to an institutional innovation, which is not merely the result of market 
mechanisms, but is based on co-construction which goes beyond the co-production inherent in all services to take employment out of the domestic sphere and enhances the standing of the tasks performed by employees. (Laville, 2003, p. 612, emphasis mine)

In the quote above (from an article written in English), Laville distinguishes between co-production, and co-construction, which is the term used more frequently in the francophone literature (from France, but also from Quebecois scholars publishing in both English and in French). In the francophone academic literature, co-construction is elaborated by Quebecois researchers to refer to the involvement of citizens and associations further 'up stream' in creating public policy, as distinguished from co-production, which is thus defined as the involvement in the implementation of public policy (Vaillancourt, 2009; Jetté and Vaillancourt, 2011). Co-construction is thus more analogous to the way that 'co-planning' or 'cogovernance' are used in England, whereby citizens are involved in setting forth priorities and contributing to policy-making, rather than in delivering services. Like co-production in the UK, co-construction has entered public discourse and has become increasingly promoted practice by government bodies and associations in France (Kacza and Peigney, 2016).

Whilst there are some clear similarities and crossovers between these narratives of co-production and co-construction, the lack of terminology and discussion in the French literature of practices that comprise citizen involvement in both decisions and delivery is striking and has implications for comparative research. In crossnational or cross-cultural research, the researcher must be cognizant of one's own cultural subjectivity and endeavour not to impose foreign concepts that do not 
accurately reflect local conventions (Mangen, 1999). In this instance, is the lack of discussion of co-production reflective of the lack of practice in French? Or are different narratives used to describe these practices? I will reflect further on this challenge of language in international comparative research in Chapter 4.

\subsection{Gaps and weaknesses of the co-production literature}

Several of the key weaknesses in the co-production literature have been mentioned in the previous sections, including the lack of conceptual agreement across studies and the dearth of empirical evidence to support some of the claims about the benefits of co-production. In this section, I discuss these in greater depth and introduce some further arguments in order to demonstrate the contribution of the current study. I focus on the importance of clarifying the unit of analysis or the element that is being co-produced, the issue with framing co-production as a change in organisational culture, and finally the lack of comparative international studies of co-production as key weaknesses, and discuss how this research will address these issues.

\subsubsection{Co-production of what?}

One of the major stumbling blocks that characterises the variety of literature on coproduction is that the term means different things to different theorists. If we speak about co-production, we must assume that something is being produced. One of the divisions in co-production theory is the focus on what is being co-produced, or what exactly participants are contributing to. There appear to be two interpretations of 
this in relation to public services - one that looks at the co-production of services, and another that focuses on co-production of outcomes or benefits - but other researchers also focus on co-production of knowledge (Edelenbos et al., 2011) and co-production of research (Beebeejaun et al., 2014). This first split between coproduction of services or outcomes is evident in the evolution of Bovaird's work in particular. His 2007 definition (discussed in the previous section) is juxtaposed here with more recent work:

The provision of services through regular, long-term relationships between professionalized service providers (in any sector) and service users or other members of the community, where all parties make substantial resource contributions. (Bovaird, 2007, p. 847)

Co-production is about 'Professionals and citizens making better use of each other's assets, resources and contributions to achieve better outcomes or improved efficiency' (www.govint.org, accessed on 31 May 2014) - this is in keeping with Brudney's argument but emphasises outcomes rather than simply public services. (Bovaird et al., 2015, p. 2)

In the second definition, Bovaird et al. (2015) draw upon the argument from Brudney and England (1983) that the intention of co-production is to improve the quality or quantity of a service, but reject the notion that co-production must be about co-production of a service. Identifying co-production (and its barriers, enablers, impacts, etc.) of outcomes is inherently woollier than identifying the coproduction of services, where a deliberate collaboration between different actors can be studied. For instance, Parrado et al. (2013) identify "telling other people not to drop rubbish" and "trying to recycle" as examples of citizens co-producing a clean environment. This use of the term is far removed from a conceptualisation of co- 
production as a long-term, intentional collaborative relationship between individuals (service users, community members) and professional service providers, which stretches the term co-production to its limits.

In many studies, this issue of 'what' is being produced is not made explicit, rendering the possibility of comparison between studies difficult, and problematic for maintaining rigorous standards of scientific research. This issue is exacerbated by the fact that most co-production studies, in their literature reviews, fail to differentiate between studies that focus on co-production of services and those that study the co-production of outcomes, despite the fact that these can refer to very different processes and activities. This seems particularly problematic when discussing the benefits of co-production and the motivations of citizens to take part - it is difficult to imagine how a citizen's intentional decision to take part in a collaborative co-design activity with professionals or volunteer for a mentorship programme might be understood in the same way as an individual co-producing their healthcare by taking their medication, or co-producing community safety by locking their doors. This false equivalence in the literature could be resolved simply by distinguishing between the co-production of services and/or projects, and coproduction of outcomes. In this study, the research is designed to interrogate the former usage of the term, where the collaborative relationship between professionals and citizens is the focal point.

\subsubsection{Co-production as culture change}

As elaborated in section 2.2 .2 of this chapter, co-production is frequently conceptualised and framed as being part of a wider evolution in public 
administration from a traditional hierarchical system, through to the more business and management oriented phase of NPM, to new models that prioritise networked governance and collaboration. Aside from those that take the position that coproduction is an inherent part of the service delivery process (as discussed in Osborne and Strokosch, 2013) this notion that co-production is a new way of doing things is evident in articles that do not explicitly trace this trajectory. Implicit in this line of argument is that service providers previously provided services in a topdown, professional-to-beneficiary type arrangement, which had been characteristic of publicly provided services.

Beginning from this position of 'co-production as culture change' is problematic when studying co-production between citizens and professionals in the third sector. Much of the literature about the third sector, both in England and in France, (which is analysed in Chapter 5) highlights the values of community rootedness, solidarity and reciprocity that therefore lead to an assumed approach of citizen collaboration and cooperation characteristic of co-production. Studying third sector coproduction is then less about understanding changes in the way things are done, which is an approach influenced by literature on co-production with public sector professionals, who are assumed to be relatively risk averse, bureaucratic and influenced by traditional means of delivering services (Boyle and Harris, 2009). Rather, in the case of third sector co-production, we should begin from a consideration of the third sector, and whether co-production narratives and practices do or do not form part of this - i.e. how can we better understand the 
relationship between third sector organisations and citizen participation/ coproduction?

\subsubsection{Comparative studies of co-production}

The final, and perhaps most exigent, shortcoming of the co-production literature is the absence of studies that take a comparative perspective. Numerous studies examine case studies or survey respondents from multiple countries, such as Pestoff (2006), Van Eijk and Steen $(2014,2015)$ and Parrado et al. (2013). None of these, however, employ a comparative research design, and thus do not attempt to analyse what may differentiate co-production between countries. This poses several problems both conceptually and methodologically. First, there is a widespread assumption through the literature that one conceptualisation of co-production can be utilised in cross-national research and that we can assume an international coherence of theoretical understandings. As I discussed through an evaluation of the francophone literature on co-production and co-construction, this is a clearly problematic premise because of the fact that co-production does not have the same conceptual currency to French academics. Assuming that co-production is a universally acknowledged and applicable concept assumes that actors in different countries have similar understandings about the role of citizens, what it means to 'deliver' services and the relationship between third sector actors and the state.

Second, there is a need for more research that aims to understand how and why coproduction may be understood and undertaken differently in different contexts. Undertaking multiple country case studies without analysing the underlying institutional and cultural differences overlooks important factors that may influence 
other variables, such as enablers and barriers to co-production. As Pestoff hypothesises:

It is important to remember that co-production takes different forms in different welfare regimes (Esping-Andersen, 1996) and in different policy sectors in the same country. In other words politics and policy are important for promoting or discouraging citizen participation and coproduction. (Pestoff, 2009, p. 215)

Some studies have indeed investigated the way in which public policy can proactively promote co-production process (e.g. Durose and Richardson, 2016), but there has been as yet no investigation of the way that co-production practices differ under different welfare regimes.

In a broader sense, there has been limited focus on how institutions - either within one country or comparing internationally - enable or constrain third sector organisations to co-produce with service users or citizens. Because of the implicitly normative approach taken by many studies of co-production, most research has focused either on understanding exemplar case studies to support theory and models or on identifying factors that could facilitate co-production. There has been little attention paid to the ways in which political, societal and cultural factors may encourage or prevent these behaviours. Undertaking comparative international research allows for an analysis of these more systemic variables. 


\subsection{Coming to an operational definition of co-production}

The previous three sections of this chapter have sought to demonstrate the relative instability and lack of theoretical consensus about co-production as a term. This was outlined through a discussion of the various typologies that differentiate between types and aspects of co-production. What became evident upon moving from the literature review to producing the research design and methodology for this study was that while definitions of co-production are abundant and seek to offer a degree of theoretical clarity, an immense level of ambiguity arises when seeking to use these definitions to demonstrate what is and is not co-production in practice. Several divisions and debates within the co-production literature arise from these studies, which are summarised as follows:

1. Whether co-production must be an active, intentional act by participants, or whether passive activities can be considered co-production.

2. Whether a relationship or direct collaboration is required between the 'regular producers' (i.e. public service professionals) and 'co-producers' (service users, community members, other citizens) or whether actions taken independent of one another can contribute to co-production.

3. What is being co-produced - services or outcomes/benefits?

In addition, as discussed in section 4, the term co-production is almost entirely absent from literature in French. In this section, I seek to produce a workable definition of co-production that remains sensitive to these academic and theoretical discrepancies, and that delineates the concrete examples and practices that I consider to meet a definition of co-production in order to be able to confidently 
identify and define these in fieldwork. Through the course of reviewing the literature on co-production, I sought to synthesise the various definitions and develop my own that I felt was the most comprehensive and useful as a way to categorise co-production practice. The first working definition of co-production I formed was the following:

The long-term involvement of service users/ citizens in the decisionmaking, governance and/or service planning processes of the organisation whereby a degree of power is transferred from service professionals to users.

I came to this definition because I felt it was important to include three elements: 1. the idea that co-production should be long-term, rather than one-off activities, 2 . the activities or processes in which individuals are involved (i.e. decision-making, governance and/or service planning), and 3. the element of power transfer from professionals, highlighting that co-production goes beyond consultation. However, after having tested this definition in preliminary key informant interviews, I determined that my definition was perhaps overly convoluted and did not in fact clarify what I aimed to study. The element of power transfer, in particular, contradicts the argument discussed in 2.5.2 that co-production within the third sector does not necessarily require culture change. Instead, I draw upon Bovaird's (2007) definition:

The provision of services through regular, long-term relationships between professionalized service providers (in any sector) and service users or other members of the community, where all parties make substantial resource contributions. (Bovaird, 2007, p. 847) 
There are several strengths to this definition that make it clear why it is widely accepted by many co-production scholars. First, this allows for co-production between third sector professionals and citizen/ service users which differs from some other definitions which focus only on public sector co-production. It also focuses on long-term relationships - while 'long term' can certainly be interpreted in many ways, the importance is placed on trust building and communication between various actors, thereby excluding activities where stakeholders do not interact, such as the previous example of citizens co-producing environmental cleanliness by trying to recycle. Finally, making substantial resource contributions suggests that there is a degree of commitment and investment by the various parties, which necessarily omits involvement or participation initiatives where one or more parties simply "shows up" or "ticks boxes".

I have several caveats and additions to this definition in order to make it more precise and operational for empirical research. In Table 2.3, I expand upon the various aspects of Bovaird's definition in order to make it operationally applicable for this research study. 
Table 2.3: Operationalising a definition of co-production

\begin{tabular}{|l|l|}
\hline Definition & Notes \\
\hline "the provision of services" & $\begin{array}{l}\text { Or the implementation of projects that would } \\
\text { not be defined as 'services' per se. }\end{array}$ \\
\hline $\begin{array}{l}\text { "regular, long-term } \\
\text { relationships" }\end{array}$ & $\begin{array}{l}\text { Key here is the intentional collaboration } \\
\text { between citizens and professionals. }\end{array}$ \\
\hline $\begin{array}{l}\text { "between professionalized } \\
\text { service providers (in any sector) } \\
\text { and service users or other }\end{array}$ & $\begin{array}{l}\text { For the purposes of this study, the focus is on } \\
\text { professionals working for third sector } \\
\text { organisations, and service users or other } \\
\text { community members. }\end{array}$ \\
\hline $\begin{array}{l}\text { "where all parties make } \\
\text { substantial resource }\end{array}$ & $\begin{array}{l}\text { As per Bovaird's typology, full co-production } \\
\text { normally is defined as occurring when both } \\
\text { professionals and service users/ citizens are } \\
\text { involved in both planning or decision-making } \\
\text { as well as delivering or implementation (i.e. } \\
\text { co-design or co-planning plus co-delivery) }\end{array}$ \\
\hline
\end{tabular}

The first point of clarity is that I am focusing on co-production of public services, with public services referring to the provision of taxpayer funded, not-for-profit activities that aim to benefit society or are in the public interest. The activities provided by third sector organisations often fall within this category, particularly as many of these are funded with government contracts and grants. These include health and wellbeing, employment, leisure and social services. The notion of a service has the connotation of being supplied and consumed, with co-production thereby describing instances where the citizen can be involved in both of these processes. I have however expanded my understanding of public services to also include projects or events that would not typically be described as being 'provided' or 'delivered' in the same way, but which involve the same process of collaboration between citizens and professionals in decision-making and execution. These would include other types of projects and activities, such as events or trips. Broadening the 
target to include other projects, events and other non-service specific activities also recognises the range of actions undertaken by third sector organisations.

Second, I have chosen to focus on the collaboration between service users/ citizens and professionals, or activities that can be considered active co-production:

Active coproduction consists of deliberate behaviors directed toward enhancing service quality, such as working as a volunteer. In contrast, passive coproduction involves inaction (i.e. not undertaking certain actions). (Brudney and England, 1983)

For the purposes of this research, then, I focus only on activities where there is intentional joint working between citizens and professionals. As such, I discount activities that are undertaken independently of one another or where the citizen is not deliberately contributing to decision-making, service design, and/or delivery.

Finally, like Bovaird (2007), I understand full co-production to mean the involvement of citizens and professionals in both design or planning as well as in delivery or implementation of services or other activities. Co-delivery can refer to many different types of activities, such as tasks that are complementary to the main service, as explicated by Brandsen and Honingh (2015, discussed in section 2.3.1). The key aspect is that citizens/ services users are involved in the doing. This clarification is also important to make to enable me to conduct research in France, where services are not discussed as 'delivered'; rather, actors use the verbs 'welcome' and 'accompany' (accueillir, accompagner) in relation to services (Dessaulle, 2005) or when in relation to other activities, 'run/present' or 'implement' (animer, mettre en œuvre). This is an important linguistic and conceptual difference 
to account for in aiming to investigate co-delivery, and will be analysed in greater detail when considering the empirical data from case studies.

\subsection{Conclusions}

In examining the literature on co-production, it seems that the proliferation of scholarship has served to diversify the definitions on the topic rather than bringing a sense of conceptual coherence. This ambiguity, along with the difficulty in producing evidence on co-production, has meant that empirical studies have been less influential than the preponderance of theories and typologies about coproduction and different impacts that co-production might have. This is made more apparent when analysing the francophone literature, where the term co-production is seldom used and there appears to be no direct linguistic equivalent to describe practices of both co-design and co-delivery.

In this chapter, I have sought to summarise and analyse these various co-production typologies as well as the literature that supports the development of this concept, in order to establish the basis upon which this study will seek to investigate this phenomenon. In reviewing existing empirical studies on co-production, I have demonstrated the clear gap and need for research to compare the ways in which coproduction may vary between different countries.

The central point of interest of this research is on how we can better understand the role of institutions in driving and shaping co-production within third sector organisations. In order to further develop the theoretical background to the 
research, the next chapter reviews the literature on institutions and institutional logics as an analytical framework. 


\section{CHAPTER 3: INSTITUTIONAL LOGICS AND CO-}

\section{PRODUCTION}

\subsection{Introduction}

The previous chapter identified some of the key issues and gaps in the co-production literature, with particular attention paid to an analysis of differences in coproduction between countries. The purpose of this chapter is to locate these issues in a theoretical context, and to demonstrate how the theory of institutional logics can be applied to the study of co-production practice in the two contexts under investigation. The institutional logics approach presents a particularly useful conceptual tool to understand relationships and practices within organisations, such as co-production, as argued convincingly by Greenwood et al. (2010, p. 521):

Organizational forms and managerial practices are manifestations of, and legitimated by, institutional logics. Thus, to understand how and why organizations exhibit similarity and variation in such forms and practices it is necessary to trace the relationship between organizations and logics that constitute their institutional context.

I will thus discuss the relevant literature on institutions and institutional orders, followed by an analysis of the theory of institutional logics and the way in which these logics can be operationalised for study. I argue that the institutional logics approach provides a valuable framework to better understand differing 
conceptualisations and practices of co-production and that the analysis of institutions and their underlying logics is a conspicuous gap in the co-production literature.

\subsection{Institutions}

To understand the concept of institutional logics, it is first necessary to situate it within theories of institutions more generally. By 'institution' I refer to "the formal rules, compliance procedures, and standard operating practices that structure the relationship between individuals in various units of the polity and the economy" (Hall, 1986, p. 19). Similarly, Friedland and Alford define institutions as "both supraorganizational patterns of activity through which humans conduct their material life in time and space, and symbolic systems through which they categorize that activity and infuse it with meaning" (Friedland and Alford, 1991, p. 232). These definitions therefore encompass both the physical manifestations of political power such as parliament, but also formal and informal rules and procedures such as bureaucracy and traditions, or the way that people within organisations operate. Traditional institutionalist thinkers focused primarily on organisations, formal rules and procedures, and new institutionalism introduces the analysis of governance and the way in which institutions respond to change and constraints, and how these impact behaviour (Scott, 2014).

Whilst these definitions of institutions essentially concur with one another, further details and elements need to be elaborated in order to be able to recognise or 
identify an institution and the ways in which they shape organisations and individuals' behaviour within organisations. Scott (2014), for example, suggests an analytical framework where there are three key pillars of institutions, which consist of regulative, normative and cultural-cognitive elements. By 'regulative pillar', he refers to the rules and regulations that regularize behaviour, such as laws and sanctions. The normative pillar encompasses values, norms and beliefs, or ideas about preferred and desired outcomes and how things 'should' be done, based on a logic of appropriateness and social obligation. Finally, the cognitive-cultural pillar of institutions refers to the framing of issues, or the "shared conceptions that constitute the nature of social reality" (Scott, 2014, p. 67). This pillar describes the 'taken for granted' behaviours and understandings that shape common beliefs and drivers for action. Scott suggests that each pillar elicits a different form of legitimacy - i.e. legal, moral, and culturally supported.

Institutions are transmitted by and embedded in 'carriers', which Scott identifies as symbolic systems (culture), relational systems (networks, social positions), routines (structured activities and behaviours) and artefacts. Elements of the three institutional pillars will be found in different types of carriers. For instance, routines will evidence the regulative pillar in the form of protocols and standard operating procedures, the normative pillar in division of jobs and roles, and the culturalcognitive pillar in scripts (Scott, 2014). Zilber notes, however, that "social structures are constructed by people, routines are enacted by people, and cultures are interpreted by people." (Zilber, 2002, p. 236). Individuals within institutions are therefore fundamental to the creation and diffusion of institutions, and these symbols, routines and artefacts do not exist abstractly absent human creation and 
interpretation. As Zilber demonstrates, institutions result from the interplay between actors, actions and meanings. She argues that institutionalization occurs by means of human agency and the ways in which individuals frame and interpret behaviours.

Formalised rules (laws, formalised procedures, etc.) are typically straightforward to identify, but the informal aspect of institutions are less so. Several theorists have developed concepts to encompass these aspects, such as 'standard operating procedures' (Hall, 1986) or 'rules-in-use', which are distinguished from the more formal 'rules-in-form' (Ostrom, 2007). Both standard operating procedures and rules-in-use denote the norms of behaviour that may be explicitly or implicitly agreed upon by actors. Lowndes and Roberts (2013) build upon these notions and develop a typology for studying institutions, through identifying and describing three modes of institutional constraint. The authors suggest that institutions can be identified through the analysis of three modes of constraint: rules, practices and narratives.

Our argument is that institutions work through three modes of constraint - rules, practices, and narratives. The real agenda for institutionalism is to better understand how these distinctive modes of constraint interrelate in practice, and to establish what this means for ongoing processes of institutional change and prospects for institutional resistance and reform. (Lowndes and Roberts, 2013, p. 50)

These three constraints are broadly parallel to Scott's 'pillars' of institutions, but elaborate in more depth the particular elements that a researcher can analyse within institutional studies. Rules, typically the main aspect studied by 'old' 
institutionalists, refer to the formal and recorded standards, regulations, procedures and laws that constrain and define the acceptable behaviours of actors within an organisation. These provide an official structure to the way things are done. In addition to rules, institutions are constrained by practices, meaning the informal rules of the game - the acceptable behaviours that are demonstrated by other actors. "Unlike rules, these are not formally recorded or officially sanctioned. Their mode of transmission is, rather, through demonstration: actors understand how they are supposed to behave through observing the routinised actions of others and seeking to recreate those actions." (Lowndes and Roberts, 2013, p. 57). Finally, institutions are constrained by narratives, defined as the stories and frames that tie events and practices within a context together. Narratives are the spoken expression of ideas and the way that practices are justified by actors in order to create shared understandings. I will return to this typology of institutional constraints in section 3.5 where I develop my operationalised understanding of institutional logics.

What this typology allows us to do is to better explain differences in behaviours, procedures and actions between different organisations and the ways in which institutions - as in rules, practices and narratives - constrain and enable actors in particular settings. According to Greenwood and colleagues (2014), much of the research on institutions has become too concentrated on studying institutions themselves rather than using institutions as an independent variable to explain organisational processes. They call for the return to organisational studies, with an emphasis of using institutions and institutional processes as an explanatory factor. 
We need, in short, to resurrect a distinctive interest in the organizational level of analysis, treating the organization as a significant source of variability and also as prominent actors. In short, given that our general point of departure is organization theory, it follows that we should strive to understand how organizations are structured and managed, especially given the very distinctive nature and characteristics of contemporary organizations and of the challenges that they face. (Greenwood et al., 2014, p. 1210).

Rules, practices and narratives offer a way in which to operationalise the study of institutions and their impacts on organisations and individual actors. These three elements of constraint are found to be different within different institutional orders of society, creating what we understand as institutional logics.

\subsection{Institutional logics}

According to Lounsbury (2007), institutional logics refers to the cultural beliefs, norms of behaviour and rules that structure cognition and inform decision-making within organisations. Institutional logics are conceived as socially constructed and historically contingent. They are both material, in terms of organisational structures and practices, as well as symbolic, relating to assumptions, beliefs and identities within organisations (Thornton et al., 2012). In other words, an institutional logic is "the way a particular social world works" (Thornton and Ocasio, 2008, p. 101). Theorists of institutional logics posit that the approach addresses one of the weaknesses of neoinstitutional theory by including the importance of actors in context and providing a link between institutions and actions (Thornton and Ocasio, 
2008). In this sense, institutions are not immutable but are susceptible to and intricately linked to the will and the actions of the individuals and organisations that comprise them. Institutional logics explain how particular rules, practices and narratives are clustered and legitimised within certain sectors of society.

Institutional logics are conceived as existing linked to the main 'institutional orders' of society. Friedland and Alford (1991) argue that there are five primary institutional orders in Western societies - capitalism, family, bureaucratic state, democracy and Christianity. Each of these institutional orders is characterised by a particular mix of values, assumptions and structures that form its dominant logic or operating principles. Subsequent work by Thornton et al. (2012) builds upon this typology, suggesting seven ideal typical institutional orders - family, religion, state, market, profession, corporation and community (see Table 3.1). This perspective suggests that individuals and organisations will be variously impacted and driven by different logics depending on the institutional order in which they operate, and that conflicts arise when particular demands or situations clash with the dominant institutional logic. For instance, as Friedland and Alford describe, whilst elected bodies are able to make decisions by popular vote or consensus, they struggle to acknowledge or address claims of expertise or special privilege, because these conflict with the dominant democratic values.

Another of Friedland and Alford's main contentions is that institutional logics exist in hierarchical levels of society, meaning that the logics of each institutional order provide increasing levels of opportunities and limitations for behaviour of individuals and organisations. Whilst specific organisations and sectors may have 
their own defining logics, these are 'nested' within the "central institutions of the contemporary Capitalist West" which are "potentially contradictory and hence make multiple logics available to individuals and organizations" (Friedland and Alford, 1991, p. 232). These levels of analysis are the individual, organisational, field (meaning the organisations and actors that are connected or related by nature of their location or involvement in a sector of activity) ${ }^{1}$ and societal (Thornton et al., 2012). Actors face and utilise logics that may be specific to a particular organisation, but these are nested within and defined by the seven broader societal level logics. The characteristics of these seven ideal typical institutional logics can be described by identifying the sources of legitimacy, authority and identity of each, which are discussed in further detail in the following section (Thornton et al., 2012; Skelcher and Smith, 2015).

\footnotetext{
1 'Field' level can be interpreted in different ways based on the phenomenon under study for instance, for Thornton (2002), the field represents the higher education publishing industry. For the purposes of this study, field denotes the city level, and therefore comprises the constellation of organisations involved in public services and decision-making - third sector organisations, local government, funders, etc.
} 
Table 3.1: Institutional order ideal types

\begin{tabular}{|l|l|l|l|l|l|l|l|}
\hline & Family & Community & Religion & State & Market & Corporation & Profession \\
\hline $\begin{array}{l}\text { Sources of } \\
\text { legitimacy }\end{array}$ & $\begin{array}{l}\text { Unconditional } \\
\text { loyalty, } \\
\text { patriarchal } \\
\text { domination, } \\
\text { family } \\
\text { reputation. }\end{array}$ & $\begin{array}{l}\text { Unity of will; } \\
\text { belief in trust } \\
\text { and } \\
\text { reciprocity; } \\
\text { commitment } \\
\text { to community } \\
\text { values and } \\
\text { ideology; } \\
\text { emotional } \\
\text { connection } \\
\text { and }\end{array}$ & $\begin{array}{l}\text { Importance of } \\
\text { faith and } \\
\text { sacredness in } \\
\text { economy and } \\
\text { society; } \\
\text { priesthood } \\
\text { charisma; } \\
\text { association } \\
\text { with deities. }\end{array}$ & $\begin{array}{l}\text { Democratic } \\
\text { participation; } \\
\text { bureaucratic } \\
\text { domination; } \\
\text { social and } \\
\text { economic } \\
\text { class. }\end{array}$ & $\begin{array}{l}\text { Share price; } \\
\text { shareholder } \\
\text { activism. } \\
\text { Faceless. } \\
\text { Technical and } \\
\text { managerial } \\
\text { expertise } \\
\text { valued. }\end{array}$ & $\begin{array}{l}\text { Market } \\
\text { position of } \\
\text { firm; board of } \\
\text { directors, top } \\
\text { management; } \\
\text { bureaucratic } \\
\text { rules. }\end{array}$ & $\begin{array}{l}\text { Personal } \\
\text { expertise, } \\
\text { professional } \\
\text { associations, } \\
\text { association } \\
\text { with quality } \\
\text { of craft. }\end{array}$ \\
\hline $\begin{array}{l}\text { Basis of } \\
\text { norms }\end{array}$ & $\begin{array}{l}\text { Membership } \\
\text { in household }\end{array}$ & $\begin{array}{l}\text { Group } \\
\text { membership }\end{array}$ & $\begin{array}{l}\text { Membership } \\
\text { in } \\
\text { congregation }\end{array}$ & $\begin{array}{l}\text { Citizenship in } \\
\text { nation }\end{array}$ & Self-interest & $\begin{array}{l}\text { Employment } \\
\text { in firm }\end{array}$ & $\begin{array}{l}\text { Membership } \\
\text { in guild and } \\
\text { association }\end{array}$ \\
\hline $\begin{array}{l}\text { Basis of } \\
\text { strategy }\end{array}$ & $\begin{array}{l}\text { Increase } \\
\text { family honour }\end{array}$ & $\begin{array}{l}\text { Increase } \\
\text { status and } \\
\text { honour of } \\
\text { members and } \\
\text { practices }\end{array}$ & $\begin{array}{l}\text { Increase } \\
\text { religious } \\
\text { symbolism of } \\
\text { natural } \\
\text { events }\end{array}$ & $\begin{array}{l}\text { Increase } \\
\text { community } \\
\text { good }\end{array}$ & $\begin{array}{l}\text { Increase } \\
\text { efficiency } \\
\text { and/or profit }\end{array}$ & $\begin{array}{l}\text { Increase size } \\
\text { and } \\
\text { diversification } \\
\text { of firm }\end{array}$ & $\begin{array}{l}\text { Increase } \\
\text { personal } \\
\text { reputation }\end{array}$ \\
\end{tabular}

Source: Adapted from Thornton et al (2012) 


\subsubsection{Family}

The family institutional order is formed around the traditional nuclear family, which engenders values and norms of unconditional loyalty and, traditionally, patriarchal domination. Family reputation and honour are seen as important values that drive behaviour and actions. In terms of rules and practices, because the contingent unit is formed by blood rather that association or incorporation, there is limited impact of formal regulations on the family institutional logic, but informal practices and 'rules-in-use' are prevalent. In many ways, the family is often influenced by the logic of religion as well, with family values and norms traditionally defined by the church. The family logic is occasionally theorised to be at odds with the market logic, a conflict investigated by Greenwood et al. (2010), and the ways in which family owned businesses react to an overarching market logic that would favour downsizing as a way to protect profitability for shareholders. In this example, the family logic evidenced in family owned companies is shown to reduce the tendency to downsize, as the family logic emphasis on solidarity and loyalty trump the market logic.

\subsubsection{Community}

Thornton and colleagues (2012) introduced the idea of a 'community' institutional order to address a gap they felt existed in Friedland and Alford's original typology of ideal typical institutional orders. "Communities embody local understandings, norms, and rules that serve as touchstones for legitimating mental models upon

which individuals and organizations draw to create common definitions of a situation” (Thornton et al., 2012, p. 52). 'Community' is defined by Brint (2001) as 
groups of people, with shared geography, activities or beliefs who are joined by some loyalty or common set of values. The community logic therefore differs from other logics in drawing its legitimacy from an emphasis on trust, reciprocity and solidarity. The idea of community is based on a shared sense of membership in a group beyond the family, which may or may not be geographically contingent. Charities and associations naturally would be expected to be strongly influenced by this logic, as both their legal forms and stated norms/ missions require adherence to a non-profit and community benefit orientation. Narratives within this institutional order are framed in terms of reciprocity, charity and neighbourliness.

\subsubsection{Religion}

Religion as an institutional order logic is rooted in the values of faith and absolute moral principles as guiding forces for all activities. "[The institutional logic] of religion, or science for that matter, is truth, whether mundane or transcendental, and the symbolic construction of reality within which all human activity takes place." (Friedland and Alford, 1991, p. 248). Friedland and Alford's discussion of religion as an institutional order specifically focuses on the role of Christianity within the Western world, which they argue has a particular set of organising principles, values and symbols that have influenced both the development of democratic states as well as the capitalist economy. Religious rules are clearly delimited through religious texts and decrees; practices are carried out in both church settings and day to day life through worship, prayer and certain mandated behaviours; and narratives are delivered through priests as well as believers' descriptions of their faith and how it affects the things they do. 


\subsubsection{State}

The state is discussed in most definitions of institutional logics (Thornton and Ocasio, 2008). Within this institutional order, legitimacy is determined by democratic participation, the source of authority is bureaucracy and hierarchy, and membership is defined by citizenship. Interestingly, Friedland and Alford distinguish between a (bureaucratic) state logic - characterised by regulation and bureaucratic hierarchy, and a democratic logic - defined by an emphasis on participation and popular sovereignty in society, which we might expound to assume that there is an inherent contradiction within government bodies between sources of authority and legitimacy. Greenwood and colleagues' 2010 study investigates the role of the state logic (in addition to a family and market logic) on business approaches to downsizing in Spain, but recognises that two distinct historical periods in Spanish history produced two different approaches to the role of the state - one highly centralist and one decentralised, celebrating regional community differences. This study highlights the complexity inherent in studying institutions and the importance in recognising that logics are historically and contextually contingent. Thornton and colleagues' 2012 typology note that the basis of strategy of the state is to increase 'community good', a point that highlights the inherent blurriness of boundaries between the level of community and that of the nation-state.

\subsubsection{Market}

The market as institutional order is theorised to be about maximising share price or generating surpluses that can be distributed to owners or shareholders. The 
characteristics attributed to a market or commercial logic by Thornton (2002) include a mission of building a competitive position, a focus on resource competition and strategy of acquisition and growth. The main practice and aim of this institution is to sell goods and services. This logic then is clearly associated with the business world. However, as Friedland and Alford claim, "Capitalist firms cannot exchange unpriced human activities that may be rational for an organization or useful to individuals" (Friedland and Alford, 1991, p. 249). In relation to public services, the market logic is associated with the strategies of NPM, such as contracting out services, performance management and evaluation, and a view of service users as 'customers' (Vickers et al., 2017). In many studies of institutional logics, particularly in the case of 'hybrid' organisations, it is therefore this market or commercial logic that most commonly comes into conflict with another competing logic - such as a therapeutic (Spitzmueller, 2016), social welfare (Pache and Santos, 2013), family and regional state (Greenwood et al., 2010) or editorial logic (Thornton, 2002). In terms of narratives, the market logic is associated with ideas of efficiency and profitability, frequently manifested in for-profit organisational structures with hierarchical control.

\subsubsection{Corporation}

Whilst Friedland and Alford describe only five institutional orders, with capitalism being one, Thornton and colleagues distinguish between the market and corporation as institutional orders. The corporation is distinct in being centred on the reputation and performance of the firm as a unit of focus. Legitimacy within this institutional order is bestowed by the board of directors (as opposed to 
shareholders in the case of the market), and bureaucracy and hierarchy are defining characteristics. Evidently there are some commonalities between the corporation and the market, both with a focus on business success, but the corporation is distinguished as an institutional order in the focus on organisational structure, hierarchy and governance as appropriate practice and means of conveying legitimacy of decisions and behaviours. Fligstein (1990) suggests that distinct conceptions of control and decision-making are exhibited within the corporation, such as the motivations of executives to exercise power in particular ways, which distinguish it from other institutional orders.

\subsubsection{Profession}

The logic of professions revolves around the valuing of personal expertise within particular professions. Here, the transmission of the institution is through relationships between practitioners or professionals and the valuing of particular forms of experience and expertise over others. Unlike the corporation, the primary source of legitimacy within the professions is with individuals and the relationships between them, as opposed to at the organisational level within bureaucratic hierarchies (Thornton, 2002). Rules of the professions are established by professional associations and practices are transmitted through informal codes of behaviour. For example, legitimacy of medical professionals stems from their exclusive level of expertise, and the narrative of promoting the 'NHS ethos' (Vickers et al., 2017). Similarly, in Thornton's studies, the professional logic within publishing was demonstrated through personal reputations of editors, relational 
networks between editors and authors and professional reputation gained through the publication of successful books.

\subsection{Impact of Institutional Logics}

The literature on institutional logics argues that they have several important impacts on the strategies and behaviours of organisations and individuals. Friedland and Alford claim that institutional logics produce actor identities through the creation of symbols and practices and shape or reinforce organisational legitimacy.

Institutional logics represent frames of reference that condition actors' choices for sense-making, the vocabulary they use to motivate their action, and their sense of self and identity. (Thornton et al., 2012, p. 12)

Institutional logics shape decision-making and other actions of individuals within organisations in four key areas: determining which sources of power are legitimate, drawing the attention of decision-makers towards particular issues and problems as priorities and shaping the 'rules of the game', delimiting which potential solutions are appropriate to problems and issues that arise, and finally by affecting how well organisations adapt and change over time (Thornton, 2004). Numerous studies have used this concept as an analytical framework to explain a range of different phenomena and behaviours within organisations. I will analyse the studies that have focused on the interplay between multiple different logics.

Studies have thus sought to analyse the ways in which institutional logics impact various behaviours and practices within organisations. Thornton $(2002,2004)$, for 
instance, investigated the impact of a shift from a professional to a market dominant institutional logic had on restructuring processes within the higher education publishing sector. Her evidence suggests that over time, a shift in the industry from the dominance of a traditional editorial logic towards a market logic impacted governance structures and growth strategies within publishing companies. Thornton argues that institutional logics are important because they focus decision makers' attention on issues that correspond with the overarching dominant institutional logic. Implicit in Thornton's argument is the existence of one overarching prevailing logic which drives identities, structures and strategies within companies.

However, other studies suggest that organisations may be characterised by a multiplicity of logics, which may be competing, complementary or compartmentalised (Skelcher and Smith, 2015). In a study of mutual funds in Boston and New York, for example, Lounsbury (2007) demonstrates the varying impact of competing logics on organisational cultures and practices. Lounsbury suggests that whilst many studies on institutional logics increasingly recognise the existence of multiple logics in a particular field, the tendency has been to assume that one particular logic will be dominant and that this will promote 'isomorphic' responses (DiMaggio and Powell, 1983). "Extant research on logics has tended to emphasize how a dominant logic uniformly shapes organizations in a field, reinforcing notions of stability and institutionalization that harken back to early neoinstitutional formulation" (Lounsbury, 2007, p. 289). This emphasis on isomorphism provides weak explanations for organisational change and differences through time and across organisations, as several studies demonstrate that logics are contextually and 
historically contingent, thereby producing different impacts in different settings and at different points in time (Greenwood et al., 2010). As discussed, Thornton (2002, 2004) demonstrates the transition of dominant logics over time in a particular industry and the way that practices evolve as a result of a shift in logic. Thornton hypothesised that two distinct logics dominated the higher education publishing industry at different periods of time - an editorial logic in the 1960s and 1970s, and a subsequent prevailing market logic.

Many of the studies on competing institutional logics focus on the way that private firms negotiate a market logic and another competing logic, such as the professional (editorial) logic in the case of Thornton (2002, 2004). Further developing the literature on the impact of multiple logics, Greenwood et al (2010) seek to investigate how organisations manage the conflict between the prevailing market logic and two non-market logics - state or regional, and family - on companies in Spain. This study shows that the impact of family and regional pressures do not uniformly impact the firms that they study. In looking at how firms respond to institutional complexity, Greenwood and colleagues' study demonstrates that the logic of the state disproportionately influences organisations in particular regions and that processes at a community level may be obstructed or enabled by more centralised governance structures. "Where liberal principles are highly institutionalised, as in the U.S., regional pressures may have less force and less symbolic appeal, and thus their historical contingency may be less visible" (Greenwood et al., 2010, p. 535). This study is particularly relevant to the current $\mathrm{PhD}$ research as it indirectly opens a call for more comparative research on the impacts of institutional logics in different contexts. If, as the study suggests, state 
and community logics will have variable strengths and impacts in different regions, this is likely to be particularly evident in two countries with different governance structures and levels of centralisation.

Continuing this stream of research, Pache and Santos (2013) recognise a weakness in the literature in explaining the different ways in which hybrid organisations respond to competing institutional logics. "What is missing is a clearer picture of which elements of the logics organizational actors enact as they try to navigate competing demands as well as what factors drive these behaviours. This gap is important to address in order to account for the microfoundations of hybrid organizational forms" (Pache and Santos, 2013, p. 973). Whilst previous studies either suggest that organisations must necessarily be driven by the dominant logic of their institutional field or risk failure, others recognise that multiple competing logics exist for a single organisation or individual, but do not necessarily delineate the ways in which these logics are combined, conflicting or complementary. Pache and Santos show that in the case of work integration social enterprises (WISEs) in France, individuals and organisations are able to selectively interpret and enact various aspects of competing commercial (or market) and 'social welfare' logics. This selective coupling and decoupling of logics is argued to be a particular characteristic of 'hybrid' organisations (Skelcher and Smith, 2015).

The institutional logics perspective has some identified limitations that should be noted. One critique is that institutional logics as an analytical framework fails to attribute sufficient weight to the role and experience of actors within institutions. 'Institutional work' scholars aim to bridge this gap, arguing that we need to consider 
the contribution of individuals to creating, supporting and/or destroying institutions, which are after all the creation of humans (Lawrence et al., 2011). This literature prioritises the agency of actors, and often focuses on the role of institutional entrepreneurs and the ways that they instigate change from within institutions (Greenwood and Suddaby, 2006). However, this critique perhaps underestimates the capacity of the institutional logics approach.

What conjoins the institutional work and institutional logics research is an interest in practice. [...] By building upon anthropological and ethnological understandings of human action, a focus on practice has been central to the institutional logics perspective from its inception. (Thornton et al., 2012, p. 114)

Research on institutional work often presupposes that institutional logics are primarily preoccupied with more macro-level dynamics. However, as Thornton et al. argue (above), institutional logics can provide an effective lens through which to evaluate actors' decision-making behaviour and practices. In section 3.6 of this chapter, I will further delineate the way in which I operationalise the concept of institutional logics, which includes practices as one of three core components.

\subsection{Institutional logics and co-production}

Understanding the underlying logics of organisations can offer key insights in the study of co-production and the differences in co-production practices between different organisations, regions or countries. Co-production is inherently a relational process, driven both by normative aims of decreasing a democratic deficit 
and improving community cohesion and citizen empowerment, as well as more instrumental aims of increasing efficiency and improving outcomes for service users. The relative importance of these aims and strategies may be determined at the individual, organisational or broader field level. What becomes clear in analysing the literature on co-production, and particularly why and how co-production occurs, is that the focus is typically either on individuals and their motivations for taking part (e.g. Van Eijk and Steen, 2014; Vanleene et al., 2015), or on sectors and the degree to which third sector or public sector organisations are enabled or constrained to co-produce (e.g. Pestoff, 2009). Little attention has been paid either to the differences in co-production between different countries, or differences between organisations within the same service sector.

The institutional logics approach provides us with an analytical framework in order to compare and analyse both concrete and discursive differences in co-production. Institutional logics are concerned with how "cultural rules and cognitive structures shape organizational structures. [...] Institutional logics shape rational, mindful behavior, and individual and organizational actors have some hand in shaping and changing institutional logics." (Thornton and Ocasio, 2008, p. 100). This approach therefore addresses an important gap in the co-production literature - recognising that co-production practices are not solely based on the individual motivations of actors involved, but are also dependent upon and shaped by the logics of a particular sector and particular organisation. This thus allows us to better interpret differences between the approach that third sector organisations take to citizen involvement and co-production in England and France. 
In addition, a framework of institutional logics helps us to better understand decision-making and behaviour within hybrid organisations. For instance, Vickers et al. (2017) employ an institutional logics analytical framework in order to explain social innovation within social enterprises, characterised as hybrids of the state, community and market logics. They demonstrate that co-production with service users was one type of innovation identified in these organisations, which was facilitated by the co-existence of state, market and civil society logics. However, this study simply identified the existence of co-production practice as an innovation and did not interrogate different types of co-production or the way in which coproduction practices occurred. Although there is an increasing literature on the hybridity of third sector organisations, and some theorisation about how coproduction fits into this picture, this is typically in relation to how co-production forms part of a new form of more citizen-centred governance systems (Pestoff, 2014). There has been little scholarship investigating how this hybridity, or managing of multiple competing logics dictates co-production practice.

\subsection{Operationalising the study of institutional logics}

In order to identify the driving institutional logic - or combination of logics - of the third sector organisations under study for this research, it is necessary to first clarify how I operationalise the elements that constitute institutional logics in order to identify and evaluate these in the data collected from the case study organisations. Empirical studies on institutional logics have taken various methodological approaches to identifying the driving or primary logics in organisations. In this 
section, I will review the various methods used to analyse institutional logics and their impacts on behaviour within organisations, in order to develop the approach to be taken in my own research design.

According to Skelcher and Smith (2015), in order to empirically test the theories of the institutional logics approach in hybrid organisations, we must focus on four key variables and propositions: 'normative strength', meaning the degree to which the demands of a particular logic apply to an organisation or sector; 'actor identity', or the way that norms define and frame roles and actions of personnel within an organisation; the 'value commitment' of organisational members; and 'environmental turbulence', which the authors suggest may promote creativity and innovation. The identification of these variables within an organisation or field allows us to analyse the way that institutional logics exist in practice, how they influence actors and the way the environment shapes and creates demands and pressures on organisations.

The empirical studies on institutional logics take a variation of approaches in identifying whether and to what degree various logics are present. Lounsbury (2007) takes a quantitative approach by creating dummy variables to represent institutional logics to analyse a large-scale dataset. Thornton (2002) similarly presents a quantitative analysis of her data, but the two ideal types of institutional logic were identified through applying institutional logics theory to the analysis of case studies, following a research design using typologies to build theory (Doty and Glick, 1994). This was done by conducting interviews with key stakeholders about how they believed the industry had changed over the 30 year time period under 
study. She outlines the primary characteristics of the two ideal typical institutional logics, according to their economic system, organizational identity, legitimacy, authority structures, mission, focus of attention, strategy, logic of investment, and governance. Thornton does not, however, explicitly elaborate on how the particular elements of the two ideal type institutional logics were disaggregated from her interview and document data.

By contrast, in order to analyse behaviours and the influence of two institutional logics, Spitzmueller (2016) takes an organisational ethnography approach in his study of mental health organisations and the conflict between an incumbent therapeutic logic (emphasising responsiveness, engagement and selfdetermination) and a new managerial logic of fee-for-service reforms. The description of these two logics was developed through an analysis of the theory of institutional logics, combined with an overview of the historical and policy context in the case study area. The author contends that the managerial logic was introduced as a result of policy reforms:

The managerial logic offee-for-service reform is based on the belief that private sector solutions will be effective in the public sector, and it emphasizes cost efficiency, standardization, and accountability. Over time, successive reforms in financing and governance altered the regulatory environment of community mental health services in Illinois. These policy reforms transformed the symbolic landscape of mental health service delivery in the state and restructured the material conditions of street-level organizations. (Spitzmueller, 2016, p. 44)

Spitzmueller hypothesised that staff behaviours would be impacted by the conflict between the managerial and therapeutic logics. The impacts of the two logics were 
explored through interviews with staff members, direct observation of day-to-day activities and analysis of organisational documents, enabling the researcher to triangulate his data and compare any similarities and differences between official protocol and actual practice.

Pache and Santos (2013), by contrast, take a grounded approach to identifying the existence of institutional logics within their case study organisations. The authors employ a multi stage strategy to collecting and analysing their data on work integration social enterprises in France. Through a first stage of coding and analysing archival material and expert interviews, they identified recurring discussion themes relating to 'duality and tensions', and then recoded their materials in line with four main themes that emerged. This led to an identification of the 'competing belief systems' of two field-level logics, typologised by four key characteristics: the appropriate goal of an organisation; the accepted organisational form to achieve this goal; the governance mechanisms; and sources of professional legitimacy. These findings were triangulated through analysis of other research materials that describe the institutional contexts of the case study organisations. These characteristics are subsequently broken down to identify the particular demands that the two driving institutional logics (a 'social welfare' and 'commercial' logic) exert in each area, giving the authors lenses through which to analyse their case study data. 


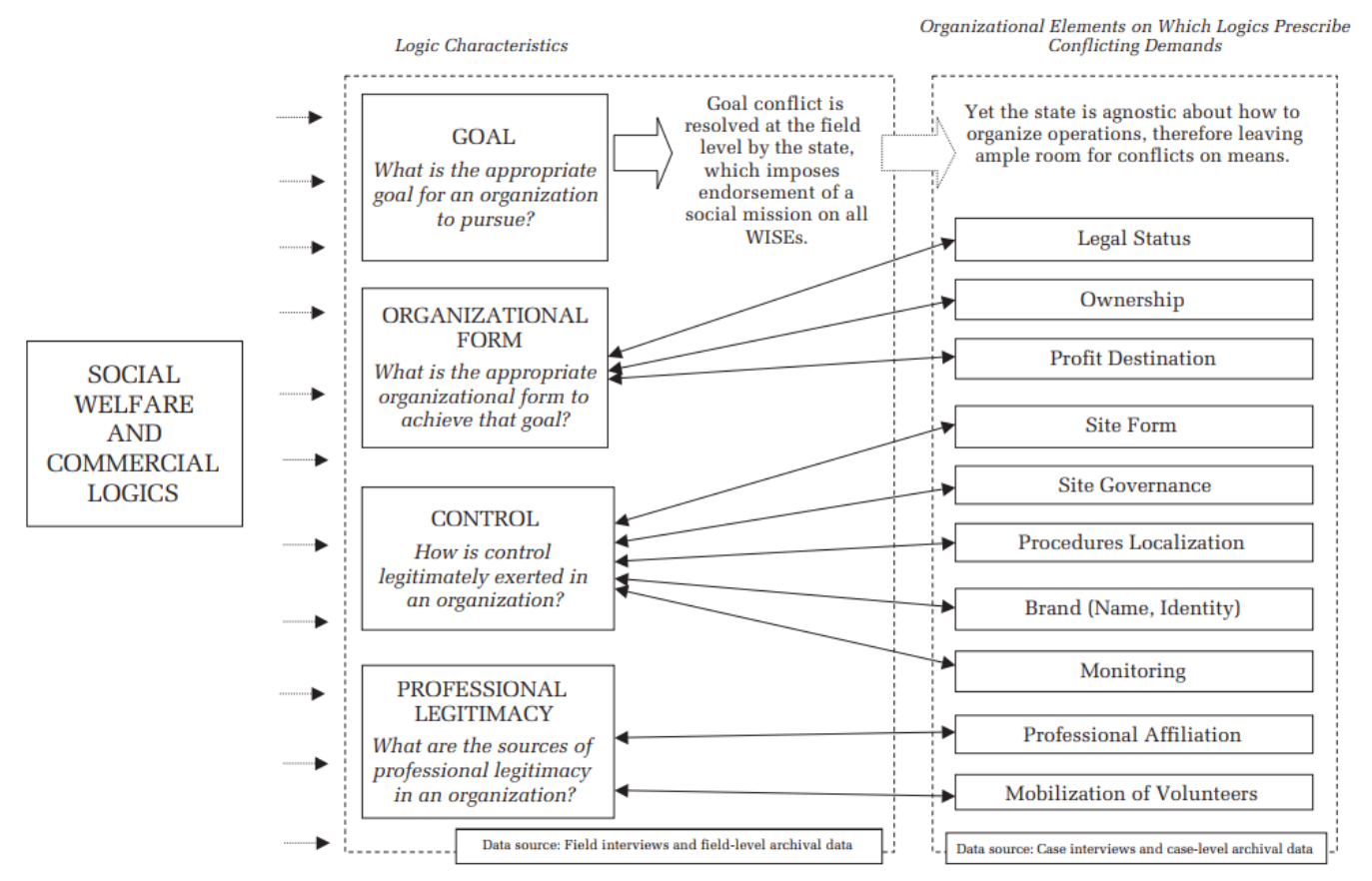

Figure 3.1: Data structure

Source: Pache and Santos, 2013, p. 983

Pache and Santos' methodology produces a particularly clear model for recognising the existence of multiple institutional logics in different organisations or contexts. This typology of the elements that make up a logic (i.e. goal, form, governance and legitimacy) can be employed by further research to aid in the analysis of institutional logics. Whilst the most commonly used definitions of institutional logics, such as Thornton and Ocasio's (1999), “socially constructed, historical patterns of material practices, assumptions, values, beliefs and rules" (emphasis mine) provide a number of clear elements that comprise an institutional logic, these must necessarily be operationalised in a more concrete manner in order to provide rigorous empirical evidence of the existence and impact of logics. In Figure 3.1, we see a clear identification of the more material aspects of institutional logics - i.e. organisational form, control and governance. These elements are typically rather 
straightforward to identify and link to a particular logic. For example, an organisation legally constituted as an 'association loi de 1901' ('an association based on the 1901 law') in France or a charity in England can reasonably be expected to be driven by the community logic as both legal forms prevent the redistribution of profits to members or owners and the organisations must be run for social or community benefit.

More difficult to identify are the abstract aspects of institutional logics - the "assumptions, values, beliefs". Pache and Santos appear to encapsulate these aspects within their categories of 'goals' and 'professional legitimacy'. In their model, however, organisational goals are fully determined by the external environment, specifically funders and regulators, who define the appropriate purpose of the organisation. "By granting WISEs the right to operate, by monitoring the accomplishment of their social mission, and by expelling contravening organizations from the field, the state sends a clear signal about the appropriate goal for WISEs and punishes deviant behaviour" (Pache and Santos, 2013, p. 981). This highlights the nested nature of institutional logics and how, in this instance, one clear determinant of an organisational logic is defined externally. Although Pache and Santos discuss observing indicators of organisational culture and norms in their methodology, these other abstract aspects of the two ideal typical logics that they identified appear to be absent from the data structure.

This exact model and data structure is, however, insufficient for the purposes of this study because of their greater emphasis on material structures and processes, with a comparatively weak analysis of values and beliefs. Co-production behaviour 
cannot be predicted by identifying governance and organisational structures alone - it requires an analysis of the norms of behaviour of staff members and the relationships between professionals and service users or community members. "We understand co-production as a notion that refers to exchange relationships that include several dimensions of interaction (e.g., dialogue, practical matters and cooperation); it can relate to individual service relationship at the micro level, as well as to the links between organizations at the meso level of the welfare system." (Ewert and Evers, 2012, p. 61) Often these behaviours are not formally delineated and thus it is necessary to elaborate upon the approach taken by Pache and Santos to better utilise the institutional logics approach to study co-production within different organisations.

\subsubsection{Rules, practices and narratives}

I return to the theoretical literature on institutions and institutional logics, and observe that each definition or typology incorporates three elements: the regulative, normative and cultural-cognitive (Scott, 2014). When these elements are conceived in terms of their incorporation into and impact on behaviour, cognition and decision-making, we understand them as institutional logics.

While Friedland and Alford's approach is both structural and symbolic, and Jackall's is both structural and normative, Thornton and Ocasio's (1999) approach to institutional logics integrates the structural, normative, and symbolic as three necessary and complementary dimensions of institutions, rather than separate structural (coercive), normative, and symbolic (cognitive) carriers, as suggested by alternative approaches (e.g., Scott, [1995] 2001). (Thornton and Ocasio, 2008, p. 101) 
Lowndes and Roberts' (2013) three modes of institutional constraint - rules, practices, and narratives - maps onto the definitions of institutional logics in a straightforward and comprehensible way, allowing for an operationalisation of the concept. The identification of rules is consistent across definitions, and practices correspond to the normative element. The notion of narratives is slightly less definitive, but will be used here to accord with the symbolic elements, or values, beliefs and assumptions. I will elaborate on these concepts of rules, practices and narratives, reviewing some of the relevant literature that pertains to each element in turn.

\section{Rules}

The notion of formal rules or regulative processes appears as part of every definition or typology of institutions and institutional logics. As discussed earlier in this chapter, the study of rules and structures is primarily associated with 'old' institutionalist studies, which critics suggest focused too heavily on the structures of power without giving due consideration to more informal conventions and traditions (Judge, 2005). However dismissive of this focus of traditional institutionalism, any study of both formal and informal institutions cannot discount the role of rules. These encompass the regulations, procedures and laws that constrain actors (Scott, 2014). Rules are formal and recorded and create the boundaries and structures of institutions. They are enacted and enforced through systems of reward and punishment (Lowndes and Roberts, 2013). Rules are perhaps the most explicit and straightforward: individuals know (or are supposed 
to know) what the rules are, because they are written and/or agreed upon. However, rules are not sacrosanct.

Rules must be interpreted and disputes resolved; incentives and sanctions must be designed and will have unintended effects; surveillance mechanisms are required but are expensive and will prove fallible; and conformity is only one of many possible responses by those subject to regulative institutions. (Scott, 2014, pp. 63-64)

It is for these reasons that rules and regulations cannot provide the basis for institutional logics on their own - humans are not robots or computers that act solely in accordance with the instructions they are given. While rules may exist on paper, there are a multitude of other factors that drive behaviour and organisational decision-making. In relation to co-production, I expect that rules - in the form of government policies, organisational procedures and funder requirements - will provide a basis upon which organisations feel either urged to engage in coproduction, or constrained in their ability or capacity to do so.

External rules include national and local laws and policies, regulations, and legal frameworks that one most readily associates with this concept. In addition, I have interpreted the concept of 'rules' slightly more broadly to include the requirements of contracts, grants and other funding arrangements, because the typical definition of "standards, regulations, protocols and policies" (Lowndes and Roberts, 2013, p. 53) did not seem to cover the range of semi-formal constraints described by interviewees as a result of their funding requirements. The guidelines, expectations and targets of funders appear to inhabit a middle ground between rules and practices - these are sometimes formally recorded (such as in contracts), but 
sometimes enable and constrain organisations' behaviours through implicit expectations. Despite this ambiguity, I have chosen to categorise funding and contracts as rules because of the distinct and formal impact they have on both the French and English organisations.

Internal rules refer to the official recorded procedures that are delineated by the organisation itself, rather than by government or outside bodies. As with contracts and funding, the line between formal rules and practices is not always straightforward. Nevertheless, the analysis attempts to identify the instances where respondents have spoken about internal rules or policies that appear to be formally recorded. This is done by focusing on the following questions: what rules enable organisations to engage in co-production or constrain them from doing so? Where do these rules originate (from the organisation itself, from government or from funders)? And to what extent do these conflict or harmonise with practices and narratives? The process of identifying and analysing rules is undertaken by focusing both on the analysis of formal written documents, where rules are recorded (such as reports, strategic plans, and bid documents) as well as interviews, where individuals describe these rules, their interpretations of them and the degree to which they are perceived to impact behaviour.

\section{Practices}

The second element that comprises my definition of institutional logics is 'practices', meaning the informal behaviours, day-to-day activities and routines that are normalised by actors but not to the extent of being recorded or codified. Whether variously designated as norms or informal rules, each conceptualisation of 
institutional logics recognises the importance of these day-to-day practices in explaining the way that actors understand and behave within their particular context. Practice theorists suggest, however, that institutional theory focuses too intently on the shared ideas, narratives, structures and rules of institutions without adequate consideration of other understandings of behaviour (Schatzki, 2001). In this section, I discuss some of the arguments of practice theory, in order to demonstrate why this is an important element for examination, what the study of practices adds to my framework of institutional logics, and how this explains coproduction.

At their core, practices are simply "arrays of human activity" (Schatzki, 2001 p. 11). As discussed at the beginning of this chapter, practices are demonstrated rather than recorded and produce and uphold norms of behaviour. Studying practices prioritises the recognition of agency within institutional studies, in the sense that institutions are not just official structures, but also shaped by the actions and behaviours of human actors.

[An] empirical approach to practice recognizes the centrality of people's actions to organizational outcomes and reflects an increasing recognition of the importance of practices in the ongoing operations of organizations. This approach answers the 'what' of a practice lens - a focus on the everyday activity of organizing in both its routine and improvised forms. (Feldman and Orlikowki, 2011, p. 1240)

Practice theory is generally associated with social theory, based on the works of Foucault, Giddens, and Bourdieu, but this approach is applied more broadly to other schools of thought, such as philosophy, cultural theory and science and technology 
studies (Schatzki, 2001). Practices are also used within critical discourse analysis, where discourse is itself conceptualised as a type of practice, and studying discursive practices as the way that discourses play out in reality (Reckwitz, 2002). This is an important point to consider in understanding the interplay between practices and narratives as part of my framework of analysis - as Lowndes and Roberts (2013, p. 53) argue, "Practices often form the basis of narrative; [and] narrative accounts can present prevalent practices in a positive or negative light." The fundamental point raised by practice theorists that is particularly relevant to my conceptualisation as it forms part of an analytical framework of institutional logics is that practices are about appreciating actions, routines and behaviours in social life. Studying practices helps us to understand the everyday lived experiences of actors.

Thus, practices represent the things that individuals do within an organisation, and how they do them. This is naturally a necessary consideration when studying coproduction, as co-production is a way of describing a particular way of doing things - designing and delivering services, running programmes, etc. When we study coproduction, what we are studying are practices. These are best identified and analysed through observation of the day-to-day activities of research participants. Because the research design included a limited number of observations of events, meetings and activities rather than taking a fully ethnographic approach, the data on practices was supplemented by analysis of the practices described in interviews as well ${ }^{2}$. For the purposes of this study, several questions are considered in relation

\footnotetext{
${ }^{2}$ See section 4.4 .3 for a more in depth discussion of observation as a research method.
} 
to practices. First, does co-production feature in the practices of an organisation? If so, how - what day to day activities and behaviours take place that form these coproduction practices and do these practices coincide with my definition of coproduction? If not, why not? This final question transitions into organisational narratives, which is the analysis into the third element of logics.

\section{Narratives}

The final component of the institutional logics approach involves the non-material aspects - variously denoted as "assumptions, values and beliefs" (Thornton et al., 2012), "cultural beliefs" (Lounsbury, 2007) or "symbolic constructions" (Friedland and Alford, 1991). These represent the ways that practices and rules are expressed and made meaningful by actors. In order to identify the symbolic and value-based elements of logics, I operationalise these elements through examining actors' narratives. While rules act as recorded constraints and enablers, and practices are 'what people do', we use narratives to identify 'what people believe' or the 'why' behind 'what people do'. There is a vast extant literature on discourse and narratives, which I will not endeavour to review in its entirety. This section will serve to summarise some of the key arguments in the literature that pertain to the use of narratives within organisations, to explain how I identify and use the concept analytically.

Narratives are defined by Lowndes and Roberts (2013) as the spoken expression of ideas and the way that practices are justified by actors in order to create shared understandings. Narratives consist of stories that individuals tell in order to 
understand and frame organisational life and communicate information necessary for decision-making (Feldman et al., 2004).

Narratives are useful data because individuals often make sense of the world and their place in it through narrative form. Through telling their stories, people distill and reflect a particular understanding of social and political relations. Stories are a common, habitual method people use to communicate their ideas. (Feldman et al., 2004, p. 148)

Narratives can be used to express more than values and beliefs - they can be used to describe the objective realities of both practices and rules. However, what we seek in analysing narratives are the underlying ideas and perceptions of the actors describing these actions, constraints, events, etc., through the way that they describe and talk about these. I am therefore using the concept of narratives essentially as a proxy tool to identify the third element of the institutional logics approach: individuals' beliefs, assumptions, motivations and values. Some indicative questions were devised in interrogating my data for narratives: How does co-production feature in the stories that people tell? How do people describe co-production? (What words do they use? What values and beliefs do they associate with participation and co-production practices?)

There are two primary ways of looking at narratives that involve different units of analysis - we can look at the overarching structure of the story or narrative, or focus on the words used within these stories (Gee, 1986). As Franzosi (1998) notes, French structuralists distinguished these elements as histoire versus discours, or story versus discourse. While narrative analysis focuses on the former, critical discourse analysis studies the latter. For this study, I will draw upon elements of 
both methods to analyse actors' use of language and stories to reveal their beliefs and motivations (but will be borrowing from critical discourse analysis rather than employing it as a methodology).

The first focus of analysis is on the stories that individuals tell. Feldman et al. (2004) describe narrative analysis as an interpretation of "why the story was told that way and what the storyteller means" (p. 148), examining both the content of the story and its structure, including the links between particular concepts. Coming back to the analytical framework of institutional logics and the way this can be used to understand co-production, this type of narrative analysis can reveal the ways in which actors are motivated and driven by the pressures or values associated with the community, state and market logics. In other words, how actors interpret things - such as roles, structures and ideas - can help us better understand what they do.

Secondly, I analyse interviewees' discourse. Discourse refers to language used as "a form of social practice, and discourse analysis is analysis of how texts work within socio-cultural practice" (Fairclough, 1995, p. 6). Language and discourse are important components of action and can be used to generate meanings and enact particular strategies, but discursive strategies are contextually sensitive (Hardy et al., 2000). Hardy et al. also argue that the way that we talk about actions and strategies and the language we use also have political implications. This means that the discourses used in the two case study contexts are likely to vary, and will help to construct a picture of the different logics embedded in each. Suddaby and Greenwood differentiate this notion of discourse analysis as concerning itself with the use of discourse as social practice with rhetorical analysis, which focuses on the 
use of discourse to persuade, particularly in the context of political or social aims (Suddaby and Greenwood, 2005). In their study of a new organisational form created by the purchase of a law firm by an accounting firm, they use rhetorical analysis to expose the competing institutional logics contained within the identities of the previous organisations. This demonstrates that discourse and language plays a strong role in defining institutional logics at the organisational level.

Thus the narratives of motivations, values and ethos that an organisation expresses can directly influence the importance of citizen participation and co-production within the organisation's structure, as discourses define distributions of power and systems of control within an organisation (Hodge, 2005). This type of analysis is however laden with methodological challenges given the comparative nature of the research, and the fact that data was collected in two languages. Rather than relying solely on my own interpretation of the vocabulary used by interviewees, I frequently asked them to clarify their choice of words, and enlisted the help of a French-English translator to collaborate on the translation of quotes. I will discuss the linguistic concerns of the project in greater details in Chapter 4 in relation to my methodology, but acknowledge at this stage that conducting analysis of discourse that aims to compare and contrast uses of vocabulary in two languages requires particular care and attention. 


\subsection{Conclusions}

This research project seeks to understand differences between co-production within third sector organisations in two different country contexts. In order to undertake this type of comparative study, I have chosen to employ an analytical framework of institutional logics, which provide a relatively comprehensive structure for investigating differences between political, institutional and cultural contexts and how these may in turn impact practices such as co-production. This framework of analysis has the advantage of allowing the researcher to evaluate not only what actors do at the individual or organisational level, but also identifying the broader field and societal level influences on the ways that actors are enabled and constrained to take particular courses of action.

This chapter has sought to outline the analytical framework for the thesis, through a thorough review of the literature on institutions and institutional logics, before formulating my operationalisation of the concept to be used for analysis. As elaborated in section 3.6.1, I utilize the concepts of rules, practices and narratives to comprise institutional logics. This framework and the way it was employed in the data analysis will be discussed further in the following chapter, where I turn to the design and methodology of the research. I will discuss the research methods used, the process of data analysis and the benefits and drawbacks to the research approach chosen. 


\section{CHAPTER 4: RESEARCH DESIGN AND METHODOLOGY}

\subsection{Introduction}

In this chapter, I outline the underlying research philosophy and methodology of this study, which is based on a qualitative comparative case study research design. I describe the interpretivist approach that was taken, which was underpinned by an abductive research process. The chapter elaborates on this research approach and the process of data collection, analysis and interpretation that was undertaken. I reflect upon the comparative case study method and the benefits and drawbacks of employing this research design.

In the first section of this chapter, I explain my philosophical positioning in terms of the research ontology and epistemology. Following this, I explain the design of the research including the overall methodology and research methods, and reflect upon the challenges and limitations of these. I discuss the ethical considerations of the study and the particular measures undertaken to ensure adherence to rigorous ethical standards and data protection. Finally, I outline the several stages of the data analysis. 


\subsection{Research philosophy and approach}

\subsubsection{Epistemology and Ontology}

Before outlining the design of the research, it is first necessary to elucidate my philosophy as a researcher, or in other words, my underlying epistemology and ontology. Ontology refers to ideas about the nature of social reality and epistemology is about our theory of knowledge and how one goes about gaining knowledge about this social reality (Grix, 2010).

By setting out clearly the interrelationship between what a researcher thinks can be researched (her ontological position), linking it to what we can know about it (her epistemological position) and how to go about acquiring it (her methodological approach), you can begin to comprehend the impact your ontological position can have on what and how you decide to study. (Grix, 2010, p. 67)

In considering perceptions of social phenomena (ontology), one can take a position of objectivism, meaning a belief that there is a clear, identifiable reality, or constructivism, which is the position that reality is socially constructed. One's epistemological position takes either an interpretivist or positivist consideration (Bryman, 2016). Positivism is likened to the application of the scientific method to the study of social phenomena, whereas interpretivism questions or rejects the possibility of studying human beings in the same way as the natural sciences. The purpose of this chapter is not to review the vast literature that exists to compare and contrast the various aspects, benefits and drawbacks to positivism and interpretivism, but rather to explain and support the position taken by this study, which is driven by an interpretivist philosophy. Interpretivism as an epistemology 
was founded on a reaction against the application of the scientific method to the study of human behaviour, and the belief that social interactions cannot necessarily be studied in the same way as in the natural sciences.

Interpretivists therefore believe that the aim of social research should be to try to understand rather than to explain or try to attribute cause and effect to phenomena. This was the position that I was naturally drawn to in order to reasonably address my research questions, which focus on the complex interactions between identities, values, beliefs, behaviours and practices. The orientation I intended to take regarding my research was one of negotiating the variously constructed social realities of my research participants.

When the social scientist adopts an interpretative stance, he or she does not simply reveal how members of a social group interpret the world around them. The social scientist will aim to place the interpretations that have been elicited into a social scientific frame. There is a double interpretation going on: the researcher provides an interpretation of others' interpretations. Indeed, there is a third level of interpretation going on, because the researcher's interpretations have to be further interpreted in terms of the concepts, theories, and literature of a discipline. (Bryman, 2016, p. 28)

This provides the basis for my choice to employ a qualitative research strategy. My epistemological and ontological positions compel me to take an orientation towards my research that is focused on better understanding and comparing language, cultures and the way things are done in ways that are not measurable using quantitative tools. This approach therefore requires the selection of a methodological frame and data collection tools that facilitates the understanding of 
the 'how' and the 'why', searching for themes and patterns rather than causal relationships.

\subsubsection{Grounded theory and abductive analysis}

Qualitative research is often informed by grounded theory, allowing themes to emerge inductively from the data collected, rather than entering the data analysis stage with a presumptive theoretical model to apply (Glaser and Strauss, 1999). It is more of a method of data collection and analysis rather than a theory, which leads Bryant (2014) to describe it instead as 'grounded theory method', where the researcher aims not to determine the research process by preconceived theories or ideas, allowing for information and themes to emerge that may surprise the researcher. Grounded theory insists on a fairly prescriptive process of data analysis, whereby the researcher engages in open coding (identifying and labelling passages of transcripts and documents that appear to be of thematic or theoretical significance), and using the 'constant comparison' method, meaning that the researcher continually refers back to the data as categories and themes are emerging in order to ensure connection between the data and the development of theory.

Rather than adhering religiously to a grounded theory method, which would require approaching the analysis with a blank slate in relation to theory, I used an abductive, iterative technique to collecting, analysing and interpreting my data. By this, I mean that I started my analysis with a broad idea of the theory to guide the analysis, while at the same time continuously interrogating my data and allowing new themes and ideas to emerge and coalesce (Timmermans and Tavory, 2012). Abductive 
procedures permit the researcher to be more pragmatic about methodology and avoid being shackled to one rigid theory or approach. Dubois and Gadde (2002) describe this strategy as 'systematic combining', where the development of the framework, data collection and case analysis are conducted concurrently.

\begin{abstract}
A standardized conceptualization of the research process as consisting of a number of planned subsequent 'phases' does not reflect the potential uses and advantages of case research. Instead, we have found that the researcher, by constantly going 'back and forth' from one type of research activity to another and between empirical observations and theory, is able to expand his understanding of both theory and empirical phenomena. (Dubois and Gadde, 2002, p. 555)
\end{abstract}

Taking this approach, the study was not embarked upon with a predefined map or plan for the stages of the research, where data collection is separated from the identification or development of theory - either prior to (deductive) or built through the analysis of data (inductive). Instead, I began my fieldwork with clear research questions and an imprecise idea of theory and framework, but the analytical framework of institutional logics was developed through the process of conducting and analysing interviews, as key trends and themes emerged.

\title{
4.3 Research Design
}

\subsubsection{Comparative international case studies}

In order to address the research questions of this study, I have chosen to employ a comparative case study research design. Two aspects of this research design need 
to be explained: the case study; and the international comparative research design. I will address each in turn, followed by a discussion of the perceived advantages and disadvantages of this design.

Case studies are defined by Simons (2009, p. 21) as:

an in depth exploration from multiple perspectives of the complexity and uniqueness of a particular project, policy, institution, programme or system in a 'real life' context. It is research-based, inclusive of different methods and is evidence-led.

As Thomas (2011, p. 11) elaborates, the aim of the case study is to "look at relationships and processes", as compared to looking at causation or generalisation, which would lead the researcher to employ experimental or survey designs respectively. Case studies have the advantage of allowing the researcher to conduct a comprehensive examination of an organisation or phenomenon to develop as detailed an insight into it as possible.

Comparative international research refers to the study of social phenomena in two or more countries in order to derive policy recommendations, develop new insights and/or theories and to assess transferability of policies between societies (Hantrais, 2009). This can be accomplished using a variety of quantitative or qualitative methods, or a combination of both. Yin (2014) argues that the analysis of multiple case studies can be used either for literal replication, whereby the researcher hypothesises that similar results will be found in different case studies, or theoretical replication, meaning that the cases are chosen with the hypothesis that results will be divergent but for expected reasons. The choice of design for this study 
follows the latter rationale. In addition, studying multiple case studies in a comparative perspective allows the researcher to focus more on the phenomenon itself - in this case, co-production - rather than a more intent focus on the case or cases itself/themselves. The case studies then take an instrumental purpose (Thomas, 2011).

Although I determined that the comparative case study research design was the most appropriate to carry out the research, there are some disadvantages and challenges to this approach. Case studies, whether single, multiple or comparative, are often criticised for the fact that they are not generalisable, per se. Because case studies focus on only one or a small number of cases, no effort is made to extend conclusions about the findings to the broader universe of similar cases. The aim of case study research is therefore to either test theories (using typical or deviant cases), or to generate new theories. Thus, a case study can be seen to provide theoretical generalisations rather than the statistical generalizability that quantitative research aims to produce (Silverman, 2013). The choice of cases to study is therefore crucial in ensuring that the research can produce results of theoretical importance.

The second key challenge is the issue of language, which can often be an insurmountable barrier for individual researchers interested in carrying out international comparative research. Not only must the researcher be capable of speaking the language, but also in interpreting the cultural differences that are associated with undertaking research in 'foreign' contexts. 
Each language is not only a medium for intercourse but a particular style of discourse. Thus, the linguistic dimension interacts with cultural, as well as associated intellectual and professional specificities to form the problematic of comparative analysis. The ultimate challenge is to make sense of the cognitive, connotational and functional meanings. (Mangen, 1999, p. 111)

Conducting half of my research in French, which is not my native language, was something that concerned me, particularly as the theory underpinning my research developed to include comparisons of language and narrative. Conducting interviews in French necessitated more preparation than in English, and reading and analysing documents and interview transcripts required more time and effort. I enlisted the help of a native French transcriptionist as well as a French-English translator to proofread interview quotes that I have translated myself in this thesis. Translation, I have discovered, is more art than science, and the process of translating these quotes often felt quite similar to the process of subjective interpretation of analysing the meaning behind English respondents' narratives. I will discuss the issue of conducting interviews in two languages further in section 4.4 on research methods.

\subsubsection{Case study selection}

Because of the multi-level nature of institutional logics, which form my framework for analysing co-production practices, this research was designed to focus on one city in England and one city in France, with an analysis of seven case study organisations in three sub-sectors of activity in each city. The study follows a 'nested' or 'embedded' case study design. 
With multiple [case] studies, the emphasis is on comparing clearly different examples and the contrasts found between and among the cases then throw the spotlight on an important theoretical feature. By contrast, with nested studies the breakdown is within the principal unit of analysis. (Thomas, 2011, p. 153).

The cases I study are third sector organisations, but these are nested or embedded within the city and country context. This usefully allows me to apply my analytical framework of institutional logics, which likewise operates on the same three levels of analysis, which is explored further in Chapter 5. This design therefore required three levels of sampling/ selection: countries, cities, and organisations (Figure 4.1).
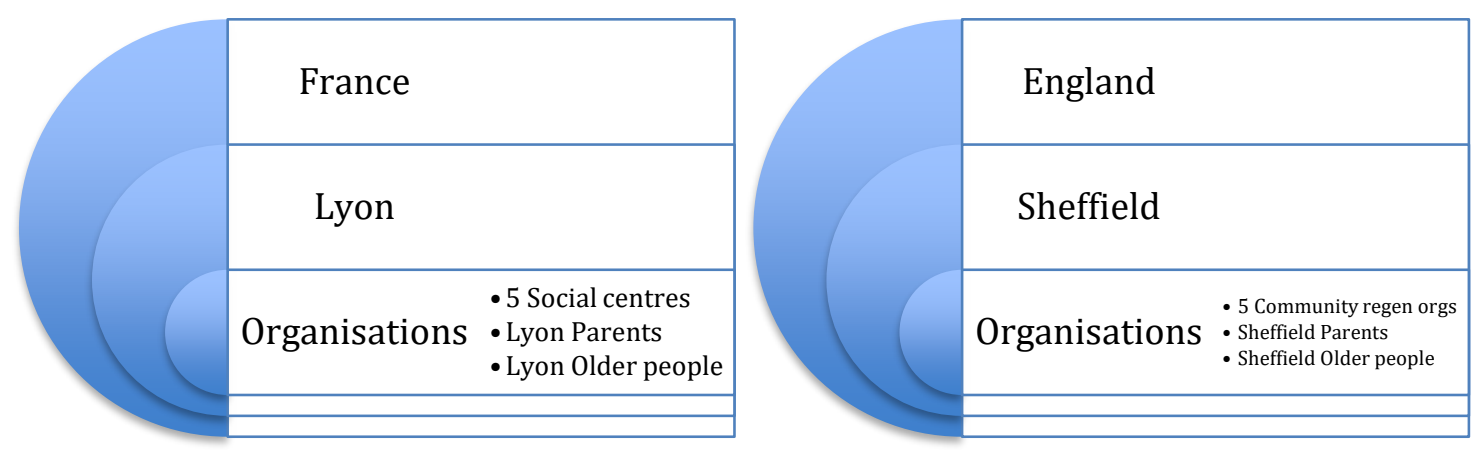

Figure 4.1: Nested case study design

France and England were selected as countries to represent 'most different' cases (Tarrow, 2010). Indeed, this study is far from being the first to be drawn to the allure of a British-French comparison (Laborde, 2000; Clark and Southern, 2006; Le Galès, 1995). Because the research questions focus on seeking to understand how institutional differences impact behaviour (which, if the research were to take a 
quantitative approach, would represent the independent and dependent variables, respectively) it is appropriate to seek cases that are markedly different in terms of culture or institutions in order to examine whether these factors impact coproduction practice, which has seldom been investigated from a comparative perspective. France and England are consistently categorised as belonging to different groups or families of welfare regimes (Esping-Andersen, 1990), non-profit regimes (Salamon and Anheier, 1998), and administrative or governmental traditions (Loughlin and Peters, 1997; Bevir et al., 2003). These theories and typologies will not be discussed in detail here, as they are elaborated in Chapter 5 , where I explain the context of the case studies. They are introduced here to justify the basis for the comparison.

The selection of a city within each country and the case study organisations within the cities followed a strategy of theoretical replication. This is informed by an intention to utilize purposive sampling, meaning choosing participants or organisations in a strategic manner based on the research questions and aims (Bryman, 2016, p. 508). I use the concept of purposive sampling with caution, as Yin argues this should not be employed in case study research designs:

You may have intended to convey that the 'purposive' portion of the term reflects your selection of a case that will illuminate the theoretical propositions of your case study. However, your use of the 'sample' portion of the term still risks misleading others into thinking that the case comes from some larger universe or population of like-cases, undesirably reigniting the spectre of statistical generalization. (Yin, 2014, pp. 42-44) 
Likewise, Thomas argues that "a sample should show the quality of the whole. A 'sample' is not what is wanted in a case study" (Thomas, 2011, p. 62). Bryman (2016) and Silverman (2013) however, see no such contradiction between research traditions, but employ the caveat that 'sampling' in relation to qualitative case studies refers to a very different process to the random sampling that is used in quantitative designs. Sampling in qualitative research is based on the careful selection of cases that help us to respond to our research question, or where we might expect to be able to identify and analyse a certain phenomenon or process. The sample in qualitative research is not intended to be a selection that can present the researcher with conclusions that can be generalised to the population.

The first stage of the sampling strategy was to choose cities that met three key criteria: (1) comparable size/population, (2) lack of political or other local impediments to co-production/ local participation, and (3) likely presence of compelling examples of co-production activities from which to collect rich empirical data. In conducting comparative case studies within 'most different' country cases, concerted attempts were made to limit variation between the cities and within the case study organisations, to ensure the greatest degree of reasonable comparability at the case level.

\section{City selection}

I based my selection of cities on recommendations from key informants during the initial scoping phase of the fieldwork. In August and October 2014, I conducted informal interviews in Marseille and Paris with four French academics and two stakeholders (a consultant and a professional from a national network) with 
knowledge of the third sector and social economy. During these interviews, I enquired about whether there were any cities which were particularly known as having a tradition of a strong third sector/ social economy, and where innovative participation/co-production activities were taking place. This approach of selecting cities that represent 'key cases' (Thomas, 2011) could be seen as a limitation of the study, because these cases are by their nature unrepresentative of the broader sector/population. However, in this instance there were no cities that were suggested as complete outliers of exemplary co-production activity, so selecting cities that are simply recognised as 'good' examples ensured that the research would be guaranteed to find some compelling activities upon which to base the analysis.

In France, the Nord-Pas-de-Calais region and Amiens were suggested twice, the Rhône-Alpes region where Lyon is located twice, and three interviewees said it would also be possible to study Paris, but that it would be relatively complicated due to the size of the city. Lyon was thus chosen because it is located in the suggested Rhône-Alpes region, and because its size (approximately 500,000 inhabitants) made it a more manageable task to 'get to grips' with the range of third sector activity taking place, compared to a city like Paris. I then investigated possible comparator cities in England that would meet my key criteria. In order do this, I relied primarily on my own prior knowledge, having worked as a policy researcher in a local government think tank and a third sector membership organisation from 2008 until 2012. Birmingham (which is twinned with Lyon) was a possible choice, but this was ruled out for two reasons. First, the population of Birmingham is approximately twice that of Lyon. Second, the structure of local government Birmingham is much 
different - Birmingham is the largest unitary local authority in Europe, while Lyon is governed by several layers of regional and local government.

I instead decided upon Sheffield as my English case location because of several useful similarities with Lyon. Sheffield has a comparable population to Lyon, and also has a history and reputation of cooperative, trade union and third sector activism. In addition, local government changes and conglomerations in both cities made for a compelling comparison from the point of view of the evolution of field level rules and narratives. In 2014, the Sheffield City Region Combined Authority was established, which has responsibility for some regional economic development and transportation issues. Similarly, in a reorganisation in 2015, the Métropole de Lyon was created, which receives some of the competences of both the Département du Rhône and Greater Lyon. While on the whole the layers of local government and powers and competencies attributed to different levels differ (which, of course, is part of the justification for these locations as 'most different cases'), the introduction of governance changes in both locations provides another element with which to analyse the approaches and behaviours in each case.

\section{Organisation selection}

In choosing the organisations in each city to focus on, I continued with a similar approach of purposive and snowball sampling. Snowball sampling refers to the use of contacts, key informants or initial research participants to recommend other potential participants (Burnham et al., 2008, p. 108). While the aim of sampling for cities was to identify cases that could provide robust contexts for comparison, at the organisational level, my strategy needed to be more flexible and adaptive to the 
potential for lack of response or agreement to participate from chosen organisations. Taking an approach of purposive and snowball sampling allowed me to be more agile in selecting and accessing potential cases, while still maintaining a theoretical justification for choices made.

Like in my selection of the two cities, my strategy began by asking for recommendations from local third sector stakeholders. At the beginning of my fieldwork, I interviewed senior staff members from local third sector/ social economy organisations in both Lyon and Sheffield who acted as key informants and gatekeepers to my case study organisations. Before these interviews, I had not decided upon the particular sub-sector of third sector activity upon which to focus, but aimed instead to find organisations providing similar services in each city that could be used as cross-national comparators. I asked local informants whether there were any organisations in the city that they felt were known for undertaking coproduction. This sampling approach of aiming to identify influential or best case examples poses a limitation of the research, as cases recognised as exemplars of coproduction cannot be argued to represent the co-production approaches of the third sector as a whole (Seawright and Gerring, 2008). This limitation was mitigated by increasing the number and breadth of organisations studied, with some chosen as best case examples and others as more typical of each service sub-sector.

I initially expected to focus broadly on organisations providing health or social services, based on the literature suggesting the benefits that co-production offers in healthcare (McMullin and Needham, 2018; Dunston et al., 2009). However, based on interviews with key informants in Lyon, I decided to take a broader perspective, 
because it was suggested to me that health services are highly regulated, bureaucratic and not known for being particularly innovative. Lyon Parents $^{3}-\mathrm{a}$ network representing parent cooperatives, and 'centres sociaux' (roughly translated as 'social centres', which will be explained in greater detail later) were recommended by these informants, so I decided to pursue these initial suggestions.

In Sheffield, the first organisation to be recommended to me was Sheffield Older People, a project that aims to reduce loneliness and isolation of older people. In addition, several of the larger community regeneration organisations in the city were cited by local informants as examples of good practice in terms of coproduction. Upon analysis and reflection, the social centres and community regeneration organisations provided examples which were comparable in many ways - both types of organisations have, broadly, the same aims (regenerating neighbourhoods and contributing to social cohesion) and provide the same types of services (employability training, leisure facilities, youth clubs, social activities and more). In addition, there are numerous such organisations in both cities, which allowed me to make a certain generalisations. I contacted 13 of the 16 social centres in Lyon (through the publicly available email address, or directly to two contacts suggested by my informant) and received affirmative replies from five of the organisations. In Sheffield, I contacted the directors of the three largest community regeneration organisations that had been recommended by numerous informants, and augmented this sample with two medium sized community regeneration organisations that I identified through internet searches.

\footnotetext{
${ }^{3}$ All organisations have been anonymised, which is discussed further in section 4.5.
} 
Consequently at this stage I had identified one clear set of paired comparators (community regeneration organisations and social centres) but the other two examples of co-production good practice (Lyon Parents and Sheffield Older People) operated in very different sectors of service provision. Through an iterative process of data collection and analysis in the first set of paired comparators (community regeneration), I began to build my theory and model to interpret differences that were emerging. While the original focus of the sampling strategy had been to identify 'good practice' examples of co-production taking place in each country, this became less of a priority when selecting the secondary cases. I hence made the decision to identify a service or project that was most comparable to Lyon Parents in Sheffield (i.e. providing services or activities for parents and children) and Sheffield Older People in Lyon (a project aiming to reduce loneliness of older people) in order best analyse the rules, practices and narratives related to coproduction within each sector, and to determine the degree to which these concurred with the findings from the community regeneration cases.

I learned about Sheffield Parents through interviews with professionals in the community regeneration case studies, who were tangentially involved in the project (which was at that point just being set up). Sheffield Parents is a programme run by a consortium of third sector actors ('Sheffield Consortium') and aims to set up parent/toddler groups and run other family events and activities in several deprived neighbourhoods in the city. Finally, I did a substantial amount of internet research and enquiring with my contacts in Lyon before I was able to find a project or organisation to act as a counterpart to Sheffield Older People. Eventually I discovered Lyon Older People, a national mobilisation tackling older people's 
loneliness, which was discussed at a third sector network event that I attended. At that stage, a network of associations was being formed to launch the project locally. I contacted a general email address I found online and was put in touch with a local politician who was coordinating the project in Lyon. Table 4.1 displays the final list of (anonymised) case study organisations, and their reasons for selection.

Table 4.1: Selection of case study organisations

\begin{tabular}{|c|c|c|}
\hline Organisation & Description & Reason for selection \\
\hline Develop & $\begin{array}{l}\text { Sheffield community } \\
\text { regeneration }\end{array}$ & $\begin{array}{l}\text { Recommended by informant for } \\
\text { co-production }\end{array}$ \\
\hline Enterprise & $\begin{array}{l}\text { Sheffield community } \\
\text { regeneration }\end{array}$ & $\begin{array}{l}\text { Recommended by informant for } \\
\text { co-production }\end{array}$ \\
\hline Leisure & $\begin{array}{l}\text { Sheffield community } \\
\text { regeneration }\end{array}$ & $\begin{array}{l}\text { Recommended by informant for } \\
\text { co-production }\end{array}$ \\
\hline Aspire & $\begin{array}{l}\text { Sheffield community } \\
\text { regeneration }\end{array}$ & Representative of sector \\
\hline Recreation & $\begin{array}{l}\text { Sheffield community } \\
\text { regeneration }\end{array}$ & Representative of sector \\
\hline Avancé & Lyon social centre & Representative of sector * \\
\hline Mouvement & Lyon social centre & Representative of sector * \\
\hline Equipe & Lyon social centre & Representative of sector $*$ \\
\hline Diversité & Lyon social centre & $\begin{array}{l}\text { Recommended by informant for } \\
\text { participation/ empowerment }\end{array}$ \\
\hline Familles & Lyon social centre & Representative of sector $*$ \\
\hline \multicolumn{3}{|c|}{ * the social centre sector as a whole was recommended by informants } \\
\hline Sheffield Parents & $\begin{array}{l}\text { Project of local parent/ } \\
\text { toddler groups }\end{array}$ & Comparator to Lyon Parents \\
\hline Lyon Parents & $\begin{array}{l}\text { Network of parent } \\
\text { cooperatives }\end{array}$ & $\begin{array}{l}\text { Recommended by informant for } \\
\text { participation/ co-production }\end{array}$ \\
\hline Sheffield Older People & $\begin{array}{l}\text { Project to reduce older } \\
\text { people's isolation }\end{array}$ & $\begin{array}{l}\text { Recommended by informant for } \\
\text { co-production }\end{array}$ \\
\hline Lyon Older People & $\begin{array}{l}\text { Social movement to } \\
\text { reduce older people's } \\
\text { isolation }\end{array}$ & $\begin{array}{l}\text { Comparator to Sheffield Older } \\
\text { People }\end{array}$ \\
\hline
\end{tabular}


This snowball strategy of recruiting organisations had advantages, but also some drawbacks. Approaching key informants for suggestions of third sector organisations to take part in the research, without having yet determined the type of organisations (in terms of size or service sub-sector) meant that the recommendations I initially received varied widely. Developing a clear plan for paired comparison was initially a challenge as it seemed that many of the options I had in one city were completely unrelated to those in the other city. This also meant that I undertook several interviews with individuals in organisations that I did not end up including in the study because it was difficult to see how they would 'fit'. These interviews were, however, extremely valuable and I have included them as part of my analysis of city/field level narratives (Chapter 5) rather than as case studies. Furthermore, discounting health and social care services because I was dissuaded from this sector in France presents a clear limitation of the research as it suggests that the findings are unlikely to be applicable to these types of organisations/ services in France ${ }^{4}$. Had I employed a different analytical framework, for instance, focusing on the benefits of co-production, then perhaps the comparability of the exact sector of activity of each case study would be of less importance. However, my evolving theoretical framework and research questions aimed to interrogate, in part, how rules impact on co-production behaviour, and these are often sector-specific. This meant that it was necessary to find

\footnotetext{
${ }^{4}$ In Sheffield, I attended a meeting and interviewed a professional of a mental health project that aimed to better involve service users in their own recovery plans, but I found limited evidence of service user co-production despite the rhetoric employed. For example, I was told that the project was being co-produced because two 'service users' (who were paid professionals but happened to also identify themselves as mental health service users) were present at the meeting.
} 
organisations or projects in each country that operated within the same sphere of activity.

\subsubsection{Participant selection}

Unlike sampling at the country, city and organisational level, I did not undertake a structured sampling approach in selecting the individuals from each organisation to take part in the research. On the whole, my technique was to contact the organisation's director or chief executive, and to interview them if they agreed. These directors then acted as gatekeepers in suggesting other participants for the research (principally frontline professionals, and a few volunteers). Unlike the community regeneration organisations and social centres, Sheffield Parents and Lyon Older People are projects rather than incorporated organisations and have no directors, so I contacted the staff member in charge of the project in the former case, and a coordinator in the latter. These contacts took the same role as gatekeepers and helped me to make further contacts. Efforts were made to speak to as many people at different levels of seniority in all of the case study organisations.

Gaining access to research participants (who, at the director/CEO level, also determined whether or not an organisation would participate as a case study) was an important consideration of the research design and methodology. As discussed in relation to organisational selection, I was not always able to get access to all of the organisations and participants that I approached because of the approach I took to sampling. In order to gain access to research participants, my initial tactic was to contact them by email, explaining the subject and purpose of my research and requesting their participation. I did not receive any outright rejections to my request 
for participation in the research, but non-response was quite common (as, obviously, people are very busy). If I did not receive a reply to my initial email, often I followed up with either another email several weeks later, or a phone call. On three occasions, I attended a public event run by the organisation and introduced myself in person to the individual I had attempted to contact via email. While perhaps a bit aggressive, I found this to be a very successful tactic.

\subsubsection{Fieldwork}

Fieldwork was undertaken through the course of 2015 and 2016. For the French fieldwork, this was done over five trips to Lyon (of between one week and one month each), allowing adequate time to connect with a range of organisations and individuals and to build relationships with stakeholders. Spreading the fieldwork over several trips also allowed me to strategically plan visits that coincided with events and meetings I could attend, for instance during my trip for the month of May 2016 which enabled me to attend three of the social centres' AGMs and an event for Lyon Parents. For the English fieldwork, interviews and observations were conducted over the same time period, but during day trips to Sheffield. The extended fieldwork stage also allowed for a concurrent analysis of the data and constant comparison between the cases in the two cities, as informed by my strategy of systematic combining (Dubois and Gadde, 2002). 


\subsection{Research methods}

While methodology refers to the overall philosophy and process underpinning the research, research methods refer to the tools used to collect and analyse data. To an extent, the researcher's ontological position helps to determine the methods that are most appropriate, but these are also considered according to which tools are most practical in order to address the research questions. Because the research is based on an interpretivist and constructivist position, I have chosen to employ qualitative research methods. A multi-method approach was used to gain a richness of data, as well as to triangulate the findings. As Laws argues, "The key to triangulation is to see the same thing from different perspectives and thus to be able to confirm or challenge the findings of one method with those of another" (Laws et al., 2013, p. 143). Taking this into consideration, I utilised qualitative interviews, document analysis and observation as my research methods.

\subsubsection{Qualitative interviews}

The primary method used for data collection was the semi-structured interview. Semi-structured interviews are one of the preferred methods used in qualitative research, because they allow the researcher to gain an in-depth, first-hand account of a respondent's beliefs, ideas and opinions. In a semi-structured interview, the interviewer is prepared with a list of questions or interview guide, but "'rambling' or going off at tangents is often encouraged - it gives insight into what the interviewee sees as relevant and important" (Bryman, 2016, p. 466-467). This choice of semi-structured interviews was the rational decision to investigate ideas, beliefs and behaviours, rather than structured interviews (where the interviewer 
cannot deviate from a strict question guide) or unstructured interviews (where the conversation goes in whichever direction the respondent chooses). The majority of a semi-structured interview is composed of open-ended questions, which allow the interviewee to develop their own narratives and allow the researcher to be flexible to explore themes in greater or lesser detail depending on the path taken by the discussion.

No research method is without its challenges and drawbacks, and interviews are no exception. In semi-structured interviews, the interviewer has the opportunity to probe on particular topics or themes brought up by the interviewee. As these cannot necessarily be anticipated beforehand when designing the interview guide, the interviewer must be extremely well prepared and confident in their ability both to put the interviewee at ease (and remain relaxed oneself) as well as to guide the discussion towards topics of interest to answering the research questions (Flick, 2014). This adaptability of the question guide also means that each interview is likely to produce different results and data, which must be carefully considered at the analysis stage. Another concern is the careful attention to language and question wording, ensuring that the language used is familiar to interviewees.

$$
\begin{aligned}
& \text { You need to word questions so as not to narrow the options for } \\
& \text { answering or overly restrict how the interviewee approaches the } \\
& \text { question. [...] When wording main questions, be cautious about } \\
& \text { imposing your own understanding in ways that limit the interviewees' } \\
& \text { freedom to respond. (Rubin and Rubin, 2012, pp. 132-133). }
\end{aligned}
$$

This was of particular note in the context of my research, given that 1) a main focus was on being able to analyse respondents' narratives and 2) interviews were 
conducted in both French and English, making the choice of language doubly important. Using terminology that was familiar to interviewees and allowing them to respond in their own words was a tactic that I deliberately employed throughout the fieldwork. Special attention was paid to my own use of the word 'co-production' because this is often perceived as policy jargon. In Chapters 6 and 7 where I analyse my empirical data, I continuously reflect on this importance of the use of language in interviews.

Furthermore, as discussed in section 4.3 .1 of this chapter, conducting half of the interviews in my second language also presented an obvious challenge. I ensured that my language skills were as close to bilingual as possible, by taking intensive French courses in Paris (for the month of August, 2014) prior to commencing fieldwork, and by studying for and passing the Diplôme approfondi de langue française $\mathrm{C} 2$, the highest level French competency exam available. Passing the DALF C2 gave me a certain degree of confidence in my second language, but this did not, however, prevent the inevitable cultural faux pas of whether to address someone with 'tu' or 'vous'. Thankfully, I found that my interviewees were not only extremely patient about my mistakes, but often took the time to explain or rephrase things if they were worried I had not understood.

Prior to commencing fieldwork, a broad interview question guide was devised in English (Appendix 1). This was composed of 18 possible questions or topics to enquire about, with some clarifying/ probing questions and prompts. Questions were grouped into four main sections - overview (of the organisation, its history and services) and overview of co-production/ participation, funding, governance 
and decision-making, and barriers and enablers to participation. Because the interviews were semi-structured, the interview rarely followed this exact format, but the question guide acted as an aide-memoire to ensure that I broadly covered these subjects. The areas that I focused on developed over the course of the fieldwork, from more on the funding arrangements and descriptive co-productive practices, to probing more deeply on ideas, motivations and values associated with co-production as I began to develop my theory and analytical framework.

I translated my question guide into French for the interviews in France, because only two of these interviews were conducted in English (one interviewee was originally from the United States, and another spoke fluent English and appreciated the opportunity to practice). I received advice from one of my key informants in Lyon on question wording and the subjects I intended to cover. This informal discussion was one of the first occasions in which I began questioning my own use of language and discourse, and illuminating some of my own erroneous assumptions about the way that respondents were likely to discuss their work in France, which provided the rudimentary origins of my analytical framework. As I began to discover at this stage, translation necessitated not only the translation of words but the translation or conversion of ideas and concepts, which often were discussed using different terminology. Some of these differences would not become clear until I conducted several interviews and realised that my choice of words did not always match up with those of my interviewees (although they generally appeared to understand the point I was trying to make or enquire about). 
I conducted 19 interviews with participants from the Lyon case study organisations and 18 in Sheffield (see Appendix 5 and 6). With the consent of respondents, all interviews were audio recorded to preserve the distinct narratives and use of language of participants. Audio recording interviews has the advantage of ensuring that the researcher obtains a complete record of the conversation rather than relying on note-taking abilities or memory, as well as ensuring that you can provide the interviewee with your undivided attention. At the same time, however, placing a recorder in front of an individual occasionally makes them anxious and impacts their level of openness and honesty (Blaxter et al., 2001). I attempted to anticipate and mitigate any anxiety or suspicion by beginning all interviews by explaining the purpose of my research, having participants sign a consent form and emphasising that all recordings would be fully confidential and anonymised. In the few instances that a respondent expressed uneasiness about something they were about to say being recorded, I reiterated the points about confidentiality and anonymity, and assured them that I could stop recording if it would make them more comfortable.

Relatively little attention is paid to the importance of transcription in methodology, but this is an oversight because of the crucial role that it plays in the production of data for analysis. During the process of transcribing recordings, the researcher (or professional transcriber) makes subjective decisions about what to include and what not to include (such as laughter, utterances and grammatical mistakes), and we often lose important context such as facial expressions, tone, and non-audible events (McLellan et al., 2003). Mistakes, inaudible passages or misinterpretations by a transcriber can lead to a disjuncture between an interviewee's intended 
meaning and the way the researcher interprets the narrative in the course of analysing the data (Witcher, 2010).

I made the decision to transcribe my interviews 'intelligent verbatim', meaning that the speech was transcribed exactly as said, but I omitted utterances such as 'um', 'uh', 'you know', etc. in order to improve readability without detracting from the overall meaning. As an experienced professional audio transcriber, I transcribed all of the Sheffield interviews myself, along with all but four of the Lyon interviews. I hired a native French transcriber to transcribe these four interviews for me, because I found that I was struggling to understand $100 \%$ of what the respondent was saying in the recording because of their accent or speed of speaking and felt that transcribing just the 'gist' was insufficient to ensure that I could accurately dissect respondents' narratives.

\subsubsection{Document analysis}

Alongside the main method of interviews, I also conducted thematic content analysis of organisational documents, publications and website text. Especially in the cases where I was only able to conduct an interview with one individual (generally because of scheduling or communication problems), I aimed to

supplement the data with publications that would give further insight into the organisation's rules, practices and narratives and whether/how co-production formed part of these. It was also important to triangulate the interview data with documentary evidence because of the nature of my research questions. As the focus of the RQs is on the level of the organisation, every attempt was made to compile an illustration of the practices, ideas and beliefs of the organisation, which necessitated 
the collection and cross-validation of various viewpoints from professionals. Organisational documents, such as mission statements, plans and reports provided a more objective reporting of these variables, which are less tempered by one individual's experience or perceptions. Drawing upon documents as another source of data also allowed me to assess whether there were any conflicts or contradictions between formally recorded rules and day-to-day practices, as described by interviewees or observed by the researcher (Lowndes and Roberts, 2013; Ostrom, 2007).

Documents are not, of course, completely objective and absent of bias. In conducting analysis of document data I remained cognizant of several key considerations: Who produced the document (i.e. the case study organisation or another body)? Who was the intended audience for the document - internal or external, a funding body, or the general public? What was the document's purpose or aim? (Duffy, 2010) Keeping these questions in mind whilst undertaking the analysis of the documents allowed me to assess why particular language or narratives might be employed. For instance, several individuals said in interviews that they would use the word coproduction with funders or policy-makers, but not with clients or service users. This calculated use of language and terminology is equally present in documents depending on whether the document is a funding application to a foundation, or a pamphlet that describes services to potential service users.

Selection of relevant documents was relatively straightforward for the Lyon case studies, because the French associative norm is to produce detailed, publicly available organisational plans, charters and mission statements, which provided 
invaluable data about official organisational rules and values. I obtained the fouryear 'social plans' (projets sociaux) of the five social centre case studies, which provide extremely detailed evaluations of the previous plan, strategies for the coming four years, and outlines of the resident involvement and consultation processes that had gone into producing the plans. Because each of these plans were 60 to 80 pages long, and some of which I received only paper copies of, I only uploaded to NVivo and analysed the passages I found particularly relevant. For Lyon Parents and Lyon Older People, I also analysed meeting notes and brochures, which allowed me insight into both the external face and internal narratives portrayed by the organisations.

The documents available from the Sheffield case studies generally took a different form to those I obtained in Lyon, utilising more of a summary and bullet point format to illustrate targets met and other statistics rather than providing more in depth narrative accounts. I analysed operational plans, annual reports or strategic documents from four of the five case studies and bid documents from Sheffield Parents. These nevertheless provided some support to the themes and narratives identified in interview accounts. In addition, an interviewee from Sheffield Older people provided me with their 'co-production action plan'. As will be discussed in Chapter 7, Sheffield Older People was the only organisation that explicitly employed the term co-production to describe their practices, so this document provided a valuable insight into both their narratives and practices.

Finally, I also collected several documents produced by other local public bodies and organisations in order to identify the rules and narratives present at the field level 
and to evaluate the degree to which co-production practices are encouraged and enabled by other actors. These included reports published by local government, networks and third sector umbrella organisations. The focus of this aspect of the analysis was specifically on how co-production and participation were discussed at this level - i.e. whether local field level actors prioritise this type of practice and what type of discourse is used to describe it.

\subsubsection{Observation}

Finally, I employed observation as the third research method. Observation is frequently used in organisational ethnography as a way to identify day-to-day practices or routines, but is also increasingly used in non-ethnographic studies as well. Because practices are informal and unrecorded, and because interviewees' accounts of practices are tempered by their own perceptions and biases, observation and other ethnographic approaches are the preferred method for studying these (Lowndes and Roberts, 2013).

Ethnographic observation of, and participation in, particular organizations, locations and social activities is now frequently noted for its utility in providing in-depth insights into what people and organizations do on a day-to-day basis. This picture of day-to-day activity has been used to inform a broad array of actions from the augmentation of strategy processes to the design of mobile phones. (Neyland, 2008, p. 6)

Neyland notes, however, that there are several drawbacks that the researcher faces in using ethnographic observation, such as time, access and the ability to write rich, detailed and accurate field notes. In addition, the researcher should aim to maintain 
a sense of objectivity, and be aware that the events or practices observed may not be typical of the organisation - particularly if observations are undertaken over a limited time period, such as my attendance and observation of a small number of meetings and events.

Due to the abductive strategy of the research (discussed in section 4.2.2) I had not fully developed and operationalised my analytical framework of institutional logics as rules, practices and narratives prior to commencing fieldwork and therefore did not incorporate observation into the initial research strategy. The identification of opportunities for observation was thus not as systematic as the recruitment of interview participants and collection of documents for analysis. However, I was able to attend and observe the annual general meetings/ assemblées générales of several of the community regeneration organisations and social centres, as well as some events and activities as listed in Appendix 7.

Because annual general meetings (AGMs) are fairly structured and formal, these were often more appropriate for analysing rules and narratives rather than practices - particularly as these are not spaces where it is possible to observe dayto-day co-production activities. These did, however, afford me the opportunity to hear staff members and volunteers discuss services and activities in a context where, unlike an interview, I was not the primary audience, thereby reducing participant/ interviewee reactivity to my presence or position as researcher (Rosnow and Rosenthal, 1997). While reactive effects are typically argued to be a potential downside to observation, i.e. "people's knowledge of the fact that they are being observed may make them behave less naturally" (Bryman, 2016, p. 494), this was 
less the case in the events and meetings I was observing as an attendee, where my presence as a researcher was unknown (or irrelevant) to the majority of other attendees.

Several of the events I observed also included booths, posters and displays set up to highlight various projects, many of which described specific co-production practices, which will be analysed in Chapters 6 and 7. In addition to the formal AGMs, I also attended the two mental health 'social cafes' (Enterprise) and a family craft day (Sheffield Parents) on the advice of interviewees, who suggested that these were good examples of co-production. These were the only opportunities I had to observe services or activities in practice. Unfortunately, I was not able to organise similar observations in Lyon due to limited availability during my fieldwork visits.

During these events, I took detailed field notes which I inputted into NVivo as part of my wider dataset, and I took photographs of several of the presentations (see Figures 6.2, 6.3, 7.1 and 7.2) that showed relevant examples of co-production practice, with permission. Field notes were not coded and analysed in the same systematic manner as documents and interview transcripts because these were my own interpretation and language, rather than that of participants. Instead, I conducted more general thematic analysis of these notes and records.

\subsection{Research ethics}

The conduct of ethically informed social research should be a goal of all social researchers. Most commonly, ethical issues are thought to arise predominantly with research designs that use qualitative methods of 
data collection. This is because of the closer relationships between the researcher and the researched. Nevertheless, all social research [...] gives rise to a range of ethical issues around privacy, informed consent, anonymity, secrecy, being truthful and the desirability of the research. (Blaxter et al., 2001, p. 158)

Conducting rigorous and ethical research means that ethical considerations are not an add-on to the research design, but rather a key element that defines the process at every stage. This is particularly sensitive when undertaking qualitative research with human participants. The ethical aspects that will be considered here are the measures taken in regards to conducting interviews in regards to informed consent, confidentiality and anonymity, and the protection of data obtained as part of the research. The project received full ethical approval from the University of Birmingham Humanities and Social Sciences Ethical Review Committee ${ }^{5}$.

In conducting interviews with research participants, I made a point of being explicit about my role as a doctoral researcher, the purpose of the research and their role within it. The first step of this process was to obtain informed consent from every participant. Gaining informed consent means that research participants are given adequate information to be able to understand what the research project is about, and they agree in writing to taking part in the interview (Traianou, 2014). As Traianou explains, in some instances it is not possible to fully inform research participants before the beginning of the study, but ethically, it is desirable to supply them with as much information as possible. In the case of my research, the only instance where I deliberately withheld information was the fact that I avoided using

\footnotetext{
${ }^{5}$ Application for Ethical Review ERN_15-1172, see Appendix 8.
} 
the word 'co-production' at the outset to describe my research, because it was important to me for participants to use their own language without being influenced by my choice of terminology.

To ensure compliance with rigorous ethical standards, participants were initially asked whether they would be interested in and willing to participate in the study. Before an interview, the participant was verbally informed about the purpose my research and the general direction the interview questions would take, as well as the fact that any responses would be fully confidential and anonymised in any written outputs. By confidential, I mean that the only people who would have access to the recordings and transcripts would be myself and my doctoral supervisors, and by anonymity I mean that all names and organisation names would be given pseudonyms, and any obviously identifying features would be removed. Participants were asked whether they were happy for the interview to be recorded and transcribed, and I informed them that they had the right to withdraw at any time (which would lead to any data or information derived from their interview being destroyed and not included in the analysis). If they agreed to the above conditions (which happened in all cases), interviewees were asked to sign a consent form (Appendix 3).

Whilst the subject matter was unlikely to cause any discomfort or invade participants' personal privacy, it was possible that confidential matters could arise (such as business figures for the organisation, or personality conflicts between participants conveyed in confidence) which made it imperative to assure participants of both confidentiality and anonymity. This involved a process of 
building a rapport and trust with participants, which allowed them to be more comfortable opening up and being honest. In general, however, I found that interviewees were extremely forthright and had few qualms about discussing the subjects I enquired about. Only on two occasions did interviewees express discomfort at being recorded when they made minor derogatory comments about how a particular service was run (which, as previously mentioned, prompted me to repeat my opening statements about confidentiality and anonymity).

In meeting and event observations, I applied the same principles to my note taking, ensuring that I respected the anonymity of participants in the event. Given the public nature of these events and the fact that no individual participants would be identified in my notes or findings, there was no need to obtain consent forms from everyone present. I took some photos of presentations and posters at the AGMs (included in Chapters 6 and 7), but made sure to avoid taking any photos of individuals.

Finally, in my application for ethical approval, I outlined the way in which I would ensure protection of all data created and obtained for the research study, including contact details of participants, notes of interviews and meeting observations, interview recordings and interview transcripts. These were held as digital records and stored according to University of Birmingham guidelines for information security. 


\subsection{Data analysis: Applying the analytical framework}

In the previous chapter in which I outlined the theoretical framework of the research, I discussed some of the ways in which other theorists have operationalised the concept of institutional logics. In this section, I will further elaborate on these models and develop the analytical framework of this research, which is informed by an approach of abductive analysis.

In developing a model to operationalise institutional logics as a framework, I interrogated the approaches of other research in the field. Many of the studies that aim to understand how institutional logics impact identities, decision-making or other actions often assume the existence of particular logics due to some identified extrinsic events or practices and do not fully interrogate the concept. For instance, Reay and Hinings (2009), who study the co-existence of a dominant logic of medical professionalism with a logic of business-like health care suggest that the introduction of this second challenger logic due to a government policy. Lounsbury (2007) and Greenwood et al. (2010) take a quantitative approach by creating dummy variables to represent institutional logics to analyse a large-scale dataset. Furthermore, the majority of empirical studies of the impact of institutional logics tend to be focused on single case studies, or a small number of case studies that are not analysed comparatively.

Because of the international comparative research design of this study, I have chosen not to assume a priori knowledge of the logics that exist within the case study organisations. As will be demonstrated in Chapter 5 through discussion of the institutional typologies that demarcate England and France, the literature suggests 
that the combination of institutional logics present in third sector organisations in each country are likely to vary, making it necessary to adopt a more systematic approach to identifying these.

I planned a two stage process to coding my data. By coding, I am referring to the process of assigning names to phrases, sentences or longer passages of text in data in order to identify ideas and themes (Miles et al., 2014). During stage 1, I took a more grounded theory strategy of open coding. In stage 2, I devised a coding approach inspired by the methodology of Pache and Santos (2013), but adapted to fit my operationalised model of institutional logics. Combing through my data and coding it several times (often rethinking and reclassifying codes from the first stage of analysis during the second stage) added to the reliability and validity of my approach. In addition, I kept detailed notes and memos throughout the coding process in order to demonstrate exactly how I handled my data, as recommended by Richards (2009) and Miles et al. (2014).

\subsubsection{NVivo Analysis}

I decided to use NVivo Computer Assisted Qualitative Data Analysis Software (CAQDAS) to facilitate the process of coding my data. I came to this decision because the sheer scale of the data I had collected (45 interview transcripts, 31 documents, and 16 field notes) along with the complicated multi-stage nature of my coding design meant that coding the data would be unmanageable any other way. In addition, using CAQDAS software increases the rigour of qualitative research in enabling the researcher to demonstrate the number of instances particular things occur, rather than relying on individual anecdotes (Silverman, 2013). 
CAQDAS packages act as containers for accessing all materials pertaining to a research project and researchers' ideas, analyses and results. [...] CAQDAS packages do not dictate the way in which tasks are performed, but the tools they offer may increase the complexity of tasks that are possible and the researcher's readiness to perform them. In particular, they encourage flexibility in revisiting, rethinking, or repeating analytic processes. (Silver and Lewins, 2014, p. 614)

Having already used this software for other projects, I was experienced in its functionality, making this a natural choice that both saved an extraordinary amount of time as well as allowed me to interrogate my data in ways that would be nearly impossible if I had coded my data manually. However, I did do some manual coding of documents that I only received in physical paper form or as PDFs, which I then entered into NVivo to be able to analyse in parallel with the rest of the interview and document data.

\subsubsection{Stage 1: Open coding}

For the first stage of my analysis, I coded my data with descriptive 'nodes', whilst simultaneously grouping and re-categorising the emerging nodes into themes that were developing. This can be seen as akin to the grounded theory method of open coding. While I approached my data with an idea of the broad themes I would encounter based on my research questions, I did not pre-emptively create a coding framework at this point and instead allowed the nodes to emerge themselves.

Interviews undertaken in English and French were coded using the same nodes, although occasionally I named these nodes in both languages as a memory aide (for example 'citizen-led projects/ projets des habitants') or because the terminology 
differed between the two languages but I felt there was conceptual similarity (such as 'social cohesion/ vivre ensemble', which will be dissected in more detailed in the empirical analysis chapters). After some grouping and regrouping of nodes, the primary parent nodes that emerged were around 'values associated with coproduction', 'barriers and enablers to co-production' and 'participation and coproduction methods'. Each of these parent nodes housed approximately 10-20 child nodes, some of which contained one or two third level nodes. Some nodes did not fit neatly into these three parent nodes, but it felt important to recognise them so they were retained as their own top level nodes. The most important of these was 'terminology/ definitions', with child nodes focusing on 'community', 'customer or client' and most importantly, 'reactions to and definitions of the word coproduction'.

A list of the 'parent' and 'child' nodes can be found in Table 4.2. An asterisk indicates the presence of third level nodes, which I have not included to save space. Nodes have been sorted in descending order from most frequent references (i.e. number of instances coded in the data) to least frequent. This is by no means a scientific quantitative measure (particularly because this does not take into account the length of each code/ reference), but this gives a rough indication of the frequency or level of importance of particular nodes/themes in the data. 
Table 4.2: NVivo node hierarchy for first stage of coding

\begin{tabular}{|c|c|c|}
\hline Name & Sources & References \\
\hline \multicolumn{3}{|c|}{1 BARRIERS/ ENABLERS TO COPRODUCTION } \\
\hline Roles ** & 27 & 76 \\
\hline Clients- citizens $*$ & 18 & 28 \\
\hline Resources and time & 14 & 24 \\
\hline Political & 14 & 35 \\
\hline Organisational culture * & 14 & 29 \\
\hline Training & 13 & 18 \\
\hline Professionalism & 13 & 21 \\
\hline Targets \& evaluation & 9 & 16 \\
\hline Culture & 5 & 10 \\
\hline Tokenism & 4 & 4 \\
\hline Centralised state & 4 & 5 \\
\hline Risk & 2 & 2 \\
\hline Organisation size & 2 & 3 \\
\hline \multicolumn{3}{|l|}{1 COPRODUCTION VALUES } \\
\hline Empowerment - power & 22 & 58 \\
\hline Partnership & 19 & 37 \\
\hline Support & 18 & 49 \\
\hline Meeting needs & 16 & 45 \\
\hline Community engagement & 16 & 37 \\
\hline 'Do with not for' & 15 & 27 \\
\hline Relationships & 13 & 28 \\
\hline Voice & 13 & 21 \\
\hline Asset-based / expertise & 12 & 18 \\
\hline Vivre ensemble - social cohesion & 9 & 21 \\
\hline Cooperation / collaboration & 9 & 14 \\
\hline Community development & 8 & 18 \\
\hline Citizenship & 8 & 17 \\
\hline Solidarity & 7 & 15 \\
\hline Test and learn & 5 & 9 \\
\hline Values of centres sociaux & 5 & 6 \\
\hline Reciprocity & 5 & 5 \\
\hline Community organising & 4 & 10 \\
\hline Social movement & 4 & 4 \\
\hline Inclusive & 2 & 5 \\
\hline Personalisation & 2 & 5 \\
\hline
\end{tabular}




\begin{tabular}{|l|r|r|}
\hline \multicolumn{1}{|c|}{ Name } & Sources & References \\
\hline 1 PARTICIPATION - METHODS & & \\
\hline Citizen-led / projets des habitants & 17 & 43 \\
\hline Co-construction & 18 & 34 \\
\hline Consultation & 19 & 31 \\
\hline Informal & 17 & 29 \\
\hline Co-design - co-decision & 12 & 29 \\
\hline Co-production examples & 10 & 22 \\
\hline General participation methods & 14 & 20 \\
\hline Staff facilitation & 7 & 12 \\
\hline Evaluation of participation & 4 & 11 \\
\hline Co-delivery & 5 & 8 \\
\hline Different options & 4 & 4 \\
\hline Organisational info & & \\
\hline Services offered & 20 & 41 \\
\hline Organisation ethos & 11 & 30 \\
\hline Organisation strategy & 11 & 23 \\
\hline Funding & 13 & 22 \\
\hline Founding & 8 & 11 \\
\hline Motivation / purpose & 6 & 7 \\
\hline Terminology & 7 & 6 \\
\hline Reaction to co-production / definition & 5 & 1 \\
\hline Community & & 57 \\
\hline Client / customer & & \\
\hline Social capital & & \\
\hline Parent node with two levels of child & & \\
\hline
\end{tabular}

** Parent node with two levels of child node

* Parent node with one level of child node

I began this stage of data coding while I was still in the midst of undertaking my interviews. Given the abductive design to the research, this was a conscious decision in order to begin to start understanding what common themes were emerging and to start building theory as the research progressed.

We strongly advise analysis concurrent with data collection. It helps the fieldworker cycle back and forth between thinking about the existing data and generating strategies for collecting new, often better, data. It 
can be a healthy corrective for built-in blind spots. It makes analysis an ongoing, lively enterprise that contributes to the energizing process of fieldwork. (Miles et al., 2014, p. 70)

This simultaneous data collection and analysis allowed me to tweak my interview question guide to be more targeted about the issues I wanted to probe on. For example, as I began to develop my institutional logics framework and recognised the importance of narratives and word choice in defining organisations' approaches to co-production, I began to probe interviewees more specifically about what they meant by certain terms which previously had been taken for granted (such as coproduction and community in English, and co-construction and participation in French) as well as on their motivations for and values associated with involvement and participation.

After this stage of coding and inspecting the groups of nodes that had emerged, I began to develop some rudimentary ideas about what differentiated co-production between the English case studies and the French ones. The key initial distinctions that I identified were around the funding to organisations, organisational ethos and some of the language used to describe activities. This led me to begin to interrogate this notion of ethos, as it seemed the primary distinguishing feature between the Lyon and Sheffield organisations related to something around "statements of 'mission', 'values', and 'ethics'” (Cloke et al., 2005, p. 385). This, however, seemed to be an insufficient explanation for the interplay of beliefs about co-production and actions to involve citizens that were emerging from the data. Kenny's notion of 'operating frameworks' (2002) - comprised of values, assumptions and principles that underpin organizational forms and day-to-day practices - provided a stepping 
stone to developing a clear, cogent analytical lens through which to analyse and typologise my case study organisations. It was from this point that I began to unpack the theory of institutional logics, which helped me to begin putting the pieces of the puzzle together.

\subsubsection{Stage 2: Theoretical coding}

In developing a method to identify institutional logics, it was useful to consult Pache and Santos (2013) whose methodology produces a clear data structure for identifying and analysing logics, as discussed in Chapter 3. To reiterate briefly, in their study, the authors take a grounded, multi-stage data collection and analysis approach. They first identify recurring themes in order to categorise four elements (goals, organisational forms, control/governance, and professional legitimacy) of two competing logics. Organisational elements impacted by the conflicting demands of these two logics (such as legal status, profit destination, brand, monitoring and mobilisation of volunteers) were grouped within these logic characteristics within their data structure. Because their data structure lacked the sufficient acknowledgement of the more abstract and value-based elements of institutional logics, I have instead based my theoretical coding on Lowndes and Roberts' typology of institutional constraints, which corresponds well with the definition of institutional logics.

If we want to research political institutions and their effects, we should study rules, observe practices, and interpret narratives. (Lowndes and Roberts, 2013, p. 69, emphasis mine) 
Drawing upon Pache and Santos' method of data analysis, I coded for institutional logics using these three elements - rules, practices and narratives. Prior to commencing this stage of coding, I carefully defined each element so that I could aim for reliability in coding.

Rules are taken to mean regulations, laws, contract requirements and internal organisational rules and procedures. Because these are formal and recorded, these are typically straightforward to identify.

For practices, I refer back to Lowndes and Roberts' definition of "informal institutional rules [...] specific to a particular political or governmental setting, they are recognised by actors (if not always adhered to), have a collective (rather than personal) effect, and can be described and explained to the researcher" (2013, p. 47). For the purposes of coding my data, I focus more specifically on co-production or general involvement/ participation practices, as opposed to general day-to-day routines and procedures, because this is the key area of investigation for my research questions.

Finally, narratives is the element that can best be used to identify the 'assumptions, beliefs and values' aspect of an institutional logic. I coded this element through the ways that people describe their motivations, and how practices and rules are justified. "Narratives are especially important modes of institutional constraint to the extent that they provide an account not just of how we do things around here, but also why we do things the way we do." (Lowndes and Roberts, 2013, p. 64). The passages/ elements that I coded as 'narratives' focused specifically on ideas, beliefs, identities, values and the shared sense of reality that individuals expressed. 
In speaking candidly, interviewees do not neatly disentangle rules, practices and narratives, and there were many instances where a passage could be indicated as two or all three of these elements. This frequently arose, for example, in describing a particular participation activity (practice) and in explaining why it was done in such a way, or what benefit it had (narrative). In these examples, I double or triple coded for rules, practices and/or narratives, as this did not in any way detract from the analysis.

\subsubsection{Stage 3: Analysis}

The next stage of data analysis involved using NVivo to query the nodes I had created and to see whether any clear themes emerged across and between the cases. While I conducted stage 1 and stage 2 of the analysis across all of the case studies simultaneously, at this point, I focused on one sub-sector at a time, in order to focus on the comparative analysis of the community regeneration organisations and social centres, Lyon Parents and Sheffield Parents, and Lyon Older People and Sheffield Older People. Analysis of the coded material was undertaken by using NVivo to query for content that was dual coded at each of the three primary parent nodes barriers/ enablers to co-production, co-production values, and participation methods - with each of the three theoretical parent nodes - rules, practices and narratives.

What immediately became clear upon querying the data was that the themes that emerged from the open coding displayed a large degree of similarity and coherence

with the theoretical coding that was subsequently developed, i.e. barriers and enablers to co-production largely matched with rules, participation methods with 
practices, and co-production values with narratives. A matrix coding query illustrated that about $35 \%$ of the passages coded for narratives were also coded as 'co-production practices', and $40 \%$ of the practices references were also coded as 'participation methods' 6 . This measure is not included to act as a kind of quantitative measure, due to the fact that coded references very tremendously in length and importance as part of each individual interview, but this acts as a rough confirmation of the coherence between the themes identified in open coding and the analytical framework that was applied.

1. Open coding

- Themes emerging:

1. Barriers/enablers to

co-production

-2. Participation methods

-3. Co-production values
2. Theoretical coding

-1. Rules

2. Practices

-3. Narratives

\section{Analysis}

- Querying content coded

at each of open coding

nodes + each of

theoretical coding nodes

\section{Figure 4.2: Data Analysis Process}

The coded content was then thoroughly interrogated to identify emerging themes and ideas relating to each element of institutional logics and whether and where co-

${ }^{6}$ The matrix coding of 'barriers/enablers to co-production' crossover coding percentage with 'rules' and 'practices' (about 15-20\% each), which can be explained by the fact that the child nodes under 'barriers/enablers' included a range of factors from legal and political barriers to cultural barriers and practices. 
production fit within these. Focusing on rules, practices and narratives successively allowed me to clearly formulate a picture of how the case study organisations undertook co-production and the reasons (both objective and subjective, nonmaterial or perceived) for doing things one way or another. In Chapter 6 and 7, I present the empirical findings from this analysis, structured to focus on the comparison between the community regeneration organisations and social centres (Chapter 6) followed by a complementary examination of the parents' organisations and older people's organisations in Chapter 7.

\subsection{Conclusions}

The purpose of this chapter was to explain the methodological approach that was devised in order to address the aims and objectives of the thesis. I have outlined how the choice of design and methodological approach was informed by an interpretivist epistemology, which focuses on better understanding and interpreting the

differences between the cases, as opposed to explaining or proving causal relationships. The chapter explained the choice of comparative international case studies as a research design. The choice of this design, along with the benefits and challenges associated with conducting qualitative research in two languages was considered, along with the limitations of this approach.

The research was conducted through a mixed methods approach of semi-structured interviews, observation and document analysis in order to allow for data triangulation, which improves the validity of the results. Finally, the iterative data 
analysis approach was explained, which involved a three stage process of open coding, theoretical coding, and analysis/ interpretation of the results. 


\section{CHAPTER 5: CONTEXT FOR THE RESEARCH: SOCIETAL}

\section{AND FIELD LEVEL LOGICS}

\subsection{Introduction}

Having discussed the research design and methodology in the previous chapter, this chapter aims to describe and analyse the contexts in which the case study organisations operate, before turning to the empirical analysis of the case study organisations in Chapters 6 and 7. This discussion of the country and city contexts serves two purposes: first, a descriptive purpose - characterising and describing the two locations where the empirical analysis takes place and second, an analytical purpose - reviewing and analysing institutional typologies, government documents and data from interviews with local stakeholders, in order to characterise the institutional logics that exist at the field and societal levels which contribute to shaping decision-making and behaviour at the organisational level. This second aim of the chapter assumes the majority of the content in the chapter, and I review both secondary and primary documents and data concurrently.

As discussed in Chapter 3, Friedland and Alford (1991) assert that while organisations may have their own defined logics, these are nested within the "central institutions of the contemporary capitalist West" (Friedland and Alford, 1991, p. 232). Applying this theory to the study of co-production, then, we can posit 
that whilst individual organisations may have their own motivations and approaches to co-production practice, they will also be influenced by field and societal level logics (Thornton, 2004). Thus, the purpose of this chapter is to present an analysis of the factors that contribute to the societal level in England and France, and the field level in Sheffield and Lyon, through discussing rules and narratives. In so doing, I aim to explore the differences between the two locations and the existence of dominant or interacting logics at each level.

In the first section of this chapter, I begin by examining and comparing institutions at the societal level in England and France, focusing on institutional typologies in the academic literature and the ways that these two countries are categorised. While we understand there to be seven societal level ideal-typical 'institutional orders' in Western society, each with their own distinctive logics (Thornton et al., 2012), the degree to which these are drawn upon, blended or assimilated at the organisational level may depend on the culture and traditions of each country. In addition, this notion of societal wide logics emanating from seven institutional orders which are consistent across Western societies merits interrogation, particularly for the purposes of comparative research.

In the second section, I shift the focus to the 'field' level - in this instance referring to the city/ municipal level and the interrelationships between different actors (particularly public sector and third sector) in this space. The field level exploration draws upon both secondary data and literature as well as primary research conducted with local stakeholders outside of the case study organisations. This section aims to provide an illustration of the field level logics that impact the case 
study organisations, through an analysis of the rules and narratives that persist at the local level.
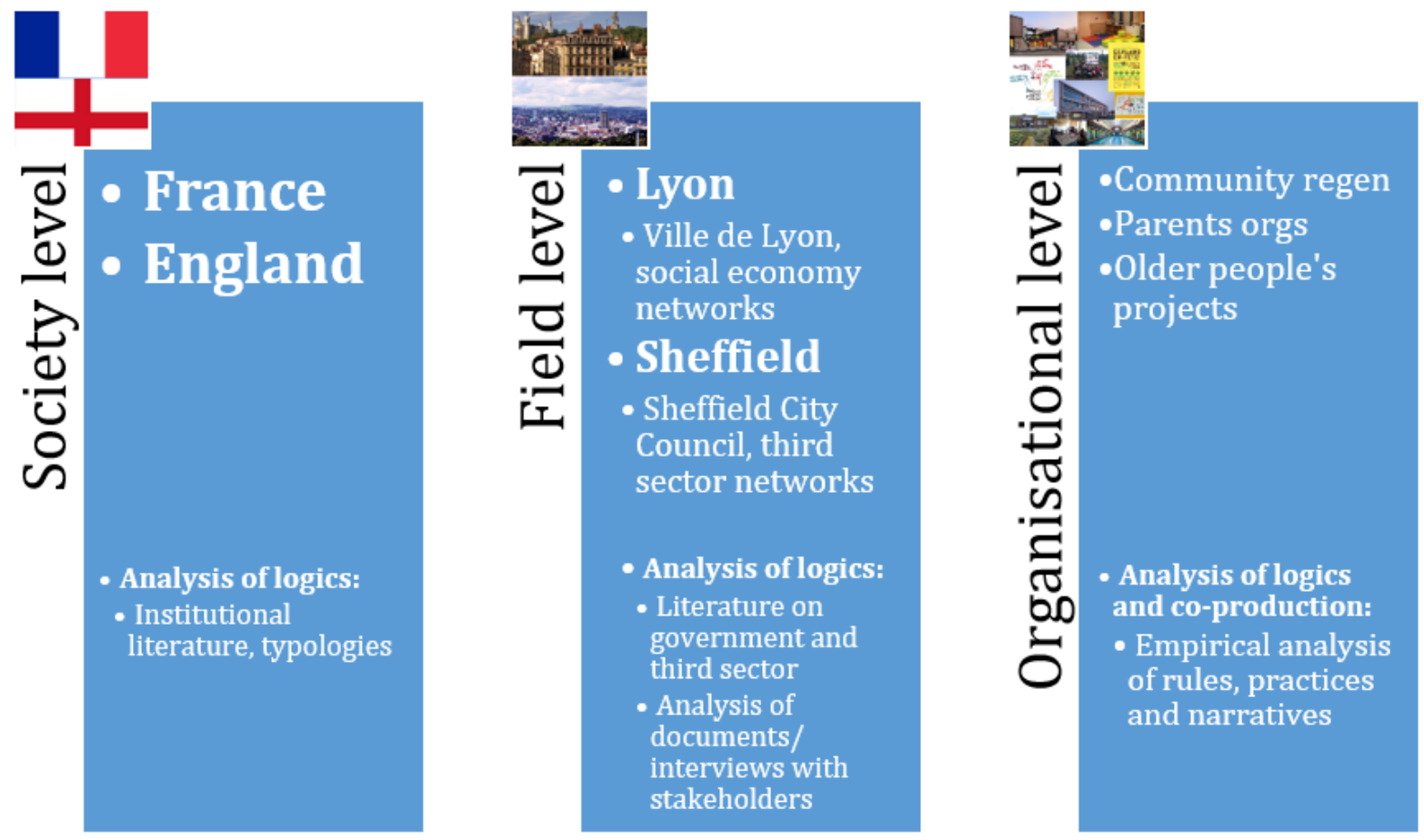

Figure 5.1: Levels of institutional analysis

\subsection{Societal Level: Institutional Typologies}

All three levels of analysis [individuals, organizations, and society] are necessary to adequately understand society. Each level of analysis is equally an abstraction and a reification; each is implicated in the other; none is more 'real' than the other. Individual action can only be explained in a societal context, but that context can only be understood through individual consciousness and behavior. We conceive of these levels of analysis as 'nested', where organization and institution specify progressively higher levels of constraint and opportunity for individual action. (Friedland and Alford, 1991, p. 242) 
I aim to evaluate this theory of the hierarchy of logics and the way they affect action by interrogating other institutional typologies that surmise that there are key differences between countries and societies that must be recognised in order to design comparative empirical studies. These institutional differences in turn impact the logics that are available at the individual and organisational levels, which I theorise will determine co-production practices. In this section, I analyse the literature on welfare regimes, non-profit regimes, and administrative or governmental traditions and the ways in which these typologies help us to understand differences between the societal level logics that accordingly shape the lower level logics available to actors.

\subsubsection{Welfare and non-profit regimes}

In order to understand variations between the combinations of dominant logics within different countries and how these impact the third sector, Esping-Andersen's (1990) typology of welfare regimes provides a useful lens through which to explain differences in service provision and to build a basis for a comparative study. EspingAnderson's notion of welfare regimes categorises countries based on the degree of commodification in social policy, social stratification and employment. He classifies Western capitalist countries as one of three ideal types: liberal, corporatist or conservative, and social democratic. (Further studies, such as Ferrera, 1996 and Arts and Gelissen, 2002, have suggested four or more ideal types). A welfare regime is understood as "a particular constellation of social, political and economic arrangements which tend to nurture a particular welfare system, which in turn supports a particular pattern of stratification, and thus feeds back into its own 
stability" (Taylor-Gooby, 1996, p. 200). Esping-Andersen classifies the United Kingdom ${ }^{7}$ as liberal, meaning a low level of welfare provision, focused on providing for only the most needy. France is classified as corporatist, with welfare benefits based on social insurance and a strong link between professional or occupational status and entitlements. Although Esping-Andersen's model has been critiqued and updated by subsequent authors, the UK and France are consistently placed in different categories (Ferragina and Seeleib-Kaiser, 2011).

This theoretical typology not only provides a justification for focusing on England and France as two case study locations (as 'most different cases') but also provides some theoretical basis for understanding possible differences in institutional logics present at the field and organisational level in each context. Differences between welfare regimes provide an insight into a state's ideology about public service provision, in terms of who is entitled to benefits and services, what services should be funded by the state or provided privately, and what types of organisations should be tasked with providing these services. The welfare regimes approach involves an implicit confirmation of the differential influence of institutional logics within countries categorised under different welfare regimes. For instance, in the 'Southern/Mediterranean' model described by Ferrera (1996), a weak welfare state is partially predicated on the strength of the family and religion logics in the provision of social and welfare services. By contrast, the United Kingdom as a liberal

\footnotetext{
${ }^{7}$ The focus of this study is on England specifically, rather than the UK as a whole, because of the differences between the third sectors and certain social service policies between the nations (England, Scotland, Wales and Northern Ireland) of the United Kingdom (Alcock, 2010). However, in this chapter, I will be referring to the UK insofar as this is the focus of most institutional typologies.
} 
welfare regime is the only one of the three categories where we would expect the market logic to play a marked role in the welfare system. France's conservative or corporatist welfare regime is greatly influenced by the state logic, as the government is somewhat paternalistic in making determinations about the extent of welfare provision.

The welfare regimes approach has also been used to build a theory to explain the development of the non-profit sector in various countries, allowing us to further appraise the differences between societal and field level logics between countries. Salamon and Anheier's 'social origins' of civil society theory explains the development of the non-profit sector in different countries as attributable to each country's social, political and economic relationships, rather than assuming a purely supply/demand or market failure explanation (Salamon and Anheier, 1997, 1998). The social origins approach suggests that there are several courses of third sector development that align with countries' class relationships and the relationship between the state and society. Their macro-institutionalist model features four types of non-profit regime - based on the scale of non-profit operations (amount of employment and volunteer time), and sources of funding.

Similar to the welfare regimes model, Salamon and Anheier distinguish four 'nonprofit regimes' - liberal, social democratic, corporatist and statist, with the UK classified as liberal, or Anglo-Saxon (Archambault, 2009), and France as corporatist. Both France and the UK are defined in this model as being characterised as having large non-profit sectors, but echoing Esping-Andersen's welfare regimes model, the liberal non-profit regime sees comparatively low government spending on social 
welfare, whereas corporatist non-profit regimes like France have a high degree of welfare spending, particularly targeted at this sector as delivery organisations. As an illustration of the difference in practice, in France, $60 \%$ of the welfare provision workforce is employed in non-profit organisations compared to $26 \%$ in the UK (Archambault et al., 2013; Clark et al., 2010).

Taylor (2004) critiques Salamon and Anheier's categorisation of the UK as a liberal non-profit regime and argues that grouping it with the United States overlooks some important aspects of the development of the British third sector in relation to the welfare state.

In fact, this classification of the UK overlooks a number of features. The first is that, while the liberal philosophy has been apparent throughout British history, other currents have tempered and, at times, overlain it. Bagguley (1994) claims that the UK forces Esping-Andersen to the very limits of his model and argues instead for a classification that acknowledges the overlapping historical traditions that go to make up current patterns of welfare in the UK. (Taylor, 2004, p. 125)

The development of a strong, state-provided welfare system in the post-war period is more in line with the continental European welfare regimes, and it was not until later in the $20^{\text {th }}$ century that the government moved more towards privatisation of welfare (a trend that has accelerated since Taylor's assertion). Taylor also notes that the role of the third sector in the welfare mix is indeed recognised in British government policy, which would indicate that the UK is actually situated somewhere between the liberal and corporatist ideal types. 
These critiques highlight some of the weaknesses of the welfare and non-profit regimes approaches, but these typologies nevertheless reveal some important distinctions between the societal level logics that characterise France and England, which we would expect to influence both the field and organisational level logics differently in each context. If, as Verschuere et al. (2012) postulate, a country with a strong third sector may also have a tradition of co-production, then this is likely to be the case in both England and France given their types of non-profit regime. However, this assumption masks differences in the institutional arrangements and logics that govern these complex terrains. France with a 'corporatist' welfare system and the UK with a 'liberal' welfare system have very different structures of provision and delivery of social services. France's third sector having developed to a large degree alongside the welfare state as a major provider of services makes it a more corporatist partner in this arena, with some even arguing that the third sector is treated as no more than an arm of the state in some cases.

The French associative movement is, more than any other in the Western world, worked by a dialectic between integration and protest, institutional mimicry and affirmation of the voluntary group. (Barthélemy, 2000, p. 99, translation mine)

In England, the voluntary and community sector has a much longer tradition of delivering social services completely independent of the state. The sector's identity of charity and philanthropy is founded on an ethos of collaboration with citizens to deliver services to the poor to address needs unmet by the state. Thus, we can see how the state and community logics exhibited in England and France demonstrate 
some nuances between the rules and narratives that comprise them, which will provide explanatory value when shifting the analysis to the organisational level.

\subsubsection{Administrative traditions}

Another variable contributing to the differentiation between institutional logics at the societal level is the concept of administrative traditions (Loughlin and Peters, 1997) or governmental traditions (Bevir et al., 2003). While third sector organisations are independent from government, in France and England like many countries, they are highly reliant upon and linked to the public sector and therefore influenced by the particular traditions in this context. Third sector organisations provide public services and many are funded by grants and contracts from the government. Changes in political control may impact not only the rules that constrain third sector actors, but also the dominant narratives and acceptable practices available to them. Public bureaucracies, however, despite some significant reforms, exhibit enduring characteristics that make them distinctive and arguably more resistant to major disruptions (Painter and Peters, 2010b). Classifying countries according to their administrative/ state traditions contributes to the comparative analysis of societal level institutional logics.

Peters defines an administrative tradition as "a historically based set of values, structures and relationships with other institutions that defines the nature of appropriate public administration within society" (Peters, 2008, p. 118). This involves notions of accountability, the primacy of law or management in driving public administration, relationships between politics and civil service, and crucially for the purposes of this study - the relationship between the state and 
society. Similarly, Bevir et al. (2003) employ 'governmental traditions' to mean "a set of inherited beliefs about the institutions and history of government" (p. 6), drawing the focus more towards actors' beliefs about institutions, structures and history whereas work on administrative traditions assumes that these variables themselves determine action. Traditions guide how the public sector interacts with other sectors, and the relationship with citizens. Differences between the administrative or governmental traditions of countries are a key component of the way that policy is decided as well as implemented.

Painter and Peters identify nine groups of administrative traditions, which place the United Kingdom and France into distinctly different categories, similar to the welfare and non-profit regimes (Painter and Peters, 2010a). France belongs to the Napoleonic tradition, defined by a hierarchical, centralised state which exists to unite society and overcome cleavages. The Napoleonic tradition has a strong legal tradition whereby the law serves to regulate the relationship between the state and citizens, and as a driving force in decision-making within public bureaucracies. The state is conceived as protector of the general interest of citizens and means to overcome differences within society. It is a force unto itself and exists independent of society.

By contrast, the United Kingdom is categorised within the Anglo-American, or Anglo-Saxon (Bevir et al., 2003) tradition, meaning that the state is seen as "arising from a contract among members of society" (Loughlin and Peters, 1997, p. 50), with relationships and policy-making characterised as pluralistic. 'The state' is not a clearly constituted entity and government is seen more as an agglomeration of 
departments, whereas in France, 'the State' is conceptualised as a proper noun and legal body itself. Policy-making is negotiated between individual interests and accountability is based more on political than on legal justifications.

The French state disentangled itself from feudal society through a crucial process of institutionalization and differentiation. It was forcibly constructed contra civil society, as it were, and developed under absolutism a bureaucracy with a distinctive ethos, contrasted with the private, particularist and ultimately disruptive values of old regional, occupational and religious institutions. (Laborde, 2000, p. 547)

The analysis of administrative traditions gives rise to three key points in relation to societal level institutional logics. First, the Napoleonic tradition demonstrates a strong preference for legality in structuring public policy and decision-making, while the Anglo-Saxon tradition is described as a contractual agreement with an emphasis on negotiation. When considering this in relation to my operationalised conception of institutional logics (i.e. rules, practices and narratives), we can then expect to see the primacy of rules as a key institutional constraint in France. In England, the more pluralistic and negotiated administrative tradition means that we would expect formal, recorded rules to play a less important rule in structuring behaviour and identities, with more focus on day-to-day practices or rules-in-use.

Secondly, the conceptualisation of the state and its identity vis-à-vis society has important implications for the logics of third sector organisations and their approach to co-production. In England, the state is in theory open to the influence of society (and by extension, to third sector actors and citizen co-production). The way that theorists describe the Anglo-Saxon tradition, with an emphasis on 
pluralism and openness to compromise with interest groups leaves a clear space and openness for the practice of co-production. In France, the state is conceived as the centre of political life and in many ways opposed to a society which it sees as protecting individual or group interests at the expense of the general interest of the French populace (Laborde, 2000). From this perspective, participative democracy or citizen involvement efforts become a more contentious proposition in France as the Napoleonic tradition is more heavily invested in representative democracy rather than participative approaches. Political participation therefore tends to take the form of voting in elections, with opposition articulated through strikes and protests.

Finally, the differentiation between different governmental and administrative traditions has broad implications for a country's response to reform and change, particularly related to New Public Management, which was discussed in Chapter 2. Much of the literature on NPM assumed that the entrance of a market logic into public administration was a global phenomenon, consistent in most Western capitalist countries. This increase in emphasis on efficiency and business-like logic in public administration and public services has subsequently led to an increase in competitive tenders and contracts for public services (to private and third sector providers) and a greater emphasis on efficiency, targets and performance management. However, there is a large amount of evidence to suggest that NPM did not have nearly as much of an impact in France, largely due to the administrative traditions previously discussed (Cole and Jones, 2005; Rouban, 2008). With a greater emphasis on legality rather than management within government and a strongly state-centric view of governance, the reforms that have been undertaken 
since the 1980s (when NPM was widely heralded as a new trend in public administration) have been more instrumental, rather than transformative, and take place within a restrictive, unitary state structure. This is an important element in determining the institutional logics in each country, and how these contribute to coproduction practices.

\section{Table 5.1: Societal level institutions}

\begin{tabular}{|l|l|l|}
\hline & England (UK) & France \\
\hline Welfare regime & $\begin{array}{l}\text { Liberal: Low } \\
\text { government spending } \\
\text { on social services, } \\
\text { means-tested }\end{array}$ & $\begin{array}{l}\text { Conservative/ corporatist: } \\
\text { High government spending on } \\
\text { social services, based around } \\
\text { employment/ social insurance }\end{array}$ \\
\hline Non-profit regime & $\begin{array}{l}\text { Liberal: Large } \\
\text { independent sector; low } \\
\text { government social } \\
\text { welfare spending }\end{array}$ & $\begin{array}{l}\text { Corporatist: Large sector; high } \\
\text { degree of social service } \\
\text { provision by non-profit sector, } \\
\text { high government social welfare } \\
\text { spending }\end{array}$ \\
\hline $\begin{array}{l}\text { Administrative/ } \\
\text { state tradition }\end{array}$ & $\begin{array}{l}\text { Anglo-Saxon: } \\
\text { Pluralistic, state as } \\
\text { contract with society }\end{array}$ & $\begin{array}{l}\text { Napoleonic: Unitary state, } \\
\text { antagonistic relationship with } \\
\text { society }\end{array}$ \\
\hline
\end{tabular}

\subsection{Field Level: Rules and Narratives}

Having discussed the institutional typologies that highlight differences between the societal level institutional logics in England and France, the focus now turns to the field level, which includes the interconnected organisations (public policy-making bodies, suppliers, customers, etc.) and policies that relate to these. Organisations are defined by the logics of the primary seven institutional logics that exist at the societal level, but these are also translated to and interpreted at the field level, which 
I have chosen to define as the city or municipal level. Here we will expect to see rules, norms of behaviour, values and beliefs that guide and constrain actors - at the organisational and individual levels - within it.

Prior to beginning my fieldwork, I interviewed four French academics in Marseille and Paris who study the social economy and political participation, as well as two national level third sector stakeholders (see Appendix 4). This was done in order to shape and affirm my understanding of the third sector and how academics understand the notion of co-production in France, as I was unable to identify any French academic literature on the topic of co-production and wanted to ensure that I was not missing something as an outsider to French academia. These interviews also helped me to hone in on my research questions and drove me to select Lyon as the focus of my study.

After having selected Lyon and Sheffield as my case locations, I interviewed local political and third sector stakeholders in each city as part of an initial scoping exercise. In Lyon, I interviewed four local stakeholders: two senior staff from two influential third sector network organisations, and two staff members of different levels of local/ regional government. In Sheffield, I interviewed a senior staff member of a local network organisation as well as an individual representing a partnership board of public, private and third sector leaders. Whilst the original intention of interviewing these key informants was to obtain advice and access to third sector organisations who could be studied as case studies, they also offered me an insight into city-level logics, and how these may be translated into the rules, practices and narratives of the case study organisations. 
These stakeholder interviews were fairly informal and general in content. Although I approached the interviews with a similar questionnaire to the one I used for my case study interviews, I tended to ask quite broad questions about the state of the third sector, the role of the national and local government, general approaches to co-production and what opportunities or barriers third sector organisations in the city face to co-producing. This allowed me to gather stories and narratives from these prominent local actors that reflect the citywide issues affecting local third sector organisations. In the case of Lyon, one of the interviewees also graciously helped me with the wording and focus of questions in my French language questionnaire, and explained some French terminology that I was finding difficult to understand. In addition to these interviews, I attended several national and local events and conferences in each country (see Appendix 7).

To remain consistent with my analytical framework, I have employed the notions of rules and narratives to structure my analysis of the field level logics and how these pertain to co-production. I begin by briefly discussing field level rules, including an explanation of the local political institutions in each city, in order to establish the context in which third sector organisations are located and operate. Some of the rules (laws and policies) discussed in this chapter were not necessarily mentioned by case study interviewees, but are included because stakeholders indicated that they were relevant and influential, or because I have identified them through documentary analysis. The practices aspect of institutional logics is omitted from this analysis because whilst there is likely to be some influence of the day-to-day routines of other field level actors upon those of the case study organisations, I determined that this would not be a broadly fruitful analysis, given the difference in 
functions between the stakeholders' organisations and those of the case study organisations. To the extent that stakeholders' participation practices provide a relevant backdrop and contextual significance to the third sector, these are discussed in relation to narratives.

\subsubsection{Rules: Local Government and Laws}

Lyon and Sheffield are similar cities in terms of size, with a population of just over 500,000 in the city of Lyon and 1.3 million in the Lyon Metropolitan area (Métropole de Lyon), compared to 560,000 in Sheffield and 1.8 million in the Sheffield City Region ${ }^{8}$. While France is known as being a highly centralised state, there are paradoxically far more levels of local governance and decision-making in Lyon than in Sheffield (see Figure 5.2). Third sector organisations in Lyon have dealings with three levels of local government (the city, the Métropole de Lyon, which was created in 2015 to replace the Urban Community of Lyon and takes some territory from the Rhône Department, and the Region). The city of Lyon is also subdivided into nine arrondissements, each of which are responsible for managing some local facilities, and have an elected mayor and citizen committees, although they do not manage their own budgets. In contrast, the only political administrative division below the national government in England is the local authority (Sheffield City Council), with some responsibilities (primarily related to transport and economic development) held at the level of the Sheffield City Region Combined Authority.

\footnotetext{
8 'La Metropole de Lyon', 2015; 'Sheffield City Region Baseline Report', 2013
} 


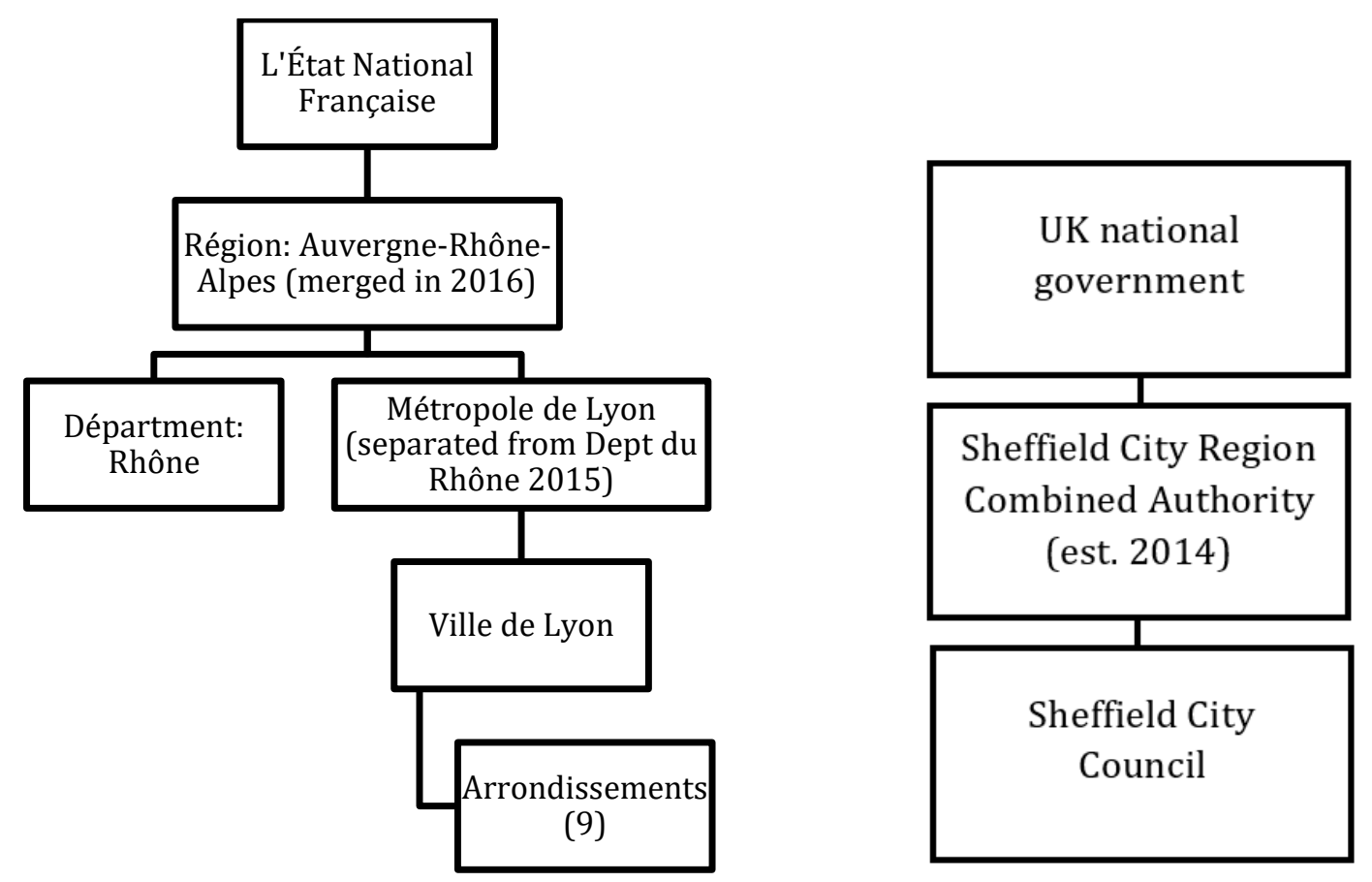

Figure 5.2: Local Government in Lyon and Sheffield

This division of administrative responsibilities and political power is significant for third sector organisations because it means that the landscape in which the Lyon organisations operate is far more complex and convoluted than the Sheffield organisations. The city council is the only level of government with whom third sector actors in Sheffield regularly interact, in terms of bidding for contracts, and in various partnership groups and networks (although some have contracts to deliver public health initiatives from the Clinical Commissioning Group, the local arm of the National Health Service). In Lyon, third sector actors regularly manage policies and grants from the city, the Département (and now the Métropole de Lyon) and departments at the level of national government, in particular the Social Security and Family policy branch. Each of these levels of government thus produces rules to which third sector organisations are subject. 
In the following empirical analysis chapters, I will analyse and discuss in detail the rules that form part of the case study organisations' logics. Many of these are shared between organisations and emanate from public bodies at the local and national levels, but there are some rules (formal, recorded policies and laws) that were identified and discussed by stakeholders that provide a relevant basis for understanding the genesis of the logics within the third sector. Several laws (lois) were mentioned by stakeholders as being particularly important and influential for social economy organisations and associations in Lyon.

- Loi du 1er juillet 1901 relative au contrat d'association: Introduced the right to form non-profit associations. This established the legal framework for the third sector.

- Loi $n^{\circ}$ 2002-2 du 2 janvier 2002 rénovant l'action sociale et médico-sociale: Along with establishing a charter of rights for patients/ service users, the Loi 2002-2 requires that certain types of service providers establish service user groups that can be consulted on or involved in decision-making.

- Loi $n^{\circ}$ 2014-173 du 21 février 2014 de programmation pour la ville et la cohésion urbaine: Established the requirement of citizen councils in 'priority' deprived areas.

- Loi $n^{\circ} 2014-856$ du 31 juillet 2014 relative à l'économie sociale et solidaire: Established a legal framework for organisations of the social and solidarity economy, enabling them to get access to government grants and contracts.

I have summarised these four laws because they were identified as significant by several of the academics and stakeholders with whom I spoke in France. The Loi 
1901 was mentioned by nearly all, and many associations often refer to themselves as being 'une association loi 1901' ('an association based on the 1901 law'), demonstrating the continuing centrality of this law (rule) in shaping the narratives of associations. The Loi 2002-2 and Loi février 2014 were discussed in conversations about health and social care services (for the former) and in relation to neighbourhood renewal (for the latter), but both arose as a response to my enquiry about the concept of co-production.

"That's co-production - a movement from both sides. There is a law in France, which is the law 2002-2. This law says that you have to put service users at the centre of the plan. [...] The law required a committee, once a month or once... It depends, where professionals and service users meet each other and exchange. It was really something new in 2002. It has revolutionised the associative sector." (Stakeholder, Lyon)

French stakeholders' and academics' attention to the rules and the legal framework of third sector organisations is of note when compared to my corresponding discussions with actors in England. Neither of the stakeholders I interviewed in Sheffield mentioned a single law in our discussions of the third sector and the barriers, constraints and enablers that impact these organisations. The only exception was in response to my direct question about the Localism Act, which the respondent deemed to be having a limited impact on the third sector: "I don't think it's just about the [Localism] Act, but the whole agenda, I don't think it's actually happening in reality at the extent that we feel would be positive." (Assistant Director, Sheffield Network 1) 
Through my evaluation of stakeholder interviews and documents produced by Sheffield City Council and local third sector network bodies, the rules that appear to be discussed as most influential for third sector organisations are around contracts and funding arrangements, rather than laws and government policies. Both stakeholders I interviewed spoke at length about cuts to services and the impacts that this is having on third sector organisations, both in their abilities to survive as organisations as well as in their capacities to engage in co-production.

"I wish they [third sector organisations] would shift their narrative into 'how can we do co-design and co-production better', rather than 'why don't you give us more money'. [...] They could really lead the way, but they... For completely understandable reasons, they go on about the council changing its commissioning and procurement processes, the council basically making some of its own staff redundant and giving the money to them because they're cheaper. I just think, it just boxes the council in and isn't really helping us move forward in new ways of working." (Director, Sheffield Network 2)

As this quote demonstrates, the rules that constrain organisational behaviour and decision-making also blend into third sector narratives, particularly in the way that they understand their relationship to the local council and the reduction of grants and funding. The other stakeholder in Sheffield made similar assessments about the role of public service cuts on third sector organisations' capacity to engage in coproduction, and indeed the majority of the interview focused on austerity and the vulnerability of the third sector. 


\subsubsection{Rules and Narratives: Conceptualising the Third Sector}

One of the key differences that differentiate the field level logics in Sheffield and Lyon are the way in which the 'third sector' is conceptualised, which has implications for the field level logics, and contextually specific opportunities and constraints on organisational actors. The conceptualisation of the third sector in many ways can be attributed to both rules and narratives, which is why these will hence by considered together.

In order to understand any differences that exist between the logics of third sector organisations and how these drive co-production practices in England and France, it is important to understand the ways in which the conceptualisations of the third sector differ between the two countries. As discussed in section 5.2, institutional theorists typologise France and the United Kingdom as belonging to different welfare regimes and non-profit regimes, due to different welfare state trajectories and relationships between the non-profit sector and the state. At the field level, there are significant differences between the values attributed to third sector organisations and their role within society. While I refer to 'field level' to refer to local contexts, it is important to note that these third sector conceptualisations are not particular to Lyon and Sheffield but rather represent the understandings more generally within each country about these types of locally based organisations.

Although the United Kingdom is often typologised as belonging to the US 'non-profit' approach, which defines the third sector by a constraint on the distribution of profits to members or shareholders, the British third sector can be characterised by two narrative streams or traditions - philanthropy and charitable giving, and mutualism 
(Kendall and Almond, 1999; Taylor, 2004). The concept of charity has its roots with the 1601 Statue of Charitable Uses, which defines a charity as being for the public benefit, for the relief of poverty, the advancement of education, or the advancement of religion. Many of the organisations that were founded on the basis of this statute were therefore church-based, providing services to the poor and running orphanages. Charities can be constituted as a number of legal structures, including unincorporated associations and companies limited by guarantee, the latter of which requires that the organisation be governed by a board of trustees who are not employees of the organisation. In practice, this means that charities are provided a large degree of flexibility in deciding the degree to which service users or community members are involved in organisational governance. While charities must pursue activities related to the 'public good', the rules specifying how this is done are inexplicit, and the practices are determined by each organisation.

The other defining tradition of the English third sector is mutualism. The first consumer cooperative, the Rochdale Equitable Pioneers Society, was formed in 1844 and paved the way for the subsequent formation of mutual aid and friendly societies, which aimed to help the poor to pool resources for sickness and old age, savings, or other common purposes. Like the Charity Act, the legal status that came into place as a framework for mutuals (the Industrial and Provident Society laws in the 1880s) is still in place today. Over the past few decades, this driver of community benefit and reinvesting profits into service provision and communities has also led to the development of social enterprises, which embrace both these drivers of philanthropy/ charity and mutualism. In contrast to charities, the legal forms for these types of organisations - industrial and provident societies (co-operatives) and 
community interest companies (social enterprises) - do require some degree of involvement of local communities, employees and/or service users in the decisionmaking of the organisation. The increasing pervasiveness of social enterprises as a new type of third sector organisation reflects the influx of the market logic into the associative sector.

While these two important traditions form the value basis of the third sector in England, it is the first - philanthropy and charity, or voluntary activity - which tends to dominate the narrative of public officials, politicians and third sector professionals. The third sector is often referred to in the UK as the 'charity' or 'voluntary and community' sector, highlighting the significance of volunteering, donation and grassroots community activity, to the exclusion of mutuals, cooperatives and (to an extent) social enterprises, which do not meet the non-profit constraints necessary to be legal constituted as charities. These legal requirements (rules) form the basis of some of the co-production practices undertaken, but also from an important part of the narratives and value basis of third sector organisations in England, who define "why we do things" according to these rules and norms.

In France, the third sector is a relatively young phenomenon as associations and interest groups have historically been distrusted by the state and seen as upsetting the balance of power and challenging the protection of the public interest (Tilly, 1986). In fact, associations were not legally recognised until 1901 which draws a striking comparison to the long history of mutual aid, charitable and philanthropic organisations in the UK (as noted by the 1601 Statue of Charitable Uses). France's 
third sector is now reasonably sizeable due to the social policies of Mitterand in the 1980s, during which time the state greatly increased investment in welfare services contracted to be delivered by third sector organisations.

The French third sector is also conceived differently to that of the UK (i.e. by understanding the third sector as the organisations that take particular legal forms), with a more socio-political perspective that defines the sector more by its activities and values basis. The French third sector tends to be identified as the 'social economy' or the 'social and solidarity economy', broadly defined as organisations that aim to benefit the community, are democratically governed and which privilege people over capital in the distribution of incomes (Evers and Laville, 2004). Social economy is meant not as a way to classify types of organisations, but rather as an analysis of different modes of exchange and organisational operations, where public and community rationalisations take precedence over market logics. With a strong influence of the cooperative movement, emphasis is put on the democratic international operations of social economy organisations. According to Moulaert and Ailenei, "The term social economy designates the universe of practices and forms of mobilising resources towards the satisfaction of human needs that belongs neither to the for-profit enterprises, nor to the institutions of the state in the narrow sense." (2005, p. 2042).

There are several legal forms that French third sector organisations can take, with different implications for the involvement of service users. Associations (defined by the Loi 1901 discussed in section 5.3.1) are non-profit organisations, which may be incorporated or unincorporated, thereby encompassing both small, neighbourhood 
organisations and larger, service-providing non-profits. For co-operatives, there are two legal forms - société coopérative et participative and société coopérative d'intérêt collectif. The former is a more traditional worker cooperative, where decisionmaking is entrusted to workers, but the latter has a broader remit of including multiple stakeholders (including service users and representatives from local associations) in the organisation's governance. The ethos of internal democracy through voting is a cornerstone for these organisations.

Emphasis is therefore put on the democratic internal operations of social economy organisations and on a desire to reconceptualise political economy, which is a wholly different notion to that of charities using volunteer efforts to improve the lives of the poor, as per the more dominant stream of the British tradition. Social economy is defined by democratic decision-making within organisations and typically involving more co-operative and collaborative approaches to working (Defourny and Nyssens, 2006). While much of the literature refers to the social and solidarity economy (and indeed, this is the language used in public policy and discourse, e.g. Loi relative à l'économie sociale et solidaire), some theorists suggest that the solidarity economy is distinct, with a stronger emphasis on using services and voluntary work to improve social cohesion (Espagne, 2002). The term solidarity is used frequently by associations to describe both the mission and values of the organisation as well as to describe types of services and actions undertaken. 
Table 5.2: Third sector narratives and rules

\begin{tabular}{|l|l|l|}
\hline & England & France \\
\hline $\begin{array}{l}\text { Conceptualisation } \\
\text { of the third sector } \\
\text { (Narratives) }\end{array}$ & $\begin{array}{l}\text { Charities, voluntary and } \\
\text { community sector: Based } \\
\text { on traditions of } \\
\text { philanthropy and } \\
\text { volunteering, as well as } \\
\text { mutual aid }\end{array}$ & $\begin{array}{l}\text { Social and solidarity } \\
\text { economy: Based on ideas of } \\
\text { democratising the economy } \\
\text { and participatory decision- } \\
\text { making }\end{array}$ \\
\hline $\begin{array}{l}\text { Legal forms of } \\
\text { third sector } \\
\text { organisations } \\
\text { (Rules) }\end{array}$ & $\begin{array}{l}\text { Charity: Established for } \\
\text { charitable purposes/ public } \\
\text { benefit, no distribution of } \\
\text { profits to shareholders. }\end{array}$ & $\begin{array}{l}\text { Association: Non-profit } \\
\text { organisation }\end{array}$ \\
$\begin{array}{l}\text { Industrial \& Provident } \\
\text { Society: Cooperative, either } \\
\text { for benefit of members or } \\
\text { benefit of the community }\end{array}$ & $\begin{array}{l}\text { Société coperative et } \\
\text { participative: Employees on } \\
\text { board, power/profit sharing, } \\
\text { decision-making stays local }\end{array}$ \\
$\begin{array}{l}\text { Community Interest } \\
\text { Company: Social purpose } \\
\text { business, profits reinvested } \\
\text { into community }\end{array}$ & $\begin{array}{l}\text { Société cooperative } \\
\text { d'intérêt collectif: Brings } \\
\text { together numerous } \\
\text { stakeholders to work } \\
\text { together on local } \\
\text { development }\end{array}$ \\
\hline
\end{tabular}

While the narratives, histories and traditions described above relate to the field levels of the third sectors generally in France and England, interviews and documentary analysis in Sheffield and Lyon reveals some narratives that are particular to the field - consisting of the interacting networks of public, private and third sector organisations - in each city. I proceed now to a consideration of the narratives expressed by field level stakeholders that relate to their local conceptualisation of the third sector.

In Lyon, a key theme that emerged in stakeholders' narratives was the role of the history in creating a clear sense of identity and value basis within the social and 
solidarity economy. Lyon was chosen as the French case study location because several French academics had indicated that the Rhône-Alpes region, in which Lyon is located, was known for having a strong history of social economy activity, and this was verified by stakeholders in the city who maintained that the region has over 23,000 social economy organisations. In Lyon, the city's particular topography and history have shaped the history and value basis of its associative sector. As recounted to me by both directors of local networks I spoke to, the city has two main hills which were historically known as the 'hill that prays' and the 'hill that works', due to the location of the Fourvière Basilica and convents on the former and concentration of silk workers who inhabited the latter. Silk workers' protests in the 1830s against poor wages and working conditions led to the creation of the first consumer cooperative in France, an épicerie sociale (social grocery store), as well as a large number of mutuals and health services. The social and solidarity economy is now still shaped by these two strong value traditions - Catholicism on the one hand, and workers' self-organisation on the other. While these value bases resemble those described of the British third sector, in Lyon these are combined with a democratic rather than charitable ethos.

In Sheffield, aside from highlighting the strength and importance of the voluntary and community sector over time, stakeholders did not present a similarly unified narrative about the importance of history and location in defining the identity of the local sector. It is important to note that this may be as a result of my position as an England-based researcher - while the interviewees in Lyon saw me as an outsider coming to Lyon (for the first time, in the case of the interviews with two key informants), interviewees in Sheffield likely felt that I was familiar with the context 
in the city as someone who had previously worked for a national third sector organisation (Urban Forum) and as a frequent visitor to Sheffield. The important historical and contextual details that were relayed were related to funding.

"So there are layers of infrastructure. There's less of it around now than there used to be of course, and we as an organisation have shrunk in the last few years, since 2008 or 2009. Prior to that, I guess from around late '90s until around that time, for the sector - and you'll know this from Urban Forum - there was quite a lot of money around in various shapes and forms. A lot of regeneration money in South Yorkshire and Objective 1 European funding. There was a lot of funding from the RDAs, which have now been abolished. And generally, public funding was much greater, so at our biggest we had about 68 staff and we now have 43." (Assistant director, Sheffield Network 1)

Recognising that the stories relayed to me are likely to have taken a different focus in Sheffield than in Lyon, I analysed several documents to assess the degree to which a similar sense of history and collective identity in the Sheffield third sector. However, there did not appear to be a similar common theme or story that defines a set of values or beliefs about the third sector at the field level in Sheffield as in Lyon. The values in key documents produced by network organisations are primarily elucidated through statements such as:

"Voluntary and community action is vital to the health of society. The people and groups leading social action are a pivotal part of public services." (Voluntary Action Sheffield Social Impact Report 2016)

"The voluntary and community sector in Sheffield occupies an important strategic position between policy development, service 
provision and everyday life." (Sheffield State of the Voluntary and Community Sector 2016)

The emphasis of the narratives contained within these key documents is centred instead on what organisations do (what services they deliver) and how they are or will be impacted by cuts to public funding, as opposed to a coherent, clearly delineated set of values and beliefs. Linking these to ideas about participation and co-production, some themes arise that may help to predict differences in approaches to and narratives about co-production. The Lyonnais values-driven narrative highlights the importance of mutualism and workers' self-organisation suggests a cooperative ethos to participation and involvement. By contrast, the context in which third sector organisations operate in Sheffield is dominated by discourses about public service delivery. While the sector is no doubt motivated by strong values and beliefs as well, the emphasis on service delivery suggests that coproduction might be seen as part of this overall purpose, e.g. bringing service users into the decision-making and delivery of services. This brings the analysis to the third element of field level logics: narratives of participation.

\subsubsection{Narratives: Participation and Co-production}

Third sector organisations' values, beliefs and identities that define their coproduction practices are not entirely self-determined, but are shaped to an extent by other field-level actors such as local government and third sector networks and representative organisations. Given this assumption of the nested nature of institutional logics, it is important that the case study organisations are not studied in isolation, but understood as being determined by their particular contexts and 
the narratives promoted by these other local actors. In this section, I analyse the field-level narratives in relation to citizen participation and co-production in order to better evaluate organisational level logics and practices of co-production. I consider the local participation narratives according to stakeholders and documents produced by public and third sector network organisations.

In addition to discussing the third sector in general with key informants and stakeholders, I also enquired about citizen participation and co-production. These questions concerned both conceptual understandings of participation as well as the practices, including barriers and opportunities, for third sector organisations locally. For these interviews, which primarily took place at the beginning of my fieldwork, I described the purpose of my research as being about co-production and the third sector, although later in my research I made a conscious choice to avoid the term coproduction at the beginning of interviews, and attempted to use more general terms in relation to citizen participation, only bringing up the word co-production later in the interview to discuss the vocabulary of involvement more specifically.

Several stakeholders in Lyon and academics elsewhere in France indicated that they believed that one of the biggest barriers to citizen participation and co-production is French administrative and political culture, which appears to be consistent with the literature on administrative traditions discussed earlier in this chapter (Peters, 2008; Painter and Peters, 2010a). The centralisation of power within the French state, as well as the conceptualisation of public service and public benefit were discussed as creating barriers for third sector organisations aiming to engage in more creative and co-productive practices. There seemed to be consensus amongst 
stakeholders that France, in general, is a laggard when it comes to adopting citizen participation initiatives.

"Today, we're starting to talk to citizens. So that's to say that in the logic, the political logic, even if it's put in practice by an association who defends the service user, who puts them at the forefront, who tries to coconstruct with the service user, it's not in the culture, in fact. The culture is really that public policy is constructed by the state and even if it's pushed by associations, it's constructed by the state and then associations are managers of services, in fact." (Director, Lyon Network 1)

Two important points are raised in the quote above. First is the attitude that French political culture prevents public powers from undertaking citizen involvement initiatives, or prevents those from being effective. This position echoes findings from Sintomer and De Maillard (2007) who studied the politique de la ville, an urban renewal and participation programme (which impacts several deprived neighbourhoods in Lyon) and found that there has been limited success in implementing participation initiatives because of the tension between representative and participative democracy in France (or, as Yves Sintomer quoted in an interview I conducted with him - "I would say the political culture could be one barrier. The traditional French republican political culture is very inhospitable to this").

Also notable in the stakeholder quote above is the use of the word 'co-construct' (coconstruire in French) which I have directly translated because interviewees in Lyon tended to prefer the term co-construction to co-production. (To provide consistency, I have then also translated 'la politique publique construite par l'état' to 'public 
policy constructed by the state' despite the fact that this is an awkward translation in English and would more eloquently be translated as 'public policy is made by the state'). This reflects the same language used in the academic literature and respondents who spoke about co-construction tended to assume it had the same meaning as co-production. However, upon probing it becomes clear that stakeholders' meaning associated with co-construction has a slightly different emphasis, namely on co-constructing policy, in activities that we would perhaps more readily associate with co-design or co-decision in English. This theme of the lack of vocabulary that describes the combination of co-design and co-delivery will be discussed further in analysing the narratives of the case study organisations.

In Sheffield, stakeholders did not express that they felt there was a similar clash between the dominant political culture and co-production or participation. Indeed, one stakeholder felt that the third sector organisations' own culture of dependence on the state was a barrier to co-production. The one theme that continued to arise in Sheffield, both in interviews and through an examination of various documents, was the issue of contracts, funding and cuts to public services.

"People know the constraints there are on public services, particularly health and social care. So it's a difficult time for people to have that role [of co-producing], really, isn't it? People will feel - some people, there will be a whole range of different views - that they've got a real part to play in the solution to the problems. Other people will be suspicious about why they're involved or that it's just a shortcut to doing things more cheaply. Other people just won't want to touch it with a barge pole, because they just want public services delivered by the statutory sector and delivered well for them and they'll maybe be consulted, but they 
don't want to do more than that." (Assistant director, Sheffield Network 1)

Co-production is described by this stakeholder as an approach that has been made more challenging by the fact that most third sector organisations are currently under financial strain. There are two underlying justifications for this position - one is that organisations no longer have the capacity to be able to involve service users in more intensive, collaborative activities, which are seen as more resource intensive. The second is a feeling that service users may be suspicious about the motivations for co-production and the belief that involving users, especially in the delivery of services, may be perceived as a way to cut costs, at the expense of jobs, quality, and/or quantity of services.

Despite the perceived barriers between French political culture and more participative approaches, there have been increasing efforts by public bodies and third sector actors in Lyon to discuss service user involvement and work in partnership to make this more mainstreamed practice across services. A "Service User Participation" partnership group, which includes professionals from the public and third sectors, has been initiated to meet and discuss issues surrounding service user involvement and how to improve it in the local area. Like other narratives, there is a preference within documents produced by this group for 'co-construction' rather than 'co-production', but with supporting language that echoes much of the vocabulary typically associated with co-production.

"The 'doing with' but not 'for':

- Construct with the person, sign up together to co-construction 
- Do not embody a position of 'all knowing'

- Draw on their competences: start from a position that everyone has competences, resources and potential." (PowerPoint, Service User Participant Group)

This narrative contains many of the points that are emphasised in literature on coproduction - e.g. 'doing with, not for', taking an assets-based approach, recognising that service users are experts by experience and have resources to offer to professionals. The co-construction element, however, typically focuses more on the involvement in decision-making:

“Co-construction, co-production, I think it's roughly the same idea. And it's in that spirit that the citizen councils were put in place. That is to say something that takes place over time, that allows an authentic dialogue, that isn't too 'instrumentalised' between elected politicians and residents. And that we involve them in important decisions. In any case, on the subjects that they want to be involved in and mobilise for." (Staff, Ville de Lyon)

This interviewee, speaking in particular about local council-led participation initiatives as part of the politique de la ville, raises some similar issues to points raised in Sheffield specifically and England more generally about co-production (or, as the respondent articulates, co-construction) as a way to move beyond traditional consultation towards a more inclusive process. Again, however, it is important to note that co-construction makes no claims about involvement in anything beyond decisions, i.e. in the implementation or delivery of services. This aspect, which was only described by stakeholders in relation to volunteering, appears to be conceptualised as an entirely separate issue and process. 
In discussing other 'co-'s, respondents in France only ever referred to co-decision, with no mention of co-design (co-conception) or co-delivery, which I understand to translate to co-prestation, but 'delivery' appeared not to be part of the French public service lexicon. This is an important point, as it reveals some of the defining values that are associated with participation in France that contrast with the anglophone conceptualisation of co-production. The French notion of co-construction is fundamentally about participative democracy and promoting collaboration between professionals and citizens in decision-making, which illustrates a veiled manifestation of the state logic. Although volunteering was discussed as an aspect of third sector activity, this was generally framed as a separate concern unrelated to co-construction. In England, discussions about participation and co-production took a much broader interpretation of the activities in which service users could be involved, and service delivery was included as a no less important part of that array.

Finally, returning to the word co-production itself, in Sheffield, the term has become relatively widely used in official documents and reports by the local council and network organisations, but there appear to be different meanings associated with the term. In a third sector network meeting report, for instance, co-production is used to refer to partnership working, which concurs with Brandsen and Pestoff (2006):

"One of the key enablers to successful cross-sectoral working is coproduction, where equal partnerships between professionals, the VCF and the public are crucial to improving services." ${ }^{\prime 9}$

\footnotetext{
9 'Thriving Voluntary Community and Faith Sector Leadership Group - progress report', 8 April 2015
} 
By contrast, meeting minutes from Sheffield City Council's Housing, Enterprise and Regeneration Housing Equalities Group in 2016 demonstrates a different interpretation:

"BW asked what was meant by 'co-production' as DG had used the term several times with different meanings implied. BW said co-production means allowing users to make decisions from the very beginning of a process and this should be clear in the strategy." 10

Other documents from the city council and network organisations refer to coproduction in relation to commissioning of services and service delivery, without making a specific definition explicit. However, one key document that discusses coproduction is a 2013 report produced by the Sheffield Fairness Commission (a partnership of actors from the city council, voluntary and community sector and University of Sheffield), which delineated a clear approach to co-production with citizens as part of its recommendations related to "What Citizens and Communities Can Do":

"The Fairness Commission recommends: All organisations involved in delivering public services in the city consider how and where they could apply a co-production approach more widely so that in 10 years' time co-production is the norm. Co-production has been defined as 'delivering public services in an equal and reciprocal relationship between professionals, people using services, their families and their neighbours. Where activities are co-produced in this way, both services and neighbourhoods become far more effective agents of change.' (Nesta

${ }^{10}$ Housing, Enterprise and Regeneration Housing Equalities Group; 30 June 2015 
2010 'Co-production: Right here, Right now')." (Making Sheffield Fairer, 2012)

These reports show the increasing prevalence of the discourse of co-production in Sheffield over the past decade. Interestingly, however, neither the 2016 nor the 2017 annual reviews of the Sheffield Fairness commission report refer to coproduction in their discussion of "What Citizens and Communities Can Do" (although there is reference to co-design activities in the 2017 report), suggesting that co-production's time may have passed as the de rigeur term for citizen and community involvement in the city. This local discourse of co-production is especially important to note because, while I will not attempt to trace the provenance of discourse and language at the individual and organisational level, the ubiquity of the term at the field level provides some indication that organisations within this field are likely to be conversant on the concept.

\subsection{Conclusions}

In this chapter, I have begun to analyse the differing combinations of institutional logics present in at the macro level in England and France, as well as the meso or field level in Sheffield in Lyon, in order to build a basis for interpreting differences in rules, and co-production narratives and practices at the organisational level in the case studies. My intention has been to demonstrate how typologies of societal level institutions as well as rules and narratives at the local and field level combine to establish aspects of the institutional logics that will define and drive behaviour of third sector organisations at the local level in Sheffield and in Lyon. 
The analysis shows that typologies of non-profit regimes and administrative or government traditions suggest key differences in the relationship between the third sector and the public sector, or the State, in England and France. Whilst a narrative and values basis of pluralism and negotiation is theorised to characterise the British traditions, we see a greater degree of hierarchy, formality and antagonism between the state and civil society in the French case. By extension to the institutional logics approach, we might expect therefore that third sector organisations in France are much more driven by the state logic than those in England, where there is a larger degree of influence of the market logic due to the prevalence of NPM. At the field level, interviews with key informants and analysis of documents published by local government and networks suggest some key differentiations between the rules and narratives that relate to co-production. The conceptualisation of the third sector in each context - defined through charity and community work in England and social economy or participation in governance in France - implies a different role for service users or local residents in each context, with more emphasis on volunteering and informal collaboration in England while the French conception stresses the importance of formal involvement in governance.

The next chapter will continue to develop a critical investigation into and comparison of the institutional logics of each location and the impacts that logics have on defining and driving co-production narratives and behaviours. 


\section{CHAPTER 6: ANALYSIS OF COMMUNITY REGENERATION}

\section{CASES}

\subsection{Introduction}

In Chapters 6 and 7, I present the empirical findings from the research. The main focus of this research is on community regeneration organisations of the third sector, which I analyse to build a theory of institutional logics and co-production. This will be followed by a complementary analysis of two other types of third sector projects/ organisations - parents' organisations and older people's projects - which are used as comparators to the community regeneration sector and to assess whether the model derived from this analysis is applicable to other sub-sectors of activity within the third sector.

In this chapter, I focus on the results of fieldwork conducted in the five community regeneration organisations in Sheffield and five 'social centres' in Lyon. This chapter considers the findings from a three stage analysis of data obtained through interviews with staff and volunteers in the case study organisations and through analysis of organisational documents, in relation to the rules, practices and narratives that constitute guiding institutional logics and the ways in which these define, complement and conflict with how co-production is conceptualised and put into practice.

This chapter is structured as follows: first, I introduce the 10 case study organisations and describe the overall community regeneration history and sector 
in each city. All organisations have been fully anonymised and will be referred to by pseudonyms - Develop, Enterprise, Leisure, Aspire and Recreation in Sheffield; and Avancé, Mouvement, Equipe, Diversité and Familles in Lyon. Following the presentation of the case study organisations, I provide a synopsis of the analytical framework of institutional logics and how this will be applied to the comparative study of co-production. I then analyse the data gathered from fieldwork in the community regeneration organisations and social centres, adhering to an outline of rules, practices and narratives. The English and French organisations are analysed in parallel, to enable me most effectively to draw out themes that are common as well as contrasting between the case organisations and between the two countries.

\subsection{Sheffield community regeneration and Lyon social centres}

Community regeneration is a broad term that encompasses a wide range of programmes, services, projects and activities. Within this category, we also see reference to urban renewal, community development and urban policy. These policies and programmes feature two areas of focus: improving the physical places where people live (including better housing, environments and access to services and transport), as well as supporting and developing the people - individuals and groups of individuals - that live there (e.g. 'citizen empowerment', partnership building, community/social cohesion). The organisations studied for this project are concentrated more in the latter category, but the Sheffield organisations have been involved in some projects to improve the built environment in the neighbourhoods in which they work, which will be discussed in due course. 
As discussed in Chapter 4 in relation to the methodology, my sampling and case study selection approach was based on initially soliciting recommendations from key informants in each city. In Sheffield, a third sector network representative suggested two organisations that are well-known in the city and who operate in this field of community development/ community regeneration. In Lyon, an informant recommended a sector of organisations called centres sociaux (which I will henceforth translate as 'social centres'), which provide a similar range of services and activities to the regeneration organisations, but which are also united under a common nationally determined set of values. Five such social centres were selected as case studies in Lyon, and three further community regeneration/ community development organisations were added to the Sheffield selection. In this section, I introduce these case study organisations, describe their general activities, and explain their history and the policy context that they operate within.

\subsubsection{Community regeneration in Sheffield}

In Sheffield, community regeneration provision in the third sector today can be traced to several government policies and funding programmes of the 1990s. During this period, the city of Sheffield benefitted from an influx of several million pounds of European Objective 1 funding, which was allocated to relatively deprived neighbourhoods in order to spur economic and community regeneration, through both supporting the development of new businesses and aiming to combat local inequalities. At the same time, Sheffield also became the recipient of large grants from the Single Regeneration Budget (SRB), a national funding stream with similar aims of stimulating local economic growth, but also focusing on the creation of local 
partnerships and matching resources from the private, public and third sectors. Sheffield City Council, unlike some other cities that received this funding, chose to channel the grants into local organisations rather than undertaking the regeneration projects itself.

The combination of these two large funding streams and a city council that was prepared to support the third sector to lead on regeneration efforts contributed to the establishment of a large number of community development organisations. Many of these were funded exclusively by the SRB and Objective 1, which consequently led to their demise in the early 2000s when these schemes ended. The five organisations selected for this study (along with a few others) were able to continue their activities because they had used the regeneration funding to diversify their income streams and invest in property development or access other contracts, allowing them to continue to thrive.

\subsubsection{Social centres in Lyon}

In the deprived neighbourhoods in Lyon - as in other cities across France community regeneration efforts since the 1980s have primarily been influenced or driven by the politique de la ville, a national urban renewal programme that targets areas of disadvantage through a process of partnership building between public powers and civil society, as well as through promoting a notion of citizen participation previously unseen in France. Third sector organisations located in politique de la ville priority areas/ neighbourhoods have access to particular funding sources to put projects in place to improve social cohesion and encourage active citizenship. As discussed in Chapter 2, the success of the citizen participation, or co- 
construction, aspect of the politique de la ville has been criticised by some (Sintomer and De Maillard 2007; Hall and Hickman, 2002), but both the policy and the attached funding have greatly influenced the urban regeneration sector in Lyon broadly and social centres more precisely.

While 'social centre' would appear to be analogous to 'community centre' in English, social centres provide more than a space for community activities and are founded on more political and socially active aims. 'Social' in this case connotes the improvement of social conditions for disadvantaged populations, e.g. the social in social services, rather than a more general definition of fraternisation, e.g. the social in social club. The concept of the social centre was developed in France in the early $20^{\text {th }}$ century, modelled on the settlement movement in England, which aimed to reduce inequalities by advocating middle class volunteering alongside poor people in 'settlement houses', which provided services such as education, training, childcare and healthcare. In France, social centres grew in number with the establishment of the welfare state after the Second World War, and again with further state investment in the social sector in the 1970s and 1980s. Social centres are supported by funding from the family branch of social security (Caisse Nationale d'Allocations Familiaes - CAF) and local and regional political powers, with the remit of improving social cohesion and citizen empowerment.

There are now over 2,000 social centres in France, 16 of which are located in the city of Lyon. Social centres are, by and large, governed as associations (non-profit organisations), although a small percentage are managed directly by local councils or by the CAF. To be considered a social centre, an association must adhere to the 
three founding values espoused in the Federal Charter of French Social Centres human dignity, solidarity and democracy. Each social centre must also develop a multi-year 'social plan' in collaboration with local inhabitants, which specifies the association's priorities and the ways in which the organisation will put these into action in partnership with local people and other local associations. I will discuss these elements (the charter and social centres' plans) throughout the analysis of rules, practices and narratives as they pertain to co-production. 
Table 6.1: Case study organisations

\begin{tabular}{|c|c|c|c|c|}
\hline Organisation & $\begin{array}{l}\text { Year } \\
\text { established }\end{array}$ & $\begin{array}{l}\text { Number } \\
\text { of staff }\end{array}$ & Facilities & Services \\
\hline Develop & 1998 & 58 & $\begin{array}{l}\text { Purpose-built facility with } \\
\text { commercial workspace }\end{array}$ & $\begin{array}{l}\text { Public health initiatives and employment support, nursery and } \\
\text { youth club, support two local community forums }\end{array}$ \\
\hline Enterprise & 1998 & 35 & $\begin{array}{l}\text { Building that houses a library and } \\
\text { housing advice services }\end{array}$ & $\begin{array}{l}\text { Large range of health and wellbeing services (e.g. counselling, } \\
\text { health trainers), employment services (e.g. job clubs) and training }\end{array}$ \\
\hline Leisure & 1998 & 78 & $\begin{array}{l}\text { Leisure centre, café and volunteer- } \\
\text { run library }\end{array}$ & $\begin{array}{l}\text { Large range of health, employment, social and leisure activities } \\
\text { for adults and children }\end{array}$ \\
\hline Aspire & 1999 & 21 & $\begin{array}{l}\text { Second-hand shop, community } \\
\text { hub, online centre, library }\end{array}$ & $\begin{array}{l}\text { Job clubs/ employment support and training, social activities for } \\
\text { older people, health trainers, management of a small library }\end{array}$ \\
\hline Recreation & 1997 & 14 & $\begin{array}{l}\text { Manage a council-owned } \\
\text { community facility (former school) }\end{array}$ & Work clubs, adventure playground and community organising \\
\hline Avancé & 1972 & 26 & Community centre & $\begin{array}{l}\text { Social activities for all ages. Majority of focus on activities for } \\
\text { older people who make up a large percentage of the membership }\end{array}$ \\
\hline Mouvement & 1967 & 57 & $\begin{array}{l}\text { Moving between facilities at the } \\
\text { time of the research }\end{array}$ & $\begin{array}{l}\text { Crèche, activities for youth and families, administrative support } \\
\text { and advice for local neighbourhood groups }\end{array}$ \\
\hline Equipe & 1957 & 90 & Community centre & $\begin{array}{l}\text { Social activities for all ages, education support for youth, training } \\
\text { (employment, French language) for adults }\end{array}$ \\
\hline Diversité & 1972 & 62 & Three community centres & $\begin{array}{l}\text { Crèches and activities for children, training and support (e.g. } \\
\text { French language, computer classes) for adults }\end{array}$ \\
\hline Familles & 1990 & 43 & Two community centres & $\begin{array}{l}\text { Youth clubs, homework help, leisure activities for all ages. } \\
\text { Majority of focus on youth and children. }\end{array}$ \\
\hline
\end{tabular}




\subsection{Institutional logics}

As elaborated in Chapter 3, I define institutional logics in accordance with Thornton and Ocasio (1999) as:

the socially constructed, historical pattern of material practices, assumptions, values, beliefs, and rules by which individuals produce and reproduce their material subsistence, organize time and space, and provide meaning to their social reality. (Thornton and Ocasio, 1999, $p$. 804)

Like other uses of institutional logics, this definition highlights three key components, which I have operationalised for in order to identify and empirically analyse logics in our data. These are 1) rules, 2) practices and 3) narratives. Figure 6.1 summarises the operationalisation of this concept and the coding framework devised to analyse the data, which were outlined in Chapter 3 and Chapter 4.

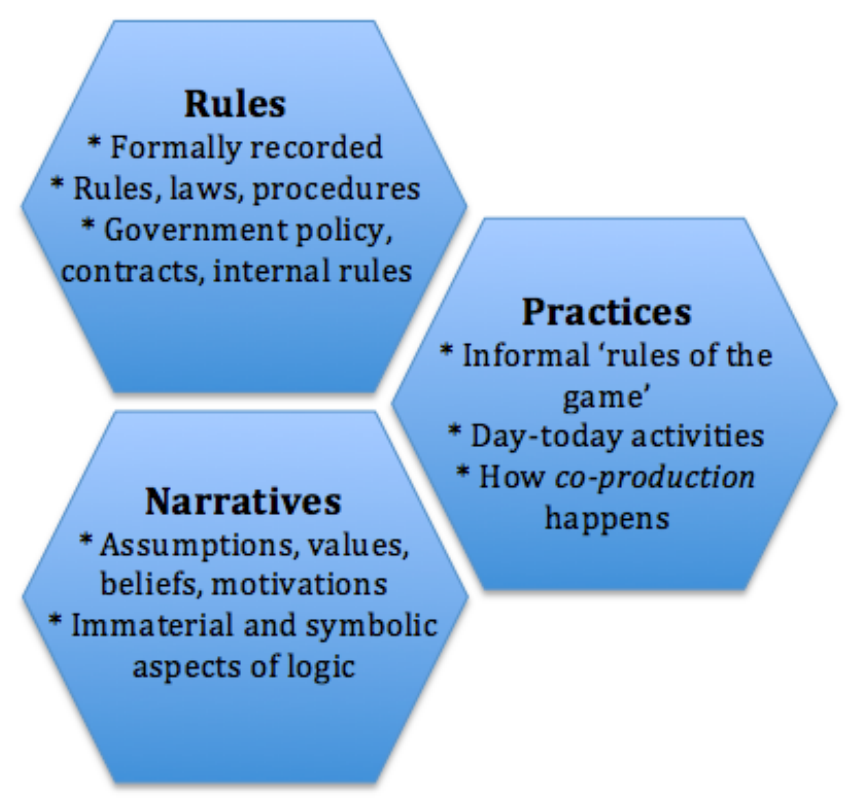

Figure 6.1: Three elements of institutional logics 


\subsubsection{Institutional orders}

As Friedland and Alford (1991) contend, institutional logics are linked with one (or more) of the seven institutional orders that characterise Western society. These seven institutional orders were explained in detail in Chapter 3, which will not be repeated in full here. The three orders that are of particular interest for the purposes of this study are the community, state and market, as summarised in Table 6.2. While the professional logic is frequently posited as a barrier to co-production in sectors like healthcare where co-production requires a reprioritisation of forms of knowledge and expertise (McMullin and Needham, 2018), the professional logic did not emerge nearly as frequently in coding the data for this study. This is likely because the types of services being delivered by the case study organisations are less highly professionalised, as compared to, for example, doctors or teachers (Needham, 2011). The family, religion and corporation logics were not deemed to be relevant to the analysis. The analysis will reflect upon the way in which each of these institutional orders, or relative combinations of the three, plays a role in defining the rules, practices and narratives of the case study organisations and where and how co-production fits within this. 
Table 6.2: Institutional order ideal types

\begin{tabular}{|l|l|l|l|}
\hline & Community & State & Market \\
\hline $\begin{array}{l}\text { Sources of } \\
\text { legitimacy }\end{array}$ & $\begin{array}{l}\text { Unity of will. Belief in } \\
\text { trust and reciprocity. } \\
\text { Commitment to } \\
\text { community values and } \\
\text { ideology. Emotional } \\
\text { connection and } \\
\text { reputation. }\end{array}$ & $\begin{array}{l}\text { Democratic } \\
\text { participation. } \\
\text { Bureaucratic } \\
\text { domination. Social and } \\
\text { economic class. }\end{array}$ & $\begin{array}{l}\text { Share price. } \\
\text { Shareholder } \\
\text { activism. Faceless. } \\
\text { Technical and } \\
\text { managerial } \\
\text { expertise valued. }\end{array}$ \\
\hline $\begin{array}{l}\text { Basis of } \\
\text { norms }\end{array}$ & Group membership & Citizenship in nation & Self-interest \\
\hline $\begin{array}{l}\text { Basis of } \\
\text { strategy }\end{array}$ & $\begin{array}{l}\text { Increase status and } \\
\text { honour of members and } \\
\text { practices }\end{array}$ & $\begin{array}{l}\text { Increase community } \\
\text { good }\end{array}$ & $\begin{array}{l}\text { Increase efficiency } \\
\text { and profit }\end{array}$ \\
\hline
\end{tabular}

Source: Adapted from Thornton et al (2012)

The aim of this chapter is to demonstrate the ways in which the above institutional logics present themselves through the rules, practices and narratives of the community regeneration organisations and social centres. I argue that this framework of institutional logics provides a basis for explaining differences between the conceptualisation and practice of co-production in each context. In the following sections, I discuss the empirical findings.

\subsection{Rules}

Rules are formally recognised constraints on behaviour that exist primarily in the form of laws, policies and regulations. Because they are recorded and formal, rules can easily be attributed to their source, whether at the national, field or organisational level. I categorise rules in two ways 1) externally imposed rules and policies and 2) internal rules. External rules include these traditional constraints, 
including laws and regulations created and enforced by government and regulatory bodies. I expand this to include contract and grant requirements, which are often recorded (in funding agreements, for instance), but are sometimes implicit rather than explicit. This notion of the implicit requirements of funding arrangements will be explored through the analysis. The second type of rules are internal organisational rules and policies, such as formal conventions, policies and other recorded guidelines. I have distinguished between externally imposed and internal rules because this provides a clearer delineation of the institutional order or orders that influence the creation and enforcement of rules.

\subsubsection{Externally imposed rules/policies}

\section{Contracts and funding}

External rules that constrain the community regeneration organisations in Sheffield and social centres in Lyon take two primary forms - government policies, and contract/ funding requirements. While the first category was evidenced as extremely influential to the Lyon cases, it was the rules imposed by contracts that were more commonly indicated by the Sheffield regeneration organisations as constraining their behaviour, particularly in relation to co-production. Funding requirements have provided an important basis of the rules that constrain the Sheffield case studies since their formation, when all five organisations became recipients of large regeneration grants from the national government and European Union. The rules that these grants imposed demonstrate the influence of the state, community and market logics, which came into conflict in some instances. 
"They said for example, you can spend money up to this point, this geographical point, but not a centimetre beyond that. So you'd get, on a particular street, you might have houses 1-20 that were included in the geographical area that was entitled to Objective 1 money. But then house \#21 was outside so they weren't allowed to benefit." (Director, Aspire)

In this instance, we see a conflict that ensues between the state logic - which favours redistribution and overall improvement of neighbourhoods - and the community logic, which in this case reveals a more holistic and community-centred approach to defining boundaries for the distribution of regeneration money. After several years, these regeneration grants came to an end and the Sheffield organisations were forced to adopt more business-like behaviour in order to remain sustainable and viable as organisations. This resulted in the introduction of the market logic, which primarily can be seen through their changes in practices and narratives, but also to rules in the sense that organisations began to seek other contracts and sources of funding. This led to a degree of instability and challenge to the identities of organisational staff, who had to adjust from being local community activists working together for the betterment of their neighbourhoods to professionals who deliver services and must be concerned about economic viability.

The rules imposed by contracts and funders continue to play an important role in defining the logics of the Sheffield regeneration organisations. The balancing of the state, market and community logics that characterise these rules can, however, conflict with some of the more community-driven narratives.

"Everything we do, whether it's a contract that we're delivering or it's a service that we are supporting ourselves, it's got to be based on 
community development principles and practice, which is a bit of a challenge when it comes to contracts. [...] When you've got a contract, you've got a very tight specification. Sometimes, they don't tell you what outcomes they want, they tell you how they want you to deliver it. Sometimes that can be at odds with our ethos. So we have got quite clever at delivering the outputs that they want but doing it in our way, because I don't think there's a single contract that we've delivered where we've not over delivered on the outputs." (Director, Develop)

This example demonstrates how a conflict between external rules and an organisation's narrative, or how it defines its fundamental values and reason for taking a particular approach, affect the organisation's practices. The chief executive interviewed suggested that adhering to the organisation's values has required them to be somewhat creative in their practices - adapting their 'rules-in-use' because of the incompatibility of the 'rules-in-form' (Ostrom, 2007) with the organisation's narrative. The director of this organisation went on to explain that they had clashed with the local authority about their approach to delivering a family support service, which the council expected to be achieved in the scale of six weeks, which they believed to be an unreasonably short time scale. In order to take a more collaborative and personalised approach, the organisation reconciled this by signing service users off the programme at the end of six weeks and then right back onto the programme. "In the end, I think we won the argument that actually - it had to be led by the family's needs and you just had to keep identifying the outcomes and the progress made" (Director, Develop).

This issue of contract rules providing an impediment to co-production practices was also expressed by the directors of Enterprise and Recreation. The director of 
Enterprise, like the director of Develop quoted above, suggested that they have simply ignored the rules in order to undertake practices that reflect their narratives and values. For Leisure, responding to the market logic has led to accepting the necessity of bidding for contracts, such as the Work Programme - a controversial government welfare-to-work scheme which compensated contracted third sector provider organisations on a payment-by-results basis. For Recreation, however, the short-term and restrictive nature of the contracts and grants they rely on has forced them to adapt their practices to constantly be looking towards the next source of funding, prohibiting them from developing more co-productive practices.

This difference in the impact of these rules can be explained by the fact that Enterprise and Develop are two of the largest community regeneration charities in Sheffield, who benefit from widespread name recognition and influence with the local authority, whereas Recreation does not own any of its own assets and depends heavily upon short-term contracts for survival. The two larger organisations, having assimilated the market logic into their practices (by generating some income through trading) are thus often able to ignore the targets and timescales imposed by contracts, and do things according to their ethos of community development or personalised attention. This demonstrates how rules often conflict with norms of behaviour when it comes to co-production, as well as the way that the size of organisations allows them more flexibility in determining their own narratives and practices that may contravene external rules.

By contrast, rules provided by contracts and funders formed a limited part of the discussions about rules in the social centres in Lyon. This is a function of the way 
that social centres are funded, which also provides a telling indication of the fundamental logics impacting these organisations. Unlike the Sheffield organisations who rely on a mix of commercially earned income, contracts to deliver specific services, and a small number of project-specific grants, the Lyon social centres are funded primarily through accords with the CAF, the City of Lyon, and the Lyon metropolitan area. This funding is provided on the basis of their being designated a social centre, or an organisation that is in charge of social service activities (une association d'animation vie sociale). This means that funding is received as an overall allocation/grant and is linked with the purpose of the organisation, rather than to particular services or the need to deliver specifically defined outcomes.

"For us, it's an advantage because we really have this funding for our basic operation and based on that, we've got the opportunity to develop some... It's not the heart of our activities, but because we are funded for the services we are providing, plus we have subventions (sic: funding) for our general activities, with this funding, we can really develop activities targeting the issues of empowerment, co-construction, codevelopment, co- whatever you want with not so much pressure from our funders." (Director, Diversité, interview conducted in English)

All five social centres have the same legal standing, and therefore similar funding arrangements that support their mission and values to co-construct with local residents. The other four directors expressed similar experiences of a lack of rules imposed by funding bodies, which provide a stark contrast to the experiences of the Sheffield regeneration organisations. This does not mean that there is a complete absence of rules that arise from funding arrangements. The director of Diversité 
explained that while grant funding is not restrictive, some funders (particularly the European Union) are beginning to request that recipients of contracts prove results and outcomes - a requirement that is a relatively new and unfamiliar phenomenon in France, a country that has been considerably less influenced by the norms and rules advocated by New Public Management. Aside from this one example, there were virtually no instances that suggested the presence of a market logic (in the broadest sense, as it concerns performance management) defining the social centres.

In Sheffield, while contract rules were more commonly associated with constraints on co-production practices, there was one example frequently discussed where a particular grant funder requires co-production and community involvement from the projects and services they fund. Four of the five community regeneration organisations are involved in Sheffield Older People (which is discussed as a case study in Chapter 7), a project that aims to reduce loneliness and isolation of older people. Interviewees argued that contract rules forced them to undertake co-design and co-delivery in a more structured way than their normal practice.

"[Funder] have a handle on it now, but when we were tendering for various contracts, they said, 'The whole programme has to be coproduced.' We said, 'Well, you're asking us to define, to explain through the tender process what our project will look like, but if it's going to be co-produced, we can't know what it looks like, can we? Because we haven't engaged with any clients yet. If we do tell you what it looks like, then that's being prescriptive and it's not being co-produced.' They got flummoxed by it and had to have a rethink. It's quite tricky." (Director, Aspire) 


\section{Government and external policies}

While contracts and grants are the primary source of rules that constrain the Sheffield regeneration organisations, laws and policies from the government and other external organisations play a more influential role in this regard for the Lyon social centres. The first of these sources of external constraint is the National Charter of Social Centres, a document to which each association must become a signatory in order to be designated a social centre, which defines such an organisation as "a centre of initiatives brought by local people, supported by professionals, capable of defining and pursuing a plan of social development for the entire population of a territory." (Charte fédérale des centres sociaux et socioculturels de France, 2000). Signing the charter means agreeing to adhere to the founding values of human dignity, solidarity, and democracy (which are discussed in detail in relation to narratives) and that the association will take an approach of collaborating with local residents.

This essentially means that co-production is formalised as a requirement or rule of becoming a social centre. The importance of this charter in defining the adherence to values as a rule presents an interesting interconnection between different elements of these organisations' logics. In describing the relationship between rules, narratives and practices, Lowndes and Roberts suggest that "narratives are often used to justify the existence of rules; [and] rules often formalize well-established practices" (Lowndes and Roberts, 2013, p. 53). In this case, however, the rules defined by this charter not only provide a formal codification of practices, but also provide the main defining narratives of social centres, rather than narratives 
justifying the rules. In these rules, the boundaries between the logic of the state and that of the community are blurred. The existence of a charter to formalise these values mirrors the French republican emphasis on constitutionality, while at the same time, the rules themselves are very much indicative of a community ethos of local unity and cooperation.

Social centres are also influenced by rules that stem from government policies, most notably the politique de la ville, a national urban renewal programme that targets areas of disadvantage through a process of partnership building between public powers and civil society. Three of the social centres suggested that this policy has been extremely influential in shaping their rules, especially in relation to policies of involvement and co-production. However, there was also some scepticism about the way the policy is designed and implemented and the degree to which it has been successful at changing practices.

"[Politique de la ville] tried to introduce this idea of co-construction, coconstructing the contract which will define the urban renovation, but in practical (sic), it's not done. For example, the new contract which is defining the amount of money that will be put into this suburbs for the next five years, they were supposed to be developed with a group of citizens, but it hasn't been done. They have been signed without any consultation." (Director, Diversité, interview in English)

The director of this social centre expressed some frustration with the government policy and its lack of success in encouraging a new culture of enhanced citizen participation in deprived urban areas, a feeling which echoes some of the sentiments expressed by the directors of community regeneration organisations in Sheffield when discussing the European Objective 1 funding and Single Regeneration Budget 
from the 1990s. Although the state and community logics are primarily blended, this example shows an instance where there is occasionally conflict between the centralised state logic and the fact that the social centres would prioritise the more community-centred logic.

While the politique de la ville was primarily discussed in relation to the policies and rules it introduces, it also acts as a source of grant funding, and its guidelines and requirements have created similar conflicts for the social centres as the Sheffield regeneration organisations have experienced. Neighbourhoods that are designated as 'priority areas' (zones prioritaires) are allocated grants under the politique de la ville, and changes to the policy that determines which areas are priorities have recently impacted Familles. One of the two neighbourhoods covered by this social centre was reclassified as no longer considered a zone prioritaire and therefore no longer eligible to be covered under the policy (despite, as the chief executive argued at the social centre's AGM, the neighbourhood still being home to a large number of families in difficulty). This issue of the changing rules and boundaries of the politique de la ville and its implications on funding, while not mentioned by interviewees from other social centres, is a topic that was considered in the social plans of Diversité and Équipe as well. The problem of arbitrarily defined boundaries impacting the distribution of funding corresponds closely with the experience told by the director of Aspire in Sheffield, demonstrating the existence of some shared experiences of rules regarding funding in both countries, and the ways in which this can make implementing more innovative, co-productive projects more challenging. 
The rules imposed by the state (as in the proper noun État in French, which defines the state logic) also come into conflict with the community logic in other instances where social centres attempt to take a co-productive approach. The director of Familles described an innovative alternative education project that the organisation designed to support difficult teenagers by giving them work experience placements at the social centre, rather than allowing them to drop out of school. The aim was to work in partnership between teachers, professionals at the social centre, and the teenagers themselves to co-produce an educative programme for them. The project, however, was met with some resistance by education authorities who are strongly driven by a state-centric logic of national education. The social centre faced considerable barriers in receiving funding and permission to take the project forward, which is evidence of the community logic of collaboration and local smallscale initiatives splintering from the state logic.

\subsubsection{Internal policies}

One of the differences between the Sheffield and Lyon cases is the ability to identify clear, recorded internal rules and policies. By internal rules, I refer to governance procedures, constitutions and other formal policies that define how the organisation should undertake its work. As with the externally imposed rules, internal rules in Lyon demonstrate a blend between the state and community logics. These types of internal rules appear to be afforded considerably more importance in the French cases than in England.

The rules of governance provide a significant part in defining organisational identities and the practices related to co-production in the Lyon social centres. Not 
unlike charities in the UK, social centres are governed by an elected board of trustees (conseil d'administration). As defined by the National Federation of Social Centres, an important aspect of social centres is that these trustees must be local residents (as opposed to, for example in the case of many British charities, representatives of other local community groups who may actually be paid staff of those groups). The conseil d'administration was described by several of the respondents in Lyon as playing an important role in defining the direction of the social centre.

"As far as the board of trustees is concerned, the administrators (trustees) are very present and very invested in their role as administrators and volunteers of the social centre. Where we could perhaps improve things as a social centre, it's in linking better with local people - how do we go meet them, and how do we construct with them and propose activities?" (Development officer, Mouvement)

This importance of involving local residents in organisational governance was highlighted by the other four social centre directors as well. Social centres are also membership associations - in order to use (most) services, take part in activities, or stand for election to the board, local residents must join the organisations as feepaying members. Like the adherence to the National Charter of Social Centres, the governance structure of being run by local residents forms an important part of social centres' identities, again linking the existence of formal rules with narratives in creating a driving institutional logic. This demonstrates another example where collaboration between paid professionals and local residents is institutionalised within social centres, as well as the way in which the state logic is transposed to the 
local level, with democratic representation playing a key role within each association.

Another important source of internal rules for the social centres is a document, the 'projet social' (roughly translated as 'social plan' or 'social project') that each association is required to produce once every four years that outlines an evaluation of the local area, the organisation's activities and its plan and strategy for the coming four years. Similar documents have been produced by the Sheffield organisations (e.g. operational plans, impact reports and annual reports), but the Lyon social centres plans are considerably longer, in-depth (an average of 40 to 80 pages each) and they devote considerable space to elaborating how local residents and members have contributed to defining the aims of the association. Many of the objectives and strategies for accomplishing these (for example, one social centre's lists the strategic objective of "working towards social cohesion", and then outlines an action plan towards achieving this) are not dissimilar to the aims of the organisations in Sheffield. However, in Sheffield these tend to be expressed more through practices and narratives, while in Lyon these are codified into official documents which become a source of organisational rules.

In Sheffield, in terms of governance, the community regeneration organisations are technically governed by similar arrangements as the Lyon organisations, but staff and directors did not accord the same degree of import to this function, particularly insofar as local residents are involved. Legally, the five community regeneration organisations in Sheffield are constituted as charities, meaning that they are governed by a board of volunteer trustees who are residents and/or representatives 
of local voluntary and community groups, elected as per the organisations' constitutions. Despite this official rule of having a board of local people to hold the organisation to account, official governance mechanisms appear to assume a limited role regarding the involvement of local people in co-production. Board members are seen more as advisors and representatives to give voice to particular groups of communities, rather than as the key decision-makers of the organisation.

Furthermore, aside from the rules directly related to contracts, funding and government programmes (particularly in regards to the regeneration funding streams that were instrumental in the establishment of all five organisations) there were in fact limited instances of formal rules in the interviews conducted in Sheffield. Formal written constitutions, guidelines and standards were generally not made available to the researcher - although this is, of course, not to say that they do not exist. Respondents from the Sheffield community regeneration organisations tended to describe their decision-making and service delivery processes as guided more by informal practices or rules-in-use rather than being constrained by formal rules. In this sense, there is far more influence of the community logic in Sheffield compared to Lyon, where the insistence on formality and codification indicates a blend with the state logic.

\subsection{Practices}

While rules are formal, codified restrictions and constraints on behaviour, practices are the day-to-day actions or 'informal rules of the game'. In employing the concept 
of practices for this study, I focus primarily on co-production practices and other daily routines and activities that support co-production and participation initiatives. Because practices involve daily, informal behaviour, identifying them from documents and interviews alone is somewhat problematic, as this relies on an analysis of formal recorded material in the first case, and the recall and interpretation of individuals in the second case. I have therefore triangulated the use of interview transcripts with some observations, but I recognise the limitations of my data and approach the analysis with a degree of caution insofar as I can accurately deduce all of the practices that take place within normal organisational operations. I observed the 'general assemblies' of three of the five social centres in Lyon (Avancé, Mouvement and Familles), and two annual general meetings (AGMs) of the Sheffield community regeneration organisations (Aspire and Recreation). In addition, I attended and observed two mental health social cafes run be Enterprise and a community forum meeting associated with Develop. Analysis of documents such as strategic plans, website text that describes activities, and newsletters was also carried out to establish "the way we do things around here" (Lowndes and Roberts, 2013, p. 41).

\subsubsection{Community engagement}

In Sheffield, 'community engagement' forms an important part of the practices of community regeneration organisations. This is often vaguely defined by actors, but tends to refer to building relationships and maintaining a dialogue with service users and local residents about the design and delivery of services. 
"Maybe it's the kind of embedded, the thing about the relationship with the clients is embedded in the nature of the relationship we try to develop with the client from the start. Rather than being a kind of formalised, bureaucratic process of filling in forms and all that kind of stuff, it's about the dynamics of the relationship between staff and clients." (Director, Enterprise)

"The simplest, easiest bit of life I guess is the informal - people chat. So any of our service users, they talk to staff, they talk to other service users. [...] We have staff working with different groups of people, and doing a lot of work with local residents, service users, there's that informal that happens a lot." (Former director, Leisure)

An emphasis on the practices of community engagement naturally stems from the community logic. This is described (by two of the five Sheffield organisations in particular) more frequently in terms of community development, or, "making contact with individuals, supporting groups of people to set up their own activities, and basically consulting with local people, engaging with local people" (Director, Develop). In responses to questions about day-to-day activities, each of the five directors and three of the staff members described an ambiguous strategy of "listening and gathering people's views" (Staff A, Leisure) and "working with local people" (Staff, Develop), without delineating the exact process for realising this, which suggests that these actions fall under the category of practices rather than rules.

Because of the degree of informality in this type of engagement and collaboration, these practices are particularly difficult to clearly establish through interview data alone. In addition, it is important to note that six of the 11 interviews with community regeneration staff were with organisation directors or senior staff, who 
may not themselves be privy to the day to day norms of behaviour of their frontline staff. I was able to attend one activity/ service that was suggested as a good example of co-production - a social café for people with mental health problems - and observed this type of informal listening and engagement between staff and attendees, but the consistency, import and impact of this practice could not be determined. The extent to which community engagement translates to real decisionmaking power is often unclear. As articulated in the quotes above, the engagement or involvement that occurs is often informal, ad hoc and managed by professionals, often framed more as "responding to needs" rather than collaborating with service users on an equal footing.

It could be argued that the methods and practices described above are influenced by the principles of community organising - such as active listening, relationship building and empowerment of the disempowered (Speer and Hughey, 1995). None of the organisations, even the two that define themselves as community development organisations, can be described as purely carriers of the community logic. The reality of community development work is that these organisations are still partly funded by the state to deliver public services, which has required the strategic reconciliation or combination of the state and community logics.

\footnotetext{
"In terms of pure community development work, [after a neighbourhood management pilot project] we lost all the capacity. So when Community Organising came along, it became an opportunity for us. We got on board with that programme. It was all run through DCLG [Department of Communities and Local Government]. Again, small amounts of money to do stuff, but we managed to maintain that programme for three years,
} 
and that... We had three people doing community organising in the area." (Director, Recreation)

Although community organising practices suggest an almost self-explanatory invocation of the community logic through the emphasis on relationship building and empowering people to effect social change in their local area, the official Community Organisers Programme was paradoxically a programme developed and funded by the national government. As such, the state logic of centralisation and bureaucracy is evident in the top-down design and evaluation of this particular programme.

In comparison, this influence of the state logic is far more prevalent across the practices and accepted ways of doing things in the Lyon social centres. Day to day activities are strongly influenced by the formal constraints produced by national laws, the National Charter of Social Centres, and the social centres' own strategic plans which provide explicit guidelines for the organisation's priorities for the coming four years, as well as action plans for achieving each goal. Discussions with directors and staff members reveal that, unlike many cases where actors' practice diverge from or conflict with official rules (Lowndes et al., 2006b), social centre staff tend to adhere to the protocols set out in their strategic plan documents.

"Here in our social centre, we have many, many volunteers. I think there are more than 100. So in the social centre, we function with 'commissions de travail' (work groups). So there is a group for 'vie associative'. There is an activities group and there is a group... In the social plan, it's all written. And the third... it takes up the three priorities of the social plan." (Volunteer A, Avancé) 
It is important to note that this quote was made by a volunteer at the social centre, rather than a staff member, demonstrating the reach that bureaucracy has within this organisation (which is representative of the practices observed at the other Lyon social centres). The 'Napoleonic' administrative tradition, discussed in Chapter 5, which favours codification of standards and practices means that there is a strong emphasis on ensuring that there are particular rules and procedures in place for many elements of the way that associations operate (Peters, 2008).

In Sheffield, along with the dominant community logic and elements of the state logic already discussed, the market logic also plays a role in defining the community regeneration organisations' practices, albeit to a lesser extent. One way that this plays out is in a necessity to base many decisions on the impact on business performance and sustainability, which shapes views of the appropriateness of or place for co-production (or more general participation) in particular activities. Enterprise, whose director employed discourse and narratives that align most with the market logic (such as referring to citizens as 'clients' and to the organisation as a business, as well as focusing to a much greater extent than other interviewees on the organisation's investments and revenue), appears to employ a business-like approach to tackling local issues.

This is demonstrated through a focus on providing activities that meet people's needs as efficiently as possible, which means that co-production is not undertaken if it is viewed to be too time or resource intensive. In Enterprise, clients are therefore not included on broader strategic or organisational decisions, but their views are seen as important to consider on an individual basis at the level of specific services, 
to ensure that the organisation is providing what they want. Co-production is therefore part of the demand and supply process of service provision, using involvement to ensure that supply matches. In this approach, the market and state logics are arguably assimilated in the sense that co-production practice is seen to instrumentally improve the design of services and their outcomes, with comparatively less emphasis on a social justice or active citizenship framing.

\subsubsection{Participatory democracy}

The difference between a service framing and a social justice framing is another way in which the Lyon social centres' practices of participation differ from those of the Sheffield organisations - participation is often an explicitly political project that invokes a blending of the state and community logics. This is evidenced in the emphasis on participatory democracy in organisational decision-making. Like the adherence to the National Charter of Social Centres, the fact that social centres are membership organisations governed by local residents forms an important part of their identities, again linking the existence of formal rules with narratives in creating a driving institutional logic. This was also reflected in the AGMs of the social centres, which are widely publicised as an important function in determining the strategy and priorities of the organisation. This demonstrates another example where collaboration between paid professionals and local residents is institutionalised within social centres, as well as the way in which the state logic is transposed to the local level, with democratic representation playing a key role within the association. 
As part of my fieldwork, I attended three out of the five social centres' AGMs and found that they were extremely well attended (with an estimated 30 to 40 members/ local residents in attendance at two of the meetings and at least 80 to 90 at the third). These meetings involved not only the formal procedures of electing representatives to the board of trustees but also posters and displays of activities and a performance by children from one of the association's programmes (Familles), interactive games and contests (Mouvement), and participative workshops (Avancé). The workshop I attended during the AGM of Avancé was about ideas to introduce more political debate to the activities of the social centre (see Figure 6.2). All three AGMs were followed by a drinks reception or meal, offering an integration between the official, formal and political aspects of involvement and the solidarity and reciprocity of community. 


\section{ATELIER 2}

Sur quels sujets qui vous intéressent pourrions-nous apprendre à débattre / de quelle manière?

$1 \%$ BRAIN STORMING

- 3 espaces « inspirants \#

1 table avec des programmes de débats

1 mur d'images

L Lyon à Double Sens

grandes feuilles affichées au mur

Thèmes/sujets à envisager

Méthodes proposées et outils d'animation

Craintes
Intérêts

Conditions d'organisation et communication

- Objectif : venez portager vos ides, remaraves

ECHANGE ENSC

IECHANGE EN SOUS-GROUPES

\begin{tabular}{l|l} 
Groupe & Quels sujets de société ? Quels débots ? Quelles \\
"Themes/sujets » & problématiques conten
\end{tabular}

Groupe a
touche?

outils d'animations s" Comment animer les débats? Qui anime? Quels objellis ?

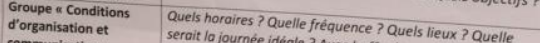

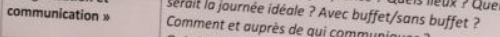
Quivise-t-on?
Q

Figure 6.2: Photos from workshops at the AGM of Avancé.

Photo 1: "What topics are you interested in debating about? In what way?"

Photo 2: "Why debate? [...] To bring democracy to life, to get to know one another, to promote tolerance"

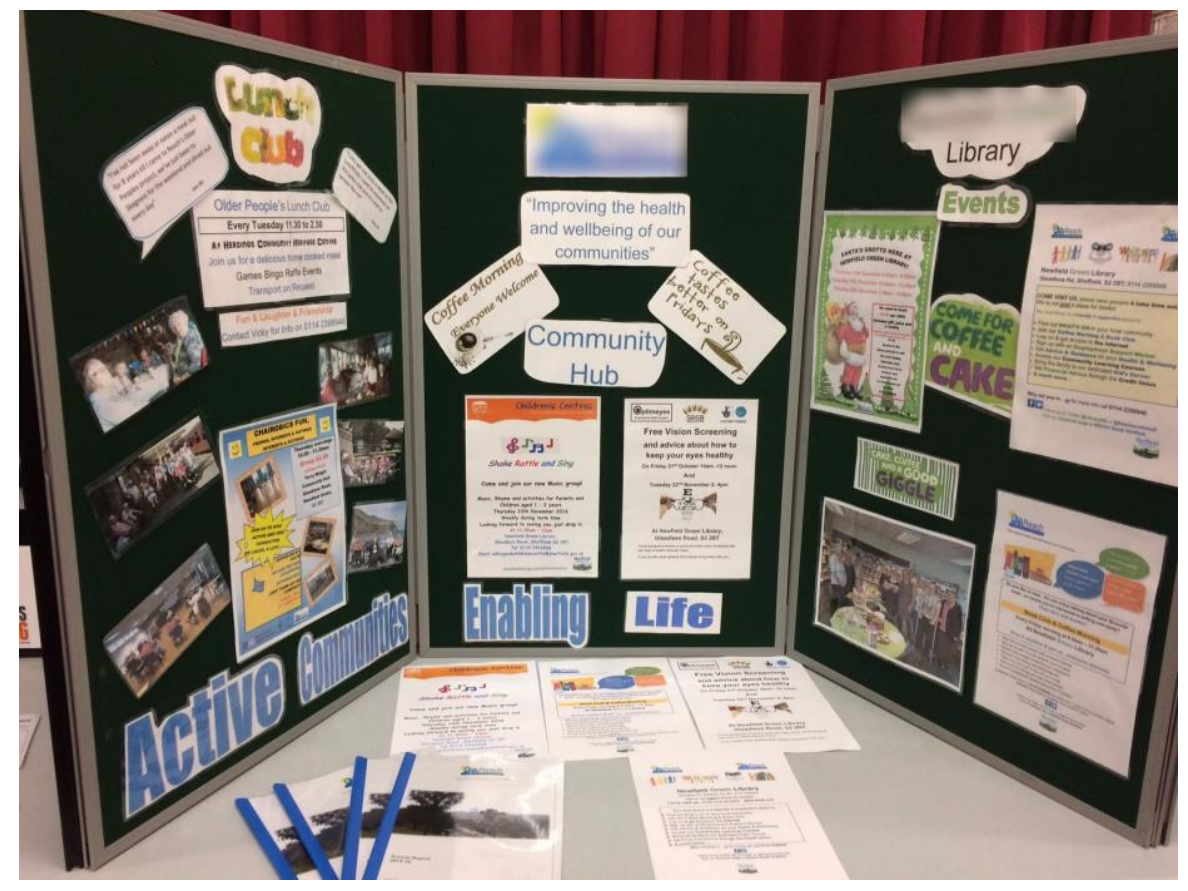

Figure 6.3: Display of organisational activities at Aspire AGM 
This centrality of the annual general meeting and participatory democracy in Lyon is in direct contrast to the practices of the Sheffield organisations. I attended the AGMs of Aspire and Recreation, and enquired about the AGM of Enterprise, but was told that it was "just a business meeting" (personal email with Director of Enterprise). At the two I attended, a much smaller number of people were present (about 20 at Aspire, and fewer than 10 at Recreation), most of whom were representatives of local community groups and city-wide charities. Aspire's AGM was run in a similar format to those of the social centres, with a meal beforehand, presentations about various activities (see Figure 6.3), and a volunteer award ceremony followed by formal business (acceptance of accounts, election of board members). For the other community regeneration organisations, the AGM is held as a matter of protocol, rather than as a proactive tool to co-produce the organisation's strategy with members. As one director explained,

“We had our AGM a couple of weeks ago. We're very different from [local network] in that our members are members of the local community. If you have an AGM at 6:30 in the evening because you want your trustees to be there because they're working during the day, you're not going to get 100 people from the community turning up to an AGM because... what's the incentive?" (Director, Leisure)

This demonstrates that the formal norms of internal democracy, voting and representation of citizens in the organisation's governance simply do not form part of the practices of the Sheffield community regeneration organisations, whereas for the Lyon social centres, this is absolutely central. 


\subsubsection{Citizen-led projects}

One area in which the co-production practices of several of the Lyon and Sheffield organisations overlap is in the practice of supporting local residents to develop and run their own projects. This practice was highlighted by Develop, Enterprise and Recreation in Sheffield, and Avancé, Mouvement and Familles in Lyon. For Mouvement, this was framed primarily as providing support and expertise to enable residents to set up community groups, and to support already existing small groups; while for the other five organisations, respondents gave examples of small services or projects that were citizen-led but supported by paid professional staff. Respondents from these organisations contended that one main role of staff members was to be available to empower local people to design and actualise their own projects, events and activities, by offering them skills (such as IT and marketing skills) and resources (printing, facilities, event spaces, staff and volunteer time).

Within Avancé, the two volunteers and the director who were interviewed described several projects, such as a 'gratiferia' (market where everything is free) and a weekly community picnic during August when the social centre building was closed. Both projects were suggested to staff members by local residents. Paid staff at the social centre supported the residents by designing and distributing flyers, and organising necessary permits, whilst the local residents recruited volunteers and brought food, drinks and activities to the picnics. This practice of encouraging local people to propose projects and activities that can then be supported with professional help from staff is a key tenet to the way that social centres design their work and, again, reflects the strength of the community logic in defining practices. 
In terms of the practices of social centres, this is in fact the most detached from the state logic, in that the support of citizen-led local projects celebrates local differences and does not require formal authorisation or democratic representation.

The practice of supporting citizen-led projects by Develop in Sheffield represents one element of its approach to community development. As illustrated in Table 6.4, several examples were indicated by the director and a staff member of the practice of providing support to empowering local people to run activities themselves.

"It's not about us running the sessions or us running anything. Initially, we start... What I like to do as a worker is I like to go in, speak to local people, find out what it is they need, get key people from the community to come along and help us get something started. Then eventually, I should just be able to walk away, because it's about building capacity of local people so that they can just run it for themselves, really." (Staff, Develop)

One difference in the way that this staff member describes this practice of support and empowerment, compared to the descriptions of the gratiferia and picnics from volunteers at Avancé, was that all of the examples in Sheffield appeared to be initiated by paid staff members, whereas the Lyon projects - at least in these cases - were proposed and managed by local residents themselves. These few examples are by no means presented as representative of the range of activities and services delivered by the five organisations in each city. However, in examining the data, there were more instances of interviewees from the Lyon social centres mentioning examples of local residents being the instigators of new projects, whereas the Sheffield regeneration organisations staff spoke more of implementing programmes because of 'identified need' and subsequently recruiting residents as volunteers to 
run these. In terms of the embedding of institutional logics in these practices, the citizen-led, staff member supported approach clearly demonstrates the strength of the community logic. Without overstating its impact, it is perhaps due to the influence of a degree of paternalism from the state logic that influences the Sheffield staff-led approach. Nevertheless, in both of the examples discussed, the community logic is the primary driver in these organisations developing these practices of support.

"We [...] are trying to say, we are not here just to develop services, but to be a place where people can come, where we can help them identify the issues they want to develop, help them build projects and put them in the heart of our activities. We are really far from the empowerment issues, but trying just to put co-construction of projects to start with before moving more with empowerment, so just putting the place of the public to be able to construct with us, to build with us the activities, was the first step we have been trying to do. (Director, Diversité. Interview conducted in English)

These formalised priorities and aims do not always translate into reality with great ease. The directors of Diversité (quoted above), Avancé and Equipe spoke about the barriers the social centres faced in trying to improve their processes of involving local people, and indicated that their participation practices fell somewhere short of the rhetoric of their social plans.

\subsubsection{Respondents' examples of co-production practices}

One of the strategies I used to identify practices was to straightforwardly ask organisation directors whether they could offer any concrete examples of coproduction within their organisation. In some instances, these examples arose 
organically either in the process of discussing service user/ citizen participation generally, or after I explained that my research was specifically about co-production (which was not until at least mid-way through each interview, in an effort not to bias interviewees with my own language). Often this was in the form of me asking, "The word that I'm using in my PhD is 'co-production' - is this a word that you use?"11 which elicited examples of practices that interviewees considered to be coproduction. Where possible, I endeavoured to follow up on these examples through observation, interviews with front-line staff involved in the service or activity, or further document analysis. This enabled me to ascertain what practices these senior staff members perceived to be co-production, while the use of other research methods to triangulate allowed me to observe and corroborate the demonstration of practices, and the degree to which these could be considered co-production.

I refer back to Bovaird's (2007) typology of co-production that was introduced in Chapter 2 (Table 2.1). After interrogating my data, it became clear that this typology fails to accurately capture the range of co-production experiences of third sector organisations. To address this gap, I have added a category that of activities where service delivery is not applicable or required, and where co-design is the end unto itself (category F in Table 6.3 - indicated by bold outline).

11 The language used in response to this question is discussed in relation to co-production narratives and discourses in section 6.6.2. 
Table 6.3: Types of co-production

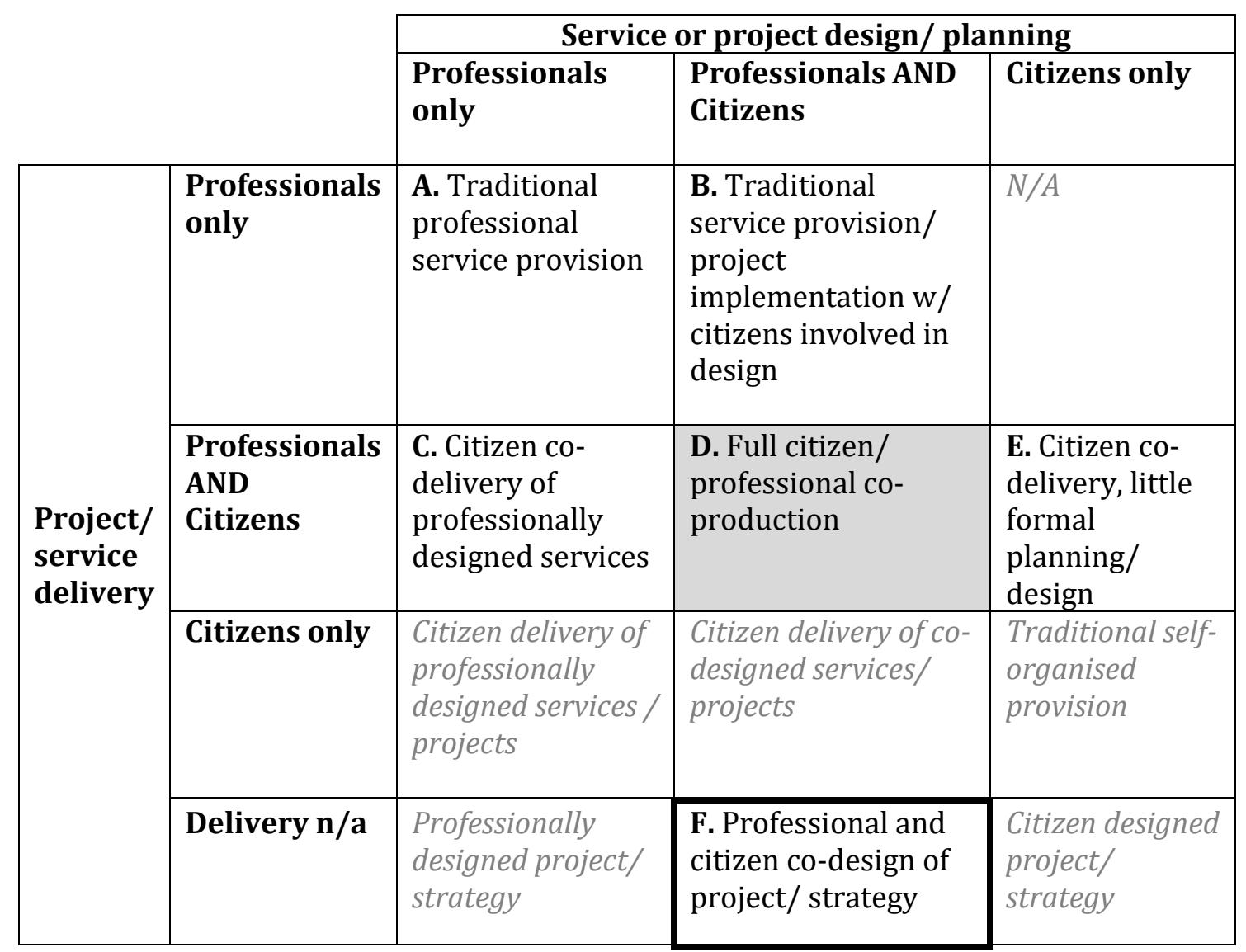

Adapted from Bovaird, 2007

The examples identified in the community regeneration case studies fall into five of the original eight variations of co-production, which differ according to whether professionals and/or citizens are involved in the process of design and/or delivery. These are: A. Traditional service or project provision, where there is no coproduction with citizens; B. Services or projects that are co-designed with citizens, but traditionally delivered by professionals; C. Services or projects that are designed by professionals, but co-delivered with citizens; D. Full co-production between professionals and citizens, and E. Co-delivery of projects initiated or designed by citizens only. I have adapted the table to include an option where there is no delivery of a service (or implementation/ realisation of a project) because it is not directly 
'deliverable' in the same sense, which leads to: F. Professional and citizen co-design of strategy. Where possible, I have indicated in Table 6.4 and Table 6.5 the category that each example of co-production belongs to. In several instances, it was impossible to determine a category from the data collected, so the two possible categories have been indicated. 
Table 6.4: Sheffield co-production examples

\begin{tabular}{|c|c|c|c|c|}
\hline $\begin{array}{l}\text { Sheffield } \\
\text { organisations }\end{array}$ & $\begin{array}{l}\text { Co- } \\
\text { production } \\
\text { example }\end{array}$ & Description & $\begin{array}{l}\text { Identified } \\
\text { through }\end{array}$ & $\begin{array}{l}\text { Co-production } \\
\text { assessment }\end{array}$ \\
\hline \multirow{3}{*}{ Develop } & $\begin{array}{l}\text { Community } \\
\text { clean-up day }\end{array}$ & $\begin{array}{l}\text { Collaboration } \\
\text { with local } \\
\text { authority, } \\
\text { business } \\
\text { owners, } \\
\text { landlords, and } \\
\text { residents to do } \\
\text { litter pick and } \\
\text { remove large } \\
\text { rubbish }\end{array}$ & $\begin{array}{l}\text { Interview } \\
\text { only }\end{array}$ & $\begin{array}{l}\text { D. Very clear } \\
\text { example of multiple } \\
\text { actors engaging in } \\
\text { co-design and co- } \\
\text { delivery }\end{array}$ \\
\hline & $\begin{array}{l}\text { Community } \\
\text { forum }\end{array}$ & Monthly forum & $\begin{array}{l}\text { Interview, } \\
\text { observation } \\
\text { of meeting }\end{array}$ & $\begin{array}{l}\text { A or F Formal, } \\
\text { traditional meeting. } \\
\text { Attendees were } \\
\text { primarily third } \\
\text { sector reps rather } \\
\text { than private citizens }\end{array}$ \\
\hline & Coffee morning & $\begin{array}{l}\text { Weekly get } \\
\text { together for } \\
\text { isolated older } \\
\text { people }\end{array}$ & $\begin{array}{l}\text { Interview } \\
\text { only }\end{array}$ & $\begin{array}{l}\text { C or D Initiated by } \\
\text { community } \\
\text { development worker } \\
\text { with aim of enabling } \\
\text { volunteers to run it } \\
\text { themselves }\end{array}$ \\
\hline Enterprise & $\begin{array}{l}\text { Mental health } \\
\text { social café }\end{array}$ & $\begin{array}{l}\text { Weekly get } \\
\text { together for } \\
\text { people } \\
\text { suffering from } \\
\text { mental health } \\
\text { problems }\end{array}$ & $\begin{array}{l}\text { Interview, } \\
\text { observation }\end{array}$ & $\begin{array}{l}\text { A or B Director } \\
\text { suggested that } \\
\text { clients have control } \\
\text { over how these are } \\
\text { run, but they } \\
\text { appeared to be run } \\
\text { entirely by paid staff }\end{array}$ \\
\hline Leisure & Youth club & $\begin{array}{l}\text { After school } \\
\text { activities for } \\
\text { teens }\end{array}$ & $\begin{array}{l}\text { Interview } \\
\text { with } \\
\text { director } \\
\text { and staff }\end{array}$ & $\begin{array}{l}\text { A or B Director gave } \\
\text { as an example of co- } \\
\text { production, but } \\
\text { unclear from } \\
\text { description of staff } \\
\text { member if/how this } \\
\text { takes place }\end{array}$ \\
\hline Aspire & $\begin{array}{l}\text { Involved as } \\
\text { sub-contractor } \\
\text { in Sheffield } \\
\text { Older People }\end{array}$ & $\begin{array}{l}\text { Peer } \\
\text { mentorship } \\
\text { service for } \\
\text { larger Sheffield } \\
\text { Older People } \\
\text { project }\end{array}$ & $\begin{array}{l}\text { Multiple } \\
\text { interviews }\end{array}$ & $\begin{array}{l}\text { Director sceptical } \\
\text { about the rhetoric of } \\
\text { co-production and } \\
\text { its use with } \\
\text { disadvantaged } \\
\text { communities - } \\
\text { prefers informal } \\
\text { engagement }\end{array}$ \\
\hline Recreation & $\begin{array}{l}\text { No clear } \\
\text { examples given }\end{array}$ & & & \\
\hline
\end{tabular}


Table 6.5: Lyon co-production examples

\begin{tabular}{|c|c|c|c|c|}
\hline $\begin{array}{l}\text { Lyon } \\
\text { organisations }\end{array}$ & $\begin{array}{l}\text { Co- } \\
\text { production } \\
\text { example }\end{array}$ & Description & $\begin{array}{l}\text { Identified } \\
\text { through }\end{array}$ & $\begin{array}{l}\text { Co-production } \\
\text { assessment }\end{array}$ \\
\hline \multirow{3}{*}{ Avancé } & $\begin{array}{l}\text { Writing of } \\
\text { social plan }\end{array}$ & $\begin{array}{l}\text { Co-design } \\
\text { through } \\
\text { activities and art } \\
\text { project }\end{array}$ & $\begin{array}{l}\text { Interview } \\
\text { with } \\
\text { director }\end{array}$ & $\begin{array}{l}\text { F. Example of co- } \\
\text { design but not co- } \\
\text { delivery }\end{array}$ \\
\hline & 'Gratiferia' & $\begin{array}{l}\text { 'Free market', } \\
\text { where all goods } \\
\text { are donated and } \\
\text { residents can } \\
\text { take what they } \\
\text { like }\end{array}$ & $\begin{array}{l}\text { Interview } \\
\text { with } \\
\text { director and } \\
\text { volunteer }\end{array}$ & \multirow{2}{*}{$\begin{array}{l}\text { D. Clear co- } \\
\text { production: both } \\
\text { projects initiated } \\
\text { by residents, able } \\
\text { to carry out with } \\
\text { admin and on the } \\
\text { day support from } \\
\text { professionals }\end{array}$} \\
\hline & $\begin{array}{l}\text { Summer } \\
\text { picnics }\end{array}$ & $\begin{array}{l}\text { Weekly } \\
\text { neighbourhood } \\
\text { picnics in August } \\
\text { when the } \\
\text { community } \\
\text { centre is closed }\end{array}$ & $\begin{array}{l}\text { Interview } \\
\text { with } \\
\text { director and } \\
\text { volunteer }\end{array}$ & \\
\hline Mouvement & $\begin{array}{l}\text { Writing of } \\
\text { social plan }\end{array}$ & $\begin{array}{l}\text { Citizens involved } \\
\text { in priority- } \\
\text { setting, co- } \\
\text { constructing the } \\
\text { plan through } \\
\text { surveys }\end{array}$ & $\begin{array}{l}\text { Interview } \\
\text { with staff } \\
\text { member }\end{array}$ & $\begin{array}{l}\text { F? Difficult to } \\
\text { assess whether } \\
\text { this is co-design or } \\
\text { consultation }\end{array}$ \\
\hline Equipe & $\begin{array}{l}\text { No clear } \\
\text { examples } \\
\text { given }\end{array}$ & & & \\
\hline Diversité & $\begin{array}{l}\text { Writing of } \\
\text { social plan }\end{array}$ & $\begin{array}{l}\text { Co-constructed } \\
\text { plan through } \\
\text { group } \\
\text { discussions }\end{array}$ & $\begin{array}{l}\text { Interview } \\
\text { with } \\
\text { director }\end{array}$ & $\begin{array}{l}\text { F? Difficult to } \\
\text { assess whether } \\
\text { this is co-design or } \\
\text { consultation }\end{array}$ \\
\hline \multirow{3}{*}{ Familles } & $\begin{array}{l}\text { Support } \\
\text { project for } \\
\text { struggling } \\
\text { students }\end{array}$ & $\begin{array}{l}\text { Joint project with } \\
\text { local college to } \\
\text { provide students } \\
\text { with work } \\
\text { experience and } \\
\text { support }\end{array}$ & $\begin{array}{l}\text { Interview } \\
\text { with } \\
\text { director and } \\
\text { document } \\
\text { analysis }\end{array}$ & $\begin{array}{l}\text { D. Co-designed } \\
\text { with students, } \\
\text { teachers, and CS } \\
\text { staff, co-delivered } \\
\text { with volunteers }\end{array}$ \\
\hline & $\begin{array}{l}\text { Writing of } \\
\text { social plan }\end{array}$ & $\begin{array}{l}\text { Citizens involved } \\
\text { in priority- } \\
\text { setting, co- } \\
\text { constructing the } \\
\text { plan through } \\
\text { surveys }\end{array}$ & $\begin{array}{l}\text { Interview } \\
\text { with } \\
\text { director }\end{array}$ & $\begin{array}{l}\text { F? Difficult to } \\
\text { assess whether } \\
\text { this is co-design or } \\
\text { consultation }\end{array}$ \\
\hline & $\begin{array}{l}\text { Language } \\
\text { workshops }\end{array}$ & $\begin{array}{l}\text { French language } \\
\text { and culture } \\
\text { workshops for } \\
\text { immigrants }\end{array}$ & $\begin{array}{l}\text { Interview } \\
\text { with } \\
\text { director }\end{array}$ & $\begin{array}{l}\text { C. Designed by } \\
\text { professionals, } \\
\text { delivered by } \\
\text { volunteers }\end{array}$ \\
\hline
\end{tabular}


One of the notable details that this chart reveals is the degree of consistency of the responses of the directors of the Lyon social centres - three of the five put forward the involvement of local people in the design/ writing of the organisation's 'social plan' (projet social, a four year strategic plan that is obligatory for all social centres to produce in collaboration with local residents) as an important example of coproduction. Because this is a strategic document, I felt it was impossible to categorise the degree to which people were involved in its delivery or implementation, since this would be more of a process of co-evaluation or coassessment which is beyond the scope of this research (Bovaird and Loeffler, 2012).

Social centres are required, by virtue of their being designated this type of organisation, to include local residents and members of the association in the writing of their strategic 'projet social'. Avancé was the only of the five case studies to describe in detail their process co-designing the social plan, which involved some innovative co-design activities. Visitors to the community centre building were encouraged to write their "wishes, proposals and requests for the four years to come" (Projet Social, Avancé) on pieces of paper shaped like light bulbs, which were displayed in the lobby. These were subsequently collated, analysed and developed into priorities within the plan. For the other three case studies that discussed the involvement of residents in the creation of the social plan, they described this as involving intensive consultation of (through surveys and discussions), often described as a process of co-construction. An attempt to categorise these practices as either co-design (B or F in the table of Bovaird's typology) or more traditional 
consultation reveals the fuzziness between these categories - at what point does consultation move into the stage where "the planning and design stages closely involve users and community members"? (Bovaird, 2007, p. 849, emphasis mine)

Notwithstanding this ambiguity between consultation and co-design, this involvement of local people in defining the strategic direction of the social centres in Lyon reflects the importance of the community logic in organisational practices. Here, the informal valuing of community members' views and priorities is privileged above the bureaucratic dominance or regard for democratic voting as the sole legitimate source of decision-making that characterises the state logic. The social plan provides a platform to develop the concrete activities and actions that will support the value of participatory democracy that is established by the national federation, thus formalising what might otherwise be informal practices.

Across the case study organisations, only four of the examples proposed clearly meet the definition of "full citizen and professional co-production", where both citizens and professionals are involved in design or decision-making as well as delivery of a service or the actualization of a project. The examples put forward by both the Sheffield and Lyon case studies (a community clean-up day, 'free market', neighbourhood picnic, and student support project) exhibited similar practices - the project was shaped through a collaborative effort between organisation staff and volunteers from the local community, and realised through this continued collaboration, with "all parties mak[ing] substantial resource contributions" (Bovaird, 2007, p. 847). 
These practices diverge from Bovaird's conceptualisation of co-production in two key ways - first in the sense that none of these 'best practice' examples relate to services per se, but are instead related to activities, projects or events. Second, distinguishing between involvement in design and involvement in delivery produces an artificial division that does not accurately reflect these organisations' practices. While the opinion of the directors interviewed (in addition to my own assessment as a researcher) is that these examples warranted being described as co-production, it is often impossible to isolate the process of design or decisionmaking from the delivery or implementation process, which often happen concurrently and are indistinguishable.

In several other cases, the practice that was described to me more clearly demonstrated co-delivery only, with the project or service being design by professionals without the clear input of service users or residents (such as Develop's older people's coffee morning, or Famille's French workshops). In the case of several of the examples discussed in Sheffield, interviewees described examples of coproduction between professionals and citizens (Enterprise's mental health café, and Leisure's youth club) but observations and follow-up interviews with frontline staff revealed that perhaps these were in fact more traditionally designed and run. On the one hand, this again exposes the ambiguity of co-production as a concept in attempting to label practices. On the other hand, the willingness of directors to employ the term co-production to describe their practices in Sheffield (whether or not these practices exist) demonstrates more about the narratives that define these organisations than their actual practices. Because of the near universal perception in England of co-production as a beneficial practice in the third sector, it is likely 
that when candidly asked about co-production, interviewees felt compelled to give examples of their practices.

The discussion here does not by any means aim to provide an exhaustive analysis or interpretation of the co-production activities of the community regeneration organisations and social centres, which is beyond the scope of the data collected. However, the presentation of the practices identified by interviewees as coproduction brings to light some of the underlying institutional logics embedded within the organisations in each country, as well as the complex interplay between narratives and practices in defining the case study organisations' logics. Overall, the community logic plays the strongest part in defining the practices of all of the case studies, with an emphasis on solidarity, informal collaboration and cooperation being a dominant characteristic of the practices described by interviewees and observed in fieldwork.

In both Sheffield and Lyon, this is also combined with the state logic in some instances. In Sheffield, the state logic is somewhat present in defining top-down programmes such as the Community Organisers programme. In Lyon, by contrast, the state logic is regularly engaged in organisational practices, particularly in the emphasis that social centres attribute to internal democracy and governance. Finally, there is some evidence of the market logic in the practices of the Sheffield community regeneration organisations, who have been compelled to adopt business-like practices and therefore sometimes employ co-production practices as part of business decisions to improve the efficiency of services. As we will see in the 
discussion of narratives, the market logic is embedded more in the way that individuals describe their beliefs and activities more than their actual practices.

\subsection{Narratives}

The final element of my institutional logics framework relates to the nonmaterial, symbolic or belief-based elements which I identify through analysing actors' narratives. Narratives are the spoken expression of ideas, as structured through the use of stories. As outlined in Chapter 3 where I established my analytical framework, I draw upon methods from both narrative and discourse analysis. This is undertaken at two levels - the narratives told by interviewees, meaning the stories they tell and the structure of these; and then the vocabulary and language within these stories. The analysis will be organised to first concentrate on the broader narratives told by participants and how these divulge the motivations for engaging in co-production along with the various values and beliefs associated with these practices. This is followed by a focus on the specific language and discourse employed in relation to co-production with particular attention to the ways that research participants reacted to and interpreted the term itself.

\subsubsection{Stories and narratives}

\section{"Tell me about your organisation"}

The first narratives that emerged in interviews were the stories that respondents (generally directors, who were the first interviews conducted in each organisation) told in response to the question, "Tell me about your organisation and what you 
do."12 Inspired by techniques of narrative interviewing (Jovchelovitch and Bauer, 2000), this broad opening question was used to solicit stories. While we might expect that this would prompt similar types of responses, the focus and themes of the narratives of the Sheffield organisations provides a striking contrast to those in Lyon. These 'establishment' or 'key purpose' narratives provide an insight into the different combinations of institutional logics embedded within the case studies, providing a basis with which actors explain their reasons for undertaking coproduction (or not).

In Sheffield, all five directors responded to this opening "tell me about your organisation" question by relaying their history, and how they developed in order to manage and deliver regeneration contracts. As outlined at the beginning of this chapter, the five case studies were founded between 1997 and 1999 as a result of European and national regeneration grants to the city. All five directors in Sheffield relayed narratives about their organisation being founded from either a local community forum or informal group of activists who came together and formed organisations in order to take advantage of the regeneration money. Despite the fact that these funding streams have ended, these establishment stories - being community-led organisations which aimed to harness local activism to improve the community - continue to contain important narratives that help to define current values, strategies and priorities.

"We were originally set up to manage a regeneration programme. It was SRB. It was a bid that was put together by local community activists with

12 «Pourriez-vous m'expliquer un peu votre centre social et ce que vous faites ici ?» 
support from the council. [...] Really, that was the starting point. We became more than an accountable body for money and we started to look at delivering the community development programme ourselves, because there was no other organisation that was really fit for purpose to do that. That's what we've become. We've become a community development organisation that actually delivers services and we've filled the gaps." (Director, Develop)

In this foundation story, several themes emerge that contribute to explaining this organisation's approach to involvement and co-production. First, the interviewee explains that the organisation was founded as a result of community activism and an agreement with the local council, establishing an early integration of the community and state logics into the organisational narrative. This activist and local council collaboration also shows how co-production is essentially part of the way in which Develop conceptualises its approach to community development. In other words, the organisation was founded because of co-production between citizens and the council, and the organisation now sees its role as continuing to take this approach in its expanded role as a service provider. While the other four organisations in Sheffield provided slightly different narratives in relation to their self-identification as a community development organisation (which will be considered in further detail), this trajectory - grassroots organising to deliver largescale government funded regeneration programmes, with growth and professionalization over the subsequent 20 years - is a shared narrative across the Sheffield regeneration organisations.

The fact that the question "tell me about your organisation" prompts stories about organisational history is an unremarkable finding on its own, but a comparison of 
these narratives from Sheffield with the responses in Lyon highlights a fundamental difference between the logics that shape the identities of the cases in each context. In contrast to the Sheffield community regeneration organisations, none of the directors of the Lyon social centres told stories about the history or establishment of their particular social centre - either in response to the aforementioned question or in fact, often ever. Instead, three of the five directors defined their organisation by relaying nearly identical narratives about the shared values of social centres.

\begin{abstract}
"So, the social centre, it's a structure that is defined by its plan and by its territory. The two are linked. The objective and the territory go together, rather than the objective being determined by the territory. And the third pillar of the definition of a social centre is the democratic functioning. That is to say, it's an associative structure that is run by a general assembly with volunteers who function under a democratic model. All social centres have these three axes - a plan, a territory, democratic functioning." (Director, Équipe)
\end{abstract}

Similarly, the other social centre directors responded by explaining that it is an association of and for local residents (Avancé, Mouvement and Familles). Only one of the five directors (Diversité) responded by highlighting the size and function in regards to service provision, but it is perhaps worth mentioning that this interview was conducted in English and the director had worked for many years for international NGOs, which may have accustomed him to different narrative frames of reference. The priorities evidenced in these 'organisational information' narratives help to explain a fundamental difference in the motivations that actors have for involving local residents or service users in co-production. For the Lyon social centres, organisational purpose and identities revolve around the shared 
values delineated in the National Charter of Social Centres, which are human dignity, solidarity and democracy. These core values will be explored in more detail in the following section. Associating through this shared narrative of values rather than history provides the social centres with a different core understanding of where coproduction fits within this. While in Sheffield, co-production provided the basis to begin to deliver services in deprived areas, in Lyon, social centres were formed with democracy and participation as ends unto themselves.

\section{Values}

In the previous section, I discussed the way in which respondents from the community regeneration organisations and social centres described their organisations to me, and noted the fact that in Sheffield, interviewees prioritised the history and description of services provided, while in Lyon, interviewees were more likely to respond by explaining the fundamental ethos and values of social centres. The discussion now turns to a more purposeful consideration of values and beliefs within the case studies and how these values form part of the institutional logics that determine co-production activities.

As noted, identifying the defining values of the Lyon social centres was straightforward, because they are codified in a national document that federates all the social centres of France and therefore common to all five organisations. Social centres' 'benchmark values' are: human dignity - referring to being inclusive and respectful of cultural differences; solidarity - building social cohesion and neighbourliness; and democracy - opting for a governance arrangement that values debate and sharing of power (Charte Fédérale des Centres Sociaux et Socio- 
Culturels de France, 2000). The importance of internal democracy has been examined in the previous sections focusing on rules and practices, so the analysis of values will focus more on these first values of human dignity and solidarity together as they ally with notions of participation and co-production.

The concept of solidarity formed an important part of the social centre descriptions of values. This term frequently appears in organisational documents (such as the social plans of all five social centres) as well as at the field level of the National Federation of Social Centres. In interviews, respondents often spoke about solidarity as discursively linked with notions of mutual aid and fraternity as well as to describe projects that would more likely be categorised as charity. In the social plans of two social centres, solidarity is described as the following:

"Solidarity: The social centre supports the construction of a space for exchange and sharing, where each local resident has their place. A space where social and intergenerational links are created." (Projet Social, Mouvement)

"Solidarity: Considering men and women as showing solidarity with one another means being capable of living together [vivre ensemble] in society is a continuing conviction of Social Centres since they began." (Projet Social, Avancé)

In the second quote, solidarity is also linked with the concept of 'vivre ensemble', which translates to English roughly as 'living together', but can probably best be understood in English as something akin to 'peaceful coexistence' of different groups in society. Many translations of French texts to English equate vivre ensemble to 'diversity' but I believe that diversity does not adequately convey the particularity 
of the French conception. Vivre ensemble is a uniquely French way of resolving ideas of fraternité and solidarité with the reality of an increasingly diverse population in France. The idea of multiculturalism conflicts with the French conceptualisation of citizenship, where everyone - regardless of religion or ethnicity - is French and French alone, with no space for different communities within this identity. Thus vivre ensemble represents an essential element of the logics of social centres, as a blend of the state and community logics in a way that self-consciously aims to allow for individuals to be both French and acknowledge their religious or other cultural identities. For example, one of the social centres has as a strategic priority to "promote the 'vivre ensemble"” in their social plan:

\section{Reinforcing the act of 'reaching out' to residents, no matter their age} or sociocultural origins.

Adapting our offer to be attentive to different populations (to make cultural mixing [diversity] work, it's necessary that different people share the same service or the same activity). [...]

\section{Paying attention to welcoming vulnerable populations. (Projet} social, Familles, emphasis in original)

These complementary values - human dignity, solidarity and vivre ensemble contribute to the logic that defines social centres' engagement in co-production. In other words, a mainstreamed, fundamental value of social centres is to provide spaces where local people of all backgrounds are 'welcomed' - both just to attend, but also to contribute to decision-making. Like the rules and practices discussed, these values in Lyon exhibit a blending of a state logic that advances a singular 
notion of nationhood and citizenship with a sense of local belonging that typically characterises the community logic.

In many ways, there are similarities between the central values of the Lyon organisations and those in Sheffield, but these are expressed using different narratives that highlight the variations between how institutional logics are integrated in each context. In Sheffield, a narrative emerges about being 'community-led' that has some similarities with the Lyon vivre ensemble stories, but demonstrates a different balancing of logics. As we saw in the establishment stories, the Sheffield community regeneration organisations define themselves by their history of being founded through community activism. This now translates to narratives about their primary raison d'être of being driven by the needs and aspirations of local 'communities'. The varying mix of the market, state and community logics in each of these organisations means that these values are strategically assimilated into what I identify as two overarching narrative structures that convey slightly different values - a social enterprise ethos, and a community engagement or community development ethos.

A social enterprise ethos, where the focus is on utilising business activity as a means to achieve social or community ends suggests the embeddedness of the community, state and market logics (Defourny 2001; Defourny and Nyssens, 2006) was evidenced most strongly in the narratives from Enterprise and Leisure. Interviewees from these organisations described models of being responsive to client demand, and delivering outcomes for service users or clients, with little direct mention of the importance of participation or citizenship. 
"Sometimes I describe it [the organisation] as a charitable social enterprise to make it clear there's a charity, but we're also a business. The one thing I think that we all kind of collectively learned, we are a registered charity but we're not a charity in that we don't give money away. It has to stack up as a business. We need to be as smart and entrepreneurial as anybody else." (Director, Enterprise)

Thus the market logic is leveraged in order to further the social aims, i.e. the community logic. This social enterprise ethos also incites a particular approach to co-production, whereby increased involvement of service users in design and delivery forms part of an approach to social innovation, and co-production is valued as a means to achieve organisational aims (such as improved communities, or improved outcomes for individuals). This extends to the language used to describe service users - while most of the Sheffield community regeneration organisations spoke about 'local people', 'residents' or 'service users', the director of Enterprise spoke about 'clients', which he explained was an intentional decision in an effort to conceive people as customers rather than beneficiaries of services. This evidences another way that institutional logics define co-production practices, because the terms that are used to describe citizens convey implicit value propositions and status assumptions (McLaughlin, 2009).

In my discussion of practices, I discussed the approach of community engagement that characterises the practices discussed by the Sheffield community regeneration organisations. Community engagement, or more specifically community development, also represents a mainstay of the narratives and value basis for Develop, Aspire and Recreation. The practices related to this notion focused on informal collaboration, building relationships and supporting local people. 
Changing perspective to consider the narratives around community development, we can identify some clear values and beliefs that explain why actors choose to take this particular approach to practices. The community development narratives are supported by theory from Paolo Freire (1970) and Saul Alinsky (1971), with the idea of valuing the contribution of individuals and, as one interviewee described, "It's about challenging inequalities, tackling injustice. It's about working with people, not doing things to them" (Director, Develop). The focus of these narratives is exclusively defined by the community logic, valuing trust, reciprocity and cooperation as main priorities.

In Sheffield, ideas of participation and co-production are inextricably linked with ideas about community - people often employ the term to refer both to the individuals that live in an area as well as the physical area itself. At a surface level, ideas of 'solidarity', more commonly used in France, and 'community' appear to be similar and complementary. However, the difference between the focus of these narratives in each country attests to the differences in the interplay of logics that defines these narratives. One must take into account the particular political traditions of France to understand that these values are indeed a blend of the state and community logic in the French case. I have conceptualised the 'community' logic in accordance with Thornton et al. (2012) and others, with a focus on local cooperation, neighbourliness, trust, reciprocity and personal investment in a particular group (which may or may not be territorially bound). Defined in such a way, a large percentage of passages from the Lyon interviews were coded as including elements of the community logic. However, it is important to note the baggage associated with the term 'community' in France, where it is seen to be 
antithetical to the unity of the French Republic. Solidarity is therefore preferred as a value that emphasises joining together with other people as fellow citizens.

\subsubsection{Co-production discourse}

The narratives and stories discussed in the previous section, particularly those pertaining to values, may appear to exhibit more similarities than differences between the English and French organisations. In many senses, this is true - all of the community regeneration organisations and social centres have narratives that explain values like social cohesion, supporting people, and working together to improve neighbourhoods. In many ways, these similarities extend to the way that these values structure the stories about co-production as well, such as the belief that professionals should "do with, not to" local people. Within these narratives, however, there exist discrepancies of meaning between the words and concepts employed by actors that expose differences between the logics integrated into organisational life. This was touched upon in the previous section where the usages of the terms 'solidarity' and 'community' were explored as they related to the values and narratives of the case study organisations. In this section, I bring the focus to the term co-production itself. As in the section on co-production practices, an evaluation focusing specifically on the usage of the term provides valuable insight into the logics driving decision-making and behaviour.

In Sheffield, the word co-production did not naturally arise in any of the interviewees' narratives, and the term often proved to be surprisingly controversial 
when I introduced it. When questioned directly about co-production ${ }^{13}$, respondents were by and large familiar with the term, but often extremely sceptical about it. Most interviewees produced a definition of co-production that is roughly in line with the academic literature, although often in more ambiguous terms that could be construed as 'involvement' or 'consultation' more generally. Frontline staff members were found to be less familiar with the term, with most (three of the five interviewed) indicating that it was not a term they would be confident defining or using in their work. The two that did indicate a familiarity with the term were a community development officer, and an officer working directly on the Sheffield Older People project, which (as will be discussed in Chapter 7) is the only of the case study organisations to use the word co-production to describe their work.

The sense of scepticism and negativity towards the term co-production was unanticipated, and was so prevalent amongst the community regeneration chief executives that I began coding 'reaction to the term co-production' as part of my data analysis.

“Okay... I think we do co-produce. I just really hate that word. (Laughs) It's nothing personal. It's because I think it is so... It's sexy at the moment, but I think people use it and abuse it. I don't think... a lot of organisations talk about co-production, but actually, they don't do it." (Director, Develop)

"I'm quite happy with it, totally understand co-design, co-production, yeah, with it. I think it's a bit of a thing about labels and jargon, what's

13 Typically towards the middle to the end of an interview, I asked, "The word I'm using in my PhD is 'co-production'. Is that a word that you use? / What, if anything, does that mean to you?" 
fashionable, though, because to me, it doesn't feel much different to what we've been doing forever and a day. But it's like this week, you put this label on it." (Former director, Leisure)

While three of the directors in Sheffield indicated a distaste for the term coproduction, all of them expressed similar narratives of feeling that their organisation, nevertheless, does co-produce with service users. The scepticism expressed about co-production as a term, illustrated in the two quotes above, takes two forms - first, the opinion that there is a disconnect between the rhetoric and practice of co-production in other organisations, or in other words, a gentle accusation that other organisations employ the narrative but not the practice. Conversely, as the former director of Leisure expresses, there is also the suggestion that co-production has been a part of organisational practices 'forever', but that it is just a new buzzword. The commonality between these two narratives is a recognition of the current normative appeal of the term co-production, but a feeling that it does not accurately correspond to practices (either because it is talked about but not done, or paradoxically because co-production is framed as a new practice that is, in fact, longstanding).

Like in Sheffield, the term co-production was never employed in Lyon, but this was because none of the individuals interviewed felt that this was a word that was commonly used in French. Consistent with the findings from the literature review, 'co-construction' appeared to be the preferred term. When specifically asked whether 'co-production' was a word they would use to describe their activities, one interviewee responded: 
"Yes... Co-construction. Rather, we would talk more of co-construction, but co-production would be more in writing: co-production of plans. As I mentioned, social centres re-write their social plan every four years for the CAF. So, in fact we re-question ourselves on the values that we'll share and for the next four years, what are the actions that we'll prioritise?" (Staff, Mouvement)

Respondents defined co-construction as having multiple stakeholders at the table to define projects or services, and the idea of partnership between public powers, associations and citizens. As discussed in Chapter 2, the term co-construction rather than co-production is in line with trends in the francophone literature, where it is elaborated by researchers (primarily in Quebec) to refer to the involvement of citizens and associations further 'up stream' in creating public policy (Vaillancourt, 2009; Jetté and Vaillancourt, 2011). Co-construction is thus more analogous to the way that 'co-planning' or 'co-governance' are used in England, whereby citizens are involved in setting forth priorities and contributing to policy-making, rather than in the implementation or delivery phase.

A similarity that emerged between the Sheffield and Lyon discourses related to coproduction and co-construction was a frustration about misappropriation of terminology by politicians or other organisations who do not actually engage in coconstruction practices, which was expressed about related narratives of empowerment as well:

"The problem is at the moment, is that the government, the political parties are using it [empowerment] is really for me, it's not only a buzzword but it's a way to cover the fact that they're only making consultation and they're just rewording the consultation as 
empowerment and trying to let us think that they're doing empowerment while they're only doing consultation. They're doing exactly the same." (Director, Diversité, interview conducted in English)

"Before every election, politicians say, 'Listen, we're going to co-design together. You'll see, we'll listen to you. It will be great. Vote for me.' And that's a real trap. I think that words... it's complicated, because on the one hand we need concepts. At the same time, as soon as there's a bit of a strong word, it's quickly captured by the media, by politicians. And it quickly becomes what we call elements of jargon. There are people who don't change what they do for years, and suddenly they adopt the discourse." (Director, Avancé)

This grievance is not as ubiquitous amongst the Lyon social centres as the Sheffield organisations (only the directors of Avancé and Diversité expounded upon this complaint, whilst the others spoke only positively or neutrally about the term coconstruction). This is likely due to the perceived ownership or provenance of the respective terms - while co-construction is widely associated with the social centre sector, as it relates to the notions of citizen participation and governance, coproduction in the UK is perceived by third sector actors as having been coined elsewhere to describe practices they had conceived using different vocabulary.

This distinction between co-production and co-construction may seem minor, and indeed interviewees frequently assumed the words were interchangeable. However, the distinction between the two terms and the way they are employed in each country exposes a difference in the way that institutional logics are combined in the narratives of community regeneration organisations. Co-construction affords a greater weight to the involvement of local people in governance and decisionmaking, or the democratic participation aspect of involvement and collaboration - 
thus applying the state logic to the values and narratives of participation. Coproduction, on the other hand, focuses more on the doing - the involvement of community members and services users in producing their services, through contributing time and resources, volunteering, etc. This emphasis on the production or delivery of services is illustrative of the way in which the Sheffield organisations assimilate the state, community and (to a somewhat lesser, but by no means absent extent) market logics.

Interviewees in both countries also employed discourse relating to empowerment of local residents or service users, but this word has to some extent fallen out of favour in England, where it is associated with programmes of the pre-2010 Labour government (e.g. 'Communities in control: real people, real power', 2008). French respondents frequently employ the English word 'empowerment', because attempts to translate the word have been somewhat less effective discursively, with "le pouvoir d'agir" ("the power to act") being the closest alternative, although this cannot be eloquently used as a noun, verb and adjective like empowerment, to empower, and to be empowered. Looking closely, the way that people use the word empowerment in England, compared to the way people use the word empowerment or pouvoir d'agir in France reveal some important contrasts between how this narrative informs co-production practices.

“We are very good in providing services, but we wanted to move towards more places where people can come and develop projects, but also developing the idea that the people are also citizens and they have to develop their capacity, their empowerment. That's where we're trying to move." (Director, Diversité, interview in English) 
Here, along with other narratives from the French social centre respondents, empowerment is discursively linked with citizenship - the idea of empowering local people is about enabling them to gain the skills and confidence to exercise their rights as citizens. This then leads to a more overtly political conceptualisation of involvement (and hence co-production) where people are involved in activities with the implicit motive of making them able to engage politically. In addition, while supporting active citizenship appeared as a priority or objective in all five Lyon social centres' social plans (e.g. "encourager la dynamique citoyenne des habitants" and "développement de la citoyenneté de proximité", both meaning roughly "encourage active citizenship"), none of the analogous documents of the Sheffield community regeneration organisations contained any reference to citizenship.

In England, the use of the term empowerment is less overtly political and more aligned with Osborne and Strokosch's conception of user empowerment: "User empowerment is concerned with the ability of individual service users to control their experience of a public service and contribute to their own desired outcomes. As such it is best approached through the mode of consumer co-production." (2013, p. S38). Enterprise, for example, includes empowerment in their "client progression model", whereby empowerment is conceived as the point in a client's pathway where they can self manage their health or have secured employment. Because empowerment is conceived as pertaining to individuals (generally as consumers or users of services), this likewise impacts the motivation for co-production, which is primarily conceived through a more pragmatic and individualistic lens. 


\subsection{Conclusions}

In this chapter, I have presented the empirical findings from the Sheffield community regeneration and Lyon social centre case studies. The analysis focused on five organisations in each city, which provide the principal focus of the research. The first section of the chapter explained the community regeneration sector in Sheffield and the concept of the social centres in Lyon, providing an overview and basis for the comparison between the five organisations in each city. The empirical analysis sought to explore and build theory to understand differences in coproduction in the two contexts. This was done through employing a framework of institutional logics, which was operationalised through the concepts of rules, practices, and narratives.

The analysis showed that, first, different types of rules were variously influential between the two countries, illustrating different ways that different, often competing, logics are reconciled. In Lyon, all five social centres exhibited impacts of the state logic in a contextually specific blending with the community logic, as the five organisations described the role of government and federation policies in providing rules that constrain their behaviour, as well as formalising their approach to co-production, which is mainstreamed into their definition as social centres. This codification of co-production practices also extends to internal rules, which are manifest in governance procedures and organisational 'social plans'. By contrast in Sheffield, the only rules that were described as influential were those imposed by contracts or grants, which can create conflicts between the state, community and market logics for organisations to engage in co-production practices. 
Moving to practices, in both countries, the community logic dominates, particularly when focusing on co-production practices. In Sheffield, we also see some assimilation of the market and state logics in this, while in Lyon, the market logic appears completely inconsequential, and the state logic norms of bureaucracy and democratic participation are blended with the community logic. This is manifested through the informal practices of community engagement in many of the Sheffield organisations and the more official involvement in participatory democracy in Lyon. In both countries, a similar area of co-production practice involving citizen-led (and professional supported) projects was also evidenced.

Finally, organisational narratives proved to be illuminating in demonstrating the various weight of the state, community and market logics in each case and how these served to define the values and motivations underscoring co-production. These narratives reprised the theme of a cautious assimilation of the state, community and market logics in Sheffield - although the state and market logics often come into conflict with the prevailing community logic in respondents' descriptions of coproduction and their values. In Lyon, again, co-production narratives demonstrate a specifically French blend of state and community sensibilities, where coproduction is defined using vocabulary of citizenship and national values, notions that typically are associated with the state, but rendered into the local by means of associations.

In the next chapter, I continue to analyse the empirical data from the research, moving from community regeneration to the comparator case study areas: parents' organisations and older people's projects. The following chapter will consider the 
themes discussed in this chapter in relation to the identified combinations of institutional logics and place for co-production within these rules, practices, and narratives, in order to determine the wider relevance and better understand the third sector as a broader whole in each city and country context. 


\section{CHAPTER 7: COMPARATOR ORGANISATIONS - PARENTS}

\section{AND OLDER PEOPLE'S PROJECTS}

\subsection{Introduction}

In order to analyse the role that institutional logics play in shaping co-production, I have chosen to analyse two further areas of third sector service provision as comparators. This approach will allow me to determine the degree to which the combinations of logics identified in the community regeneration organisations in Sheffield and social centres in Lyon are unique to this particular sector, or whether we may be able to draw broader conclusions about how institutional logics impact co-production in the third sector more broadly in each case city. As a result of discussions with representatives from third sector networks in each city, I have identified two key sub-sectors for analysis: childcare/parents' organisations, and projects aiming to reduce isolation of older people.

\subsection{Children's services and older people's projects}

Children's services (including childcare as well as services for parents and children) and projects to reduce isolation of older people were chosen as areas for focus based on theoretical sampling. I interviewed key informants (third sector representatives in both Lyon and Sheffield) and asked for recommendations of organisations that 
would be considered models of good practice in terms of citizen participation. Lyon Parents was recommended to me by the director of a key third sector representative body as an organisation that is widely recognised for its participative approach. Likewise, I interviewed the deputy chief executive of a third sector network in Sheffield and enquired about projects or organisations that could be seen as examples of co-production, and it was recommended that I speak to Sheffield Older People. Given that the organisation and project suggested as best practice operate in different service areas in each country, I felt the most appropriate approach would be to identify an organisation that was as comparable as possible in terms of the primary aims or area of service delivery in order to identify the ways in which institutional logics influence approaches to co-production and whether these are a) contextually specific and b) specific to the area of service delivery within the third sector in each country.

\subsubsection{Parents' organisations}

Childcare has received a great deal of attention in previous research on coproduction, particularly Victor Pestoff's research in Sweden (Pestoff, 2006, 2009; Vamstad, 2012) but also in Canada (Prentice, 2006) and the UK (Pemberton and Mason, 2008), and some discussion of parent participation in France as part of a large scale European study on childcare provision (Fraisse and Bucolo, 2003). Pemberton and Mason analyse the Sure Start programme in the case of the UK, which was launched in 1999 and extended and revised in 2002 partially in order to increase the involvement of parents in the delivery of services. Sure Start is a government programme that aims to tackle areas of disadvantage for young 
children, through childcare services, community development, and support for parents and families. However, the authors found mixed results from their case study, indicating that the revised Sure Start programme at that point had failed to offer meaningful opportunities for co-production.

As discussed in the methodology, Lyon Parents was selected based on a recommendation of their co-productive approach, which was verified by staff at two other organisations (As an interviewee from Avancé social centre said, “They're one of the best organisations on that subject [participation]. They're great. They're awesome.") Lyon Parents is the local branch of a national network/ membership organisation of parent cooperative day care centres which has been in operation for 30 years, and they have built their mission around a collaboration between parents and professionals in childcare provision, projects to support parenthood and strengthen the role of parents, and collaborative research projects around parenting issues.

I then attempted to find a similar organisation in Sheffield (i.e. a parent cooperative or children's services provider with a significant parent participation component), but was unable to identify anything comparable. The Midcounties Co-operative, a consumer co-operative, operates 44 nurseries across England, but none of these are located in Sheffield. (Furthermore, based on an analysis of Co-operative websites and documents, these nurseries also do not appear to mainstream and prioritise the day-to-day co-production - e.g. such as requiring parents to volunteer in the nursery - as Lyon Parents.) In Sheffield, the involvement of third sector organisations in directly providing childcare services is not commonplace, but the third sector is 
involved in providing other services for children and parents. I identified Sheffield Parents through an interview with a staff member for one of the community regeneration case study organisations, as she and her organisation had recently become involved as a partner in the project. Sheffield Parents is a three-year project which began in 2015 with the aim of starting up and supporting parent and toddler groups, family activities and support services for parents in three deprived neighbourhoods in Sheffield. Sheffield Parents is delivered by Sheffield Consortium (anonymised), whose primary role is to act as a membership body of third sector organisations in the city, and to bid for grants and contracts that can be subcontracted to its members. Its position as the grant holder for Sheffield Parents is thus unusual for the organisation, which typically takes a coordinating rather than delivery role.

The cases selected in Sheffield and Lyon are not directly equivalent, both because of the structure of the organisation/ project, as well as the fact that only Lyon Parents was selected on the basis of a recommendation of co-production best practice. However, they both operate in the same sector of childcare, children's services and services for parents, which allows for a theoretically rich comparison in regards to the institutional logics that shape these sectors. Both Lyon Parents and Sheffield Parents are involved in several comparable services and activities for parents and children, and their primary aims are similar (promoting the role of parents and supporting local people to work together for local children and families). The difference between the structures of the Sheffield project and the Lyon organisation will be discussed in the analysis of the national and local rules that define the logics in each case. 
The analysis of Lyon Parents is based on four interviews that I conducted with staff members and volunteers, along with observation of and informal participation in an family fun day to celebrate the organisation's anniversary. I also analysed several of the organisation's documents and publications. For the Sheffield Parents case study, I undertook formal semi-structured interviews with two staff members involved in the project, and attended one of the project's family activities, where I spoke informally to a practitioner. I also spoke at some length about Sheffield Parents with one of the community regeneration interviewees, who is involved in the project. I likewise conducted analyses of bid documents, press releases and project plans.

It is worth noting that there is also considerable collaboration and partnership working between Lyon Parents and a local social centre (not one of the case study organisations), as well as between Sheffield Parents and three of the community regeneration organisations (whose directors sit on the board of the organisation that is funded to deliver Sheffield Parents). This is likewise the case with the older people's projects and the community regeneration organisations/ social centres (which will be discussed in the second half of this chapter). This allows for some depth of analysis and cross case comparison as to the impact of the local context across these different sectors/ service areas.

\subsubsection{Older people's projects}

Sheffield Older People was recommended by numerous leaders in the third sector as a notable example of co-production, which prompted me to choose to include projects for older people as a third theme of the research. Sheffield Older People is a project funded by a national charity funder, with the primary aim of tackling 
loneliness and isolation amongst people over aged 50 in Sheffield. The contract is held by a local third sector body (which I anonymise as Sheffield Older People Contractor, SOPC), which subcontracts projects out to third sector organisations, including Sheffield Consortium (the organisation that runs Sheffield Parents), which further subcontracts to three of the community regeneration case studies (Enterprise, Aspire and Leisure). Because these organisations are involved in delivering the programme, passages from their interviews where they discuss Sheffield Older People have been included as part of this analysis.

Following the approach I took with the children's services case studies, having identified an exemplar of co-production in one city, I then sought to select a comparable case in the other. After some difficulty in finding a suitable comparator, I heard about Lyon Older People during the annual conference of a third sector network, where Lyon Older People was mentioned as one of a number of recent initiatives that had been launched in the older people's services sector. Lyon Older People is not an organisation or a project per se, but is rather a national level social mobilisation and network of institutions and associations that sign a pledge to tackle social isolation of older people in their areas.

Sheffield Older People provides a range of services, activities and projects that are delivered by third sector organisations across the city. These include befriending programmes, counselling for lonely older people, and a programme to help older people use public transport more confidently. At the time I conducted my fieldwork, the older people's project in Lyon had only recently been established locally. As a network of local associations that already have some activities within the field of 
services for older people, Lyon Older People does not itself deliver services, but rather acts as a social movement and network that associations can join to identify themselves as working towards similar ends. It also provides a mapping function to identify gaps and locate activities already taking place to fight isolation.

This approach of identifying a best practice example of co-production, Sheffield Older People, and comparing with Lyon Older People, which has nearly identical stated aims, again allows for a rigorous analysis of the ways that institutional logics explain the structures, the everyday practices, and values and identities held within. In terms of data collected, I interviewed seven individuals associated with Sheffield Older People (see Appendix 5) - three staff and two volunteers of the organisation that holds the contract for the project, and two staff members of community regeneration case study organisations who have been sub-contracted to deliver particular projects. I also analysed relevant documents such as a bid document and 'co-production action plan' document. For Lyon Older People, I interviewed four professionals from three local associations who have signed up to the movement, and a local politician who has been instrumental in launching the network locally (Appendix 6). I likewise obtained and analysed documents, meeting notes and online publications related to the project.

\subsection{Institutional logics and co-production: Parents' organisations}

I have taken the same approach to analysing the data derived from the parents' organisation and project, as well as with the older people's isolation projects as I 
have with the community regeneration organisations in the previous chapter. Thus, in the following section I will analyse the presence of rules, practices and narratives in each case study and the way in which these elements of logics impact the conceptualisation and practice of co-production.

\subsubsection{Rules}

External rules/policy

For Sheffield Parents, funding has been the primary determinant of how the project has been designed and what they are able to achieve, evidencing the role of the market logic. The project was initially conceived as a bid for a $£ 50$ million grant from a charity funder to provide services and projects to improve outcomes and life chances for young children and families in the most deprived areas of the country. Sheffield City Council's initial expression of interest was shortlisted and, because of the scale and scope of the 10-year grant, they were allocated a development grant to further develop a bid. The funding agency in charge of the programme provides grants and contracts exclusively to third sector organisations, so the city council put the bid out to tender for a project lead, and Sheffield Consortium won the role of lead for developing the bid for the programme.

Sheffield Consortium undertook a six month process of partnership building and community engagement in order to write the bid, but they were unsuccessful in being awarded the $£ 50$ million grant. Despite this setback, Sheffield Consortium were informed that the funding organisation would instead allocate them a smaller, $£ 500,000$ grant in order to focus on one aspect of the original bid - reducing the 
isolation of parents with young children in three targeted areas in the city. Naturally, this reduction from a possible $£ 50$ million to $£ 500,000$ in funding has meant a restriction in the scale and ambition of the programme, but the co-productive approach that Sheffield Consortium took in originally producing a bid is partly the reason that the funding organisation took a continued interest in their approach.

“We didn't win the bid, but as part of the process, [Funder] scored us highest out of all 15 on our community engagement because we felt - or I felt - that without community engagement there's very little point in doing anything for under threes. You need communities on board. So as part of that process, we had to work in three areas of the city, three very disadvantaged areas in Sheffield." (Staff A, Sheffield Parents)

As I found in the analysis of the data from community regeneration organisations, grant and contract arrangements have been a key determinant of rules, particularly insofar as organisations are constrained or enabled to engage in co-production. With a reduction to just $1 \%$ of the initial projected budget of the project, Sheffield Parents was forced to completely redefine what they would be able to offer and deliver. Instead of providing a comprehensive, city-wide set of programmes, services and interventions aiming to support parents and young children to lead better lives (with indicators focused on diet and exercise, strengthening communities, and improving relationships and parenting skills), the programme was reduced to three areas of Sheffield, and focusing on one key goal of reducing isolation of parents with young children. Aside from this constraint of considerably smaller funding, the rules imposed by the grant funder are relatively few. The Consortium was chosen for the reduced grant funding on the basis of the community engagement and co-design work they had undertaken with local communities, 
which is an approach that the funding organisation is known for supporting. Indeed, as will be discussed later in this chapter, Sheffield Older People is funded by the same organisation and has taken a fervently enthusiastic approach to co-production.

For Lyon Parents, the role of contracts and grants in defining rules and constraints is limited, echoing the experiences of the social centres. In fact, there was comparatively little discussion of the funding that the organisation receives, suggesting that this is something that does not present noticeable difficulties or constraints.

"There are a certain number of difficulties regarding civil servants. There is a tendency to say that all nurseries should be managed in the same way as a public service. However, here we promote what comes under the grant agreement, because the idea behind that, from a philosophical point of view is that it's a group of residents who have an initiative, who put forward a project and who will defend this project to the collectivity who will finance the project." (Senior staff, Lyon Parents)

Similar to the Lyon social centres, Lyon Parents is primarily funded by the CAF (family social security branch), as well as grants from several government departments, the city and the region, which are tied to specific projects. These projects are, however, considerably broader and less defined than in the case of Sheffield Parents, and several are directly related to improving parents' political participation, suggesting an interesting way in which the state and community logics are integrated. For instance, one interviewee discussed funding that is received from the Departmental Directorate of Social Cohesion ${ }^{14}$ which are targeted at 'developing

${ }^{14}$ Direction départementale de la cohésion sociale, 'Department' referring to a subdivision of the region. See Figure 5.2 for an illustration of the levels of local government in France. 
associative life'. Another grant from the Rhône Region has been allocated to support the organisation's 'participative approach'. As the previous quote from a Lyon Parents senior staff member suggests, rather than being funded to deliver quantifiable results, Lyon Parents puts forward a social and political project, and receives government funding towards supporting these aims and values. This clearly shows a recombination of the community and state logics, with an absence of the market logic.

The logics of both the Lyon and Sheffield case are also impacted by rules derived from government policies. In Sheffield, although the programme is funded by an independent funding organisation, government policy and the decrease in provision of children's services has been the main driver for a project like Sheffield Parents to be established.

"A lot of the reason why we've done what we've done is in these three areas, all three areas had a Sure Start. And all that provision has gone. Nothing has remained. [...] So we are starting from scratch and it's taken us absolutely months and months and months and years to get them to trust that what we're doing, we're doing with a view to keeping and sustaining and making sure that communities, they won't need us, they'll be able to take this on and run it." (Staff A, Sheffield Parents)

Austerity measures in England have meant that many third sector organisations have attempted to fill gaps where public services were previously provided. The fact that the space for parents' groups and children's activities has been left relatively open in these particular communities has meant that Sheffield Parents has more flexibility to determine its own rules, rather than having to negotiate the political landscape, which they have used to their advantage in designing and promoting a 
model of early years service that promotes partnership with and empowerment of local parents. Receiving funding from a prestigious national funder also has meant that their legitimacy has increased in the eyes of the local council, which has been looking at how it can duplicate the community partnership model across the city. Here again, the rules derived from external policy demonstrate a strategic negotiation of the state logic (which defines public policy), the community logic (favouring local solutions to social problems) and the market logic (which requires a demonstrable return on investment - in this case social targets).

The establishment of Sheffield Parents, which was prompted by funding cuts and the inadequacy of state provision, provides a contrast to the foundation of Lyon Parents which conversely arose due to opposition to the way the state was providing childcare. Cooperative crèches began in Lyon as a social movement in the 1980s in opposition to the approach taken by municipal childcare services, which at that time were highly professionalised and medicalised (for example, children were required to be washed and put into new clothes upon entering the crèche). Parents began self-organising crèches sauvages ('wild' crèches) run by parents, often in different parents' homes. Lyon Parents and its national representative body were formed soon after to provide a regional and national voice for parents, to promote parental involvement in childcare and to deliver its own programmes supporting the collaboration between childcare professionals and parents.

"There is this idea that it's a closed world, led by professionals more or less in healthcare - nurses, assistants... and we found this logic of hospitals in collective crèches. The idea of parental crèches is that parents can be side-by-side with professionals, taking charge of a group 
of children. So in parental crèches, parents are on the one hand decisionmakers, members of the board of trustees of the association, putting forward a political project, and parents are also colleagues of professionals in regard to the children." (Senior Staff, Lyon Parents)

The development of cooperative crèches shows the upheaval of community efforts against the prevailing professional logic of childcare. Within Lyon Parents, we can see the way in which government policies and procedures were challenged. Coproduction in this instance is framed as a reaction against the rules that had been imposed by the state.

\section{Internal rules}

In analysing internal rules, it is again necessary to acknowledge that Sheffield Parents is a single project while Lyon Parents is a longstanding organisation, which necessarily means that the internal rules that define their logics are necessarily quite different. Sheffield Parents, as part of their redesigned smaller project proposal, set up 'community partnerships' in the three areas in which the project was to run which are comprised of local parents and community members, as well as representatives from other local voluntary and community groups. The community partnership structure exists so that parents are actively involved in designing the projects, events and activities that are run in their area. In addition, each partnership is allocated a small budget.

"It is absolutely 100\% driven by parents. We attend the community partnerships to report on progress. So even though we are the lead organisation and we're accountable for the cash and accountable for the outcomes of the programme, they certainly drive the delivery and 
the activity. Each partnership has also got a little budget. [...] So they can decide in their area what they want to do, whereas another area might want to do something different. And they have been very different. One area is looking at isolation during pregnancy. One is looking at food poverty and the other one is looking at parenting, specifically around BME ${ }^{15}$ families." (Staff A, Sheffield Parents)

The above quote demonstrates how the community partnership structure of decision-making prioritises the needs and preferences of the parents involved, advocating an approach of co-design or co-decision. A key element to note in this description of the community partnerships is that this decentralisation allows for community partnerships to recognise the differences between neighbourhoods (geographically) or communities (in terms of the local population) and that coproduction results in local differences. This recognition of the varying needs and desires of different communities is something which characterises the approach to co-production in England, but which is in many ways contradictory to the way in which participation and co-production are understood and put into practice in France. This notion will be discussed further in relation to narratives and coproduction.

As Lyon Parents is a representative organisation of cooperative nurseries, the involvement of parents is mainstreamed into every level of organisational governance and decision-making as a core tenet. Parents are involved in the governance of individual cooperative nurseries, in the board of trustees of Lyon Parents, and finally in the board and decision-making structures of the national level

15 Black and minority ethnic 
of the network. This widespread involvement in governance is in addition to everyday volunteering and involvement of parents in each crèche's activities, which will be discussed in relation to practices. The involvement of parents at all levels forms an essential part of how Lyon Parents is guided by rules.

"The action of [Lyon Parents] relies on the collaboration between parents and professionals, the acceptance and respect of diversity, the participation in local life and citizens. We propose activities that privilege a participative approach, associative life, the role of parents and the quality of children's services." (Brochure, Lyon Parents)

Similar again to the social centres' rules, Lyon Parents defines itself by its democratic and participative approach. This is defined even more explicitly as a collaboration between parents and professionals - suggesting that co-production is one of the key procedures for decision-making and action. While both Sheffield Parents and Lyon Parents present examples of parental involvement in governance and decision-making, the Lyon example is more formalised and demonstrates a stronger impact of the state logic, as the parent representatives are democratically elected and decisions are often made through voting. The community partnerships, in comparison, are characterised more by the community logic, which favours informal collaboration and negotiation between participants.

\subsubsection{Practices}

In general, I found that practices - i.e. "the way we do things" - were considerably easier to identify in Lyon Parents and Sheffield Parents than in the community regeneration organisations and social centres. This may be because the community regeneration organisations (particularly the larger of the cases) are responsible for 
running a large number of services and deliver numerous projects and activities. As such, the norms of behaviour may not have been uniform across the organisation, or the staff with whom I spoke may have chosen to express a more strategic, higher level narrative than the more routine day to day actions and activities. The identification of practices was clearer in the parents' organisations, where staff and volunteers provided rich descriptions of the unrecorded, informal rules that drive and constrain activities.

The descriptions of practices by Sheffield Parents staff were primarily associated with how toddler groups are organised and children's/family activities are run. The main focus of the programme is on setting up parent and toddler groups across three neighbourhoods in Sheffield, in order to fill the gaps left by the cuts to previous provision. These groups are initially organised by a paid member of staff, while another staff member trains and supports parent volunteers to become group leaders, with the intention of making the groups self-sustaining with only volunteer time and management. This approach rests on an idea of recognising existing assets within the communities and building upon these, rather than designing and introducing a completely new programme. Because of the reduction in the size of the project from the initial bid, accommodations were made to be more realistic about the scale and ambition. For instance, rather than building a new venue, Sheffield Parents has organised events and activities in existing facilities, such as churches and community centres. Interviewees framed their work and the aim of the project in terms of delivery of their objectives and of outcomes, although with a clear caveat that the project is aiming to provide qualitative improvements in reducing social isolation of parents, rather than focusing on targets and evaluations. 
Furthermore, Sheffield Parents takes a consciously informal approach to establishing relationships with parents, highlighting the centrality of the community logic in defining practices. In addition to the establishment of toddler groups, the project provides drop-in sessions, where parents can informally speak to staff members for advice and signposting, or take part in cooking, crafts and other family activities. Informal community engagement, which both staff members described broadly as speaking with local residents (or "with communities") as well as encouraging local people to take part in activities.

"I've gone and walked just around the community and talked to parents in the street, on the park, outside school. I've gone and chatted with them. They must think, 'Oh, there's a crazy woman coming towards me with a big smile,' and I've got my ID and I'm like, 'I'm not selling anything or whatever, I'm just telling you about a group. '”'(Staff B, Sheffield Parents) "Staff A: We engaged with 600 families before we started the three areas. And we continually engage obviously since that, since the start of the programme in September, our target is to engage 300 adults a year, who report that they feel isolated.

Interviewer: When you say 'engage' with over 300, what do you mean by engage?

Staff A: They attend sessions that we run." (Sheffield Parents)

The community logic, which "connotes the collective relationship between people that emphasize the interpersonal and particularistic" (Thornton et al., 2012, p. 52) is the clear driver for these practices, which are informal and flexible, focusing on proximity and local connections. The role of the state and market logics seem to bear 
little impact on the way in which staff go about their daily work and achieve project aims.

In comparison, in Lyon Parents, every description of what the organisation does or how things are done are enmeshed with the ways in which parents are involved, which again appears to blend the state logic of democracy with the more localised, relationship basis of the community logic. In many ways similar to social centres, coproduction is mainstreamed into the definition of Lyon Parents and as such, it forms an important part of all decision-making, which is always done in collaboration between parents and professionals. One may say that co-production is in fact the primary "informal rule of the game", which takes place because it is formally specified by rules.

"Participation being obligatory allows each person to participate, but we focus on participation that makes it possible for each person to participate, because not everyone has the same level of engagement or the desire to do things, or the availability, etc. What we say a lot in the network is that the more participation is diversified - i.e. that one can be president, one can be treasurer, one can lead an outing to a market, run a cooking workshop with children [...] The more varied the possibilities for participation, and thus the wider the diversity of audiences that is reached." (Senior Staff, Lyon Parents)

As discussed in relation to rules, parent participation is a formal requirement of Lyon Parents. In terms of practices, this plays out in several spaces, which are highlighted in the photo competition at the Lyon Parents' birthday celebration (shown in Figure 7.1). Attendees were asked to vote on the best photo that demonstrated 'parent and professional collaboration', which showed people playing 
music, going on field trips, sharing meals, chatting, etc. Another example of this multi-faceted approach to participation is shown in Figure 7.2, a board game developed to identify the needs and desires of parents in different parts of the region. Playing pieces were made by a local artisan, game questions were devised by local people, and game board photos are customised for each local area.

Within each cooperative crèche, parents are required to volunteer a certain amount of time each month in the crèche - such as providing snacks for the children, cleaning the childcare facility or supporting professionals in activities. Interviewees acknowledged that many parents who place their children in a cooperative crèche do so not because they are attracted to the democratic ethos, but rather because of convenience of location or other factors. As noted in the quote above, parents are however encouraged to participate beyond the required minimum of volunteering, in both participating or leading activities as well as in more strategic and decisionmaking roles. The importance of parent participation and the motivations behind it are a driving democratic and empowerment ethos, which will be discussed further in relation to narratives. 


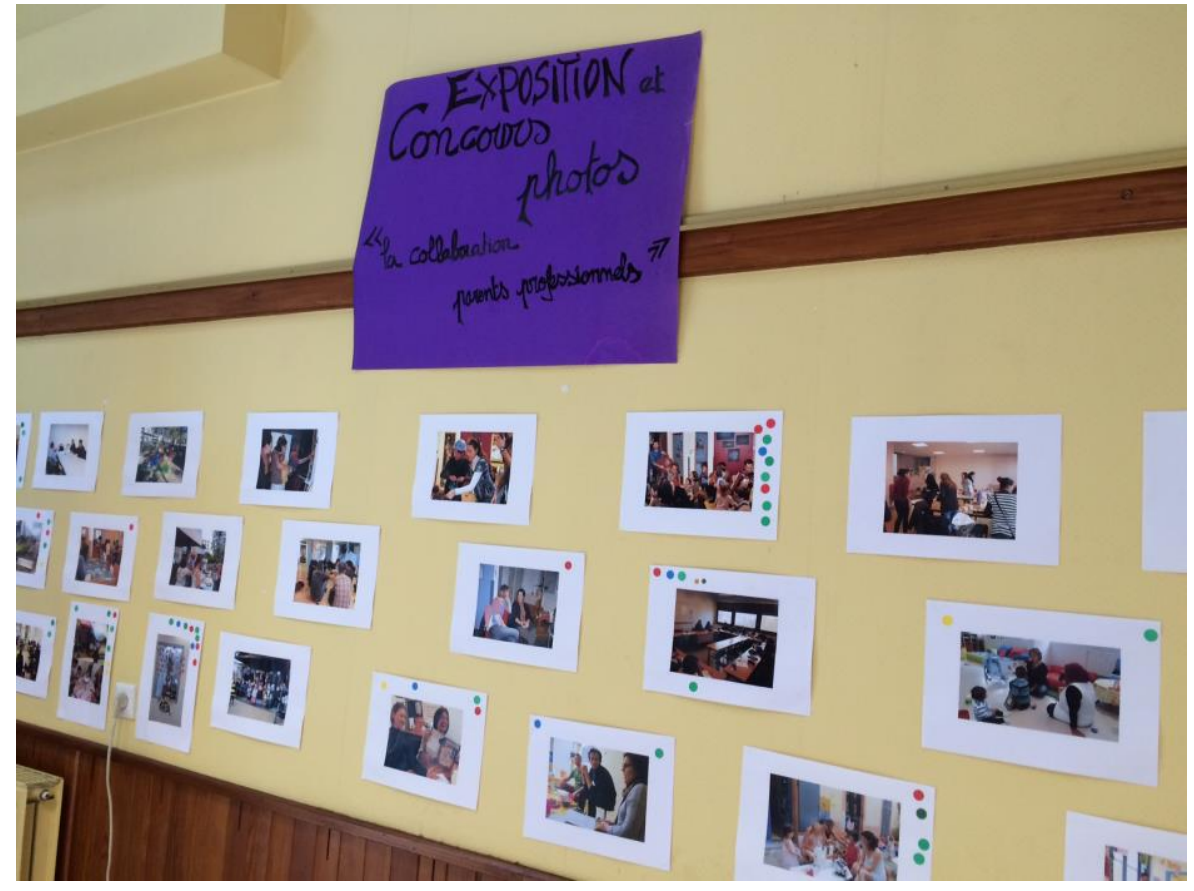

Figure 7.1: Photo from Lyon Parents birthday celebration "Photo exhibition and competition: 'parent and professional collaboration'”

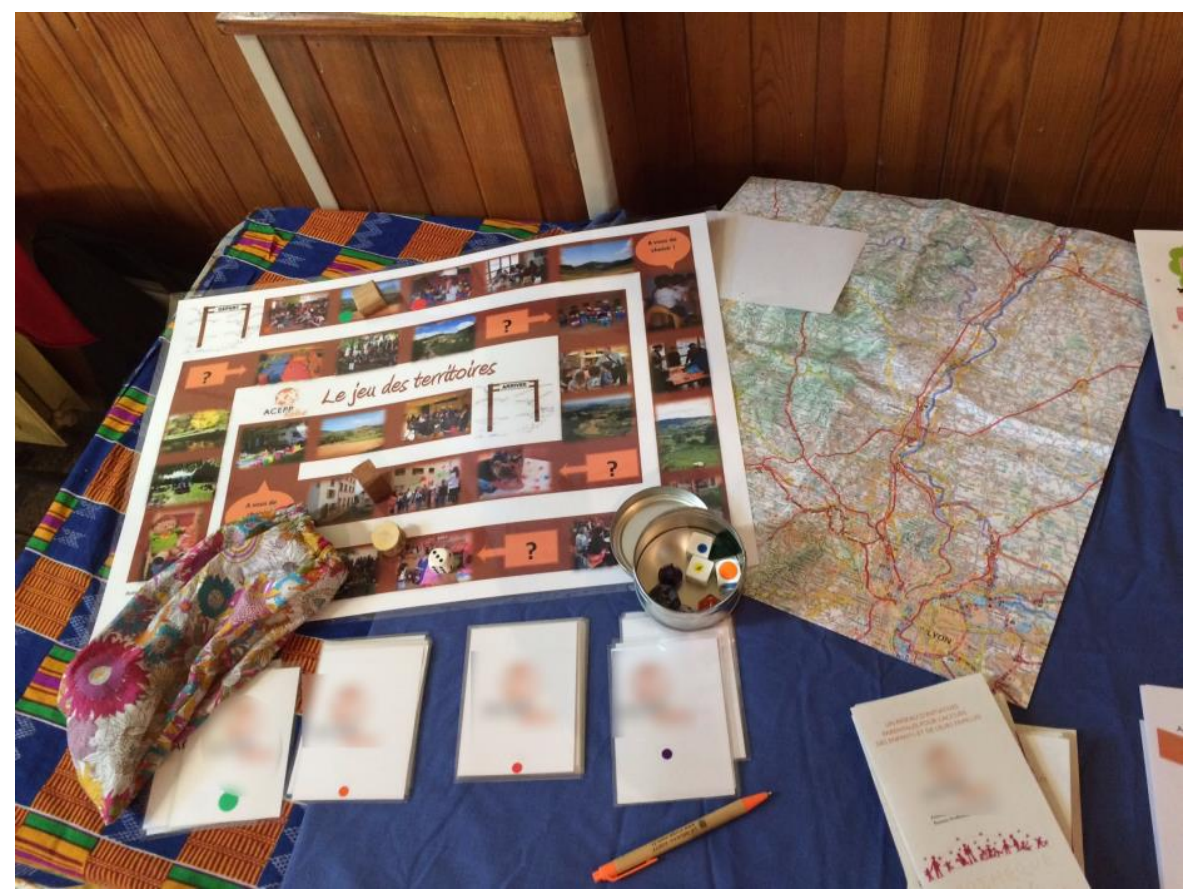

Figure 7.2: Photo of Lyon Parents 'participative diagnostic' game 
A key similarity between the practices of Sheffield Parents and Lyon Parents is the emphasis on supporting parents to make decisions about the activities they would like to run, and staff supporting them to run or deliver these themselves. Staff in both cities described events or activities where they provide support to parents, but that they hoped the parents would be able to take full responsibility in the future.

"They choose - it's often the mothers - they choose which theme they want to do [for a workshop]. For example, next week, there is a workshop to make gifts for Mother's Day and Father's Day. It's one of the mothers who is taking care of it. That is, I don't deal with getting the necessary materials; she takes care of it. She is there, and ultimately I don't even need to be there." (Staff, Lyon Parents)

"Then once they [volunteers] have completed that eight week training, we allocate them a venue and open up... Support them to open up a toddler group. So there's resource budget, there's rent for a year, and insurance for a year. What they get with that is support from the community earlyyears practitioner - there's one in each area that we've just taken on, just employed, and myself and [Staff A] as well. They get support from us to set up and work with them over the year to look at sustainability so that after the first year, they can sustain that group." (Staff B, Sheffield Parents)

Whilst the description of practices is relatively similar in both of these accounts the role of staff being to provide support and assistance for parents to decide what activities they want to provide and how, in order to do these themselves - there are latent distinctions between the rules and narratives that support or drive these practices. For Lyon Parents, 'supporting' parents in this way is linked to narratives of empowerment and citizenship, which is explicitly elaborated in one of Lyon Parents' brochures as "Parental involvement: A citizen act". Parent participation in 
childcare activities is framed as being about parents exercising their rights and developing themselves politically in order to promote and protect the role of parents.
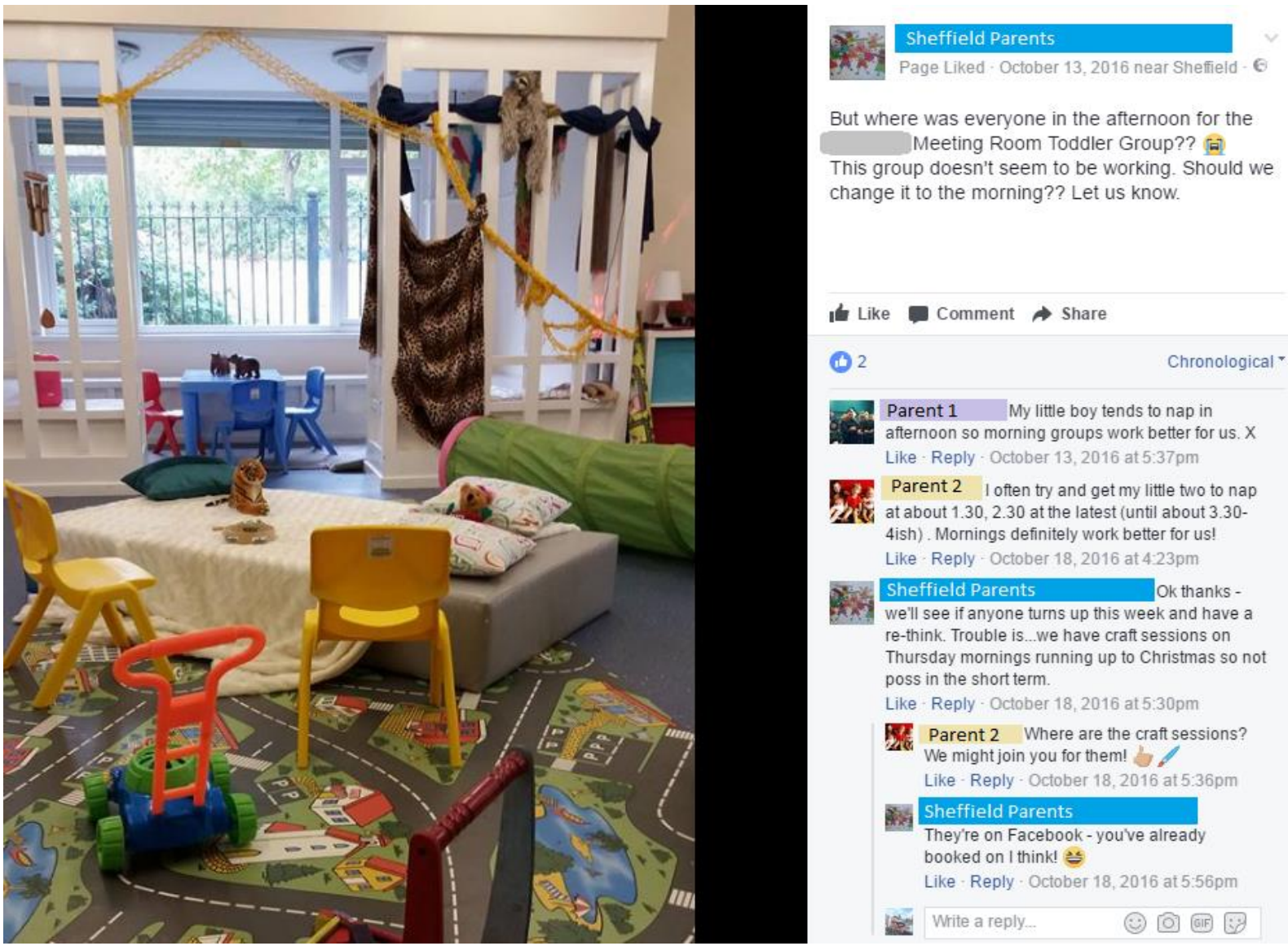

Figure 7.3: Sheffield Parents Facebook group - communication with parents

In Sheffield, parental involvement is very much tied up with the limited resources that the project has as its disposal - involving parents, particularly in co-delivery, is conceived as a pragmatic way to ensure that the activities can continue beyond the end of the contract. This is another demonstration of the way in which coproduction is impacted by the market logic, in that it is framed as a practice that makes business sense, improving efficiency and sustainability. The rules or 
limitations imposed by contracts act to both enable and constrain practices as far as co-production is concerned. Although the project's original aims have been curtailed because of cuts, this has also meant that staff have been more creative and resourceful in making use of the skills, expertise and time of parents in order to ensure the long-term sustainability of the parent/toddler groups and family activities. This means that parental involvement often takes a more ad hoc approach, such as engaging parents and soliciting quick opinions about projects through social media (Figure 7.3), rather than taking a more structured, purposeful approach.

In summary, in both of the children's services cases, involvement of parents in coproduction forms an important part of how things are done, but this is often framed more politically in Lyon and more pragmatically in Sheffield. This further confirms the conclusions I reached about the different institutional logics operating in each city in regards to the community regeneration organisations - in that the Lyon organisations blend the state and community logics, while the Sheffield organisations demonstrate an assimilation of the state, community and market logics. While there are clear differences in the formal rules that impact Lyon Parents and Sheffield Parents, with Sheffield Parents considerably more impacted by contracts and funding, and Lyon Parents exhibiting more formalised internal governance structures, there are considerable similarities in the practices of each organisation. Both promote a parent-centred approach whereby day-to-day routines are focused on supporting parents to become involved in activities, and to design and deliver their own projects. 


\subsubsection{Narratives}

In this section, I will analyse the non-material aspects of institutional logics and the ways in which these shape the motivations for and framing of co-production activities in Lyon Parents and Sheffield Parents. My analysis of these narratives aims to investigate the ideas and values behind co-production practices. Namely - what motivates each organisation to engage in co-production (or not)? What values guide these practices? Finally, what ideas or beliefs are linked to co-production?

At Lyon Parents, the narratives of staff members and volunteers demonstrate a clear, shared sense of identity and purpose that support a mainstreamed practice of parent participation throughout the organisation.

"At [Lyon Parents] we have three fundamental values, which we find in all our projects. The fundamental values are that the parent is the first educator of their child [...]. Our second value is the collaboration between parents and professionals around the child, and by extension, it has turned into activities like this one, that cooperation between citizens and institutions that take into consideration the child in the city. The third value is that family services, the places where children come for day care, these are first and foremost local places for social development - far from being centres for profit, centres that charge. It creates links between people; it creates networks of solidarity; it allows parents to be supported because they are no longer alone with their children but are now in a network. So we try to put that in practice everywhere." (Senior Staff, Lyon Parents)

Parent participation as a stated element of the organisation's defined values demonstrates the centrality of co-production to Lyon Parents. Indeed, without prompting, all of the Lyon Parents interviewees independently discussed examples 
of parent and professional collaboration in projects and various aspects of organisational operations. This collaboration is expressed as driven by an ethos that is based on empowering individuals as citizens and as parents to both exercise their democratic rights as well as to join together in solidarity - notions that are associated with both the community and state logics. Furthermore, this emphasis on parent participation was framed as a reaction against the previously discussed 'medicalised' approach to childcare provision, which essentially pitted this community/state logic against the incumbent professional logic of the 1970s-1980s. Like the social centres, the core values of Lyon Parents are explicitly codified in organisational documents, effectively meaning that the non-material elements of the logic (values, beliefs) become material rules by which professionals' behaviour is guided.

Another defining element of the values and identities of Lyon Parents is around helping to give parents a voice, and recognising and challenging traditional power structures. One of Lyon Parent's projects is around l'éducation populaire, 'popular education'16, a collective movement to support groups of parents in deprived areas to join together and research a theme related to parenthood, conducted with the support of an academic researcher. This project allows people and their lived experiences and expertise as parents to be valued as co-researchers. These research projects in turn were used to empower parents and support them to become active citizens and have a voice about the issues that matter to them.

16 In this context, 'popular' refers to 'working class'. 
"[In the cooperatives crèches], it's the parents who have the power. And here [Lyon Parents], it's the same - it's the volunteers who have the power. There are a lot of things that are internally managed, but when there's really a decision to be made, it's made by the volunteers. And the staff don't have the right to vote in those cases." (Volunteer, Lyon Parents)

"The idea of [popular education project] is how to give a voice on parenthood to parents themselves because we were saying a lot of things, usually produced by researchers, etc. But the voice of parents, we didn't hear it, it was imperceptible... That's the question - how do we support a voice, a position that's sufficiently audible so that politicians and institutions start to recognise something? The [project], at the same time as the parents lead the research, they lead what we call citizen actions - they participate in a certain number of events to talk about their projects, talk about the research that they lead, etc." (Senior Staff, Lyon Parents)

This project again shows the politicised framing of co-production held by Lyon Parents. Rather than simply viewing crèches as a place where parents drop their children during the day, childcare and children's services are reconceptualised as a way to join parents together to assert their rights and responsibilities and gain confidence in this role. While the interviewees at Lyon Parents did not use the word 'empowerment' (which was something that arose as important for some of the social centre respondents), this notion was expressed several times in terms such as "capacity-building" and "supporting citizenship" (Senior Staff, Lyon Parents). The shared identity and driver of Lyon Parents staff then is to act to support parents to gain confidence, skills, and power. 
For Sheffield Parents, the primary ideas and motivations expressed through narratives are considerably less political and more directly influenced by a local community logic. There was comparatively little discussion about what values motivate a focus on parent participation or co-production. Similar to what was found in the community regeneration organisations, the primary narrative expressed by Sheffield Parents staff, and in project documents, is one dominated by explanations of day to day practices, rather than values and beliefs that underpin those. The logic of Sheffield Parents is therefore more pragmatic - with a focus on meeting needs, achieving goals and filling gaps in service provision in identified communities. As part of this, community engagement was frequently discussed as a means to this end.

"We'd said that our programme was designed out of the community engagement and what came out of that, they [funder] said that that is very unique across the country of what they've seen. It's quite a unique way and so it's a unique programme. [...] This is what a lot of organisations don't get. They know that that's common sense, but they then have their own ideas of, 'Well, we think this is what you need,' and go in and do it. It doesn't work. That's been proven with the children's centres, with what they've said." (Staff B, Sheffield Parents)

'Community engagement' as a central narrative (which, as discussed in relation to practices, was often slightly opaquely defined as having informal discussions with local people) is seen by staff as a way that Sheffield Parents is differentiated from other providers, argued to be overly driven by a professional logic, while Sheffield Parents identifies more with the community logic, prioritising trust and relationship-building in each local area. Despite probing, it was often difficult to 
ascertain the degree to which this sort of community engagement meets my definition of co-production or whether it is more in line with traditional notions of consultation, where professionals remain the primary decision-makers. However, as a narrative, community engagement is a key value of Sheffield Parents and defines the way that staff see their roles and purposes in relation to local people.

Co-production for Sheffield Parents also acts as a way to best address the needs and desires of particular communities within the city of Sheffield, promoting the idea that "one size does not fit all" (Staff A, Sheffield Parents) when it comes to service provision. The project operates groups in three different deprived neighbourhoods of the city, and it is implicitly expected that engaging with local parents and having parents active in each of the three community partnerships will lead to the design of different types of services and projects in each locality. For instance, each community partnership is allocated a small budget which they can use for a project of their choice, taking consideration of the differences between the community populations of each locality - ranging from looking at food poverty in one area to a focus on the parenting skills of BME families in another area. This recognition of community difference and the way that co-production with local people can lead to very different emphases and outcomes is notable because of the contrast it provides with the case studies in France, where community is seen as a negative term and participation is meant to strengthen similarities between different areas rather than celebrate differences. In Sheffield, we see that the community logic, with validation of group membership, is strong in defining these ideas, beliefs and values. 
One of the narratives that is common to Lyon Parents and Sheffield Parents is the importance of recognising parents "as the first educator of their child", framing parent and professional collaboration as a way to promote the value of parenting, and valuing parents as 'experts by experience'.

"These are their children. They're not our children. They are the professionals when it comes to their children. They understand what their children's needs are and they understand what their aspirations are for their children. We have no right to come in and tell them how they should be doing it. We can give information and lead by example, but I don't think we should disempower and I think that's what we did before." (Staff, Develop).

"At [Lyon Parents], we have this well-known phrase, that parents are the first educators of their children. And it's highlighted in the cooperative nurseries and highlighted throughout [the organisation]." (President, Lyon Parents)

The importance of these statements is that both Lyon Parents and Sheffield Parents adopt an approach that values the expertise of parents, and sees them as assets - an idea that is argued in much of the literature on co-production. Bovaird and Loeffler even take this idea so far as to define co-production as "The public sector and citizens making better use of each other's assets and resources to achieve better outcomes or improved efficiency" (2012, p. 1121). This narrative of co-production is premised on the idea that service users should be seen as 'experts by experience' and that services should be decided and done with users, rather than to them. In relation to children's services, this idea was reflected in the narratives of professionals in both Lyon and Sheffield but with, again, a more political slant to the Lyon conceptualisation than in Sheffield. While both quotes above exhibit that the 
organisations derive some value from the family institutional logic, Lyon Parents' discourse around recognising parents' rights is also driven by a blend of the state and community logics, while in Sheffield in this instance the community logic prevails.

\subsection{Institutional logics and co-production: Older people's projects}

As outlined at the beginning of the chapter, Lyon Older People and Sheffield Older People are both projects with the primary aim of reducing loneliness and isolation of older people in their respective cities. This coherence of purpose between the two projects allows for a rigorous theoretical comparison of the ways in which institutional logics drive behaviour within the organisations involved in each project, how the projects are shaped and differentiated, and the role that coproduction plays (or does not play). With both projects, there are two levels of analysis to take into consideration 1) the level of the city-level network in Lyon and the grant-holding organisation in Sheffield, and 2) the level of the associations/ community organisations involved in each project (as signatories for Lyon and as sub-contractors for Sheffield). I continue to analyse the ways that institutional logics impact co-production activities through evaluation of the rules, practices and narratives for each project, being mindful of these two levels of analysis.

\subsubsection{Rules}

Lyon Older People is conceived as a social movement, which would typically be defined as a citizen-led mobilisation to engage in collective action in support of a 
cause, with a shared collective identity among participants and a common opponent (often government) (Della Porta and Diani, 2006). Using this definition, Lyon Older People as a social movement is a bit of an anomaly. The project was initiated by a government minister, who established a working group to discuss the issue of older people's isolation across the country. The working group then developed a charter, to which associations, mutuals and other actors in the field of older people's services could sign, promising to take part in the movement to tackle loneliness and isolation amongst older people. In a clear manifestation of the state logic, the mobilisation was launched to coincide with the preparation of a law on the 'adaptation of society to an ageing population'. The guiding aim of the 'movement' is to increase collaboration and cooperation between associations which work for older people, but the logic guiding its establishment demonstrates a uniquely French understanding of the relationship between civil society and the state: even a social movement, which is typically grassroots-led and characterised by a fluidity of organising principles, is defined by the rules of a formal, legalistically-defined charter.

Because this notion of signing a charter in order to start a social movement or the cooperation between associations seemed an unnatural concept to me, coming from the UK, this was something I probed the Lyon interviewees on - asking why associations would sign the charter, and what signatories would be required to do (if anything) as a result:

"Really, it involves them in doing actions, making the network [Lyon Older People] known, motivating the citizen teams." (Regional representative, $L O P$ ) 
Another interviewee indicated that signing the charter helped create links between associations and public powers and open new doors to communication. When I suggested that signing a charter would not be the way to initiate these kinds of partnerships in England, she responded, "Yes, it's cultural" (Staff, LOP Organisation 3). This notion of signing charters and codifying values was also evident in the social centre case studies and Lyon Parents, which provide some of the rules that define each organisation's driving logic. Unlike the social centres, Lyon Older People does not explicitly elaborate the importance of citizen participation or co-production in its charter. Rather, signatories agree to "participate in the support and deployment of '[Lyon Older People] citizen teams', respecting their choice of membership" (Charter, Lyon Older People). The wording of the agreement allows for flexibility in how associations interpret and translate these rules into practices, which will be discussed in the following section about informal practices.

The external rules that constrain Sheffield Older People and define the way in which they involve people in decision-making and service delivery are derived in part from expectations of the project's funder. Sheffield Older People is impacted in much the same way as Sheffield Parents and some projects run by the community regeneration organisations in taking an approach of co-production because it aligns with the rules or guidelines set by funders. In many ways, the expectation that services will be co-designed and co-delivered is a perception of a rule, rather than a rule itself - Sheffield Older People wrote their bid using the language of coproduction because they knew that their funding organisation favoured those types of practices and narratives. 
“Grant funding from people like the Department of Health, Public Health England, so national grant funders, Big Lottery, people like that are a lot hotter on it [co-production], get it and ask for it in their bids. Where we're looking at other kinds of funding, so typically local authority, longer term contracts for things like a floating support service rather than a grant funded new project... [...] there may occasionally be a question on probably personalisation, not co-production." (Senior Staff, $S O P C)$

Sheffield Older People has taken the approach of mainstreaming co-production throughout the entirety of the project. The grant holder (SOPC) sub-contracts smaller older people's projects and services to third sector organisations across the city, and it then imposes its standards and procedures of co-production upon the sub-contracted organisations. At this level, projects being fully co-design and codelivered with older people was established as a formal rule.

"The main other co-production we've done for [Sheffield Older People] so far is all the different delivery partners are going to be co-designing absolutely everything they do. So they've all come up with action plans, co-production action plans. So it's just got exactly what it is they want to do, so their co-production objective; the actions that they need to do it, who's going to be responsible, how they're going to evidence that they've done it and when they want to do it by." (Staff B, SOPC)

This rule can sometimes come into conflict with the more informal and flexible dayto-day routines or practices that some third sector organisations favour. For example, in a quote that was discussed in relation to the community regeneration organisations, when Sheffield Older People tendered for contracts around the city, they specified that the programme/project needed to be completely co-produced, but at the same time expected organisations to outline exactly what it would look 
like before it began or any co-design with citizens could have taken place. The fluidity of co-production as a notion means co-production as a rule is problematicit is difficult to define what qualifies as co-production, and therefore what does not qualify as co-production is equally challenging to pinpoint. Rules are sanctioned by "coercive action through formal rewards and punishments" (Lowndes and Roberts, 2013, p. 53), but unless actors can define the terms and perimeters of a rule, it is unenforceable.

In comparing the rules discussed by Lyon Older People and Sheffield Older People, some differences in the dominant institutional logics that drive third sector organisations in each country arise. In regards to Lyon Older People, there is a large degree of consistency with the social centres and Lyon Parents insofar as the state logic provides a strong influence on the rules that professionals describe as guiding and constraining their actions. Throughout the Lyon organisations and projects, there is a reference to laws, government policies and legalistic formulations of rules such as the aforementioned charters which form an important organising force for many third sector organisations. The state norms of bureaucracy and hierarchy as means to protect the public good are highly influential in shaping the logic of third sector organisations in all three of the service sectors investigated. In Sheffield, the older people's project is a bit of an outlier in that it was the only project or organisation studied that not only explicitly and regularly used the word coproduction to describe their activities, but made co-production a formal rule to be applied throughout the project. This is partly attributable to an attempt to meet a funder's expectations (consistent with findings of rules in other organisations in 
Sheffield), but Sheffield Older People is unique in translating this rule to an internal rule across the organisation.

\subsubsection{Practices}

There appear to be some similarities between Lyon Older People and Sheffield Older People's practices at a strategic level, in terms of the way respondents described how the projects operate. Equally important for both projects is the practice of working in partnership with other local third sector actors and public powers. Initiating partnerships and networks between third sector organisations and other actors within the field of gerontology is a main tenet of Lyon Older People, and partnership between organisations was often discussed as part of the way the project frames its understanding of involvement and cooperation. In practical terms, Lyon Older People has established a local network through inviting interested organisations to sign the charter, and through organising a series of formal meetings, events and roundtables to link third sector organisations together. This type of collaboration occurs at the level between organisations, however, rather than between professionals and citizens themselves, and does not therefore meet my definition of co-production. The reliance on formal meetings and official procedures to establish the project reflects the degree to which the state logic, with its emphasis on hierarchy and bureaucracy to ensure social protections, permeates the third sector in Lyon. This is evidenced as well in that several of the individuals who I interviewed argued that collaboration was a relatively foreign practice within the third sector, and that creating this partnership around a shared goal (defined in the charter) of fighting older people's isolation seemed relatively innovative. 
Individuals in both cities also discussed undertaking asset mapping, or identifying projects, services and activities that are already taking place, as well as enabling easier identification of potential volunteers. Professionals involved with both projects described aiming to avoid duplication of provision by conducting mapping exercises of organisations or projects operating in the area that are already working to tackle loneliness of older people. For Lyon Older People, this is a central aspect of the project's practices as it enables them to identify key areas where there is a need to introduce 'citizen teams' to be mobilised to support lonely older people.

"We're actually going to get older volunteers to go out and map the area and decide what assets the area has got, where we can hold our different [Sheffield Older People] activities. Everything that we're going to do in the area, they're going to decide where it's done." (Staff B, SOPC)

"We drew a map... It's both about mapping and statistics. In fact, we mix the two, which makes it possible to know if in a certain place there are things going on to fight isolation or not. In fact, the idea we had is that once our map is filled, we can see where there's nothing happening. There are two hypotheses: either there is really nothing, or there are things happening but people haven't turned up because... When we send questionnaires, if people don't fill them out, we don't know if something is happening, but in that case, it's okay." (Regional representative, LOP)

For both projects, mapping was also framed in terms of valuing the expertise and experience of citizens and local groups that are already working towards the same aims. For Sheffield Older People, this effort was also used as a way to understand the differences between various communities and ways in which activities could be targeted to specific ethnic or religious minorities predominant in certain neighbourhoods, allowing interventions to be specifically targeted. 
"When we did some things with BME communities, we did some work with Afro-Caribbean community where we had a bit of a kind of jamboree event and we had lots of food, really energetic, active, open doors in this big building, lots of people coming in and out, really busy and interactive. But then we did another event with South Asian community where we did kind of a men's event and a women's event, very quiet, people took it in turns to speak individually. Very different approaches that we needed to do to understand their communities." (Senior staff, SOPC)

Many of Sheffield Older People's practices designed to involve older people in codesign and co-delivery are oriented more towards individual co-production, rather than group or community co-production. Co-production is framed by staff members as "taking a person-centred approach" (Senior staff, SOPC), which translate into practices that emphasise the individual collaboration between professionals, volunteers and/or isolated older people. For example, one of the key streams of the programme is a peer mentorship project, where older people who have previously experienced loneliness and isolation are paired with individuals who are currently feeling isolated or "at risk of social isolation" because they have "a big life event coming up or it could be something's happened, like the death of a loved one or retirement or end of carer responsibilities." (Staff, Enterprise).

"They (volunteers) will be able to sort of work with them to sort of draw in their own experiences of social isolation, so how they got out of it, what helped them, so it might be sort of just being there to listen, offer advice. But ideally, it would be to kind of go out and develop support networks for them, get them a bit more involved in activities, so give them the confidence and the skills that they need to be able to kind of 
get out there and start being able to do things on their own a bit more." (Staff, Enterprise)

This one-to-one or personalised approach taken in the programme's mentorship and befriending projects is echoed in the efforts to co-design interventions. A document outlining a 'co-production action plan' (which Sheffield Older People requires its sub-contracted organisations to produce for each intervention) demonstrates a clearly delineated approach to how individuals will be involved in various processes of the project, and which individuals will be targeted. One staff members explained that this approach to co-design goes so far as to seek out individuals in their homes.

"Then to reach the most isolated, we've done work on a one-to-one basis. So I went and saw an old lady who's had to have a hip replacement. [...] So it's people like her that [Sheffield Older People] really needs to work with, so by actually travelling to her house, we wouldn't have been able to get her opinion and her experience. So by going to see her, we've made sure that she's included in the co-design of [Sheffield Older People]." (Staff B, SOPC)

This type of personalised approach is a reflection of the changing landscape of public services in the UK, where personalisation constitutes a 'valence' issue, where all parties agree that services should be tailored for each individual service user (Needham, 2011). The move towards personalisation of public services indicates both the influence of a market logic of public service procurement and design, where providers are encouraged to treat service users more as customers, as well as the state logic, valuing service users as citizens and designing services to produce better outcomes for them. 
For Lyon Older People, the focus of participation and involvement takes a more societal, larger-scale approach, focused on forming groups of citizens that share the same national-level goal. Aside from the agreement of charter signatories to work towards this goal, the day-to-day practices of each of the constituent organisations is not controlled by Lyon Older People, and thus their practices in regard to involvement and co-production differ. For my fieldwork, I spoke to staff members at three involved organisations - a small local association, a housing association and the local branch of a large, national charity. Given the variation in organisational size and types, it is perhaps unsurprising that there are disparities between the practices described by staff members. The two staff at the small association described an approach of informal day-to-day consultation and reliance on volunteers to help design and deliver services and activities, while the interviewee at the large housing associated discussed a number of EU-funded social innovation projects that her organisation was involved in, such as working with older people on digital literacy. It was thus difficult to identify any consistent themes across the practices of the Lyon Older People organisations.

\subsubsection{Narratives}

As discussed in Chapter 4 and Chapter 6, when I originally designed my participant information sheet and explained to interviewees what my doctoral research was about, I explained that the topic was about co-production and the third sector. However, after a few initial interviews using this approach, I realised that including the word 'co-production' in my explanation often led people to describe their work 
in particular ways in order to meet what they interpreted my definition of coproduction to be. For example, one of the community regeneration interviewees stated, "So we do this customer survey. Sometimes we do specific, more consultation activities and I can call them co-production if it helps. We'll talk about co-production, because yeah..." (Former director, Leisure). In order not to lead interviewees to adopt terminology of co-production that was unnatural for them, or to describe their participation activities as co-production in order to appear more innovative, I revised my participant information sheet to be more general, and explained that I was interested in service user or resident 'participation' or 'involvement', and allowed them to interpret what that meant to them.

Given this conscious change in my own language, it is worth noting that respondents from Sheffield Older People were the only interviewees to independently use the word co-production without being prompted. Taking a co-productive approach forms a significant portion of the narratives of Sheffield Older People staff (and respondents from other involved organisations when speaking about Sheffield Older People). The entire identity and purpose of the project is grounded in an idea that every aspect of it will be co-produced with older people who have themselves experienced loneliness and isolation.

"The main reason that we've got someone specifically for this job known as co-production coordinator is because, I'm sure [staff member] has explained to you, but when we put the funding in for [Sheffield Older People], we went with a massive co-production angle. So we said everything we do is going to be co-designed, co-delivered, co-evaluated, because of this. It's going to be better. We're going to do it better than 
anyone else can do it. So that's one of the main reasons, if not the main reason, that we received the funding from the [Funder]." (Staff B, SOPC)

Co-production is so central to the narrative and values of Sheffield Older People that several jobs have been created with 'co-production' in their title, as described by this staff member. The description of "everything being co-designed, co-delivered, co-evaluated" was common to the three Sheffield Older People staff members who I interviewed, indicating that this word and notion has clearly been mainstreamed through organisational discourses, rather than remaining within the rhetoric of directors and senior staff, which appears to be the case in some community regeneration organisations.

There are several concepts to which co-production is discursively linked within Sheffield Older People, helping to explain the values and beliefs that underpin this idea and practice. Many of these are consistent with the findings from the cases in the community regeneration and parents' sectors, such as valuing services users' expertise and providing services that are more tailored to the needs and desires of participants. A narrative that commonly arose in discussions with Sheffield Older People staff was the notion of co-production being about assuming risk and taking a 'test and learn' mentality. This type of discourse was only drawn upon by two other interviewees (one from Sheffield Parents, and one from Leisure). For Sheffield Older People, taking an approach of co-production means recognising that not everything will work, accepting this, and learning from mistakes to better design programmes in the future. Interviewees described this ethos as allowing them a greater degree of freedom to do things differently. Finally, as expressed in the quote in the previous paragraph, staff believe that co-production is necessary in order to provide "better" 
services, which is generally linked with being more "person-centred" and delivering what older people want, rather than what professionals believe they need.

However, this attention to co-production is not without its critics, and some individuals from other organisations involved in the project did not feel it resonated with them as a concept.

"If you'd come here about six months ago, I would have gone, 'Coproduction! Wow, that's really interesting. That's really good fun' But sadly, [SOPC], they bang on about co-production every five minutes and everybody across the city that's got a contract with them - and that's quite a few organisations - is absolutely sick of hearing it. Especially because, and I mean no disrespect to anybody at [SOPC], we get on really well with them and they're trying very hard, but when they first put out the tender spec, probably six, eight months, maybe a year ago now, and it talked about co-delivery and co-production, I don't think they actually understood what they meant themselves what they were looking for." (Director, Aspire)

This quote demonstrates the ways in which narratives may conflict with or contradict the preferred language of an organisation, or its day-to-day practices. Whilst the stories told by Sheffield Older People staff are overwhelmingly about coproduction and the importance of involving older people in the design and delivery of all projects and services, there is some scepticism by other actors about what this actually means, and whether the practices live up to the rhetoric. This theme of a divergence between the vocabulary of co-production and how professionals understood their work arose across Sheffield, but came into particular focus as Sheffield Older People was the only organisation to readily use the term coproduction to describe their approach. Several frontline staff (three of the four from 
community regeneration organisations and one of the two from Sheffield Parents) were either completely unfamiliar with the term co-production, or recognised it but felt unable to define it or were uncomfortable employing it to describe their practices.

In Lyon, the individuals interviewed in relation to the older people's project did not employ language related to co-production - although one respondent did explain that they would tend to use the term 'co-construction' - which is consistent with all of the French cases. Because Lyon Older People is a network rather than a programme or project itself, there are two levels of narratives - those at the network/ strategic level, and those of the signatory organisations themselves. These associations are independently responsible for designing and delivering their own projects and services to reduce isolation of older people and can thus speak more to the co-production with citizens. For the three respondents who are directly involved in facilitating the mobilisation of the network locally, the primary narrative was around forming partnerships and relationships, as well as improving cooperation between associations and public bodies, and between associations themselves.

"The main objective of [Lyon Older People] is to recruit volunteers, it's to ensure that there is a larger network of volunteers, mobilised on this prevention of isolation of older people. That's the aim. On the other hand, in the process we are far from co-design at the moment - we are more focused on the support of existing associations." (Staff, LOP Organisation 1)

The way that involvement is conceptualised by the actors involved in Lyon Older People is more about cooperation and collaboration of citizens (who are, implicitly, 
volunteers for community groups and associations), as compared to the type of coproduction that Sheffield Older People advocates whereby professionals co-produce services with older people - the service users - themselves. In other words, Lyon Older People valorises collective co-production and Sheffield Parents consists more of activities of individual co-production (Brudney and England, 1983). In Lyon, there was an admission by two of the interviewees that involving lonely older people in the design and/or delivery of the interventions of Lyon Older People organisations was not a particular aim or priority, aside from the fact that many volunteers and activists do tend to be older and retired.

"What I would say is that in France, we are very focused on the question of ageing in relation to the loss of autonomy and dependence. In the Anglo-Saxon world, you are more about 'empowerment', it seems to me. It's not quite the same way of looking at things." (Staff, LOP Organisation 1)

Because Lyon Older People is conceived more as a common cause under which associations who are already working to fight older peoples' isolation can unite together, it does not have one uniform narrative in relation to whether or how coproduction with citizens is undertaken. Indeed, the intention is to allow for flexibility in terms of how local associations interpret the mission and operationalise it into concrete practices.

"In fact, [Lyon Older People] is not very hierarchical. It's a mobilisation, so it means that it's citizens who must take up the action and who create their team. A team can be, I don't know, five or six people who visit... But each can have their own range of actions. It's not necessarily... it can be 
variable. It depends on the people that will mobilise and their time."

(Regional Representative, LOP)

Interestingly, this narrative contradicts much of what I deduced from the French case studies. One of the themes that arose from most of the analysis of organisations in Lyon was the fact that the French state logic discourages the notion of differentiation between communities, meaning that the 'community' logic appears to be more of a translation of the national state logic into local contexts. French republicanism promotes a uniformity of the values, cultural beliefs and norms that constitute the narrative aspect of institutional logics. As such, co-production or involvement activities which explicitly accept that a variety of outcomes will arise or that some communities may hold different values than others is generally viewed with suspicion. The description of locally based citizen teams working for Lyon Older People is therefore uncharacteristic of the typically formalised and hierarchical and controlled approach that most of the interviewees in Lyon described. However, the fact that a national level 'social movement' exists to promote these values and aims of reducing older people's social isolation in local areas is consistent with the French republican state logic.

\subsection{Conclusions}

This chapter has considered the findings from two further sub-sectors of activity to complement the analysis of the community regeneration and social centre case studies in Chapter 6. Parents' organisations and older people's projects were chosen in order to ensure that themes that emerged from the comparison of the community 
regeneration organisations and social centres were not unique to this particular sub-sector of the third sector, and to see whether or not the analysis of coproduction using an institutional logics framework could be applied to other types of services or projects within the third sector. In focusing my case selection to one city in each country, this has also allowed me to draw some conclusions about how these logics are culturally and contextually specific. The analysis demonstrated that the themes that emerged in Chapter 6 were relatively consistent with the findings from Sheffield and Lyon Parents, as well as to a lesser degree with Sheffield and Lyon Older People.

A theme emerges in comparing the French and English organisations across the three sub-sectors. In Lyon, the overarching narratives used to describe their organisation or project are about what 'we' believe in - why the organisation or project exists, and what founding values and objectives unite members. In Sheffield, the narratives are focused more on what 'we' do and how these things are done focusing more on the services that are provided, projects, and the organisation's approach to undertaking these. This is nowhere more evident than in comparing Sheffield Parents and Lyon Parents, and again relates back to the difference in approach to and narratives about co-production. As Sheffield Parents (similar to the community regeneration organisations) self-defines according to what it does and how parent participation forms part of this approach - focusing on how parents can contribute to the overall functioning and outcomes of the project. Lyon Parents, on the other hand (again, in line with the findings from the social centres) prioritises its three founding values in describing what the organisation is about. Coproduction with parents is a central aspect of this self-identification and therefore 
takes place not in order to meet some other aim or goal, but because it is a central mission in and of itself.

This finding of 'what we believe' versus 'what we do' will be explored as part of the interpretation of the findings in the next chapter. I critically analyse the empirical findings and discuss the theoretical implications of the research, including critically assessing the usefulness and applicability of the analytical framework, which allows me to develop models of institutional logics and co-production that help us to better understand the similarities and differences between the cases. 


\section{CHAPTER 8: MODELS OF INSTITUTIONAL LOGICS AND CO-}

\section{PRODUCTION}

\subsection{Introduction}

In Chapters 6 and 7, empirical evidence was presented that relates to the institutional logics - operationalised as rules, practices and narratives - that drive decision-making and actions within third sector organisations and how these thence determine organisations' approaches to co-production. The analysis in Chapter 6 focused firstly on community regeneration organisations in Lyon and Sheffield as the primary cases for analysis, which was followed by a further investigation in Chapter 7 of comparator organisations delivering projects for 1) parents/ children and 2) older people, as a way to assess the conclusions drawn from the community regeneration organisations analysis and determine the degree to which these theorisations are more broadly applicable. The purpose of this chapter is to analyse the themes that arise across the cases, continuing the international comparative perspective, and locating these findings within the analytical framework. The chapter therefore aims to present a theoretical model of the ways in which varying combinations of institutional logics in the case study organisations in Sheffield and Lyon serve to define two distinguishable narratives and approaches to coproduction. This model and evidence aim to challenge assumptions made in both 
the institutional logics and co-production literatures that have a tendency to neglect differences between international contexts.

\subsection{Reconceptualising institutional orders}

Returning to the concept of institutional logics discussed in Chapter 3, we are reminded of the main institutional orders, conceived by Thornton et al. (2012) as the family, religion, state, market, profession, corporation and community. Each institutional order is said to have characteristics that are universal across Western societies, defined by a particular set of values, beliefs, identities, rules and practices. This study focuses primarily on the state, community and market logics, for reasons elaborated in Chapters 3 and 4. However, in order to adapt these abstract ideal types for comparative empirical research, it is necessary to reformulate them to account for contextual differences. In this section, I explain the differences between the state and community logics identified in England and France and the way in which a universal application of a singular definition proves problematic in accurately describing the driving logics at the field and organisational levels. While the community and market logics described in the institutional logics literature are consistent with what was observed in the English cases, the community logic requires some reformulation to be applicable to the French cases. In addition, the two countries exhibited variations of the state logic that will be typologised. This is followed by an elaboration of my model of the two unique combinations of logics identified in each context and the ways in which these drive and shape approaches to co-production. 


\subsubsection{State logic}

As discussed in Chapter 3, the state logic has been defined in multiple ways in previous studies. Friedland and Alford (1991) demarcate a 'democratic' logic, which emphasises popular sovereignty and citizen participation, and a 'state' logic, which is defined more by hierarchy, public administration and bureaucracy. Thornton et al. (2012) challenge this categorisation on the grounds that 'bureaucracy' is a characteristic that can equally define other institutional orders (such as corporations), and that 'democracy' is a particular ideology and therefore a variable to describe states or governments, rather than its own institutional order. In a different distinction, Greenwood et al. (2010) qualify between a highly centralist state logic and a decentralised, regional state logic, in the case of different historical periods in Spain. Aside from these two examples, most studies on institutional logics use one overarching definition of a state logic. However, the majority of research examining the impacts of institutional logics focus on one particular country (and usually one or a small number of organisations within that country context), removing the necessity to be sensitive to variations in conceptualisations of the state as institutional order and the logics arising from this. 
Table 8.1: State logic

\begin{tabular}{|l|l|}
\hline & State \\
\hline Root metaphor & Redistribution mechanism \\
\hline Source of legitimacy & Democratic participation \\
\hline Source of authority & Bureaucratic domination \\
\hline Source of identity & Social \& economic class \\
\hline Basis of norms & Citizenship \\
\hline Basis of strategy & Increase community good \\
\hline
\end{tabular}

Source: Adapted from Thornton et al (2012)

The elements that Thornton et al. (2012) identify as distinguishing the state logic (Table 8.1), such as the importance of democratic participation and citizenship, are universal characteristics of the state as institutional order in the contemporary West. However, a greater level of contextual specificity is required to operationalise the notion of the state to determine a state logic. France is defined by a republican ideology, whereby the State is a strong central authority which exists to protect the values of the Republic and to promote the general interest. This differs from the Anglo-Saxon, or 'no-state' tradition (Bevir et al., 2003) where there is no legal basis for the state and it exists only as a result of a contract with society. Furthermore, additional differences between notions of the 'general interest' or 'public benefit' divide the state logics of England and France. The French conception of the general interest is considered to be a theoretical construct protected by the state, which is superior to the individual interests of citizens and transcends partisan preferences (Bacqué and Gauthier, 2011). This is contrasted with the Anglo-Saxon concept of 
'common good', which can be seen as a negotiation between numerous competing individual and/or group interests.

Considering institutional logics as rules, practices, and narratives, it becomes clear how these variables or elements of the state logic may differ considerably from country to country. For instance, the state logic in France is far more informed by the importance of rules and legality to determine appropriate action, while in England there is more acceptance of 'rules-in-use' or more informal practices. The values, beliefs and assumptions associated with the state logic also vary, particularly as concerns the strategy of 'increasing community good', which will be elaborated further in the next section on the 'community' logic.

\section{Table 8.2: Revised model of state logic}

\begin{tabular}{|l|l|l|}
\hline Rules & Anglo-Saxon state & Napoleonic State \\
\hline Practices & Common law/ contract & Constitutional law \\
\hline $\begin{array}{l}\text { Narratives } \\
\text { (values, beliefs) }\end{array}$ & $\begin{array}{l}\text { Public benefit as } \\
\text { negotiation of individual } \\
\text { interests }\end{array}$ & $\begin{array}{l}\text { State as protector of general } \\
\text { interest }\end{array}$ \\
\hline
\end{tabular}

The Anglo-Saxon state and Napoleonic State outlined in Table 8.2 (recognising the French State as a proper noun but not the British state) represent two subcategories of the state logic that account for the differences between each country's particular administrative and government traditions. These two variations create different applications of co-production, as observed in the case study organisations, in the ways that the third sector (as organisations) and citizens (as individuals) 
understand their relationship to the 'state' or to 'government' and what the available and appropriate spaces for participation are. The ways in which third sector organisations are driven by the two versions of this state logic and how that affects co-production will be explored in section 8.5 .

\subsubsection{Community logic}

The second logic that was found to be clearly influential to all of the case study organisations was the community logic, defined by Thornton et al. (2012, p. 52) as "connot[ing] the collective relationships between people that emphasize the interpersonal and particularistic". The community as an institutional order draws legitimacy from trust and reciprocity and typically involves individuals in close proximity geographically (although communities of interest and online communities increasingly are included in this definition). Studies using an analytical framework of institutional logics have variously interpreted this logic at the field level as a 'civil society logic' (Vickers et al., 2017) and a 'social welfare logic' (Pache and Santos, 2013). The concept of community - community engagement, community development, community organising - formed a significant part of the narratives of third sector professionals and volunteers in Sheffield, and the logic was identified as playing a key role in defining co-production narratives and practices there. 
Table 8.3: Community logic

\begin{tabular}{|l|l|}
\hline Root metaphor & Community \\
\hline Source of legitimacy & Unity of will, belief in trust \& reciprocity \\
\hline Source of authority & Commitment to community values \& ideology \\
\hline Source of identity & $\begin{array}{l}\text { Emotional connection, ego-satisfaction \& } \\
\text { reputation }\end{array}$ \\
\hline Basis of norms & Group membership \\
\hline Basis of strategy & $\begin{array}{l}\text { Increase status \& honour of members and } \\
\text { practices }\end{array}$ \\
\hline
\end{tabular}

\section{Source: Adapted from Thornton et al (2012)}

Given the importance of local rootedness of community organisations and associations, it is perhaps unsurprising that the logic of this institutional order would play an important role in defining rules, practices and narratives. However, in France, the idea of 'community' is somehow 'not French' (or, as one interviewee jokingly put it, “C'est pas frenchy, ça!”). A representative from a regional network of social centres explained:

\footnotetext{
"In France, talking about 'community' isn't allowed because that refers to the private sphere, and what we share in France in terms of being citizens, that's what must be shared in the public sphere." (Social centre network representative)
}

Community has a negative connotation in France because it is linked to communitarianism, which the French associate with splintering cultural communities that do not adhere to the values of the Republic. Local difference is typically admonished, rather than celebrated, and the idea of strengthening local 
communities is viewed as a way to diminish the power of the state. This again recalls the notion of the French state as protector of the general interest, and the fact that organised interest groups are conceived as being contradictory to this aim.

This antagonism towards the idea of community in theory presents a curious puzzle when analysing the logics of third sector organisations in France. Clearly, assuming the existence of a community logic in a context where this concept has negative overtones would be to shoehorn in a foreign notion and try to force conceptual equivalency. At the same time, however, the empirical analysis does demonstrate that associations in Lyon are influenced by a logic other than that of the state (but which is also not related to the other five institutional orders). In many ways, the state logic defines the community logic in France - in the sense that many of the rules, practices and narratives that define traditional community work and associations are the same as those that emanate from the government, but in a way that is locally translated and implemented.

When referring back to the typology of Thornton et al. (2012) (Table 8.3), several of the variables that define the community as institutional order are clearly applicable to both France and England. The definition of an identity formed by a common boundary is common to both locations - in the case of France described as the quartier (neighbourhood) or the territoire (a term which was frequently used and which I can only roughly translate as the 'territory'), while in England community was the preferred term, although there were some mentions of neighbourhoods. Legitimacy based on trust and reciprocity is, again, a clear defining feature of the local or community logic that drives local activity in both countries. However, 
beyond these, the French case diverges, as it is the concept of a shared set of values and ideology of a community that the French find unacceptable - as the only appropriate set of shared values in the public realm are those of the French state, shared together as French citizens. Recognising identity based on group membership in a community is equally inadmissible.

This distinction between two types of community or civil society logic has tangible effects when it comes to understanding its role in enabling and constraining coproduction in each country. As we saw in Chapter 2, the extant literature on coproduction often rests on a normative presumption that collaboration in decisionmaking and service delivery between professionals and citizens can produce services that are more effective and better meet the needs of service users. However, implicit in this process is the fact that delivery of services will thereby be differentiated between one area and another and that community difference is natural. Prior to commencing fieldwork, I had hypothesised that the French unitary understanding of citizenship, national values and the protection of the general interest would prove to be an impediment to co-production. Instead, co-production in French third sector organisations is informed by a French version of this community logic, which I have labelled a 'local solidarity logic'. 
Table 8.4: Revised model of community logic

\begin{tabular}{|l|l|l|}
\hline Rules & Community logic & Local solidarity logic \\
\hline Practices & $\begin{array}{l}\text { Limited - more emphasis } \\
\text { on day-to-day practices }\end{array}$ & $\begin{array}{l}\text { Citizen participation in } \\
\text { organisational governance }\end{array}$ \\
\hline $\begin{array}{l}\text { Narratives } \\
\text { (values, beliefs, } \\
\text { identities) }\end{array}$ & $\begin{array}{l}\text { Informal discussions and } \\
\text { collaboration, co-design of } \\
\text { services, reliance on } \\
\text { volunteers }\end{array}$ & $\begin{array}{l}\text { Combination of formal } \\
\text { participatory democracy } \\
\text { procedures and reliance on } \\
\text { volunteers }\end{array}$ \\
\hline cooperation/ & $\begin{array}{l}\text { collaboration } \\
\text { Identity: Members of a } \\
\text { geographical area }\end{array}$ & $\begin{array}{l}\text { Solidarity, vivre ensemble, and } \\
\text { application of values of the } \\
\text { égalité, fraternité, laïcité) }\end{array}$ \\
\hline Identity: All citizens
\end{tabular}

Re-categorising the community logic (Table 8.4) allows the analysis to be sensitive to national values and how these define the logics of local, or community, organisations. While the English community logic remains consistent with Thornton et al. (2012)'s original definition, the French local solidarity logic rejects identities based on local group membership and the differentiation between values and beliefs of different localities, favouring instead a local application of French Republican values and identities. As we will see in the following section, these two variations of the community/local solidarity logic inform the overall combination of logics that third sector organisations draw upon and shape their co-production and participation practices. 


\subsection{Models of institutional logics and co-production}

The data revealed that third sector organisations in both England and France were driven by a combination of multiple institutional logics. In England, these were identified as a community, Anglo-Saxon state, and market logic. In France, I identified two logics - Napoleonic State, and local solidarity. The interplay of multiple logics took different forms in the two case study contexts. Skelcher and Smith (2015) suggest that non-profit organisations can theoretically take five different types of hybrid form, depending on the interplay between different logics. Segmented and segregated hybrids occur when organisations compartmentalise elements of different logics in various departments within an organisation, or into separate but associated organisations. Assimilation of plural logics may occur in response to the infliction of a new logic upon a non-profit organisation from external stakeholders, where an organisation adapts some of the demands of the new logic to the existing $\operatorname{logic}(\mathrm{s})$. This has been demonstrated by other previous studies of hybrid organisations (Pache and Santos, 2013). Blended hybrids, however, respond to multiple logics by combining them and finding ways to bridge the gaps between differing identities, practices and values. Finally, blocked hybrids result when organisations are unable to reconcile the various identities and demands of different logics, which leads to organisational dysfunction.

The analysis shows that the Sheffield and Lyon third sector organisations demonstrate two different types of hybrids. I argue that the Lyon third sector organisations demonstrate a blending of two logics (Napoleonic State and social solidarity), which I categorise a 'Social Solidarity Logic'. The Sheffield organisations 
assimilate three logics (Anglo-Saxon state, community, and market), which I designate a 'Service Delivery Logic'. These particular incorporations of different logics provide an analytically rigorous way to explain the rules, practices and narratives that define co-production in these two contexts.

\subsection{Social solidarity logic and co-production}

\subsubsection{Logic blending}

In a blended hybrid, organisations resolve the tensions between competing identities, structures and/or values espoused by the different logics that drive them by strategically mixing these together. Logic blending is often used to describe social enterprises, which are said to blend the market, community and state logics into a new type of socially conscious business (Nyssens, 2006). The logic blending evidenced in Lyon takes a different form, with third sector organisations blending two institutional logics particular to the French case - Napoleonic State, and local solidarity logics - into a new social solidarity logic, which helps us to understand the uniquely French narratives and practices of co-production.

One of the curious findings from the Lyon case study organisations that clearly exhibits this blending between the logic of the French state and society is the way in which the social centres and Lyon Older People came into existence. Respondents employed narratives about the fact that they originated from social movements, and indeed Lyon Parents has its origins as a movement of parent-led childcare cooperatives. Lyon Older People, however, is a 'social movement' that was initiated 
by a government minister, and the social centres - though influenced by the settlement movement in England - largely came into being as a result of state investment in the social sector. This is a slightly unconventional way of conceptualising a social movement, which typically is citizen-led and often acts in opposition to government, but these state-and-citizen-led movements illustrate the way in which French associations easily blend two logics that could be seen as contradictory or competing in other contexts.

Blending two institutional logics does not mean that both have equal influence on organisations' rules, practices, and narratives. Across the case study organisations in Lyon, evidence suggested that the Napoleonic State logic played an especially strong role in shaping rules. As we saw throughout Chapters 6 and 7, interviewees frequently cited national laws and charters as playing a large part in defining their identities, mission and practices. The Napoleonic State is defined as being unitary with power centralised in the national government, which then directly regulates the behaviour of local level associations. This contrasts with relatively more decentralised systems of governance where local and municipal councils have a greater role in defining the rules and practices of the third sector. The structure of the local case study associations reflects the hierarchy of French administrative traditions. While the organisations under study were all local to Lyon, each also had a national umbrella branch or network that represented similar associations in other cities. This appeared to be a relatively common phenomenon across other subsectors of the social economy that I researched, with most well-known associations in Lyon being branches of, or associated with, a national organisation. 


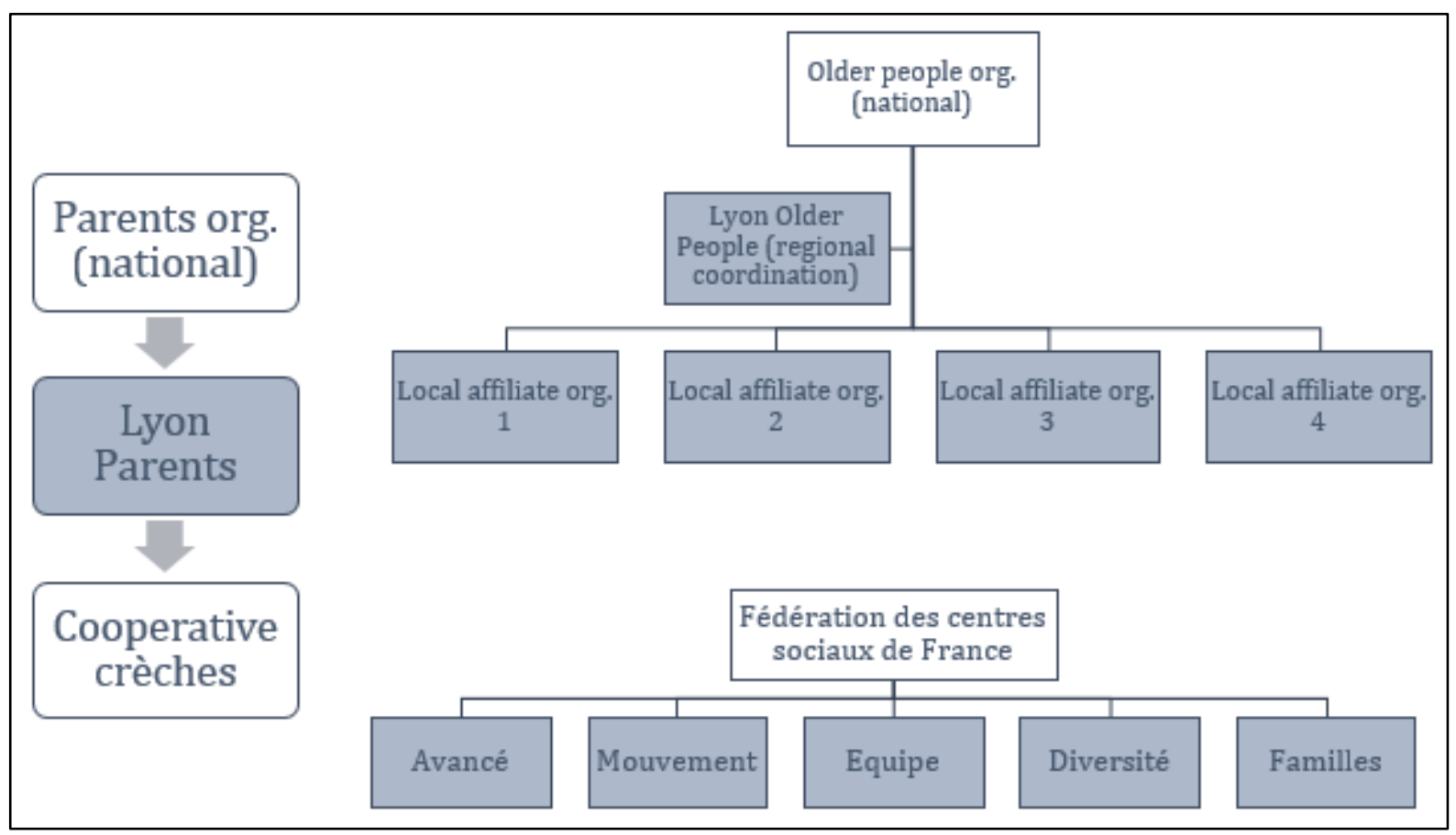

\section{Figure 8.1: Hierarchy of Lyon third sector organisations.}

\section{(Level of analysis shaded)}

Beyond the direct impact of national laws and regulations on the Lyon associations' activities, the Napoleonic State logic also informs the rules that associations implement internally, and the way in which they conceptualise rules versus practices. The local blending between a Napoleonic State logic and the local solidarity logic comes to the fore in an examination of organisational governance and internal rules. All of the Lyon case study organisations have produced organisational charters that codify their founding mission and values. While some of the organisations in Sheffield are likely to have produced similar mission-type documents, none of the English organisations mentioned such a document in interviews, demonstrating the comparatively limited import they accorded to such documents. This duty to codify values clearly demonstrates the blend on French 
state ideology with that of local solidarity - i.e. constitutions and formal records are considered valuable and necessary in order to protect rights and demonstrate an organisation's purpose and commitment. Often these charters take a primarily symbolic function, such as the Lyon Older People's charter to which signatories join in a promise to work towards tackling older people's isolation.

The local solidarity aspect of the Social Solidarity Logic reflects the French discomfort with the idea of community, because the in-group/out-group sense of community identity conflicts with the source of identity defined by the state. The reality is, however, that there is a real sense of neighbourhood belonging and territorially specific rules and practices in different parts of the country and different parts of Lyon. The narrative that perhaps best explains the translation of these notions into a French phraseology is the concept of 'vivre ensemble', which technically translates as 'living together', but is typically grouped with ideas of diversity and community cohesion. Vivre ensemble allows for a recognition of cultural, ethnic and religious differences of individuals, while still remaining true to a French unitary notion of citizenship and identity. Although this notion of vivre ensemble is promoted by the state at the national level, in practice it can only truly be understood and pursued at a local level, between individuals.

The blending of logics into a Social Solidarity Logic creates an overall identity of third sector actors that is expressed through narratives about 'what we believe'. A common theme throughout the case studies was that interviewees tended to respond to a general question of 'tell me about your organisation' by describing the primary values and beliefs that they espoused. For instance, interviewees from the 
social centres in particular tended to respond with the three founding values (human dignity, solidarity and democracy). This ethos-driven focus was less evident in the interviews with associations involved in Lyon Older People (perhaps due in part to the structure of the loose network of the citizen mobilisation, or indeed the structure of my interview questions), but an appeal to a common set of values is clearly formulated in the charter, where signatories again agree to protect a set of four fundamental values. The tendency of third sector organisations to convene around three or four key founding values is, as an interviewee suggested to me, perhaps a particularly French phenomenon that reflects the importance of 'liberté, égalité, fraternité' to the French political consciousness.

\subsubsection{Implications for co-production}

A primary assessment of the Napoleonic State logic would suggest that it presents numerous obstacles for third sector organisations to engage in co-production. Indeed, interviewees frequently cited French political culture as being an impediment to citizen participation, because of endless bureaucracy, entrenched systems of hierarchy, and elected officials' obstinacy. As one interviewee described:

"We are really still in France, much more than in UK I think, in a topdown... Even if we have been moving in the 80s from centralisation to decentralisation, but it's still at the local level very top-down and trying to introduce ideas of what we call participatory democracy is a big challenge." (Director, Diversité. Interview conducted in English)

Nevertheless, strong examples of practices that satisfy my definition of coproduction were identified in most of the case study organisations. The prevalence of co-production despite the barriers imposed by the rules and practices that form 
part of the Napoleonic State logic demonstrate how this logic's blending with the local solidarity logic allows for the emergence of space for co-production between citizens and professionals. Because of the fact that the practices of Lyon third sector organisations are informed by these two unique institutional logics, co-production is driven by different values and motivations than in the English cases, and the activities that comprise co-production vary in some cases.

\section{Co-production as a rule}

In the case of the five social centres and Lyon Parents, co-production practices and the values that motivate these are formalised and codified through charters. Lyon Older People, as a network rather than an organisation, presented a slightly different example - where signatories to the charter agreed to mobilise teams of citizens, rather than specifying anything about services. Co-production as a rule demonstrates the impact of the Social Solidarity Logic - because formal rules are deemed to be extremely important (driven on the Napoleonic State logic), practices and values that would in England be typically categorised under rules-in-use, or "the dos and don'ts that one learns on the ground that may not exist in any written document" (Ostrom, 2007, p. 23) are instead turned into rules. Co-production which is spelled out as "initiatives brought by local people, supported by professionals" by social centres and "cooperation between parents and professionals in both the design of the organisational plan as well as the running of daily activities" by Lyon Parents - is both formalised into organisational charters and mainstreamed into organisational purposes and strategies. 
This notion that co-production is mainstreamed as a rule in these cases reveals some of the weaknesses of the co-production literature, where co-production is typically described as more of an informal practice or process by which services can be designed and delivered. This assumption of informality fails to account for logics, like the Social Solidarity Logic, whereby culture and traditions drive organisations to provide formal justification and records of their values and practices. This also reveals a unique intersection of rules and narratives that is not addressed by Lowndes and Roberts (2013) - while they argue that narratives can be employed to justify certain rules, there is no mention of instances whereby rules are created to record and formalize narratives.

\section{Co-construction rather than co-production narratives}

In regards to narratives and how respondents talked about co-production, in fact, it transpired that the word co-production did not form part of the narratives of respondents at all. When directly asked, most respondents equated it with coconstruction, which is not typically defined in quite the same way as co-production. While co-production suggests that citizens or service users will be involved to some extent in the delivery of services, co-construction requires no such condition. Coconstruction is instead focused purely on the 'input' side, i.e. involvement in decision-making and planning, rather than a focus on the 'output' side of delivering services or the implementation of policy. As we saw in previous chapters, one of the impacts of institutional logics is that they determine appropriate behaviours and the 'rules of the game'. In this case, the Social Solidarity Logic delimits the appropriate arena for citizen participation to be the involvement in decision-making. This, 
however, pertains only to the narratives and not the practices of organisations. Due to the influence of the Napoleonic State logic, participation is conceived as being part of formalised democratic processes, rather than an acceptance of negotiation and pluralism. While co-production involves professionals and citizens doing things together, co-construction refers to professionals and citizens only deciding things together.

As stated in the previous section, another defining aspect of the Social Solidarity Logic is an overarching narrative about 'what we believe in'. This provides a clear and important structure for understanding the motivations for co-production. Involving citizens in decision-making is not seen as a way to improve services, but rather the inverse - services are conceived instead as a way to contribute to the overall values and aims of the organisation of supporting solidarity, vivre ensemble and citizenship. This was demonstrated most strongly in the social centres and Lyon Parents, where clear and successful examples of co-production were identified. In these instances, the services were conceived as pragmatically contributing to the value goals of the organisation.

\section{Co-production is not conceptualised as a part of service delivery}

While much of my discussion of co-production in France in this chapter has focused on the prevalence of formal involvement in governance and decision-making, I also identified numerous examples of citizen involvement in actively delivering services and projects (through volunteering or in projects directly led by citizens themselves). On the surface, these could easily be categorised as 'co-delivery' as part of a co-production definition. However, the French respondents rarely grouped 
citizen-led projects or the use of volunteers in with their discussions of participation initiatives, framing these as outside the scope of co-construction. Thus, although activities that meet my understanding of co-delivery proliferate, this was not how the French conceptualised them, which can be explained in part by the fact that services were not discussed as being 'delivered'.

An analysis of the of the language used by respondents to describe their organisation's activities reveals that the French do not frame these in terms of services being 'provided', meaning that a notion of involvement in service delivery does not correspond to how people conceptualise organisational practices. Indeed, when I attempted to explain my definition of co-production as being about co-design and co-delivery, it was difficult to inquire about 'co-delivery' because I could only awkwardly translate this to 'co-prestation' which was not a word that respondents utilised. Services tended instead to be discussed in terms of 'accueil' ('welcome') or 'accompagnement' ('accompaniment') of service users. Examples that could be considered co-delivery were instead described as "accompagner les habitants dans leurs projets" ("accompanying residents in their projects") or simply 'volunteering' or 'collaboration'. In addition, French third sector organisations in the sectors studied do not necessarily conceptualise the same hierarchy between professionals and service users because the people with whom co-production is undertaken are often members of the association. As one of the French academics I interviewed explained, "Your notion of 'service user' is a bit jarring from the French point of view, because for the social and solidarity economy, it's the members that are fundamental." This difference in language reveals a rift between French narratives and the dominant language used in the co-production literature. 


\subsection{Service delivery logic and co-production}

\subsubsection{Logic assimilation}

Unlike the French case, the way that the organisations in Sheffield respond to the existence of multiple institutional logics is not to blend these into a new logic, but rather to strategically adapt elements of the logics available to them. In this case, the logics I identified were the state, community and market logics ${ }^{17}$. The Sheffield cases tend to exhibit an assimilation of these three logics, by responding to the changes and pressures of the introduction of a market logic by strategically incorporating elements into their narratives and practices, but aiming to remain true to the values and beliefs of the incumbent (primarily community) logic.

One of the most conspicuous differences between the Social Solidarity Logic and the Service Delivery Logic is that there is little to no influence of a market logic in the French third sector. As I discussed in Chapter 5, in France, New Public Management had limited impact on public administration, commissioning and public services. This has meant that, unlike in many other Western countries, French third sector organisations that deliver public services continue to receive funding on the basis of grants from the government, and have experienced relatively little push to adopt a business-like logic that focuses more on performance management and efficiency savings. The UK, however, was one of the countries where NPM had the most

\footnotetext{
${ }^{17}$ As discussed in the first section of this chapter, I differentiate an Anglo-Saxon State Logic from a Napoleonic State Logic, but for brevity, in this section I will refer to this simply as a state logic, as its existence in England corresponds to the definition of the state institutional order in the literature on institutional logics.
} 
influence on government beginning in the 1980s. As the market logic has become assimilated with the state logic within government, so too has the third sector been compelled to assimilate this new logic with the previous state/community logics that characterised the third sector.

The rules that constrain third sector organisations therefore show an infiltration of the market logic. The stories told by professionals from the Sheffield community regeneration organisations in particular (which have been in existence since the late 1990s) demonstrate the way in which the market logic has becoming increasingly important over time, and how these organisations have had to adapt to these new rules by modifying their narratives and some of their practices. This translates into taking a more business-like approach to financing organisational activities (such as through renting out office spaces and delivering training) as opposed to relying solely on government grants, as well as adopting more 'corporate speak' in narratives to satisfy funders. For Sheffield Parents and Sheffield Older People, which are relatively new projects - and, crucially, funded by grants from the same nonprofit funding body - this assimilation does not take the form of adapting or changing in the face of a new 'challenger' logic (Reay and Hinings, 2009; Vickers et al., 2017) over time, but rather, elements of the market logic define both rules (through the requirements set out in contracts) and narratives (in discussing how various targets will be evidenced) from the outset.

In terms of both practices and narratives, the Sheffield case study organisations demonstrate attempts to negotiate or balance the aim to prioritise the community logic with the demands and constraints of the state and market logics. The 
overarching narrative identified across the organisations was a mission to 'improve communities' in some way. For Sheffield Older People, this was about tackling the problem of older people's isolation in communities; for Sheffield Parents, delivering services and projects to help and support local parents; and for the community regeneration organisations, this was framed more broadly (given the range of activities and services they deliver) in narratives such as 'tackling local issues' and 'facilitating community regeneration/ community development'. In practice, organisations operationalise these aims through delivering services, which highlights the unifying theme across the Sheffield organisations - an emphasis on service delivery. These third sector organisations conceptualise their fundamental role as about provision, which is often termed as meeting needs and filling gaps.

\section{"I always talk about it in terms of market failure, because public services were not delivering what local people needed and the private sector wouldn't operate in our area because there was no money to be made, because it was one of the poorest communities. So we've sort of filled that vacuum, really." (Director, Develop)}

This demonstrates one of the ways in which the Sheffield organisations assimilate elements of the market, state and community logics - by leveraging business skills and expertise and identifying gaps in service provision (which illustrates a more market-based understanding of public services), third sector organisations leverage their position (being 'community-based') and resources (generally non-monetary, such as knowledge, expertise and social capital) in order to deliver services that provide public and community benefit. This also highlights an evolution that has 
taken place away from a more politicised, community and social movement basis as a result of the increased contracting out of services to the third sector.

The day-to-day routines of the Sheffield organisations tend to be described as fairly informal and flexible, with practices reflecting some of the claims made about the Anglo-Saxon state and administrative traditions that were discussed in the first section of this chapter, as well as the influence of the community logic. The AngloSaxon state is said to be characterised by pluralism, negotiation of multiple interests, and a conceptualisation of the public interest or common good as an aggregate of the individual interests of all citizens. This notion is rendered into practice by third sector organisations by emphasising relationship building between staff and community members through community engagement, and efforts to bring in diverse community voices into decisions about services and how they should be offered.

This Service Delivery Logic is thus defined by a combination of a dominant narrative that stresses the importance of community engagement and improving communities, with the need to deliver public services that meet the requirements of the government (state logic), meet other funders' contract requirements, and the need to remain viable as a business (market logic). As a result, the Sheffield cases tend to define themselves by what they do, rather than - as we saw with the Lyon organisations - what they believe. This is not to say that these organisations are less value orientated, but rather that their ethos provides a basis for their practices and approaches to co-production, whereas the Lyon organisations suggest that the things they do are done in order to promote their ethos and values. 


\subsubsection{Implications for co-production}

"There are lots of different words people use. So we talk about coproduction. The framework we use is one of three key elements. So everything we do we say is co-produced. By that we mean it is codesigned, co-delivered and co-evaluated with the people it's intended for. [...] So we have co-production where basically you're the customer or user of this service, so you tell us what you want and we do it." (Senior staff, SOPC)

Like in Lyon, I found several good examples of co-production taking place within the Sheffield case study organisations, although it appeared in some instances that the narratives or rhetoric of co-production may be more developed than co-production practices themselves. The fact that co-production has become a buzzword in the UK has meant that this has impacted the way that professionals describe their practices in narratives (in some instances seizing the term once I used it, and in other instances actively rejecting it). The assimilation of the state and community logics, and the market logic to a lesser extent, has several ramifications for whether organisations do co-produce with citizens or not, and what form co-production takes.

1. Co-production is inseparable from rules related to contracts and funding

While co-production in the Lyon organisations is heavily influenced by rules in the form of laws and charters, the Sheffield organisations find their approach to coproduction more constrained by contract rules. This is partly attributable to the way that a market logic to public service contracting has been introduced in Sheffield, which has created obstacles for third sector organisations. In many of the interviews 
I conducted, one of the key areas of concern for the interviewee was the issue of bidding for contracts (marketization of services), and cuts to public services. As the government's approach to austerity has, to an extent, informed a business-like logic which urges service delivery organisations to increase efficiency, third sector organisations are struggling to maintain their level of staffing and service offering, constraining their capacity to engage in more intensive involvement activities.

This issue of cuts, sustainability and funding in general was frequently discussed in conjunction with narratives about co-production - but this took different directions for different organisations. Sheffield Parents was conceived as a result of the withdrawal of parent and toddler projects/ services, and a strategy of intensive community engagement and involvement was devised as a way to prevent unwanted programmes from wastefully being designed and implemented again. For Sheffield Older People (which is funded by the same organisation as Sheffield Parents), highlighting the fact that the project would take a co-productive approach was a key factor in their success in receiving funding. Two of the community regeneration organisations (Leisure and Aspire) were essentially forced to take over libraries and run them with community volunteers, to prevent the libraries from being closed. Finally, organisations such as Recreation feel that they simply do not have the capacity to co-produce because of lack of funding.

This intertwining of funding concerns and co-production practices was a common theme in the narratives of interviewees in Sheffield. Co-production is paradoxically conceptualised as a practice that requires large amounts of resource and professional time and capacity, while at the same time being promoted as a way to 
make services more cost effective (or to sustain services that would otherwise be cut). This duality of narratives results in a degree of scepticism towards coproduction as a practice, with some professionals expressing concern about being expected to do 'more with less' as cuts to public services have made funding to third sector organisations increasingly precarious.

\section{Co-production practices are employed to improve service delivery}

As described in the previous section, delivering services is the primary identity around which the Sheffield third sector organisations coalesce, driven by the Service Delivery Logic. This in turn defines the way in which they conceptualise and operationalise co-production, which is typically framed pragmatically as a way to improve the design and delivery of public services. In the narratives and practices of the Sheffield third sector, we see limited attention to the democratic aspect of coproduction (e.g. citizenship, empowerment, equality) and more focus on the effectiveness aspects (e.g. improving outcomes, meeting needs). At times, coproduction (or community engagement more generally) is conceptualised as being part of the unique selling point of why organisations are more effective at delivering services than, for example, the public or private sectors, which corroborates Pestoff's (2009) findings.

For example, several of the community regeneration organisations argue that they are best placed to deliver services because their proximity to and engagement with communities means they will be able to more effectively design the services that local people want. In other instances - in Sheffield Parents and Sheffield Older People in particular - co-production is a strategy or method that has been 
introduced in order to improve services. In both illustrations, the key suggestion is that involving citizens in design and delivery of services will make them, in some way, 'better'. This contrasts with the Social Solidarity Logic of the Lyon organisations, where the primary consideration is involvement and collaboration, delegating service provision as a secondary priority or a result of the engagement in co-production.

\section{Co-production as a term is controversial}

"I don't really know what co-production means. I can tell you that it means producing things together. (Laughs) But what does that mean? When you unpick it, what's behind that? I don't know. I don't know." (Director, Aspire)

"It's a buzzword. [...] I don't think... It's not a word that I particularly use, but this programme has certainly been co-produced." (Staff, Sheffield Parents)

Of the 14 individuals in Sheffield that I directly asked about co-production, all were familiar with the term, and only one suggested that they were not confident they knew what it actually meant. However, respondents from only one organisation Sheffield Older People - independently described their approach as being one of coproduction. The other respondents fell into three groups: those who expressed enthusiasm about co-production as an idea and a practice (three people); those who felt it was not a term that they would use to describe their practice, but that their organisation does co-produce (four people); and finally, those who stated that they "hate the term" or felt it was just a buzzword (three - all of whom were directors of community regeneration organisations). 
The mixture of these reactions to my use of the term co-production provides some insight about both the normative appeal of the co-production concept as well as the backlash against it (as a narrative, but not as a practice). Professionals in Sheffield recognise that co-production has become a popular term, and therefore they 'should' be doing co-production, and they 'should' be using this language to describe their practices. Those that said they hate the term co-production explained this this is because of two reasons - the first is because the term has become overused (which was directed partially at the zealousness with which Sheffield Older People has adopted the term). The second reason is because several respondents felt that many people talk about co-production without actually doing it, or in other words, that the narratives of co-production do not coincide with actual practices. As Lowndes and Roberts argue, "Narrative accounts can present prevalent practices in a positive or negative light" (2013, p. 53). In the instances described here, some actors actively reject the dominant co-production narrative of the societal and field level, while still aiming to promote the practices described by this narrative.

\subsection{Conclusions}

This chapter has presented models of the institutional logics driving third sector organisations in Lyon and Sheffield and the way that these logics in turn help to explain differences in co-production. While Chapters 6 and 7 presented empirical evidence about co-production in third sector organisations through an analytical lens of institutional logics, this chapter provided a synthesis of the key themes that were identified across the community regeneration, parents and older peoples' 
projects. I presented a reclassification of the 'state' and 'community' institutional logics into two sub-categories each, which provide a more precise model that considers the differences in institutions and traditions in France and England, in order to then illustrate the way in which these societal level institutional logics are drawn upon and combined in each context. In France, I identified a blending of what I term a Napoleonic State logic and a local solidarity logic into a Social Solidarity Logic. In England, the organisations exhibited an assimilation of the state, market and community logics into what I call a Service Delivery Logic. In both cases, these combinations of logics shape identities, decision-making and priorities in ways that result in differences in co-production narratives and practices.

The following concluding chapter reflects on the findings of the comparative analysis and the impact of institutional logics on co-production in the third sector. I also consider the broader implications and contributions of the research to the literature, and suggestions for future research. 


\section{CHAPTER 9: CONCLUSIONS}

\subsection{Introduction}

In this final chapter, I consider the original contributions of the thesis. First, I summarise and reflect on the principal findings of the research. I then discuss both the implications for theories of co-production as well as the findings that provide insight into the application of the institutional logics approach to comparative research. This is followed by a discussion of the more practical contributions of the research for policy-makers and practitioners. Finally, I outline some limitations of the present project and present some suggestions for possible future research that builds upon the conclusions and models derived from this study.

\subsection{Findings of the research}

The study had three primary aims. First, the research considered how co-production or citizen participation are conceptualised and framed by third sector organisations in England and France - two countries with recognised differences in political, administrative and third sector cultures. Second, the study aimed to examine coproduction practices in the community regeneration sector, parents' organisations, and projects for older people. Finally, I sought to better understand and interpret any differences through a lens of institutional logics. The research questions were 
developed in response to a conspicuous gap in the co-production literature with respect to analysis of how national and local contexts shape the ways that actors frame co-production and how (or whether) they undertake it, in addition to building upon evidence of third sector organisations' aptitude at co-production.

The research identified compelling examples of co-production activities in several of the organisations in both Sheffield and Lyon. This discredited the initial tentative hypothesis that the political and administrative cultures of France would prevent third sector organisations from undertaking co-production activities. Indeed, the existence of a deeply ingrained ethos of co-production in Lyon Parents and the Lyon social centres reveals a paradox between the French state tradition of centralisation and unified protection of the general interest of all citizens, and the strong evidence I have generated of co-production practices supported by narratives of solidarity. This has gone unnoticed in part because of the siloes in the French research between formal participation initiatives or co-construction, and informal collaboration and volunteering. Co-production exists at the interstices between these areas.

The case studies in Sheffield provide a contrast, in that the evidence more or less verifies the assumptions in the co-production literature about collaboration between professionals and service users, motivated by the desire to increase service quality, meet the needs of users and/or improve communities. This can be attributed in part to the fact that co-production literature is largely generated by and/or promoted by UK academics and think tanks, which has influenced the narratives and practices of third sector actors. However, the practices of coproduction were more often exhibited in informal, day-to-day engagement and 
collaboration (particularly within most of the community regeneration organisations, and Sheffield Parents) rather than clear-cut co-design and codelivery activities that the co-production literature tends to describe (with the exception of Sheffield Older People, the only organisation to explicitly describe their activities in co-production terms), reflecting the pragmatism, negotiation and pluralism associated with Anglo-Saxon norms and traditions.

Employing an institutional logics approach enabled the research to analyse both the material enablers and constraints on the case study organisations (in the form of rules and practices), as well as the more ideational (through the analysis of narratives). Through this, I developed two models of institutional logics and coproduction that characterise the cases in the two contexts under study, which were outlined in Chapter 8. The Social Solidarity Logic that defined the French third sector organisations, characterised by a blend of an interpretation of the state and community logics that is specific to the French case, were heavily influenced by the presence of official rules, and tended to engage in co-production as a mainstreamed part of their organisational ethos. In other words, co-production is more linked to organisational norms and values, or "what we believe". In England, the organisations exhibited a Service Delivery Logic, which assimilated the market, state and community logics. In terms of co-production, this informed approaches that are much more consistent with the co-production literature - focusing on co-production as a means to improve communities or improve the delivery of services and relying more upon practices to define co-production rather than formal rules. Coproduction, therefore, is conceptualised as "what we $d o$ " based on this logic. 
The aim of this typology is not to suggest that one model is preferred over another, or that one will produce 'better' outcomes than the other. Rather, the application of institutional logics theory presents one framework for identifying the factors that contribute to an organisation's approach to co-production. Simply put, the coproduction practices that emerge reflect the specifications of rules, and the values, beliefs and identities that actors express through narratives.

\subsection{Contribution to Theory}

This thesis responds to calls for a greater attention to institutions in co-production research (Verschuere et al., 2012) and the comparison of cases in different countries (Voorberg et al., 2015). The research has taken a novel approach of applying institutional logics theory to the comparative study of co-production, and in so doing addresses existing gaps in the co-production literature. As we saw through the literature review in Chapter 2, while there is an increasing number of studies that include cases or survey respondents from multiple countries in co-production research (e.g. Pestoff, 2006; Parrado et al., 2013), none do this from a position of comparing whether there are notable differences between countries. This has meant that each study tends to adopt one definition of co-production which they assume is understood in and applicable to each or all contexts.

This research challenged the assumption of co-production as both a universal concept and practice of co-design and co-delivery of services. I thus uncovered some of the cultural subjectivity to this notion between England, where co-production is 
a popular buzzword in the public and third sectors, and France, where the concept is nearly non-existent. This analysis revealed that the French actors conceive of the delivery of services as contributing to co-production (or participation, coconstruction or empowerment), rather than vice versa. This challenges one of the fundamental axioms of co-production theory, which conceptualises co-production as a way to improve the service delivery process.

Second, the analysis of organisations across three sub-sectors of activity provides a broader evidence base of co-production in the third sector. Previous studies of third sector co-production tend to analyse case studies operating in one area of service delivery, and have made generalised conclusions about the third sector as a whole (e.g. Pestoff 2009; Brandsen and Helderman, 2012). Pestoff's $(2006,2009)$ work on third sector co-production, for instance, examined only childcare cooperatives, which by their very nature are likely to exhibit different manifestations of coproduction than other types of services, because of the intrinsic buy-in of service users required by a cooperative. In employing a broader research design to include cases from community regeneration, parents' organisations and projects for older people, I have identified co-production practices and narratives that are not restricted by organisational forms or service offer.

Third, the study contributes to our understanding of the motivations for coproduction. Previous studies have demonstrated the drivers of co-production at the individual level of citizens/ service users and professionals (Bovaird et al., 2015; Van Eijk and Steen, 2015, 2016; Tuurnas, 2015), and the organisational level, comparing the public and third sectors (Pestoff, 2009). This study extends this analysis of why 
and how co-production takes place by identifying factors at the broader field (meso) level and national (macro) level that impact local organisations. While it is important to recognise the agency of individuals and organisations in their own decision-making and behaviour, an analysis of higher level institutions provides a previously lacking element to interpret why and how co-production happens and what factors enable and constrain actors.

Finally, this thesis contributes to the literature through the analysis of the narratives and discourses of co-production, which has received relatively limited attention in comparison to practices. The narratives and stories told by third sector actors relating to their perspectives on co-production reveal more than just the explicit motivations for doing so (e.g. to improve services, etc.) but also the values and beliefs that are linked and help to provide a more nuanced picture of the complex relationships between the factors that impact individuals' and organisations' justifications for behaviour. In addition, the inclusion of an analysis of the discourse of co-production reveals the limited extent to which this word has gained traction within the third sector - only one organisation of all of the cases studied uses the word to describe their work. Taking discourse as a component of social practice (Fairclough, 1995), the study demonstrates how the language that actors use and the concepts that they discursively link to the concept of co-production contribute to the overall production of meaning and practice. 


\subsection{Practical contributions}

The research also produced findings that are applicable for policy-makers and third sector professionals. Recent work has sought to describe ways that public policy can be better designed so that it promotes co-production (e.g. Durose and Richardson, 2016) and the models developed by this research can add to this literature. Understanding the logics embedded within particular types of organisations can help a) identify the types and sources of barriers and constraints that organisations face in engaging in co-production practices (e.g. laws, internal governance regulations, and/or funding and contract requirements), b) explain the drivers and motivations that actors cite for engaging in co-production (e.g. to improve services, or because the organisation sees its overall purpose as to support democratic engagement), c) provide insight into the values and beliefs of third sector actors, and how these relate to co-production.

If we better understand the wider factors that shape actors' and organisations' motivations for engaging in co-production and their aims, it becomes easier to identify the barriers that can be overcome in order to facilitate co-production. The current evidence base that exists is growing rapidly, but without considering the cultural, institutional and linguistic factors that I have identified, practitioners may be at risk of implementing 'best practice' advice or models that have been designed with different contextual factors in mind. This may be of particular use to practitioners in France, or other contexts that exhibit a similar combination of institutional logics, because the current state of co-production literature is skewed 
more towards contexts where a Service Delivery Logic defines third sector organisations.

\subsection{Limitations of the research}

While the research design and analytical framework for the research were chosen because they represented the best design to investigate the research questions, I recognise there are some limitations to this approach. First, the research design of comparative case studies, as well as a sampling approach that aimed to focus primarily on 'best practice' examples of co-production, limits the degree to which the findings are generalisable. While the models of a Social Solidarity Logic and Service Delivery Logic appear to describe the cases across the three sub-sectors within each city, it is not possible to say with certainty whether these findings are representative of third sector organisations in Lyon and Sheffield, or France and England more broadly. In order to produce generalisable findings, the study would have needed to utilise quantitative methods and a larger sample size, but this would have required a different operationalisation of the institutional logics approach, and would have limited the ability to analyse and interpret more qualitative data such as language and narratives.

Furthermore, the types of organisations selected as case studies and the sub-sectors of activity (community regeneration, older people and parents' organisations) present a potential limitation of the research. As noted in Chapter 4, I made the decision to steer away from health and social care services because I was advised in 
France that I would find limited examples of co-production. In this sector, and others like education, we might expect to see a far greater influence of a professional logic that shapes co-production practices - or that act as a barrier (Needham, 2011). Further research would be required to investigate whether the Local Solidarity Logic and Service Delivery Logic adequately characterise other types of services within the third sector.

A final limitation relates to the research methods. The identification of practices, because they are "demonstrated through conduct" (Lowndes and Roberts, 2013, p. 52), is naturally best done through observation. In selecting a research design that prioritised gaining the greatest breadth of case studies possible in the limited time scale available for fieldwork, it was necessary to sacrifice some of the depth that would have been attained through longer term immersion for observation in the case study organisations. Practices were identified through triangulating interview data with organisational documents and a limited number of observations in some of the case studies, but I appreciate there may be discrepancies between the way practices are described by actors (and in official documentation) and how they may actually be undertaken in day-to-day work. The research also encountered challenges in relation to studying narratives and discourse in two languages. The use of discourse and conceptualisation of certain terms are extremely nuanced, both within and between languages. My ability, as a native English speaker, to interpret semantics in French is limited by my own linguistic and cultural subjectivities. 


\subsection{Personal reflections}

Undertaking doctoral research on a part-time basis has, on the one hand, tested my ability to manage my time and balance a multitude of tasks, jobs and projects at once, whilst simultaneously allowing me to develop as a researcher in ways that completing full time might not have. I think that the experiences I gained through teaching, undertaking research assistance and presenting at numerous conferences ultimately contributed to my ability to complete my thesis early, and these opportunities would not have been possible had I devoted $100 \%$ of my time to my PhD.

Studying part time also allowed me the freedom to extend my period of fieldwork over the course of several trips to Lyon and countless day trips to Sheffield, which enabled me to analyse and reflect on my data in between, and to not feel the pressure to rush this process. One of the most challenging parts of completing this research was in conducting interviews and analysis of discourse in French, but I found that my confidence grew the further I got into the research and the more comfortable I became making mistakes and asking for clarification and help from participants. The reality of undertaking qualitative research is that the process was not clear-cut or straightforward, and I followed several leads (in terms of potential service sectors and case study organisations) that did not make it into the thesis, and theoretical models that were completely overhauled or scrapped when things started to click into place. 


\subsection{Future research}

One of the major outcomes of this thesis is to argue for more research on coproduction that accounts for political, cultural and conceptual differences between countries. The theory was built through the use of an institutional logics framework and developed two distinct models of co-production based on the interplay between different logics within third sector organisations in each city. This model of institutional logics and co-production opens the door for other research to investigate whether co-production is constrained by similar rules, involves similar activities and is described in the same way in different countries. The Social Solidarity Logic in France and Service Delivery Logic in England may be unique to these particular countries, and further research based in other countries - for instance, which represent other welfare regimes or non-profit regimes - would develop this model further and deepen our understanding of co-production. Utilising this approach in a context like Quebec, for example - which exhibits a unique blend of the English sense of community along with the French notions of participation and co-production (Patsias and Patsias, 2006) - would provide a particularly interesting application of this model.

This study does not draw any conclusions about the impact of co-production undertaken in organisations driven by these two different logics. Further research would be welcome that investigates whether co-production undertaken by organisations that are characterised by a Social Solidarity Logic or a Service Delivery Logic result in different outcomes such as efficiency savings and improved service outcomes, and/or more qualitative democratic benefits. Research into the impacts 
or outcomes of co-production is still underdeveloped relative to the empirical studies on factors that focus on the input into co-production. 


\section{APPENDICES}

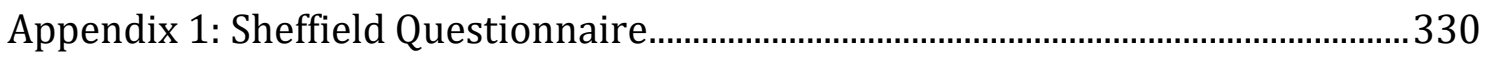

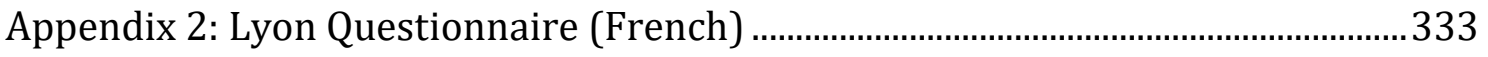

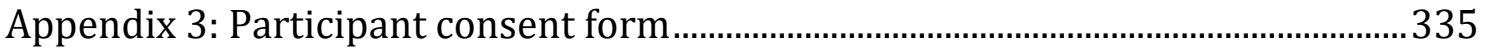

Appendix 4: List of interviews with French academics/ stakeholders......................336

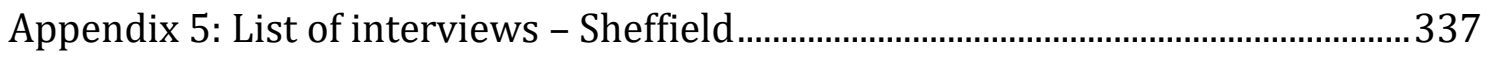

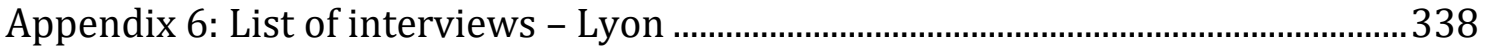

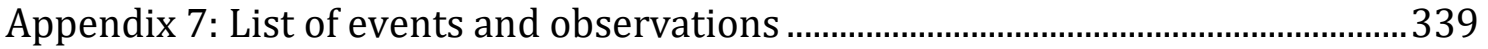

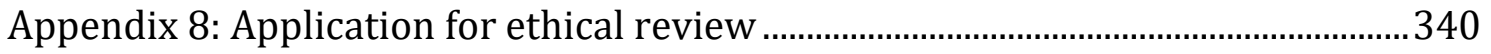




\section{Appendix 1: Sheffield Questionnaire}

Overview of research: Third sector and service user participation in England and France. Trying to understand how institutional and political context impacts the way in which TSOs involve service users/ residents/ citizens in different ways and in different activities.

\section{Overview/ Service user participation and co-production}

1. Could you tell me a bit about your organisation and the services you provide?
a. History/ formation of organisation
b. Types of services
c. Organisational objectives/ values

2. What approach does your organisation take in regards to service user/ resident engagement?

a. How was the decision made to take this approach?

3. [Do users receive any support or training in regards to participation?]

4. Do you have any groups specifically designated for user engagement?

a. How often does this group meet?

b. Does the group have any power to make decisions or is it consultative?

5. Are users directly involved in running activities/ projects?

a. Through volunteering, peer support, running activities

6. Are there any other ways in which service users contribute to the organisation?

a. Cleaning, gardening...

7. Who are the users who get involved? (i.e. how many users, what types of users)

8. Are there certain activities in which users are more involved? Are there certain activities that are led by/ managed by service users?

9. What, if anything, does the organisation do to encourage user participation? 
a. Do you think this is done effectively?

\section{Funding}

10. How is your organisation funded?

a. Who are the funders? Contracts or grants?

11. How much influence do funders have over the design and provision of your services? Do contracts specify what type of services and how they should be delivered, or do you have flexibility in developing them?

\section{Governance/decision-making}

12. If there is a membership, who are the members? (e.g. employees, community members, service users)

13. Are users represented on the board?

14. How are day-to-day decisions made?

15. Are users consulted about organisational decisions? (feedback surveys, through groups, informal)

a. What types of decisions are users involved in?

i. Budgets, priorities, organisational strategy?

ii. New services/ projects or changes to services/projects

\section{Barriers/enablers}

16. How effectively do professionals and service users work together?

a. How do staff feel about a collaborative/co-operative approach to working with service users?

17. What are the most significant difficulties that you've encountered in implementing user participation?

a. Contracts, time, resources, user characteristics, government policy

18. The concept I am studying is referred to as 'co-production' in English. Is this a term you are familiar with? What, if anything, does this mean to you? 


\section{SERVICE USER QUESTIONNAIRE}

1. Tell me about your involvement with $\mathrm{X}$ organisation.

a. How long have you been a service user/ member?

2. Role: Do you volunteer for the organisation? Are you a member of the board? Are you a member of a user group?

a. How much time do you commit to the organisation?

b. Why did you decide to get involved? Why did you decide to become a member?

3. Do you feel that your opinions have equal weighting to those of staff?

4. To what extent do you feel a sense of ownership over the project/ service?

5. What responsibilities, if any, do you have in relation to the running of the service?

6. Do you feel that the skills and ideas of service users are valued and used by the organisation?

7. Do you feel supported and encouraged by staff to participate in the project/service?

8. Is the involvement of service users something that the organisation prioritises?

9. Are you involved in any other associations? 


\section{Appendix 2: Lyon Questionnaire (French)}

\section{Questions générales}

1. Pourriez-vous m'expliquer quel est le statut (association, mutuelle, coopérative) et le fonctionnement de votre organisation et les services que vous proposez ? Combien d'employés, établissements gérés?

2. Quel est le montant et les modes de financement de votre organisation?

a. Quels sont les organismes de financement? (privés, publics)

3. Quelle influence les organismes de financement ont-ils en ce qui concerne la conception et la prestation des services?

a. Y-a-t-il un appel d'offre, appel à projet?

b. Le projet est-il porté par l'asso/ coop et financé ensuite?

4. Des contrats indiquent-ils les types de services proposés et la façon dont ils doivent être fournis?

5. Avez-vous capacité à développer d'autres services? (décision, financement)

\section{Gouvernance/prise de décisions}

6. Qui consiste l'assemblée générale ? Et le conseil d'administration ?

7. Existe-t-il
a. Des adhérents (cotisation)
b. Des membres non adhérents
c. Autres

8. Les usagers sont-ils intégrés au conseil d'administration de l'association ? (utilisateurs, personnes résidents ou accompagnées)

9. Pourriez-vous décrire le processus de prises de décisions quotidiennes ?

a. Y-a-t-il des délégations ? (Assemblée Général $\rightarrow$ président $\rightarrow$ bureau $\rightarrow$ directeur)

10. Les usagers sont-ils consultés sur certaines décisions organisationnelles?

a. Sur quels types de décisions sont-ils consultés?

Participation des usagers/ co-production

11. Selon vous, en quoi consiste la participation des usagers ?/ la solidarité ?

12. Les usagers sont-ils formés à la participation?

13. Avez-vous un CVS (conseil de vie sociale), ou autre forme de groupe de participation des usagers?

a. Combien de fois le groupe se réunit-il par an?

b. Est-ce que le groupe prend des décisions par lui-même, ou s'agit-il d'un mode de prises de décisions plus consultatif?

14. Les usagers sont-ils impliqués dans la vie collective de l'établissement (gestion des activités/projets) ?

15. Existe-t-il d'autres moyens par lesquels les usagers contribuent au fonctionnement de l'organisation ? ex bénévolat

16. Qui sont les usagers qui s'impliquent plus souvent ?

17. Existe-t-il certaines activités dans lesquelles les usagers sont plus impliqués? 
18. Comment l'organisation tente-t-elle d'inciter les usagers à participer ?

a. Pensez-vous que c'est efficace?

\section{$\underline{\text { Obstacles et facteurs facilitants }}$}

19. Les usagers et professionnels travaillent-ils ensemble de façon efficace?

a. Comment les employés considèrent-ils l'approche de travail collaborative avec les usagers?

20. Quelles sont les difficultés les plus importantes que vous ayez rencontrées dans la mise en œuvre de la participation des usagers ?

21. Le concept que j'étudie est appelé « co-production » en anglais. Connaissezvous ce terme?

22. La définition que j'emploie c'est l'implication à longe terme des usagers/ citoyens dans la co-décision/ co-élaboration et aussi dans la prestation des services avec les professionnels. 


\section{Appendix 3: Participant consent form}

\section{Service user involvement and the third sector: \\ A comparative study of England and France \\ INFORMATION FOR PARTICIPANTS}

I would like to interview you as part of my $\mathrm{PhD}$ research undertaken at the University of Birmingham, supervised by Chris Skelcher (c.k.skelcher@bham.ac.uk) on service user involvement by third sector organisations. The study seeks to investigate how different narratives, cultural and political factors influence how third sector organisations involve citizens and service users in decision-making, service design and service delivery in England and France.

If you agree to take part, interviews will be held at the location of your choosing and will take approximately 20 to 60 minutes. With your permission, the interview will be recorded and transcribed by me - no one else will listen to the recording. The transcript will be anonymised stored securely in a Dropbox folder with a two-step password verification process enabled. I am the only person that will have access to the data. Information from interviews will be used for the purposes of my $\mathrm{PhD}$ thesis and academic journal articles, but will be completely anonymised.

\section{PARTICIPANT CONSENT FORM}

Please let us know if you agree with the following by circling an answer to every question

\begin{tabular}{|c|c|c|}
\hline & \multicolumn{2}{|c|}{$\begin{array}{c}\text { Please } \\
\text { circle }\end{array}$} \\
\hline I have read the above information and I have understood it. & Yes & No \\
\hline $\begin{array}{l}\text { I am willing to take part in an interview with a researcher from the University of } \\
\text { Birmingham }\end{array}$ & Yes & No \\
\hline $\begin{array}{l}\text { I am willing for the interview to be audio recorded. Only the researcher will ever listen to } \\
\text { the recording. }\end{array}$ & Yes & No \\
\hline $\begin{array}{l}\text { I understand the interview will be about involvement of citizens/ service users by my } \\
\text { organisation, and/or participation and involvement more generally. }\end{array}$ & Yes & No \\
\hline $\begin{array}{l}\text { I understand that I can withdraw from the project at any time by contacting Caitlin } \\
\text { McMullin by email cxm257@bham.ac.uk }\end{array}$ & Yes & No \\
\hline $\begin{array}{l}\text { I know that I do not have to answer all of the questions and can stop the interview at any } \\
\text { time. }\end{array}$ & Yes & No \\
\hline
\end{tabular}

Signed

Date

Please print name

If you have any questions or need more information please contact Caitlin McMullin on cxm257@bham.ac.uk or 07964333424. 


\section{Appendix 4: List of interviews with French academics/}

stakeholders

\begin{tabular}{|l|l|}
\hline Name & Organisation \\
\hline Yves Sintomer & Université de Paris 8 \\
\hline Francesca Petrella & Université d'Aix-Marseille \\
\hline Edith Archambault & Université de Paris 1 Pantheon-Sorbonne \\
\hline Laurent Gardin & Unviersité de Valenciennees \\
\hline Gregory Azoulay & AlterSenso \\
\hline Stephanie Rizet & Mouvement Associatif \\
\hline
\end{tabular}




\section{Appendix 5: List of interviews - Sheffield}

\begin{tabular}{|l|l|l|}
\hline Name & Organisation & Category \\
\hline Assistant Director & Sheffield Network 1 & Context \\
\hline Director & Sheffield Network 2 & Context \\
\hline Director & Develop & Community regeneration \\
\hline Staff & Develop & Community regeneration \\
\hline Staff & Aspire & Community regeneration \\
\hline Director & Aspire & Community regeneration \\
\hline Director & Recreation & Community regeneration \\
\hline Director & Enterprise & Community regeneration \\
\hline Staff & Enterprise & Community regeneration \\
\hline Former director & Leisure & Community regeneration \\
\hline Staff A & Leisure & Community regeneration \\
\hline Staff B & Leisure & Community regeneration \\
\hline Director & Leisure & Community regeneration \\
\hline & Sheffield Older People & \\
Senior Staff & Contractor (SOPC) & Older People \\
\hline Board member A & SOPC & Older People \\
\hline Board member B & SOPC & Older People \\
\hline Staff A & SOPC & Older People \\
\hline Staff B & SOPC & Older People \\
\hline Staff A & Sheffield Parents & Parents \\
\hline Staff B & Sheffield Parents & Parents \\
\hline
\end{tabular}


Appendix 6: List of interviews - Lyon

\begin{tabular}{|l|l|l|}
\hline Name & Organisation & Category \\
\hline Director & Lyon Network 1 & Context \\
\hline Director & Lyon Network 2 & Context \\
\hline Staff & Departement du Rhone & Context \\
\hline Staff & Ville de Lyon & Context \\
\hline Stakeholder & & Context \\
\hline Director & Diversité & Community regeneration \\
\hline Director & Familles & Community regeneration \\
\hline Director & Equipe & Community regeneration \\
\hline Staff & Mouvement & Community regeneration \\
\hline Volunteer A & Avancé & Community regeneration \\
\hline Director & Avancé & Community regeneration \\
\hline Volunteer B & Avancé & Community regeneration \\
\hline Assistant director & Avancé & Community regeneration \\
\hline Representative & Social centre network & Community regeneration \\
\hline Regional Representative & Lyon Older People (LOP) & Older People \\
\hline Staff & LOP Organisation 1 & Older People \\
\hline Staff A & LOP Organisation 2 & Older People \\
\hline Staff B & LOP Organisation 2 & Older People \\
\hline Staff & LOP Organisation 3 & Older People \\
\hline Staff & LOP Organisation 4 & Older People \\
\hline Director & Lyon Parents & Parents \\
\hline Staff & Lyon Parents & Parents \\
\hline Volunteer & Lyon Parents & Parents \\
\hline President & Lyon Parents & Parents \\
\hline
\end{tabular}




\section{Appendix 7: List of events and observations}

\section{Event attendances}

\begin{tabular}{|l|l|l|}
\hline Location & Event & Date \\
\hline Niort, France & $\begin{array}{l}\text { National Exhibition of the Social and Solidarity } \\
\text { Economy }\end{array}$ & 19 October 2014 \\
\hline Paris, France & National Forum of Associations and Foundations & 22 October 2014 \\
\hline $\begin{array}{l}\text { Sheffield, } \\
\text { England }\end{array}$ & $\begin{array}{l}\text { National Coalition for Independent Action } \\
\text { Roadshow }\end{array}$ & 2 July 2015 \\
\hline $\begin{array}{l}\text { Sheffield, } \\
\text { England }\end{array}$ & $\begin{array}{l}\text { Involve Yorkshire \& Humber - "Politics into } \\
\text { Practice" }\end{array}$ & 17 September 2015 \\
\hline Lyon, France & Journée de Rentrée Sociale de l'URIOPSS18 & 24 September 2015 \\
\hline $\begin{array}{l}\text { Sheffield, } \\
\text { England }\end{array}$ & Voluntary Action Sheffield AGM & 17 October 2016 \\
\hline
\end{tabular}

\section{Case study observations}

\begin{tabular}{|l|l|l|l|}
\hline City & Organisation & Event/ meeting & Date \\
\hline Lyon & Avancé & $\begin{array}{l}\text { Assemblée Générale } \\
\text { (General Assembly/AGM) }\end{array}$ & 17 May 2016 \\
\hline Lyon & Mouvement & Assemblée Générale & 20 May 2016 \\
\hline Lyon & Familles & Assemblée Générale & 26 May 2016 \\
\hline Lyon & Lyon Parents & Anniversary party & 28 May 2016 \\
\hline
\end{tabular}

\begin{tabular}{|l|l|l|l|}
\hline Sheffield & Enterprise & $\begin{array}{l}\text { 2x social cafes for people } \\
\text { with mental health } \\
\text { problems }\end{array}$ & $\begin{array}{l}\text { 21 and 24 August } \\
2015\end{array}$ \\
\hline Sheffield & Develop & Community forum meeting & 27 January 2016 \\
\hline Sheffield & $\begin{array}{l}\text { Sheffield } \\
\text { Parents }\end{array}$ & Family craft day & 1 April 2016 \\
\hline Sheffield & Aspire & Annual General Meeting & $\begin{array}{l}\text { 17 November } \\
2016\end{array}$ \\
\hline Sheffield & Recreation & Annual General Meeting & 7 December 2016 \\
\hline
\end{tabular}

18 URIOPSS (Union Régionale Interfédérale des Oeuvres Privées Sanitaires et Sociales) is a network of social service providing associations. The event - 'Journée de Rentrée Sociale' can only awkwardly be translated as 'Post-holiday/ Back-to-school Social Day' where 'social' refers to social services. The event was a regional conference on political and economic issues relevant to this sector. 


\title{
Appendix 8: Application for ethical review
}

\author{
UNIVERSITY OF BIRMINGHAM \\ APPLICATION FOR ETHICAL REVIEW
}

Who should use this form:

\begin{abstract}
This form is to be completed by PIs or supervisors (for PGR student research) who have completed the University of Birmingham's Ethical Review of Research Self Assessment Form (SAF) and have decided that further ethical review and approval is required before the commencement of a given Research Project.

Please be aware that all new research projects undertaken by postgraduate research (PGR) students first registered as from 1st September 2008 will be subject to the University's Ethical Review Process. PGR students first registered before $1^{\text {ct }}$ September 2008 should refer to their Department/School/College for further advice.
\end{abstract}

Researchers in the following categories are to use this form:

1. The project is to be conducted by:

- staff of the University of Birmingham; or

- postgraduate research (PGR) students enrolled at the University of Birmingham (to be completed by the student's supervisor);

2. The project is to be conducted at the University of Birmingham by visiting researchers.

Students undertaking undergraduate projects and taught postgraduate (PGT) students should refer to their Department/School for advice.

NOTES:

$>\quad$ An electronic version of the completed form should be submitted to the Research Ethics Officer, at the following email address: aer-ethics@contacts.bham.ac.uk. Please do not submit paper copies.

$>\quad$ If, in any section, you find that you have insufficient space, or you wish to supply additional material not specifically requested by the form, please it in a separate file, clearly marked and attached to the submission email.

$>\quad$ If you have any queries about the form, please address them to the Research Ethics Team.

$\bigotimes$ Before submitting, please tick this box to confirm that you have consulted and understood the following information and guidance and that you have taken it into account when completing your application:

- The information and guidance provided on the University's ethics webpages (https://intranet.birmingham.ac.uk/finance/accounting/Research-SupportGroup/Research-Ethics/Ethical-Review-of-Research.aspx)

- The University's Code of Practice for Research (http://www.as.bham.ac.uk/legislation/docs/COP Research.pdf) 


\section{UNIVERSITY OF BIRMINGHAM APPLICATION FOR ETHICAL REVIEW}

1. TITLE OF PROJECT

The third sector and co-production of social services: A comparative study of England and France

\section{THIS PROJECT IS:}

University of Birmingham Staff Research project

University of Birmingham Postgraduate Research (PGR) Student project $\bigotimes$

Other $\square$ (Please specify):

\section{INVESTIGATORS}

a) PLEASE GIVE DETAILS OF THE PRINCIPAL INVESTIGATORS OR SUPERVISORS (FOR PGR STUDENT PROJECTS)

\begin{tabular}{|l|l|}
\hline Name: Title / first name / family name & Prof Chris Skelcher \\
\cline { 2 - 2 } Hiqhest qualification \& position held: & Professor of Public Governance \\
\cline { 2 - 2 } School/Department & INLOGOV, School of Government and Society \\
\cline { 2 - 2 } Telephone: & 01214144962 \\
\cline { 2 - 2 } Email address: & c.k.skelcher@bham.ac.uk \\
\hline
\end{tabular}

Name: Title / first name / family name

Hiqhest qualification \& position held:

School/Department

Telephone:

Email address:

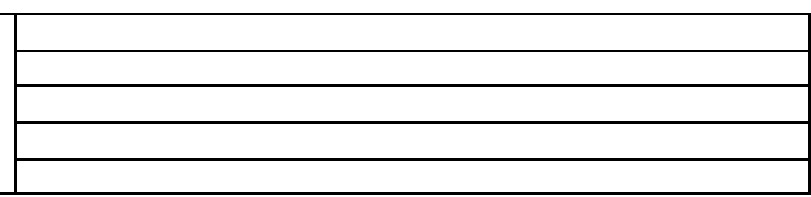

b) PLEASE GIVE DETAILS OF ANY CO-INVESTIGATORS OR CO-SUPERVISORS (FOR PGR STUDENT PROJECTS)

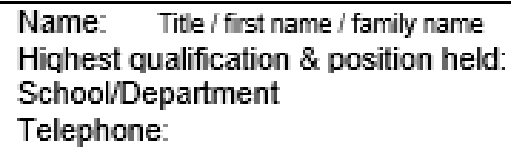

Email address:

\begin{tabular}{l} 
Dr Catherine Needham \\
\hline Reader in Public Policy and Public Management \\
\hline Health Services Management Centre \\
\hline 01214146223 \\
\hline c.needham.1@bham.ac.uk
\end{tabular}

c) In the case of PGR student projects, please give details of the student

\begin{tabular}{|c|c|c|c|c|}
\hline \multirow{3}{*}{$\begin{array}{l}\text { Name of student: } \\
\text { Course of study: } \\
\text { Principal } \\
\text { supervisor: }\end{array}$} & \multirow{2}{*}{$\begin{array}{l}\text { Caitlin McMullin } \\
\mathrm{PhD}\end{array}$} & Student No: & \multicolumn{2}{|c|}{1272555} \\
\hline & & Email address: & \multicolumn{2}{|c|}{ Cxm257@bham.ac.uk } \\
\hline & Chris Skelcher. & & & \\
\hline \multirow{3}{*}{$\begin{array}{l}\text { Name of student: } \\
\text { Course of study: } \\
\text { Principal supervisor: }\end{array}$} & & \multicolumn{2}{|c|}{ Student No: } & \\
\hline & & \multicolumn{2}{|c|}{ Email address: } & \\
\hline & & & & \\
\hline
\end{tabular}
4. ESTIMATED START OF PROJECT
Date: 


\section{FUNDING}

List the funding sources (including internal sources) and give the status of each source. $¥$

\begin{tabular}{|l|l|}
\hline Funding Body & Approved/Pending $/ T_{\text {to be submitted }}$ \\
\hline None - self-funded & \\
& \\
\hline
\end{tabular}

If you are requesting a quick turnaround on your application, please explain the reasons below (including funding-related deadlines). You should be aware that whilst effort will be made in cases of genuine urgency, it will not always be possible for the Ethics Committees to meet such requests.

\section{SUMMARY OF PROJECT}

Describe the purpose, background rationale for the proposed project, as well as the hypotheses/research questions to be examined and expected outcomes. This description should be in everyday language that is free from jargon. Please explain any technical terms or discipline-specific phrases.

The concept of 'co-production' of public services has increasingly gained attention by scholars across Europe who aim to analyse new models of public service delivery where service users collaborate with professionals and actively contribute to the delivery of the service. Co-production can be defined as the collaboration of citizens or service users and professionals in both co-design/ co-design as well as in co-delivery of services. Some scholars suggest that the third sector (defined as not-for-profit organisations, or organisations that reinvest any profits into the community) are inherently predisposed to creating more co-productive relationships with service users (Pestoff et al. 2012).

Despite the increase in research about this phenomenon across Europe and the United States, little comparative work has been conducted to analyse the institutional conditions that may enable or constrain organisations in different countries to co-produce with citizens, and many comparative studies incorrectly assume a coherence of conceptual understandings across borders. This presumption is particularly evident when investigating the differences between the literature on the third sector and co-production in England and the French literature on the social and solidarity economy, where the term 'co-production' is little used. Through my doctoral research, I seek to investigate how notions of participation and the third sector, as well as differing political and institutional contexts shape co-production practice by associations, charities and co-operatives in France and England.

Given the similarities and differences between the political and institutional contexts between England and France, these two countries make interesting cases for comparison in order to better understand whether co-production is in part determined by culture, politics, narrative framings and national contexts. In England, co-production has been advocated by a wide range of actors who suggest that it can increase efficiencies and satisfaction with public services. By contrast, in France, public powers have only recently begun to consider consultation and participation activities, and coproduction activity within the third sector is rarely described as such. I hypothesise that these contextual differences will determine both how participation and co-production are described and framed, as well as the particular activities that actors undertake.

My $\mathrm{PhD}$ will address the following research questions:

1. How is co-production conceptualised and framed by French third sector organisations, and is this different to the narrative in England?

2. How do different political and institutional factors provide favourable or detrimental conditions for third sector organisations to co-produce services with users? How are these different in England and France? 


\section{CONDUCT OF PROJECT}

Please give a description of the research methodology that will be used

The research design is a qualitative comparative international case study, focusing on Sheffield in England and Lyon in France. These two cities were selected because of size comparability (both with a population of approximately 500,000 ) and based on recommendations of academics and stakeholders who suggested the two cities as locations with a strong tradition of third sector activity. The decision was made to focus on third sector organisations because of evidence that suggests that third sector actors are more effective at facilitating citizen participation and co-production (Pestoff 2009).

I will conduct semi-structured interviews in third sector organisations in each city. Interviews in Lyon will be conducted in French, except with fluent English speakers who are happy to be interviewed in English. Interviews will be recorded with a digital recorder and transcribed verbatim. In terms of qualitative analysis of my data, I will use the constant comparative method in NVJve to code my transcripts and produce themes from the data.

\section{DOES THE PROJECT INVOLVE PARTICIPATION OF PEOPLE OTHER THAN THE} RESEARCHERS AND SUPERVISORS?

\section{Yes $\bigotimes$ No}

Note: 'Participation' includes both active participation (such as when participants take part in an interview) and cases where participants take part in the study without their knowledge and consent at the time (for example, in crowd behaviour research).

If you have answered NO please go to Section 18. If you have answered YES to this question please complete all the following sections.

\section{PARTICIPANTS AS THE SUBJECTS OF THE RESEARCH}

Describe the number of participants and important characteristics (such as age, gender, location, affiliation, level of fitness, intellectual ability etc.). Specify any inclusion/exclusion criteria to be used.

The research will focus on two case study location areas - Sheffield and Lyon. Within each city, I will aim to speak to a number of third sector organisations that provide a range of community and social services. Participants will be staff members (senior staff/ directors, frontline staff such as youth group organisers, childcare professionals, project managers, etc.) and volunteers of these organisations. When appropriate, citizens or service users who are taking part in participation/ co-production initiatives in partnership with professionals of the organisation may also be intervieved, but these will not be NHS or local authority services. 


\section{RECRUITMENT}

Please state clearly how the participants will be identified, approached and recruited. Include any relationship between the investigator(s) and participant(s) (e.g. instructor-student).

Note: Attach a copy of any poster(s), advertisement(s) or letter(s) to be used for recruitment.

In order to choose participants, I will speak to the directors of infrastructure organisations in each city and ask for suggestions of organisations that are specifically known for engaging in co-production or innovative participation initiatives. I will use purposive sampling to recruit participants from organisations that are 1. providiag services or projects in a service area that has a comparable example in the other case study city, 2. engaging in activities or projects that meet my definition of co-production. In the first instance, I will aim to interview a senior staff member of the organisation, and then any frontline staff or volunteers as suggested by that staff member.

\section{CONSENT}

a) Describe the process that the investigator(s) will be using to obtain valid consent. If consent is not to be obtained explain why. If the participants are minors or for other reasons are not competent to consent, describe the proposed alternate source of consent, including any permission / information letter to be provided to the person(s) providing the consent.

Participants will initially be asked whether they are interested and willing to participate in the study. Before an interview, the participant will be verbally informed about the purpose of the study and the general direction the interview questions will take, and the fact that all responses will be anonymised in any written outputs, and will be asked whether they are happy for the interview to be recorded and transcribed. They will be asked to sign a consent form if they are happy with the terms of taking part in the research.

Note: Attach a copy of the Participant Information Sheet (if applicable), the Consent Form (if applicable), the content of any telephone script (if applicable) and any other material that will be used in the consent process.

b) Will the participants be deceived in any way about the purpose of the study? Yes $\square$ No $\square$

If yes, please describe the nature and extent of the deception involved. Include how and when the deception will be revealed, and who will administer this feedback. 
12. PARTICIPANT FEEDBACK

Explain what feedback/ information will be provided to the participants after participation in the research. (For example, a more complete description of the purpose of the research, or access to the results of the research).

If participants are interested in any outputs of the research, I will inform them that I am happy to send them copies of any written reports I produce.

\section{PARTICIPANT WITHDRAWAL}

a) Describe how the participants will be informed of their right to withdraw from the project.

Participants will be informed before starting an interview that they have the right to withdraw from the project at any time. This will also be written on the consent form.

b) Explain any consequences for the participant of withdrawing from the study and indicate what will be done with the participant's data if they withdraw.

If a participant withdraws from the study, any data/ information derived from an interview with them will be destroyed and not used in any analysis.

14. COMPENSATION

Will participants receive compensation for participation?

i) Financial

ii) Non-financial

If Yes to either i) or ii) above, please provide details.

If participants choose to withdraw, how will you deal with compensation? 


\section{CONFIDENTIALITY}

a) Will all participants be anonymous?

Yes $\otimes$ No

b) Will all data be treated as confidential?

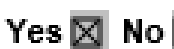

Note: Participants' identity/data will be confidential if an assigned ID code or number is used, but it will not be anonymous. Anonymous data cannot be traced back to an individual participant.

Describe the procedures to be used to ensure anonymity of participants and/or confidentiality of data both during the conduct of the research and in the release of its findings.

Whilst the subject matter is unlikely to cause any discomfort or invade participants' personal privacy, it is possible that confidential matters may arise (such as business figures for the organisation, or personality conflicts between participants which are conveyed in confidence) and therefore I will completely anonymise participants as well as case study organisations in my doctoral thesis and any related research reports/articles, by referring to individuals by their job title and producing pseudonyms for each organisation.

If participant anonymity or confidentiality is not appropriate to this research project, explain, providing details of how all participants will be advised of the fact that data will not be anonymous or confidential.

\section{STORAGE, ACCESS AND DISPOSAL OF DATA}

Describe what research data will be stored, where, for what period of time, the measures that will be put in place to ensure security of the data, who will have access to the data, and the method and timing of disposal of the data.

Research data for the project includes the contact details of participants, notes of interviews and meeting observations, interview recordings and interview transcripts. These will all be held as digital records, aside from physical notes of meetings and interviews, which will be immediately destroyed after typing them up. Digital records of research data will be filed as follows:

- Digital files (including word documents and NVivo files) will be stored in a Dropbox folder with a two-step password verification process enabled. Files will be encrypted using Boxcrypter for an extra layer of security, and any files with sensitive information (transcripts, spreadsheets with participant information) vill be password protected. EileV(ault full-desk encryption will be used on my laptop.

- Interview recordings will be stored separately on a password protected USB flash drive to ensure security.

- The only people who vill have access to the research data are myself and my supervisors.

- The data vill be kept throughout the project and upon completion of the project, fully anonymised transcripts will be preserved and made accessible for 10 years. All other files will be destroyed within six months after completion of the $\mathrm{PhD}$. If a participant withdraws from the project, any notes or transcripts from their interview will be immediately destroyed. 
17. OTHER APPROVALS REQUIRED? e g. Criminal Records Bureau (CRB) checks or NHS R\&D approvals.
YES
NO
凶 NOT APPLICABLE

If yes, please specify.

18. SIGNIFICANCE/BENEFITS

Outline the potential significance and/or benefits of the research

Co-production has gained increasing normative appeal in both practice and academic literature in England, but the evidence base around when, why and how it happens and works is currently sketchy. A particular gap in the literature is in understanding whether there is a difference in how coproduction is understand and practiced in different countries, particularly in France where coproduction research is comparatively limited. My doctoral research will provide a valuable contribution to the literature by examining co-production in two different contexts and analysing what factors - if any - contribute to differences between the two.

\section{RISKS}

a) Outline any potential risks to INDIVIDUALS, including research staff, research participants, other individuals not involved in the research and the measures that will be taken to minimise any risks and the procedures to be adopted in the event of mishap

There are no particular potential risks to individuals participating in the research or to the researcher. I have considerable experience in undertaking interviews in my previous employment as a research assistant on a large scale ESRC funded project so I am extremely familiar with the necessary precautions that should be undertaken to ensure that risks are minimised. 
b) Outline any potential risks to THE ENVIRONMENT and/or SOCIETY and the measures that will be taken to minimise any risks and the procedures to be adopted in the event of mishap.

There are no particular potential risks to the environment or society from the research.

20. ARE THERE ANY OTHER ETHICAL ISSUES RAISED BY THE RESEARCH?

Yes $\square$ No $\square$

If yes, please specify 


\section{EXPERT REVIEWER/OPINION}

You may be asked to nominate an expert reviewer for certain types of project, including those of an interventional nature or those involving significant risks. If you anticipate that this may apply to your work and you would like to nominate an expert reviewer at this stage, please provide details below.

\begin{tabular}{|l|}
\hline Name \\
\hline Contact details (including email address) \\
\hline \\
\hline Brief explanation of reasons for nominating and/or nominee's suitability \\
\hline
\end{tabular}

\section{CHECKLIST}

Please mark if the study involves any of the following:

- Vulnerable groups, such as children and young people aged under 18 years, those with learning disability, or cognitive impairments

- Research that induces or results in or causes anxiety, stress, pain or physical discomfort, or poses a risk of harm to participants (which is more than is expected from everyday life)

- Risk to the personal safety of the resegrcher

- Deception or research that is conducted without full and informed consent of the participants at time study is carried out

- Administration of a chemical agent or vaccines or other substances (including vitamins or food substances) to human participants.

- Production and/or use of genetically modified plants or microbes

- Results that may have an adverse impact on the environment or food safety

- Results that may be used to develop chemical or biological weapons

Please check that the following documents are attached to your application.

$\begin{array}{lll} & \text { ATTACHED } & \text { NOT } \\ \text { Recruitment gdvertisement } & \text { APPLICABLE } \\ \text { Participant information sheet } & & \\ \text { Consent form } & & \\ \text { Questionngire } & & \end{array}$




\section{DECLARATION BY APPLICANTS}

I submit this application on the basis that the information it contains is confidential and will be used by the University of Birmingham for the purposes of ethical review and monitoring of the research project described bereia, and to satisfy reporting requirements to regulatory bodies. The information will not be used for any gther purpose without my prior consent.

I declare that:

- The information in this form together with any accompanying information is complete and correct to the best of my knowledge and belief and I take full responsibility for it.

- I undertake to abide by University Code of Practice for Research (http://www.as.bham.ac.uk/leqislation/docs/COP Research.pdf) alongside any other relevant professional bodies' codes of conduct and/or ethical guidelines.

- I will report any changes affecting the ethical aspects of the project to the University of Birmingham Research Ethics Officer.

- I will report any adverse or unforeseen events which occur to the relevant Ethics Committee via the University of Birmingham Research Ethics Officer.

Name of principal investigator/project supervisor:

Date:

Rrof.Chris Skelsher

19 Oct 2015

Please now save your completed form, print a copy for your records, and then email a copy to the Research Ethics Officer, at aer-ethics@contacts.bham.ac.uk. As noted above, please do not submit a paper copy. 


\section{DOCUMENTS CONSULTED}

Charte fédérale des centres sociaux et socio-culturels de France (2000) Available at: http://www.centres-sociaux.fr/files/2010/02/Charte-des-centres-sociauxet-socioculturels-de-France.pdf (Accessed 18 December 2017)

Department of Communities and Local Government (2008) Communities in control: real people, real power. Available at: https://www.gov.uk/government/publications/communities-in-controlreal-people-real-power (Accessed 19 December 2017)

Grand Lyon (2015) La Metropole de Lyon. Available at: https://www.grandlyon.com/fileadmin/user upload/media/pdf/institutio

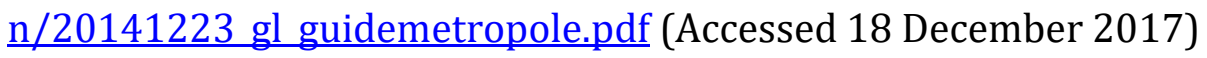

Oxford Economics (September 2013) Sheffield City Region Baseline Report. Available at: http://sheffieldcityregion.org.uk/wpcontent/uploads/2013/10/Baseline-Report.pdf (Accessed 18 December 2017)

Sheffield City Council (30 June 2016) Housing, Enterprise and Regeneration Housing Equalities Group Minutes. Available at: https://www.sheffield.gov.uk/content/dam/sheffield/docs/your-citycouncil/our-plans,-policies-andperformance/Housing\%20Equalities\%20Group\%20Minutes\%2030th\%20I une\%202016.pdf (Accessed 18 December 2017)

Sheffield Executive Board (8 April 2015) Thriving Voluntary Community and Faith Sector Leadership Group - progress report. Available at: http://www.vas.org.uk/UserFiles/File/Miscellaneous/SEB Thriving VCF L eadership Group Report Apr 2015.pdf (Accessed 18 December 2017)

Sheffield Fairness Commission (2012) Making Sheffield Fairer. Available at: https://www.sheffield.gov.uk/content/dam/sheffield/docs/your-citycouncil/our-plans,-policies-andperformance/Fairness\%20Commission\%20Report.pdf (Accessed 18 December 2017) 
Voluntary Action Sheffield Social Impact Report (2016) 90 Years and Still Doing Good. Available at:

http://www.vas.org.uk/UserFiles/File/About VAS/VAS 90 years and still doing good.pdf (Accessed 18 December 2017)

Voluntary Action Sheffield (2016) Sheffield State of the Voluntary and Community Sector. Available at:

https://www4.shu.ac.uk/research/cresr/sites/shu.ac.uk/files/sheffieldstate-of-the-voluntary-and-community-sector-2016.pdf (Accessed 18

December 2017) 


\section{REFERENCES}

Ackerman, J. (2012) 'From co-production to co-governance' in Pestoff, V., Brandsen, T. and Verschuere, B., eds., New public governance, the third sector and coproduction, New York: Routledge, 101-126.

Aderbach, J.D. and Christensen, T. (2005) 'Citizens and consumers: An NPM dilemma', Public Management Review, 7(2), 225-246.

Alcock, P. (2010) 'Devolution or divergence? UK third sector policy since 2000' in Lodge, G. and Schmuecker, K., eds., Devolution in practice 2010, London: IPPR.

Alford, J. (1998) 'A public management road less travelled: Clients as co-producers of public services', Australian Journal of Public Administration, 57(4), 128137.

Alford, J. (2014) 'The multiple facets of co-production: Building on the work of Elinor Ostrom', Public Management Review, 16(3), 299-316.

Alford, J. and O'Flynn, J. (2012) Rethinking public service delivery: Managing with external providers, Basingstoke: Palgrave Macmillan.

Alinsky, S. (1971) Rules for radicals: A practical primer for realistic radicals, New York: Vintage Books, 1989.

Archambault, E. (2009) 'The third sector in Europe: Does it exhibit a converging movement?', Comparative Social Research, 26, 3-24.

Archambault, E., Priller, E. and Zimmer, A. (2013) 'European civil societies compared: Typically German-Typically French?', Voluntas, 1-24.

Arnstein, S.R. (1969) 'A ladder of citizen participation', Journal of the American Institute of planners, 35(4), 216-224.

Arts, W. and Gelissen, J. (2002) 'Three worlds of welfare capitalism or more? A state-of-the-art report', Journal of European Social Policy, 12(2), 137-158.

Bacqué, M.-H. and Gauthier, M. (2011) 'Participation, urbanisme et études urbaines', Participations, 1(1), 36-66.

Barthélemy, M. (2000) Associations: Un nouvel âge de la participation?, Paris: Presses de Sciences Po. 
Beebeejaun, Y., Durose, C., Rees, J., Richardson, J. and Richardson, L. (2014) 'Beyond text': Exploring ethos and method in co-producing research with communities', Community Development Journal, 49(1), 37-53.

Bevir, M., Rhodes, R.A. and Weller, P. (2003) 'Traditions of governance: Interpreting the changing role of the public sector', Public Administration, 81(1), 1-17.

Blaxter, L., Hughes, C. and Tight, M. (2001) How to research, 2nd ed., Buckingham: Open University Press.

Blondiaux, L. and Fourniau, J.-M. (2011) 'Un bilan des recherches sur la participation du public en démocratie: Beaucoup de bruit pour rien?', Participations, 1(1), 8-35.

Bovaird, T. (2007) 'Beyond engagement and participation: User and community coproduction of public services', Public Administration Review, 67(5), 846860.

Bovaird, T. and Loeffler, E. (2012) 'From engagement to co-production: The contribution of users and communities to outcomes and public value', Voluntas, 23(4), 1119-1138.

Bovaird, T., Van Ryzen, G.G., Loeffler, E. and Parrado, S. (2015) 'Activating citizens to participate in collective co-production of public services', Journal of Social Policy, 44(1), 1-23.

Boyle, D. and Harris, M. (2009) The challenge of co-production: How equal partnerships between professionals and the public are crucial to improving public services, London: New Economics Foundation.

Brandsen, T. and Helderman, J.-K. (2012) 'The conditions for successful coproduction in housing: A case study of German housing cooperatives' in Pestoff, V., Brandsen, T. and Verschuere, B., eds., New public governance, the third sector and co-production, New York: Routledge.

Brandsen, T. and Honingh, M. (2015) 'Distinguishing different types of coproduction: A conceptual analysis based on the classical definitions', Public Administration Review, 76(3), 427-435.

Brandsen, T. and Pestoff, V. (2006) 'Co-production, the third sector and the delivery of public services: An introduction', Public Management Review, 8(4), 493501.

Bresson, M. (2004) 'La participation des habitants contre la démocratie participative: Dans les centres sociaux associatifs du Nord de la France', Déviance et Société, 28(1), 97-114. 
Brint, S. (2001) 'Gemeinschaft revisited: A critique and reconstruction of the community concept', Sociological Theory, 19(1), 1-23.

Brudney, J.L. and England, R.E. (1983) 'Toward a definition of the coproduction concept', Public Administration Review, 43(1), 59-65.

Bryant, A. (2014) 'The Grounded Theory Method' in Leavy, P., ed., The Oxford handbook of qualitative research, Oxford: Oxford University Press, 116-136.

Bryman, A. (2016) Social research methods, 5th ed., Oxford: Oxford University Press.

Burnham, P., Gilland Lutz, K., Grant, W. and Layton-Henry, Z. (2008) Research methods in politics, 2nd ed., Basingstoke: Palgrave Macmillan.

Clark, D. and Southern, R. (2006) 'Comparing institutional designs for neighbourhood renewal: Neighbourhood management in Britain and the régies de quartier in France', Policy \& Politics, 34(1), 173-191.

Clark, J., Kane, D., Wilding, K. and Wilton, J. (2010) 'The UK civil society almanac 2010', London: National Council for Voluntary Organisations.

Cloke, P., Johnsen, S. and May, J. (2005) 'Exploring ethos? Discourses of 'charity' in the provision of emergency services for homeless people', Environment and Planning A, 37(3), 385-402.

Cole, A. and Jones, G. (2005) 'Reshaping the state: Administrative reform and new public management in France', Governance, 18(4), 567-588.

Cornwall, A. (2008) 'Unpacking 'participation': Models, meanings and practices', Community Development Journal, 43(3), 269-283.

Defourny, J. (2001) 'From third sector to social enterprise' in Borzaga, C. and Defourny, J., eds., The emergence of social enterprise, New York: Routledge, $1-18$.

Defourny, J. and Nyssens, M. (2006) 'Defining social enterprise' in Nyssens, M., ed., Social enterprise: At the crossroads of market, public policies and civil society, New York: Routledge, 3-26.

Della Porta, D. and Diani, M. (2006) Social movements: An introduction, 2nd ed., Malden, MA: Blackwell Publishing.

Denhardt, R.B. and Denhardt, J.V. (2000) 'The new public service: Serving rather than steering', Public Administration Review, 60(6), 549-559.

Dessaulle, M.S. (2005) 'La personne en situation de handicap: Usager ou citoyen?', Gérontologie et Société, 115(4), 63-74. 
DiMaggio, P. and Powell, W.W. (1983) 'The iron cage revisited: Collective rationality and institutional isomorphism in organizational fields', American Sociological Review, 48(2), 147-160.

Donzelot, J. and Epstein, R. (2006) 'Démocratie et participation: L'exemple de la rénovation urbaine', Esprit, (7), 5-34.

Doty, D.H. and Glick, W.H. (1994) 'Typologies as a unique form of theory building: Toward improved understanding and modeling', Academy of Management Review, 19(2), 230-251.

Dubois, A. and Gadde, L.-E. (2002) 'Systematic combining: An abductive approach to case research', Journal of Business Research, 55, 553-560.

Duffy, B. (2010) 'The analysis of documentary evidence' in Bell, J., ed., Doing your research project: A guide for first-time researchers in education, health and social science, 5th ed., Maidenhead: Open University Press, 124-139.

Dunleavy, P. and Hood, C. (1994) 'From old public administration to new public management', Public Money \& Management, 14(3), 9-16.

Dunston, R., Lee, A., Boud, D., Brodie, P. and Chiarella, M. (2009) 'Co-Production and health system reform: From re-imagining to re-making', Australian Journal of Public Administration, 68(1), 39-52.

Durose, C., Needham, C., Mangan, C. and Rees, J. (2017) 'Generating 'good enough' evidence for co-production', Evidence \& Policy, 13(1), 135-151.

Durose, C. and Richardson, L. (2016) Designing public policy for co-production, Bristol: Policy Press.

Edelenbos, J., van Buuren, A. and van Schie, N. (2011) 'Co-producing knowledge: Joint knowledge production between experts, bureaucrats and stakeholders in Dutch water management projects', Environmental Science \& Policy, 14, 675-684.

Espagne, F. (2002) 'Sur l'économie sociale et solidaire', Revue internationale de l'économie sociale, 81(286), 13-22.

Esping-Andersen, G. (1990) The three worlds of welfare capitalism, Cambridge: Polity press.

Evers, A. (2006) 'Complementary and conflicting: The different meaning of 'user involvement' in social services' in Matthies, A. L., ed., Nordic civil society organisations and the future of welfare services: A model for Europe?, Copenhagen: Nordic Council, 255-276. 
Evers, A. and Laville, J.-L. (2004) 'Defining the third sector in Europe' in Evers, A. and Laville, J.-L., eds., The third sector in Europe, Cheltenham: Edward Elgar Publishing Ltd, 11-42.

Ewert, B. and Evers, A. (2012) 'Co-Production: Contested meanings and challenges for user organizations' in Pestoff, V., Brandsen, T. and Verschuere, B., eds., New public governance, the third sector and co-production, New York: Routledge, 61-78.

Fairclough, N. (1995) Critical Discourse Analysis: The critical study of language, London: Longman.

Feldman, M.S. and Orlikowski, W.J. (2011) 'Theorizing practice and practicing theory', Organization Science, 22(5), 1240-1253.

Feldman, M.S., Sköldberg, K., Brown, R.N. and Horner, D. (2004) 'Making sense of stories: A rhetorical approach to narrative analysis', Journal of Public Administration Research and Theory, 14(2), 147-170.

Ferragina, E. and Seeleib-Kaiser, M. (2011) 'Welfare regime debate: Past, present, futures?', Policy \& Politics, 39(4), 583-611.

Ferrera, M. (1996) 'The 'Southern model' of welfare in social Europe', Journal of European Social Policy, 6(1), 17-37.

Flick, U. (2014) An introduction to qualitative research, 5th ed., London: Sage.

Fligstein, N. (1990) The transformation of corporate control, Cambridge, MA: Harvard University Press.

Fraisse, L. and Bucolo, E. (2003) 'Études de cas sur Rennes et Montreuil' in Synthèse des études de cas de la recherche TSFEPS CRIDA.

Franzosi, R. (1998) 'Narrative analysis - Or why (and how) sociologists should be interested in narrative', Annual Review of Sociology, 24(1), 517-554.

Freire, P. (1970) Pedagogy of the oppressed, London: Continuum International Publishing Group, 2000.

Friedland, R. and Alford, R.R. (1991) 'Bringing society back in: Symbols, practices and institutional contradictions' in Powell, W. W. and Dimaggio, P. J., eds., The new institutionalism in organizational analysis, 2nd ed., Chicago: University of Chicago Press.

Fung, A. (2006) 'Varieties of participation in complex governance', Public Administration Review, 66, 66-75. 
Fung, A. and Wright, E.0. (2003) Deepening democracy: Institutional innovations in empowered participatory governance, London: Verso.

Gee, J.P. (1986) 'Units of production of narrative discourse', Discourse Processes, 9(4), 391-422.

Glaser, B. and Strauss, A. (1999) The discovery of grounded theory: Strategies for qualitative research, London:Routledge.

Greenwood, R., Díaz, A.M., Li, S.X. and Lorente, J.C. (2010) 'The multiplicity of institutional logics and the heterogeneity of organizational responses', Organization Science, 21(2), 521-539.

Greenwood, R., Hinings, C.R. and Whetton, D. (2014) 'Rethinking institutions and organizations', Journal of Management Studies, 51(7), 1206-1220.

Greenwood, R. and Suddaby, R. (2006) 'Institutional entrepreneurship in mature field: The big five accounting firms', Academy of Management Journal, 49(1), 27-48.

Grix, J. (2010) The foundations of research, 2nd ed., Basingstoke: Palgrave Macmillan.

Hall, P. (1986) 'Governing the economy: The politics of state intervention in Britain and France'.

Hall, S. and Hickman, P. (2002) 'Neighbourhood renewal and urban policy: A comparison of new approaches in England and France', Regional Studies, 36(6), 691-696.

Hampson, M., Baeck, P. and Langford, K. (2013) By us, for us: The power of co-design and co-delivery, London: Nesta.

Hantrais, L. (2008) International comparative research: Theory, methods and practice, Palgrave Macmillan.

Hardy, C., Palmer, I. and Phillips, N. (2000) 'Discourse as a strategic resource', Human Relations, 53(9), 1227-1248.

Hartley, J. (2005) 'Innovation in governance and public services: Past and present', Public Money and Management, 25(1), 27-34.

Hodge, S. (2005) 'Participation, discourse and power: A case study in service user involvement', Critical Social Policy, 25(2), 164-179.

Hood, C. (1991) 'A public management for all seasons?', Public Administration, 69(1), 3-19. 
Hood, C. (1995) 'The "new public management" in the 1980s: Variations on a theme', Accounting, Organizations and Society, 20(2-3), 93-109.

Horne, M. and Shirley, T. (2009) Co-production in public services: A new partnership with citizens, London: Cabinet Office.

Irvin, R.A. and Stansbury, J. (2004) 'Citizen participation in decision making: Is it worth the effort?', Public Administration Review, 64(1), 55-65.

Jetté, C. and Vaillancourt, Y. (2011) 'Social economy and home care services in Quebec: Co-Production or co-construction?', Voluntas, 22(1), 48-69.

Johnston, R. and Clark, G. (2008) Service operations management: Improving service delivery, Harlow: Prentice Hall.

Joshi, A. and Moore, M. (2004) 'Institutionalised co-production: Unorthodox public service delivery in challenging environments', Journal of Development Studies, 40(4), 31-49.

Jovchelovitch, S. and Bauer, M.W. (2000) Narrative interviewing, London: LSE Research Online, available: http://eprints.lse.ac.uk/2633 [accessed 11 December 2017].

Judge, D. (2005) Political institutions in the United Kingdom, Oxford University Press.

Kacza, D. and Peigney, F. (2016) La co-construction entre l'état et les acteurs locaux au coeur de la gouvernance du renouvellement urbain, SaintDenis: Commissariat général à l'égalité des territoires (CGET).

Kendall, J. and Almond, S. (1999) 'United Kingdom' in Salamon, L. M., Anheier, H. K., List, R., Toepler, S. and Sokolowski, S. W., eds., Global civil society: Dimensions of the nonprofit sector, Baltimore: The Johns Hopkins Center for Civil Society Studies, 179-199.

Kenny, S. (2002) 'Tensions and dilemmas in community development: New discourses, new Trojans?', Community Development Journal, 37(4), 284-299.

Laborde, C. (2000) 'The concept of the state in British and French political thought', Political Studies, 48(3), 540-557.

Laville, J.-L. (2005) Sociologie des services: Entre marché et solidarité, Toulouse: Éditions érès.

Laville, J.-L. (2010) Politique de l'association, Paris: Seuil.

Laville, J.L. (2003) 'Childcare and welfare mix in France', Annals of Public and Cooperative Economics, 74(4), 591-630. 
Lawrence, T., Suddaby, R. and Leca, B. (2011) 'Institutional work: Refocusing institutional studies of organization', Journal of Management Inquiry, 20(1), 52-58.

Laws, S., Harper, C., Jones, N. and Marcus, R. (2013) Research for development: A practical guide, 2nd ed., London: SAGE Publications.

Le Galès, P. (1995) 'Politique de la ville en France et en Grande-Bretagne: Volontarisme et ambiguïtés de l'État', Sociologie du Travail, 37(2), 249-275.

Loughlin, J. and Peters, B.G. (1997) 'State traditions, administrative reform and regionalization' in The political economy of regionalism, London: Routledge, 41-62.

Lounsbury, M. (2007) 'A tale of two cities: Competing logics and practice variation in the professionalizing of mutual funds', Academy of Management Journal, 50(2), 289-307.

Lowndes, V., Pratchatt, L. and Stoker, G. (2006a) 'Diagnosing and remedying the failings of official participation schemes: The CLEAR framework', Social Policy \& Society, 5(2), 281-291.

Lowndes, V., Pratchett, L. and Stoker, G. (2006b) 'Local political participation: The impact of rules-in-use', Public Administration, 84(3), 539-561.

Lowndes, V. and Roberts, M. (2013) Why institutions matter: The new institutionalism in political science, London: Palgrave Macmillan.

Mangen, S. (1999) 'Qualitative research methods in cross-national settings', International Journal of Social Research Methodology, 2(2), 109124.

McLaughlin, H. (2009) 'What's in a name: 'client', 'patient', 'customer', 'consumer', 'expert by experience', 'service user' - what's next?', British Journal of Social Work, 39, 1101-1117.

McLellan, E., MacQueen, K.M. and Neidig, J.L. (2003) 'Beyond the qualitative interview: Data preparation and transcription', Field Methods, 15(1), 63-84.

McMullin, C. and Needham, C. (2018) 'Co-production and healthcare' in Verschuere, B., Brandsen, T. and Steen, T., eds., Co-production and co-creation: Engaging citizens in public service delivery Routledge.

Miles, M.B., Huberman, A.M. and Sadaña, J. (2014) Qualitative data analysis: A methods sourcebook, 3rd ed., London: Sage. 
Moulaert, F. and Ailenei, 0. (2005) 'Social economy, third sector and solidarity relations: A conceptual synthesis from history to present', Urban Studies, 42(11), 2037-2053.

Nabatchi, T. (2010) 'Addressing the citizenship and democratic deficits: The potential of deliberative democracy for public administration', The American Review of Public Administration, 40(4), 376-399.

Needham, C. (2008) 'Realising the potential of co-production: Negotiating improvements in public services', Social Policy \& Society, 7(2), 221-231.

Needham, C. (2011) Personalising public services: Understanding the personalisation narrative, Bristol: Policy Press.

Needham, C. and Carr, S. (2009) 'Co-production: An emerging evidence base for adult social care transformation'.

Neyland, D. (2008) Organizational Ethnography, London: Sage.

Nyssens, M. and (ed) (2006) Social enterprise: At the crossroads of market, public policies and civil society, London: Routledge.

Osborne, S. (2006) 'The new public governance', Public Management Review, 8(3), 377-387.

Osborne, S. and Strokosch, K. (2013) 'It takes two to tango? Understanding the coproduction of public services by integrating the services management and public administration perspectives', British Journal of Management, 24(S1), S31-S47.

Ostrom, E. (1996) 'Crossing the great divide: Coproduction, synergy and development', World Development, 24(6), 1073-1087.

Ostrom, E. (2007) 'Institutional rational choice: An assessment of the institutional analysis and development framework' in Sabatier, P. A., ed., Theories of the Policy Process, 2nd ed., 0xford: Westview Press, 21-64.

Ostrom, E. (2012) 'Forward' in Pestoff, V., Brandsen, T. and Verschuere, B., eds., New public governance, the third sector and co-production, New York: Routledge, xv-xvii.

Pache, A.-C. and Santos, F. (2013) 'Inside the hybrid organization: Selective coupling as a response to competing institutional logics', Academy of Management Journal, 56(4), 972-1001.

Painter, M. and Peters, B.G. (2010a) 'Administrative traditions in comparative perspective: Families, groups and hybrids' in Painter, M. and Peters, B. G., 
eds., Tradition and Public Administration, London: Palgrave Macmillan, 1930.

Painter, M. and Peters, B.G. (2010b) 'The analysis of administrative traditions' in Painter, M. and Peters, B. G., eds., Tradition and Public Administration, London: Palgrave Macmillan, 3-16.

Parks, R.B., Baker, P.C., Kiser, L., Oakerson, R., Ostrom, E., Ostrom, V., Percy, S.L., Vandivort, M.B., Whitaker, G.P. and Wilson, R. (1981) 'Consumers as coproducers of public services: Some economic and institutional considerations', Policy Studies Journal, 9(7), 1001-1011.

Parrado, S., Van Ryzin, G.G., Bovaird, T. and Löffler, E. (2013) 'Correlates of coproduction: Evidence from a five-nation survey of citizens', International Public Management Journal, 16(1), 85-112.

Patsias, C. and Patsias, S. (2006) 'Les comités de citoyens, une transformation "par le bas" du système démocratique?', Politique et Sociétés, 25(1), 57-81.

Pemberton, S. and Mason, J. (2008) 'Co-production and Sure Start Children's Centres: Reflecting upon users' perspectives and implications for service delivery, planning and evaluation', Social Policy \& Society, 8(1), 13-24.

Pestoff, V. (2006) 'Citizens and co-production of welfare services: Childcare in eight European countries', Public Management Review, 8(4), 503-519.

Pestoff, V. (2008)A democratic architecture for the welfare state, London: Routledge.

Pestoff, V. (2009) 'Towards a paradigm of democratic participation: Citizen participation and co-production of personal social services in Sweden', Annals of Public and Cooperative Economics, 80(2), 197-224.

Pestoff, V. (2012a) 'Co-Production and third sector social services in Europe: Some crucial conceptual issues' in Pestoff, V., Brandsen, T. and Verschuere, B., eds., New public governance, the third sector and co-production, New York: Routledge, 13-34.

Pestoff, V. (2012b) 'New public governance, co-production and third sector social services in Europe: Crowding in and crowding out' in Pestoff, V., Brandsen, T. and Verschuere, B., eds., New public governance, the third sector and coproduction, New York: Routledge, 361-380.

Pestoff, V. (2014) 'Hybridity, co-production and third sector social services in Europe', American Behavioral Scientist, 58(11), 1412-1424. 
Pestoff, V., Brandsen, T., Verschuere, B. and (eds.) (2012) New public governance, the third sector and co-production, New York: Routledge.

Peters, B.G. (2008) 'The Napoleonic tradition', International Journal of Public Sector Management, 21(2), 118-132.

Prentice, S. (2006) 'Childcare, co-production and the third sector in Canada', Public Management Review, 8(4), 521-536.

Reay, T. and Hinings, C.R. (2009) 'Managing the rivalry of competing institutional logics', Organization Studies, 30(6), 629-652.

Reckwitz, A. (2002) 'Toward a theory of social practices: A development in culturalist theorizing', European Journal of Social Theory, 5(2), 243-263.

Richards, L. (2009) Handling qualitative data: $A$ practical guide, 2nd ed., London: Sage.

Rosnow, R. and Rosenthal, R. (1997) People studying people: Artifacts and ethics in behavioral research, New York: WH Freeman.

Rouban, L. (2008) 'Reform without doctrine: Public management in France', International Journal of Public Sector Management, 21(2), 133-149.

Rubin, H. and Rubin, I. (2012) Qualitative interviewing: The art of hearing data, 3rd ed., London: Sage.

Salamon, L.M. and Anheier, H.K. (1997) Defining the nonprofit sector: A crossnational analysis, Manchester:Manchester University Press.

Salamon, L.M. and Anheier, H.K. (1998) 'Social origins of civil society: Explaining the nonprofit sector cross-nationally', Voluntas, 9(3), 213-248.

Schatzki, T.R. (2001) 'Introduction: Practice Theory' in Schatzki, T. R., Knorr Cetina, $\mathrm{K}$. and von Savigny, E., eds., The practice turn in contemporary theory, London: Routledge, 10-23.

Scott, W.R. (2014) Institutions and organizations: Ideas, interests, and identities, 4th ed., London: SAGE Publications.

Seawright, J. and Gerring, J. (2008) 'Case selection techniques in case study research: A menu of qualitative and quantitative options', Political Research Quarterly, 61(2), 294-308.

Sharp, E.B. (1980) 'Toward a new understanding of urban services and citizen participation: The coproduction concept', The American Review of Public Administration, 14(2), 105-118. 
Silver, C. and Lewins, A.F. (2014) 'Computer-assisted analysis of qualitative research' in Leavy, P., ed., The Oxford handbook of qualitative research, Oxford: Oxford Unviersity Press, 606-638.

Silverman, D. (2013) Doing qualitative research, 4th ed., London: Sage.

Simmons, R., Birchall, J. and Prout, A. (2011) 'User involvement in public services: 'Choice about voice"', Public Policy and Administration, 0952076710384903.

Simons, H. (2009) Case study research in practice, London: Sage.

Sintomer, Y. and De Maillard, J. (2007) 'The limits to local participation and deliberation in the French 'politique de la ville", European Journal of Political Research, 46(4), 503-529.

Skelcher, C. (1993) 'Involvement and empowerment in local public services', Public Money and Management, 13, 13-20.

Skelcher, C. and Smith, S.R. (2015) 'Theorizing hybridity: Institutional logics, complex organizations, and actor identities: The case of nonprofits', Public Administration, 93(2), 433-448.

Smith, S.R. (2010) 'Nonprofits and public administration: Reconciling performance management and citizen engagement', The American Review of Public Administration, 40(2), 129-152.

Smith, S.R. (2014) 'Hybridity and nonprofit organizations: The research agenda', American Behavioral Scientist, 58(11), 1194-1508.

Speer, P.W. and Hughey, J. (1995) 'Community organizing: An ecological route to empowerment and power', American Journal of Community Psychology, 23(5), 729-748.

Spitzmueller, M.C. (2016) 'Negotiating competing institutional logics at the street level: An ethnography of a community mental health organization', Social Service Review, 90(1), 35-82.

Suddaby, R. and Greenwood, R. (2005) 'Rhetorical strategies of legitimacy', Administrative Science Quarterly, 50, 35-67.

Tarrow, S. (2010) 'The strategy of paired comparison: Toward a theory of practice', Comparative Political Studies, 43(2), 230-259.

Taylor, M. (2004) 'The welfare mix in the United Kingdom' in Evers, A. and Laville, J.-L., eds., The third sector in Europe, Cheltenham: Edward Elgar, 122-143. 
Taylor-Gooby, P. (1996) 'The response of government: Fragile convergence' in European welfare policy: Squaring the welfare circle, London: Macmillan, 199-218.

Thomas, G. (2011) How to do your case study: A guide for students and researchers, London: SAGE Publications Ltd.

Thornton, P.H. (2002) 'The rise of the corporation in a craft industry: Conflict and conformity in institutional logics', Academy of Management Journal, 45(1), 81-101.

Thornton, P.H. (2004) Markets from culture: Institutional logics and organizational decisions in higher education publishing, Stanford: Stanford University Press.

Thornton, P.H. and Ocasio, W. (1999) 'Institutional logics and the historical contingency of power in organizations: Executive succession in the higher education publishing industry, 1958-1990 1', American Journal of Sociology, 105(3), 801-843.

Thornton, P.H. and Ocasio, W. (2008) 'Institutional logics', The Sage handbook of organizational institutionalism, 840, 99-128.

Thornton, P.H., Ocasio, W. and Lounsbury, M. (2012) The institutional logics perspective: A new approach to culture, structure, and process, Oxford: Oxford University Press.

Tilly, C. (1986) The Contentious French, Cambridge: Harvard University Press.

Timmermans, S. and Tavory, I. (2012) 'Theory construction in qualitative research: From grounded theory to abductive analysis', Sociological Theory, 30(3), 167-186.

Traianou, A. (2014) 'The centrality of ethics in qualitative research' in Leavy, P., ed., The Oxford handbook of qualitative research, Oxford: Oxford University Press, 62-77.

Tritter, J. and McCallum, A. (2006) 'The snakes and ladders of user involvement: Moving beyond Arnstein', Health Policy, 76(2006), 156-168.

Tuurnas, S. (2015) 'Learning to co-produce? The perspective of public service professionals', International Journal of Public Sector Management, 28(7), 583-598.

Urbinati, N. and Warren, M.E. (2008) 'The concept of representation in contemporary democratic theory', Annual Review of Political Science, 11, 387-412. 
Vaillancourt, Y. (2009) 'Social economy in the co-construction of public policy', Annals of Public and Cooperative Economics, 80(2), 275-313.

Vamstad, J. (2012) 'Co-production and service quality: The case of cooperative childcare in Sweden', Voluntas, 23(4), 1173-1188.

Van Eijk, C. and Steen, T. (2014) 'Why people co-produce: Analysing citizens' perceptions on co-planning engagement in health care services', Public Management Review, 16(3), 358-382.

Van Eijk, C. and Steen, T. (2016) 'Why engage in co-production of public services? Mixing theory and empirical evidence', International Review of Administrative Sciences, 82(1), 28-46.

Vanleene, D., Verschuere, B. and Voets, J. (2015) 'Co-producing a nicer neighbourhood: Why do people participate in community development projects?', in IIAS Study Group on Co-production, Nijmegen.

Verschuere, B., Brandsen, T. and Pestoff, V. (2012) 'Co-production: The state of the art in research and the future agenda', Voluntas, 23(4), 1083-1101.

Vickers, I., Lyon, F., Sepulveda, L. and McMullin, C. (2017) 'Public service innovation and multiple institutional logics: The case of hybrid social enterprise providers of health and wellbeing', Research Policy, 46(10), 1755-1768.

Voorberg, W., Bekkers, V.J.J.M. and Tummers, L.G. (2015) 'A systematic review of co-creation and co-production: Embarking on the social innovation journey', Public Management Review, 17(9), 1333-1357, available: http://dx.doi.org/10.1080/14719037.2014.930505.

Witcher, C. (2010) 'Negotiating transcription as a relative insider: Implications for rigor', International Journal of Qualitative Methods, 9(2), 122-132.

Yin, R.K. (2014) Case study research: Design and methods, 5th ed., London: SAGE publications.

Zilber, T.B. (2002) 'Institutionalization as an interplay between actions, meanings, and actors: The case of a rape crisis center in Israel', Academy of Management Journal, 45(1), 234-254. 